UNIVERSIDADE DE SÃO PAULO

INSTITUTO DE PSICOLOGIA

VALTENICE DE CÁSSIA RODRIGUES DE MATOS FRANÇA

Desenvolvimento da acuidade visual e sensibilidade ao contraste em recém-nascidos pequenos para a idade gestacional por potenciais visuais evocados de varredura

São Paulo

2012 


\section{Desenvolvimento da acuidade visual e sensibilidade ao contraste em recém-nascidos pequenos para a idade gestacional por potenciais visuais evocados de varredura}

Tese apresentada ao Instituto de Psicologia da Universidade de São Paulo, como parte dos requisitos para obtenção do grau de Doutor em Psicologia.

Área de concentração: Psicologia Experimental.

Orientador. Prof. Marcelo Fernandes da Costa.

Co-orientador: Prof. Russell David Hamer.

São Paulo 
França, Valtenice de Cássia Rodrigues de Matos.

Desenvolvimento da acuidade visual e sensibilidade ao contraste em recém-nascidos pequenos para a idade gestacional por potenciais visuais evocados de varredura / Valtenice de Cássia Rodrigues de Matos França; orientador Marcelo Fernandes da Costa. -- São Paulo, 2012.

$120 \mathrm{f}$.

Tese (Doutorado - Programa de Pós-Graduação em Psicologia. Área de Concentração: Psicologia Experimental) - Instituto de Psicologia da Universidade de São Paulo.

1. Acuidade visual 2. Sensibilidade de contraste 3. Potenciais visuais evocados 4. Recém-nascidos 5. Desnutrição fetal I. Título. 
Nome: França, Valtenice de Cássia Rodrigues de Matos

Título: Desenvolvimento da acuidade visual e sensibilidade ao contraste em recém-nascidos pequenos para a idade gestacional por potenciais visuais evocados de varredura

Tese apresentada ao Instituto de Psicologia da Universidade de São Paulo para obtenção do título de Doutorado em Psicologia

Aprovado em:

Banca Examinadora

Prof. Dr.

Instituição:

Assinatura:

Prof. Dr.

Instituição:

Assinatura:

Prof. Dr.

Instituição: Assinatura:

Prof. Dr.

Instituição: Assinatura:

Prof. Dr.

Instituição: Assinatura: 
Esse trabalho é fruto do AMOR das mães pelos seus filhos.

Do amor da minha mãe, Telma, por mim.

Do amor da mãe da minha mãe, Eunice, por mim.

Do amor da mãe do meu esposo, Silvia, por nós.

Do amor das mães dos recém-nascidos que participaram desse estudo.

Do amor da mãe e enfermeira Selma Nishimura.

Muito obrigada mães por todo esse amor! 


\section{AGRADECIMENTOS}

Ao "Papai do céu" que tem colocado a Sua mão sobre mim, guiando os meus passos e suprindo todas as minhas necessidades. Maravilhoso És!

Ao Prof. Dr. Russell David Hamer cuja orientação acadêmica prestada ao longo dos últimos seis anos foi capaz de ensinar-me muito mais do que ser uma pesquisadora, ensinou-me a ser uma pessoa melhor. Obrigada Russell por acreditar em mim!

Ao Prof. Dr. Marcelo Fernandes da Costa pela orientação acadêmica e confiança em meu trabalho. Com você aprendi que é possível ensinar sem pressionar e acima de tudo a respeitar o tempo do aluno.

À Prof ${ }^{\mathrm{a}}$. Dra. Dora Fix Ventura, um grande exemplo de pesquisadora, pelo acolhimento no Labvis-USP e ensinamentos ao longo dos últimos seis anos.

À Dra. Edna Maria Albuquerque Diniz e a Silvia Ibidi que tornaram possível a realização desse trabalho no Hospital Universitário da USP ao disponibilizarem o espaço para a realização das triagens dos recém-nascidos e pela ajuda teórica.

À Enfermeira Selma Nishimura que mostra o seu amor todos os dias pela sua profissão no HU-USP. Uma profissional exemplar, mas acima de tudo uma amiga para todas as horas, contribuindo sempre com a triagem dos recém-nascidos.

Ao Prof. Dr. Natanael Antonio dos Santos pela iniciação científica e encaminhamento ao Labvis-USP. Sem a sua mão esse trabalho não teria sido possível.

À minha mãe Telma Maria e ao meu avô Antonio Ananias que sempre apoiaram os meus sonhos e planos de vida. Amo vocês!

Aos meus irmãos Valmont e Benilton Jr. por terem feito as pessoas mais lindas desse mundo: Maria Clara, Vanessa, Camile e Isaac. Amo ser tia! Amo vocês!

Ao meu esposo Houari Cobas Gomez por sempre usar palavras otimistas para me fortalecer e me fazer seguir em frente com os meus projetos de vida. A sua ajuda com a programação em LabVIEW foi fundamental para tornar esse trabalho mais fácil. Obrigada meu amor, minha vida! 
Às amigas Pierina Angélica Soratto, Thenille Braun e Janice Temoteo pelo companheirismo e apoio incondicional. Amigas para sempre!

Aos amigos do Labvis-USP que fizeram com que a distância de casa se tornasse menor.

Ao funcionário Claudiel sempre disposto a ajudar a todos do Labvis-USP sem medir esforços. A todos os funcionários da USP que tornaram possível a realização desse trabalho.

À Fundação de Amparo à Pesquisa do Estado de São Paulo pela bolsa de doutorado e reserva técnica. 
APOIO FINANCEIRO

Bolsa de Doutorado FAPESP \# 2008/56447-5 


\section{RESUMO}

França, V.C.R.M. (2012). Desenvolvimento da acuidade visual e sensibilidade ao contraste em recém-nascidos pequenos para a idade gestacional por potenciais visuais evocados de varredura. Tese de Doutorado, Instituto de Psicologia, Universidade de São Paulo, São Paulo.

Objetivo: Avaliar o desenvolvimento da Acuidade Visual (AV) de resolução de grades e a Sensibilidade ao Contraste (SC) de recém-nascidos de termo pequenos para a idade gestacional (PIG). Método: Medimos a AV e a SC de 126 recém-nascidos de termo com o potencial visual evocado de varredura (PVEv; Norcia \& Tyler 1985). 73 recém-nascidos (Média de Idade $=11,3 \pm$ 4,3 semanas) nasceram com o peso adequado para a idade gestacional - AIG (percentil >10; Alexander et al., 1996) e 53 recém-nascidos (Média de Idade $=9,2 \pm 3,8$ semanas) nasceram pequenos para a idade gestacional - PIG (percentil $<10$ ). Mediu-se o PVEv com o sistema PowerDiva (Norcia \& Tyler, 1985; Chen et al., 2005) o qual gerou os estímulos e analisou as respostas provocadas. O PVEv foi registrado com três canais unipolares colocados em $\mathrm{O} 1, \mathrm{Oz}$, and $\mathrm{O} 2$ relacionados ao eletrodo de referência no vertex. Utilizaram-se os estímulos de grades senoidais verticais em reversão de fase em $6 \mathrm{~Hz}$ com a luminância média de $161 \mathrm{~cd} / \mathrm{m}^{2}$. Para medir a AV, o contraste de $80 \%$ era mantido fixo e a freqüência espacial aumentava linearmente em intervalos de 1 segundo, durante 10 segundos. Para avaliar a SC, a freqüência espacial de $0,5 \mathrm{cpg}$ era mantida fixa e o contraste aumentava logaritmicamente em intervalos de 1 segundo, durante 10 segundos. Os resultados de ambas as funções visuais foram baseados na média vetorial de pelo menos três tentativas do PVEv. Analisou-se, também, a média do ruído e quatro medidas supralimiares: amplitude máxima $\left(\mathrm{A}_{\text {máx }}\right)$, razão sinal-ruído em $\mathrm{A}_{\text {máx }}\left(\mathrm{SNR}_{\text {máx }}\right)$, fase em $\mathrm{A}_{\text {máx }}\left(\Phi_{\text {máx }}\right)$ e a inclinação da reta do PVEv. Considerou-se o canal que registrou a AV e a SC mais alta, satisfazendo o critério rigoroso de fase e amplitude para assegurar que as respostas corticais eram confiáveis e significativamente acima do ruído. Resultados: O teste Qui-quadrado mostrou que uma proporção significativa de recém-nascidos PIG menores de 9 semanas de idade apresentava valores de AV e SC abaixo da média do grupo AIG com o peso ao nascimento igual ou acima do percentil 50 (P50). Além disso, nas medidas de AV, uma proporção significativa de recémnascidos PIG de 5 a 24 semanas de idade apresentava valores de $A_{\text {máx }}$, ruído médio e $S_{N R}$ máx significativamente menores que a média do grupo AIG (P50). A ANOVA fatorial confirmou que a $\mathrm{AV}, \mathrm{SC}$, ruído médio e todas as medidas supralimiares apresentaram um desenvolvimento significativo, isto é, as médias dos valores para os recém-nascidos abaixo de 10 semanas de idade apresentavam-se significativamente menores do que as médias dos valores entre 10 e 24 semanas de idade. Além disso, a taxa de desenvolvimento de $\Phi_{\text {máx }}$ era semelhante para os dois grupos, assim como para os dados de desenvolvimento de fase de Hamer e Norcia (1994). Conclusões: Os recém-nascidos de termo pequenos para a idade gestacional apresentaram alterações no desenvolvimento da acuidade visual de resolução de grades e sensibilidade ao contraste para frequência espacial baixa, principalmente nos 2 primeiros meses de vida quando as alterações nos limiares foram mais evidentes. Além disso, as alterações significativas encontradas para o ruído médio e amplitudes supralimiares durante os seis primeiros meses de vida, mostram que mesmo se os limiares de acuidade visual e contraste não fossem afetados, efeitos neuronais significantes ocorreriam nas vias visuais que conduzem a resposta gerada pelo PVEv (Mirabella et al., 2006).

Palavras-chave: Acuidade visual. Sensibilidade de contraste. Potenciais visuais evocados. Recém-nascidos. Desnutrição fetal. 


\begin{abstract}
França, V.C.R.M. (2012). Development of visual acuity and contrast sensitivity in small-for gestational-age newborns assessed by sweep visual evoked potentials. Tese de Doutorado, Instituto de Psicologia, Universidade de São Paulo, São Paulo.
\end{abstract}

Objectives: To evaluate the development of cortical grating acuity (VA) and contrast sensitivity (CS) in term infants born small for gestational age (SGA). Methods: Using the sweep visual evoked potential (sVEP; Norcia \& Tyler 1985), we measured cortical VA and CS in 126 term infants. Seventy-three (average age $=11.3 \pm 4.34$ weeks) were born with birthweight within normal limits $\left(>10^{\text {th }}\right.$ percentile; Alexander et al., 1996). 53 infants were born SGA (average age $=9.2 \pm 3.8$ weeks). sVEPs were measured using the PowerDiva system (Norcia \& Tyler, 1985; Chen et al., 2005) which generated the stimuli and analyzed the evoked responses. The sVEP was recorded using 3 unipolar channels placed at $\mathrm{O} 1, \mathrm{Oz}$, and $\mathrm{O} 2$ with a reference electrode at the vertex. Stimuli were vertical sinewave luminance gratings phase-reversing at $6 \mathrm{~Hz}$ with a mean luminance of $161 \mathrm{~cd} / \mathrm{m}^{2}$. To measure VA, spatial frequency (SF) was swept linearly from low to high during a 10-second trial, generating ten 1-sec time bins of sVEP data. Grating contrast was fixed at $80 \%$ during the SF sweep. To evaluate CS, SF was fixed at $0.5 \mathrm{c} / \mathrm{deg}$, and contrast was increased logarithmically across 101 -sec recording epochs. The resulting sVEP data from both protocols were based on a vector average of a minimum of 3 sVEP trials. In addition to thresholds, we analyzed average noise $\left(\mathrm{N}_{\mathrm{av}}\right)$, and 4 suprathreshold measures - peak amplitude $\left(\mathrm{A}_{\text {peak }}\right)$, signal-to-noise ratio at Apeak (SNRpeak), phase at Apeak $\left(\Phi_{\text {peak }}\right)$ and slope of the rising phase of the sVEP $(\mathrm{m})$. The data used were those obtained from the recording channel generating the highest VA or CS while satisfying strict phase and amplitude criteria to ensure that the responses were reliable and significantly above the noise. Results: A Chi-squared test showed that a significant proportion of the young ( $\leq 9$ weeks) SGA infants had values of VA and CS that were below the mean of control infants (with birthweights above the international $50^{\text {th }}$ percentile). In addition, mean $\mathrm{N}_{\mathrm{av}}, \mathrm{A}_{\text {peak }}$ and $\mathrm{SNR}_{\text {peak }}$ for the whole group of SGA infants were below the means of control infants across the whole age range tested. A factorial ANOVA confirmed that VA, CS, $\mathrm{N}_{\mathrm{av}}$ and all the suprathreshold measures underwent significant development; that is, the mean values prior to 10 weeks were significantly different than the mean values between 10 and 24 weeks. In addition, the rate of development of $\Phi_{\text {peak }}$ was similar for the two groups as well as to prior phase-development data Hamer and Norcia (1994). Conclusions: Birth at term with weight small for gestational age appears to significantly affect development of both cortical grating acuity and contrast sensitivity for low-SF gratings. Effects on thresholds are most evident in the first 2 months. Moreover, the significant effects we found in Nav and suprathreshold amplitudes throughout the first 6 months of life show that, even if acuity and contrast thresholds are not affected, significant neuronal effects occur in the visual pathways leading to the sVEP signal (Mirabella et al., 2006).

Keywords: Visual acuity. Contrast sensitivity. Visual evoked potentials. Newborn. Fetal malnutrition. 


\section{LISTA DE FIGURAS}

Figura 1. A média da acuidade visual em função da idade (meses lunares) pelo PVEv para a frequiência temporal de 6 Hz. Barras mostram valores de desvio de $95 \%$ de confiança (Norcia \& Tyler, 1985a). 13

Figura 2. Desenvolvimento da acuidade visual de resolução de grades pelo Potencial visual evocado de varredura para estímulos em reversão de padrão de 5 a 10 Hz. Dados de Norcia e Tyler, 1985 (círculos cheios); Norcia et al., 1990b (círculos vazios), Allen et al., 1996 (quadrados cheios pela metade); Sokol et al., 1992 (triângulos); Auestad et al. 1997 (quadrados vazios); Birch et al., 1998 (quadrados cheios). Redesenhados de Norcia e Manny, 2003. Fonte: Norcia (2004).

Figura 3. Desenvolvimento da acuidade de resolução de grades nos primeiros 36 meses de vida medido pelo PVEv (Salomão, Ejzenbaum, Berezovsky, Sacai \& Pereira, 2008). Legenda: média (•), mediana (triângulo), Percentil 95 (₫) e limite inferior $(\triangleleft)$................................................................. 15

Figura 4. Sensibilidade ao contraste em função da idade para frequiências espaciais de 0,$25 ; 0,5 ; 1,0$; 2,0; 4,0 e 8,0 cpg (Norcia, Tyler \& Hamer, 1990).

Figura 5. Estudo transversal do desenvolvimento da sensibilidade ao contraste para as baixas frequiências espaciais. Cada símbolo representa a média da sensibilidade ao contraste como uma função da idade, com o erro barra indicando um erro padrão.

Figura 6. O peso ao nascimento de acordo com a idade gestacional para os recém-nascidos PIG $(\times)$ e AIG (*), segundo as curvas de crescimento intrauterino de Alexander et al (1996)........................... 26

Figura 7. O índice ponderal de Rohrer de acordo com a idade gestacional para os recém-nascidos PIG e AIG, segundo as curvas de Ramos (1983).

Figura 8. Equipamentos de registro do Potencial Visual Evocado de Varredura. Um microcomputador Power Macintosh modelo G4 (à esquerda acima), um amplificador Neurodata Grass (à esquerda abaixo), um monitor de vídeo FIMI Modelo MD0709BRM (à direita acima), eletrodos e materiais para a sua fixação (à direita abaixo)

Figura 9. Posição dos eletrodos de registro do Potencial Visual Evocado de Varredura sobre o córtex occipital.

Figura 10. Exemplo de registro da acuidade visual (A) e sensibilidade ao contraste (B) com o PVEv para freqüência de estimulação a $6 \mathrm{~Hz}$. Determinamos a acuidade visual e a sensibilidade ao contraste pela extrapolação da resposta à amplitude zero através da regressão linear. Os pontos azuis representam o ruído neural, isto é freqüências temporais $1 \mathrm{~Hz}$ acima e abaixo da freqüência de resposta a $12 \mathrm{~Hz}$ (segundo harmônico). A linha azul no quadro superior representa a resposta visual ou sinal. A linha azul no quadro inferior indica a fase que varia entre $-\pi \mathrm{a}+\pi$. O ponto azul onde a linha vermelha toca a abscissa é considerado o limiar de acuidade. Os retângulos azuis na borda superior correspondem à estatística t-circ que mostra se uma dada amplitude é significativamente diferente da amplitude zero considerando as respostas de amplitude e fase consistentes através das tentativas. Legenda: Thrsh, limiar; Spat Freq., frequiência espacial; Noise, ruído; Sc SNR, razão sinal para o ruído máxima no registro; Pk SNR, razão sinal para o ruído máxima na média de valores usados para determinar o limiar. 
Figura 11. Desenvolvimento da acuidade visual medido pelo PVEv com a freqüência temporal de $6 \mathrm{~Hz}$

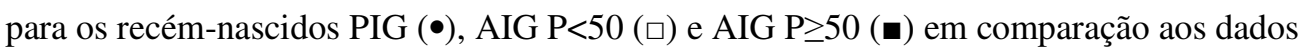
apresentados por Norcia (2004) (-४-), Norcia e Tyler (1985) (*) e Salomão et al (2008) (-\-)............ 39

Figura 12. Comparação da acuidade visual $(\log )$ entre os grupos PIG $(\bullet)$ e AIG (•) a partir do ajuste exponencial dos dados do grupo AIG $(\bullet)$ (Figura a). A Figura b mostra a diferença entre o LogAV PIG e LogAV AIG. A linha horizontal representa o grupo AIG e $n$ o número de recém-nascidos PIG...... 41

Figura 13. Distribuição dos dados de acuidade visual dos recém-nascidos PIG até 9 semanas de idade

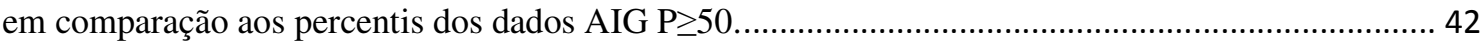

Figura 14. Distribuição dos dados de acuidade visual dos recém-nascidos PIG acima de 9 semanas de idade em comparação aos percentis dos dados AIG $\mathrm{P} \geq 50$.

Figura 15. Desenvolvimento da acuidade visual para os recém-nascidos PIG e AIG. Figura a, cada linha representa os dados obtidos para um recém-nascido AIG $(\square \mathrm{P} \geq 50$ e $\square \mathrm{P}<50)$ e na Figura b para um recém-nascido PIG (० PIG). Na Figura c, os símbolos abertos representam o teste (० PIG, $\square$ AIG

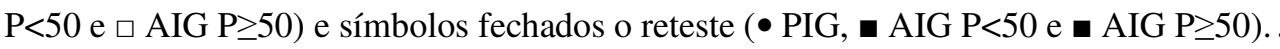

Figura 16. Sensibilidade ao contraste medida pelo PVEv com a freqüência espacial de $0,5 \mathrm{cpg}$ e frequiência temporal de $6 \mathrm{~Hz}$ para os recém-nascidos PIG (•), AIG P<50 ( $\square$ ) e AIG P $\geq 50$ (๓) em comparação às médias de sensibilidade ao contraste de Norcia, Tyler e Hamer (1990) (-口-) com as barras de erro indicando um erro padrão da média.

Figura 17. Comparação da sensibilidade ao contraste entre os grupos PIG $(\bullet)$ e AIG P $\geq 50(-)$.......... 47

Figura 18. Distribuição dos dados de sensibilidade ao contraste dos recém- nascidos PIG até 9 semanas de idade em comparação aos percentis dos dados AIG $\mathrm{P} \geq 50$.

Figura 19. Distribuição dos dados de sensibilidade ao contraste dos recém- nascidos PIG acima de 9 semanas de idade em comparação aos percentis dos dados do grupo AIG $\mathrm{P} \geq 50$.

Figura 20. Desenvolvimento da sensibilidade ao contraste para os recém-nascidos PIG e AIG. Figura a, cada linha representa os dados obtidos para um recém-nascido AIG $(\square \mathrm{P} \geq 50$ e $\square \mathrm{P}<50)$ e Figura $\mathrm{b}$ para um recém-nascido PIG (०). Na Figura c, os símbolos abertos representam o teste ( $\circ$ PIG, $\square$ AIG $\mathrm{P}<50$ e $\square \mathrm{AIG} \mathrm{P} \geq 50)$ e símbolos fechados o reteste $(\bullet \mathrm{PIG}$, $\mathrm{AIG} \mathrm{P}<50$ e — AIG $\mathrm{P} \geq 50)$.................. 50

Figura 21. Valores de fases brutos (sem tratamento) e "unwrapped" (com tratamento "phasewrapping"), obtidos durante o teste de acuidade visual para os recém-nascidos PIG (०) e AIG (口).... 52

Figura 22. Valores de fases brutos (sem tratamento) e "unwrapped" (com tratamento "phasewrapping"), obtidos durante o teste de sensibilidade ao contraste para os recém-nascidos PIG (०) e

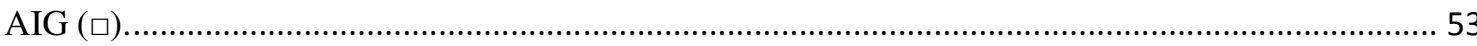

Figura 23. Registros de fase "unwrapped" para a freqüência temporal de $6 \mathrm{~Hz}$ durante os testes de acuidade visual (a) e sensibilidade ao contraste (b) para os recém-nascidos PIG (•) e AIG (ロ) em comparação aos registros de Hamer e Norcia (1994) (). 


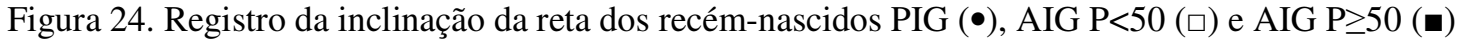
durante os testes de acuidade visual (a) e sensibilidade ao contraste (b) pelo PVEv utilizando a freqüência temporal de $6 \mathrm{~Hz}$.

Figura 25. Comparação dos valores de inclinação da reta entre o grupo PIG $(\bullet)$ e os dados AIG P $\geq 50$ (-) obtidos a partir dos testes de acuidade visual (a) e sensibilidade ao contraste (b)......

Figura 26. Valores de inclinação da reta (microvolts/cpg) para os recém-nascidos PIG e AIG obtidos do registro do teste de acuidade visual. Figura a, cada linha representa os dados obtidos para um recém-nascido AIG $(\square \mathrm{P} \geq 50$ e $\square \mathrm{P}<50)$ e na Figura b ( $\circ \mathrm{PIG})$ para um recém-nascido PIG. Na Figura c, os símbolos abertos representam o teste ( $\circ$ PIG, $\square$ AIG P<50 e $\square$ AIG P $\geq 50$ ) e símbolos fechados o reteste $(\bullet \mathrm{PIG}$, - $\mathrm{AIG} \mathrm{P}<50$ e $\square \mathrm{AIG} \mathrm{P} \geq 50)$. 60

Figura 27. Valores de inclinação da reta (microvolts/logcontraste) para os recém-nascidos PIG e AIG obtidos do registro do teste de sensibilidade ao contraste. Figura a, cada linha representa os dados obtidos para um recém-nascido AIG $(\bullet \mathrm{P} \geq 50$ e $\square \mathrm{P}<50)$ e na Figura b ( $\circ$ PIG) para um recém-nascido PIG. Na Figura c, os símbolos abertos representam o teste ( $\circ$ PIG, $\square$ AIG P $<50$ e $\square$ AIG P $\geq 50$ ) e símbolos fechados o reteste $(\bullet \mathrm{PIG}$, — AIG $\mathrm{P}<50$ e — AIG P $\geq 50)$. 61

Figura 28. Registro de amplitude máxima para os recém-nascidos PIG (•), AIG P<50 ( $\square$ ) e AIG P $\geq 50$ (ロ) durante os testes de acuidade visual (a) e sensibilidade ao contraste (b) pelo PVEv utilizando a freqüência temporal de $6 \mathrm{~Hz}$ e a frequiência espacial de $0,5 \mathrm{cpg}$.

Figura 29. Comparação da amplitude máxima registrada durante os testes de acuidade visual (a) e sensibilidade ao contraste (b) entre o grupo PIG (•) e os dados AIG P $\geq 50$ (-)

Figura 30. Valores de amplitude máxima (microvolts) para os recém-nascidos PIG e AIG obtidos do registro do teste de acuidade visual. Figura a, cada linha representa os dados obtidos para um recémnascido AIG ( $\bullet \mathrm{P} \geq 50$ e $\square \mathrm{P}<50)$ e na Figura b para um recém-nascido PIG ( $\circ$ PIG). Na Figura c, os símbolos abertos representam o teste ( $\circ$ PIG, $\square$ AIG P $<50$ e $\square$ AIG P $\geq 50$ ) e símbolos fechados o reteste $(\bullet \mathrm{PIG}, \boldsymbol{\mathrm { AIG }} \mathrm{P}<50$ e $\square \mathrm{AIG} \mathrm{P} \geq 50)$.

Figura 31. Valores de amplitude máxima (microvolts) para os recém-nascidos PIG e AIG obtidos do registro do teste de sensibilidade ao contraste. Figura a, cada linha representa os dados obtidos para um recém-nascido AIG ( $\bullet \mathrm{P} \geq 50$ e $\square \mathrm{P}<50$ ) e na Figura b para um recém-nascido PIG ( $\circ$ PIG). Na Figura c, os símbolos abertos representam o teste ( $\circ$ PIG, $\square$ AIG $\mathrm{P}<50$ e $\square$ AIG P $\geq 50$ ) e símbolos fechados o reteste $(\bullet \mathrm{PIG}, \square \mathrm{AIG} \mathrm{P}<50$ e $\square \mathrm{AIG} \mathrm{P} \geq 50)$.

Figura 32. Registro de ruído médio para os recém-nascidos PIG (•), AIG P<50 ( $\square$ ) e AIG P $\geq 50$ (•) durante os testes de acuidade visual (a) e sensibilidade ao contraste (b) pelo PVEv utilizando a frequiência temporal de $6 \mathrm{~Hz}$ e a frequência espacial de $0,5 \mathrm{cpg}$.

Figura 33. Comparação do ruído médio registrado durante os testes de acuidade visual (a) e sensibilidade ao contraste (b) entre o grupo PIG (•) e os dados AIG P $\geq 50$ (-)

Figura 34. Valores de ruído médio (microvolts) para os recém-nascidos PIG e AIG obtidos do registro do teste de acuidade visual. Figura a, cada linha representa os dados obtidos para um recém-nascido AIG ( $\bullet \mathrm{P} \geq 50$ e $\square \mathrm{P}<50$ ) e na Figura b para um recém-nascido PIG (०). Na Figura c, os símbolos 
abertos representam o teste ( $\circ$ PIG, $\square$ AIG P $<50$ e $\square$ AIG P $\geq 50)$ e símbolos fechados o reteste $(\bullet$ PIG,

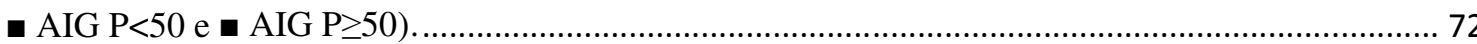

Figura 35. Valores de ruído médio (microvolts) para os recém-nascidos PIG e AIG obtidos do registro do teste de sensibilidade ao contraste. Figura a, cada linha representa os dados obtidos para um recémnascido AIG ( $\bullet \mathrm{P} \geq 50$ e $\square \mathrm{P}<50$ ) e na Figura b para um recém-nascido PIG (०). Na Figura c, os símbolos abertos representam o teste ( $\circ$ PIG, $\square$ AIG P $<50$ e $\square$ AIG P $\geq 50$ ) e símbolos fechados o reteste $(\bullet \mathrm{PIG}, \square \mathrm{AIG} \mathrm{P}<50$ e $\square \mathrm{AIG} \mathrm{P} \geq 50)$. 73

Figura 36. Registro da razão sinal-ruído para os recém-nascidos PIG (•), AIG P<50 ( $\square$ ) e AIG P $\geq 50$ (๘) durante os testes de acuidade visual (a) e sensibilidade ao contraste (b) pelo PVEv utilizando a freqüência temporal de $6 \mathrm{~Hz}$.

Figura 37. Comparação da razão sinal ruído registrada durante os testes de acuidade visual (a) e sensibilidade ao contraste (b) entre o grupo $\mathrm{PIG}(\bullet)$ e os dados AIG P $\geq 50(-)$ 77

Figura 38. Valores de SNR máximo para os recém-nascidos PIG e AIG obtidos do registro do teste de acuidade visual. Figura a, cada linha representa os dados obtidos para um recém-nascido AIG ( $\mathrm{P} \geq 50$ e $\square \mathrm{P}<50$ ) e na Figura b para um recém-nascido PIG ( $($ ). Na Figura c, os símbolos abertos representam o teste $(\circ \mathrm{PIG}, \square \mathrm{AIG} \mathrm{P}<50$ e $\square \mathrm{AIG} \mathrm{P} \geq 50)$ e símbolos fechados o reteste $(\bullet \mathrm{PIG}$, AIG $\mathrm{P}<50$ e AIG $\mathrm{P} \geq 50$ ). 78

Figura 39. Valores de SNR máximo para os recém-nascidos PIG e AIG obtidos do registro do teste de sensibilidade ao contraste. Figura a, cada linha representa os dados obtidos para um recém-nascido AIG ( $\backsim$ P $\geq 50$ e $\square$ P $<50$ ) e na Figura b para um recém-nascido PIG ( $)$. Na Figura c, os símbolos abertos representam o teste ( $\circ$ PIG, $\square$ AIG P $<50$ e $\square$ AIG P $\geq 50$ ) e símbolos fechados o reteste $(\bullet$ PIG,

- AIG $\mathrm{P}<50$ e - AIG $\mathrm{P} \geq 50)$. 79 


\section{LISTA DE TABELAS}

Tabela 1. Informações Demográficas (Média e Desvio-Padrão) ao nascimento dos recém-nascidos PIG e AIG.

Tabela 2. Classificação do estado nutricional dos recém-nascidos PIG e AIG no dia dos testes visuais, segundo critério de Gomez, modificado por Bengoa

Tabela 3 - Mostra a média e o desvio-padrão dos limiares de acuidade visual, em unidade logarítmica, e sensibilidade ao contraste para a freqüência espacial de 0,5 cpg dos recém-nascidos PIG e AIG em duas faixas etárias. $\mathrm{O}$ grupo $\mathrm{AIG}$ foi subdividido por percentil de peso ao nascimento $(50 \leq \mathrm{P}<50) \ldots 38$

Tabela 4. Resultados da análise de regressão linear das respostas de fase "unwrapped" para os recémnascidos PIG e AIG de 6 a 18 semanas de idade para a frequiência temporal de $6 \mathrm{~Hz}$.

Tabela 5. Mostra a Média e o desvio-padrão dos valores de inclinação da reta para os registros de acuidade visual e sensibilidade ao contraste para a frequiência espacial de 0,5 cpg dos recém-nascidos PIG e AIG em duas faixas etárias. O grupo AIG foi subdividido por percentil de peso ao nascimento $(50 \leq \mathrm{P}<50)$.

Tabela 6. Mostra a média e o desvio-padrão da amplitude máxima durante os testes de acuidade visual e sensibilidade ao contraste para a freqüência espacial de $0,5 \mathrm{cpg}$ dos recém-nascidos PIG e AIG em duas faixas etárias. $\mathrm{O}$ grupo AIG foi subdividido por percentil de peso ao nascimento $(50 \leq \mathrm{P}<50) \ldots 62$

Tabela 7. Mostra a média e o desvio-padrão para o ruído médio durante os testes de acuidade visual e sensibilidade ao contraste para a freqüência espacial de $0,5 \mathrm{cpg}$ dos recém-nascidos PIG e AIG em duas faixas etárias. $\mathrm{O}$ grupo $\mathrm{AIG}$ foi subdividido por percentil de peso ao nascimento $(50 \leq \mathrm{P}<50) \ldots 68$

Tabela 8. Mostra a média e o desvio-padrão da razão sinal-ruído durante os testes de acuidade visual e sensibilidade ao contraste para a freqüência espacial de $0,5 \mathrm{cpg}$ dos recém-nascidos PIG e AIG em duas faixas etárias. $\mathrm{O}$ grupo AIG foi subdividido por percentil de peso ao nascimento $(50 \leq \mathrm{P}<50)$... 74 


\section{SUMÁRIO}

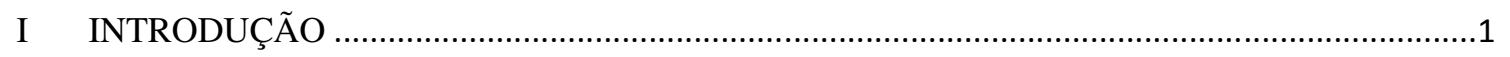

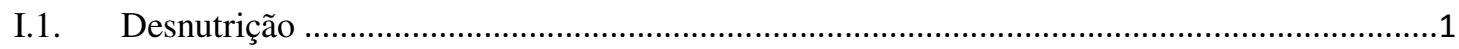

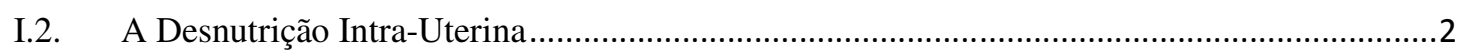

I.3. Efeitos da Desnutrição no Sistema Nervoso Central e no Comportamento ...............................4

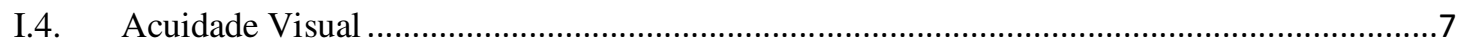

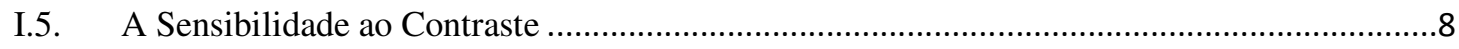

I.6. O Potencial Visual Evocado de Varredura............................................................................. 10

I.7. Ácidos Graxos versus Desenvolvimento do Sistema Visual.............................................. 17

I.8. Conseqüências da Desnutrição para o Sistema Visual Humano .......................................... 19

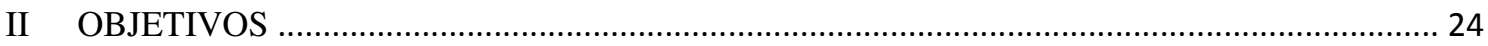

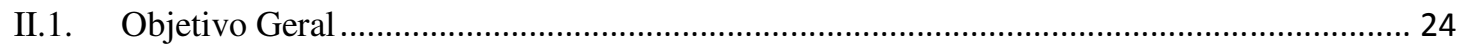

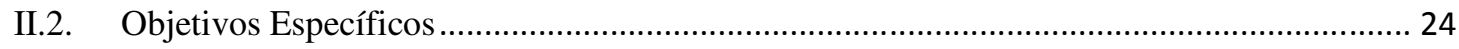

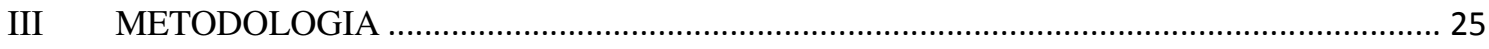

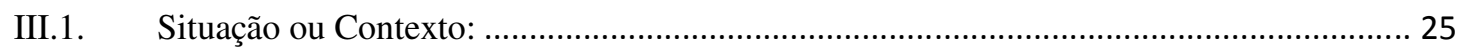

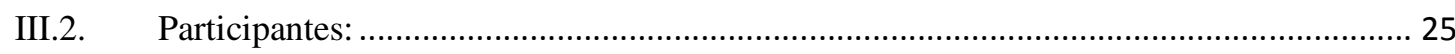

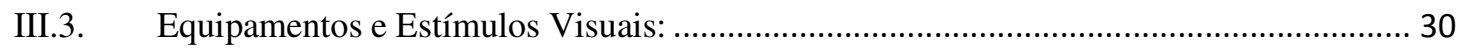

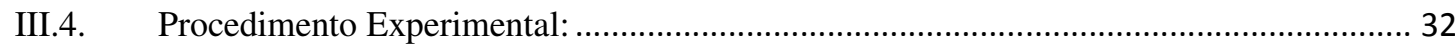

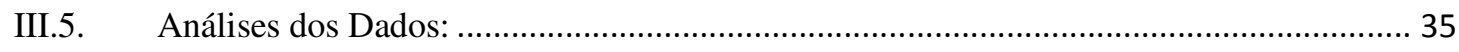

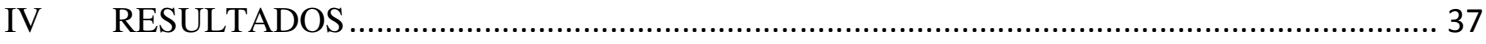

IV.1. Acuidade Visual e Sensibilidade ao Contraste de Luminância ....................................... 38

IV.2. Análises estatísticas dos registros de fase, inclinação da reta, amplitude máxima, ruído médio e SNR durante os testes de Acuidade Visual e Sensibilidade ao Contraste de Luminância51

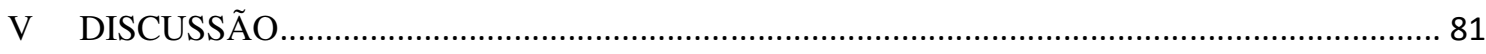

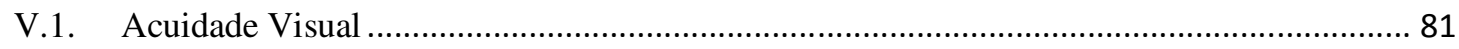

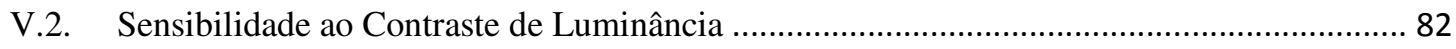


V.3. Avaliação das respostas de fase, amplitude máxima, ruído médio, SNR e inclinação da reta. 83

V.4. Avaliação de ácidos graxos em recém-nascidos de termo pequenos para a idade gestacional 84

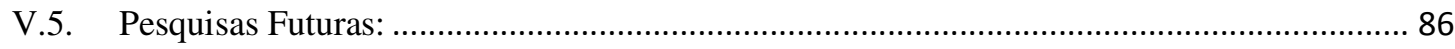

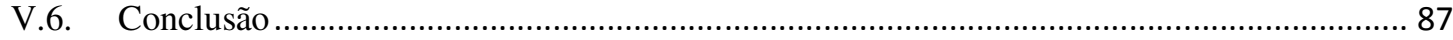

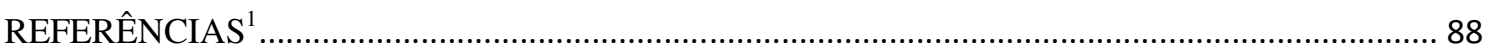

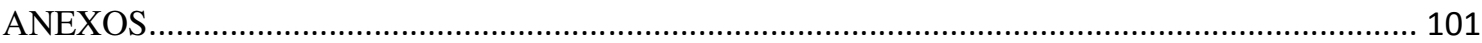

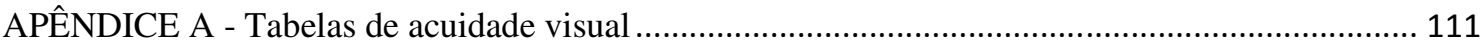

APÊNDICE B - Tabelas de Sensibilidade ao contraste ................................................................ 118

APÊNDICE C - Tabelas com as medidas antropométricas dos recém nascidos................................ 124

APÊNDICE D - Tabelas com as medidas antropométricas das mães.............................................. 132

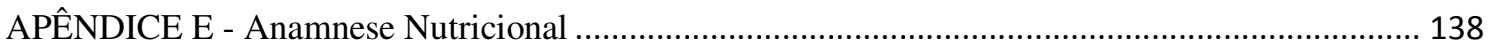




\section{INTRODUÇÃO}

\section{I.1.Desnutrição}

A desnutrição, ou subnutrição, é decorrente da ingestão insuficiente ou inadequada de alimentos que forneçam energia (classificada como tipo energética ou marasmo), proteínas (classificada como tipo protéica ou kwashiorkor), energia e proteínas (classificada como tipo kwashiorkor-marásmico), além de vitaminas e minerais (Mahan \& Escott-Stump, 2002). A

presença da subnutrição promove alterações estruturais, metabólicas, endócrinas e funcionais em todos os níveis do organismo (Nóbrega, 1998).

O diagnóstico nutricional, geralmente, é feito a partir de parâmetros antropométricos, tais como a estatura e o peso que sempre são analisados em função da idade e sexo do indivíduo (Falcão, 2000; Sigulem, Devincenzi \& Lessa, 2000). A avaliação antropométrica é mais utilizada devido à fácil execução, ao baixo custo e por não ser invasiva. Entretanto, métodos bioquímicos também podem ser utilizados para verificar carências nutricionais específicas (Sigulem et al., 2000).

Segundo o Save the Children (2012), 2,6 milhões de crianças menores de cinco anos morrem todo ano no mundo por subnutrição o que corresponde a mais de $1 / 3$ das mortes na infância; 170 milhões de crianças sofrem de desnutrição crônica e uma em cada três crianças de países em desenvolvimento sofre de nanismo.

O Instituto Brasileiro de Geografia e Estatística (IBGE, 2010) divulgou a Pesquisa de Orçamentos Familiares 2008-2009 que mostrou que a média nacional para a prevalência de déficit de altura para a idade é $6 \%$. A região Norte apresentou a maior prevalência com 8,5\% e a região Sul a menor prevalência com 3,9\%. Observou-se que a prevalência de déficit de altura diminuiu com o aumento da renda familiar (de $8,2 \%$ o estrato de menor renda para $3,1 \%$ no estrato de maior renda) e que ocorreu um declínio nos déficits de peso e altura a partir dos 5 anos de idade, no período de 1974 a 2009. Outro problema grave de saúde pública no Brasil é o grande aumento da prevalência de obesidade nas últimas décadas (1974-2009) também observado a partir dos 5 anos de idade. 
Os índices de desnutrição infantil diminuíram no Brasil, mas a situação atual ainda exige atenção permanente à segurança alimentar e nutricional das crianças (UNICEF, 2005).De acordo com o Sistema de Vigilância Alimentar e Nutricional (SISVAN, 2011), 1,3\% (37.879) das crianças menores de 5 anos de idade no Brasil apresentavam muito baixo peso para idade (desnutrição grave) e 3,2\% (95.326) baixo peso para a idade. Déficits de peso-altura, classificados como magreza acentuada e magreza, estavam presentes, respectivamente, em 2,7\% (80.515) e 3,0 \% (88.702) das crianças menores de 5 anos. A proporção de crianças menores de 5 anos classificadas com altura muito baixa para a idade (desnutrição crônica) e baixa para idade foi, respectivamente, 6,2\% (185.582) e 7,2\% (214.597). As regiões Norte e Nordeste apresentaram a maior proporção de crianças com déficits de peso-idade, peso-altura e altura-idade.

\section{I.2. A Desnutrição Intra-Uterina}

A desnutrição intra-uterina tem sido identificada com a restrição de crescimento intrauterino, sendo a responsável pelo nascimento de recém-nascidos pequenos para a idade gestacional (RNPIG). Nestes casos, o peso ao nascimento encontra-se abaixo do percentil 10 do peso adequado para a idade gestacional ou com peso inferior a dois desvios-padrão da média baseado em padrões de referências antropométricas internacionais, como por exemplo, a do Centro para Controle e Prevenção de Doenças (Centers for Disease Control and Prevention - CDC, 2002) (Lee, Chernauseck, HokkenKoelega \& Czernichow, 2003; Nóbrega, 1998; Ramos et al., 1986).

O grupo de RNPIG é constituído por recém-nascidos geneticamente pequenos para a idade gestacional e por recém-nascidos que não atingiram o seu potencial de crescimento ótimo devido a algum processo patofisiológico intrauterino. Nesse último caso, a terminologia utilizada é restrição de crescimento intrauterino (RCIU). Sendo assim, convém mencionar que nem toda criança que nasce PIG sofreu de RCIU, uma vez que podem ser constitucionalmente pequenas. Assim como, os recém-nascidos podem sofrer de RCIU durante um período gestacional curto e não necessariamente nascerem PIG (Lee et al., 2003; Maulik, 2006a). 
A restrição de crescimento intrauterino é usualmente classificada como proporcional (simétrico) ou desproporcional (assimétrico). A primeira classificação referese aos recém-nascidos com peso, estatura e comprimento cefálico reduzidos para a idade gestacional. A segunda refere-se aos recém-nascidos com o peso reduzido para a idade gestacional, mas com a estatura e o comprimento cefálico adequados para a idade gestacional (Maulik, 2006a; Nóbrega, 1998; Ramos et al., 1986).

A restrição do crescimento intrauterino pode ser decorrente de fatores maternos, placentários e fetais (Lee et al., 2003; Maulik, 2006b; Nóbrega, 1998). De modo geral, os estudos mostram que quando as carências nutricionais, cuja etiologia é a desnutrição materna, ocorrem em fases precoces da gestação, por períodos prolongados e de forma intensa, o resultado leva a restrição de crescimento proporcional. Já, quando as carências nutricionais ocorrem em etapas finais da gestação (terceiro trimestre), tem-se uma restrição desproporcional no crescimento do recém-nascido. Supõe-se que a causa mais freqüente dessa última condição seja a insuficiência placentária (Nóbrega, 1998; Ramos et al., 1986). Deve-se ressaltar que nem sempre essas diferenças podem ser claramente observadas uma vez que há múltiplas causas levando à desnutrição intra-uterina, conforme exposto em seguida.

Fatores Maternos. Há uma maior incidência de recém-nascidos PIG cujas mães durante a gravidez apresentaram doenças, tais como hipertensão arterial (Catov, Nohr \& Ness, 2008; Rasmussen \& Irgens, 2008), desordem renal (Blowey \& Warady, 2007), diabetes mellitus avançada (Haeri, Khoury, Kovilam \& Miodovnik, 2008), lúpus eritematoso sistêmico (Kim \& Lee, 2008); infecções como a malária (Meuris et al., 1993) e HIV (Habib et al., 2008); situação nutricional desfavorável como o índice baixo de massa corporal materno antes da gravidez e o ganho de peso insuficiente na gestação (Frederick, Williams, Sales, Martin \& Killien, 2008; Tsukamoto, Fukuoka, Koyasu, Nagai \& Takimoto,, 2007) ou mesmo desnutrição (Mahajan et al., 2004); uso de drogas, tais como cigarro (Ness, Zhang, Bass \& Klebanoff, 2008; Suzuki et al., 2008), álcool (Chiaffarino et al., 2006), maconha (Hatch \& Bracken, 1986), cocaína (Bandstra et al., 2001), dentre outras. Além destes fatores, o uso de alguns medicamentos, como por exemplo, antipsicóticos típicos (Newham et al., 2008) e anticonvulsivantes (Hvas, Henriksen, 
Ostergaard \& Dam, 2000) também está associado com a restrição de crescimento intrauterino.

Fatores demográficos. A idade (adolescentes ou mulheres acima de 35 anos) (Sharma et al, 2008), altura e peso maternos, assim como a etnia paterna e materna, multiparidade, histórico de filhos nascidos PIG e gestação múltipla estão relacionados ao nascimento de recém-nascidos PIG (Lee et al., 2003; Nóbrega, 1998).

Fatores placentários. Alterações placentárias, tais como placenta prévia, hemangioma, insuficiência uterino-placentária, dentre outras dificultam a passagem de nutrientes ao feto levando o nascimento de recém-nascidos PIG (Lee et al., 2003; Maulik, 2006b).

Fatores fetais. Recém-nascidos portadores de cromossomopatias (Síndrome de Down, Síndrome de Turner, Síndrome de Edward), desordens genéticas e anomalias congênitas (Síndrome de Potter e anormalidades cardíacas) têm maior probabilidade de nascerem PIG (Lee et al., 2003; Maulik, 2006b).

\section{I.3. Efeitos da Desnutrição no Sistema Nervoso Central e no Comportamento}

A nutrição tem um papel importante na maturação e no desenvolvimento funcional do sistema nervoso central, e dela depende o fornecimento de energia e nutrientes necessários para o funcionamento adequado do organismo e seu desenvolvimento morfofisiológico (Georgieff, 2007; Guesry, 1998; Morgane et al, 1993).

A desnutrição pode, portanto, afetar desfavoravelmente a maturação, a organização e o desenvolvimento do sistema nervoso central, provocando alterações sobre uma série de etapas incluindo a neurogênese, gliogênese, sinaptogênese e os processos de migração, diferenciação, mielinização e morte celular (Galler, Shumsky \& Morgane, 1996; Morgane et al, 1993). No entanto, os efeitos da desnutrição sobre o sistema nervoso central podem variar de acordo com: o tipo de desnutrição; o grau de privação nutricional; o período do desenvolvimento cerebral em que ocorre (pré-natal, peri-natal ou pós-natal); e a duração da 
privação nutricional (episódica ou se estendendo até o final da infância). Além destes, outros fatores como os ambientais e genéticos podem estar envolvidos (Galler, Shumsky \& Morgane, 1996).

Alterações morfológicas foram encontradas no córtex cerebral de crianças com desnutrição severa pós-natal, do tipo protéico-calórica, evidenciando principalmente redução no comprimento dos dendritos apicais e no número de espinhos por dendrito nas áreas motora, somestésica e occipital, além da presença de anormalidades nos espinhos dendríticos de neurônios corticais (Benítez-Bribiesca, Rosa-Alvarez \& Mansilla-Olivares, 1999).

Hazin, Alves e Falbo (2007) mostraram, com exames de imagem de Ressonância Magnética Funcional, que as crianças com idades entre 2 e 24 meses, severamente desnutridas, apresentavam uma diminuição do volume encefálico, caracterizando atrofia cerebral.

Chase et al. (1972) observaram que recém-nascidos com restrição de crescimento intrauterino (RCIU) apresentavam alterações morfológicas, tais como redução no peso e celularidade do cerebelo; e alterações bioquímicas, como por exemplo, redução na concentração de cerebrosídios e sulfatídios e redução na atividade de galactolipídico sulfotransferase.

Özdemir, Ergin e Şahiner (2009) investigaram, com a eletroencefalografia, a maturação eletrofisiológica cérebro-cortical de recém-nascidos, de termo, pequenos para a idade gestacional e concluíram que a maturação encontrava-se prejudicada nesses recémnascidos durante os três primeiros meses de vida, período único no qual foram avaliados.

As funções neurais básicas, como o processamento de informações sensoriais, as percepções correspondentes e a execução de tarefas motoras, bem como as funções neurais mais elaboradas, como cognição, consciência, emoção, aprendizado e memória podem ser afetadas pela desnutrição (Guedes, Rocha-de-Melo \& Teodósio, 2004). Estudos neuropsicológicos mostraram déficits na atenção, habilidade visuo-espacial, funções executivas, compreensão, aprendizagem e memória de crianças desnutridas (Feldman e Eidelman, 2006; Ivanovic, 1996; Ivanovic et al., 2000; Kar, Rao \& Chandramouli, 2008; Liu, Raine, Venables, Dalais \& Mednick, 2003; Scrimshaw, 1998). Além disso, Liu, 
Raine, Venables e Mednick (2004) relataram que a desnutrição predispõe a comportamentos agressivos, hiperativos e anti-sociais.

Mello, Gonçalves e Souza (2004) observaram alterações comportamentais em recém-nascidos pequenos para a idade gestacional (PIG), de termo, utilizando as Escalas Bayley de Desenvolvimento Infantil - II, com ênfase na Escala de Classificação do Comportamento (ECC). O Fator Qualidade Motora demonstrou valores das medianas significativamente menores no grupo PIG nos itens Motricidade Axial, Controle de Movimentos e Hipertonia Muscular em comparação aos recém-nascidos com peso adequado para a idade gestacional (AIG). O grupo PIG aos dois meses de idade apresentou valores das medianas significativamente menores nos itens Exploração de Objetos e de Ambiente e Interação com o Examinador em comparação ao grupo AIG.

Goto, Gonçalves, Netto, Morcillo e Moura-Ribeiro (2005) avaliaram o neurodesenvolvimento de recém-nascidos PIG de termo, no $2^{\circ}$ mês de vida, com as Escalas Bayley de Desenvolvimento Infantil e mostraram que os grupos PIG e AIG não demonstraram diferenças quando analisados quanto à performance mental e motora; no entanto, considerando a pontuação do Index Score, o grupo PIG apresentou resultados significativamente menores nas duas Escalas. De acordo com os autores, o significado clínico desse achado sugere que os lactentes nascidos PIG, embora estejam no intervalo de normalidade do desenvolvimento, possam estar em maior risco de resultados adversos, os quais podem ser detectados já no $2^{\circ}$ mês de vida.

Embora alguns estudos tenham sido feitos em humanos, a maioria dos estudos utiliza modelos animais. Estudos em ratos com desnutrição protéica ou protéico-calórica pré-natal e/ ou pós-natal revelam: (i) alterações morfológicas, tais como redução na densidade, número e tamanho das células neurais e gliais; redução no número de espinhos dendríticos e na razão de sinapses por neurônio (Galler, Shumsky \& Morgane, 1996); redução na quantidade de mielina no nervo óptico (Vargas, V et al., 2000), no número de células GABAérgicas na retina (Silveira, Gardino, Bevilaqua \& Hokoç, 2007), no número de axônios mielinizados e área de mielina no nervo óptico (Almeida, Silveira, Guedes, Hokoç \& Martinez, 2005); (ii) alterações neuroquímicas, tais como redução e/ou aumento significativo na concentração de alguns aminoácidos; redução na concentração de lipídeos, DNA, RNA e proteínas no encéfalo (Nóbrega, 1998), além de alterações no sistema de 
neurotransmissão, mostrando alterações na densidade dos receptores, bem como nos níveis e na liberação dos neurotransmissores (Almeida, Tonkiss \& Galler, 1996; Rotta et al., 2008; Soto-Moyano et al., 1993); (iii) alterações comportamentais, tais como dificuldade na extinção de comportamentos aprendidos, diminuição nas brincadeiras e na interação social (Almeida \& De Araújo, 2001; Camargo \& Almeida, 2005); (iv) alterações no estado emocional, motivacional e ansiedade, como o aumento no comportamento agressivo e na impulsividade, além de baixa ansiedade em situações aversivas expressa pela redução nos comportamentos de evitação (Galler, Shumsky \& Morgane, 1996; Levitsky \& Strupp, 1995) e (v) prejuízos cognitivos relacionados, principalmente, à aprendizagem, memória e atenção, como dificuldades em tarefas de discriminação visual (Galler, Shumsky \& Morgane, 1996; Rotta et al., 2008; Ranade et al., 2008) e diminuição na memória visuoespacial (Soto-Moyano et al., 2005).

\section{I.4. Acuidade Visual}

A acuidade visual (AV) é a capacidade do sistema visual de resolver detalhes espaciais finos (Mcllwain, 1996). Existem quatro tipos principais de acuidade visual, cada tipo relacionado a uma tarefa visual diferente: detecção, resolução, reconhecimento e discriminação (Shiffman, 2005).

A acuidade visual de detecção refere-se ao mínimo visível, ou seja, ao menor tamanho de um estímulo visual que pode ser detectado sobre um fundo homogêneo.

A acuidade visual de resolução corresponde ao mínimo separável, ou seja, a menor distância entre elementos críticos de um estímulo padronizado composto, por exemplo, por pares de pontos, grades, ou quadriculado.

Os estímulos visuais mais comumente usados para avaliar a acuidade visual de resolução são a grade quadrada e a senoidal. Uma grade é composta de barras claras e escuras alternadas que são apresentadas em diferentes freqüências espaciais. Freqüência espacial é definida como o número de ciclos por grau de ângulo visual (cpg). Ângulo 
visual é o ângulo ( $\alpha$ ) que relaciona a largura (l) do objeto com a distância (d) dele ao observador: $\alpha=(1 / \mathrm{d})$ radianos.

Acuidade visual de reconhecimento corresponde ao menor objeto que pode ser reconhecido. A tarefa, para esta medida, requer que o indivíduo testado identifique optotipos visuais isolados. Esses podem ser as letras do alfabeto para os alfabetizados e os cartões com a letra $\mathrm{C}$ de Landolt ou o $\mathrm{E}$ de Snellen para os não alfabetizados, nesse último caso o indivíduo identifica a posição (para cima, para baixo, direita ou esquerda) da abertura da letra $\mathrm{C}$ ou do $\mathrm{E}$.

A acuidade visual de discriminação mede o mínimo discriminável. A tarefa é semelhante à utilizada na tarefa de reconhecimento, porém os optotipos são apresentados agrupados em tabelas. O indivíduo deve reconhecer os optotipos e discriminá-los dos outros que estão próximos.

Na prática clínica, habitualmente avalia-se a acuidade visual de reconhecimento com crianças verbais, adultos e idosos, além da acuidade visual de resolução de grades com recém-nascidos, crianças não-verbais e indivíduos com deficiência física ou mental incapazes de responder verbalmente ou responder conforme as instruções.

\section{I.5. A Sensibilidade ao Contraste}

A Sensibilidade ao Contraste (SC) é definida como a recíproca da quantidade mínima de contraste necessária para detectar uma grade de uma freqüência espacial específica (Cornsweet, 1970). O contraste de luminância pode ser calculado com base na medida das luminâncias das superfícies a serem comparadas. No caso de uma área em um campo homogêneo, é utilizado o Contraste de Weber: CW $=\mathrm{L}-\mathrm{LF} / \mathrm{LF}$, onde L é a luminância da área a ser discriminada e LF é a luminância do fundo no qual se encontra essa área. Para padrões periódicos, como ondas senoidais ou quadradas, utiliza-se o contraste de Michelson. Este define o contraste como a relação entre a diferença da luminância máxima e luminância mínima dividida pela soma das duas. 
A SC descreve de forma eficiente o desempenho do sistema visual para a percepção de formas em níveis diferentes de contrastes. A medida de limiares de contraste pode ser feita em várias freqüências espaciais. A relação obtida entre amplitude de contraste e frequiência espacial constitui a Função de Sensibilidade ao Contraste (FSC). A AV corresponde a apenas um ponto na FSC, isto é ao ponto de corte da FSC nas altas freqüências espaciais (Schwartz, 2004).

Dentre os estudos que envolvem a mensuração da AV e SC destacam-se os que visam avaliar o desenvolvimento da visão espacial (Hamer, Norcia, Tyler \& Hsu-Winges, 1989; Norcia \& Tyler, 1985; Norcia, Tyler \& Hamer, 1990; Norcia, Tyler, Hamer \& Wesemann, 1989; Salomão, Ejzenbaum, Berezovsky, Sacai \& Pereira, 2008; Skoczenski \& Norcia, 1999); os efeitos dos ácidos graxos no desenvolvimento visual (Birch et al., 2005; Hoffman et al., 2000; Hoffman et al., 2004; Makrides, Neuman, Simmer, Pater \& Gibson, 1995); os efeitos de substâncias neurotóxicas, tais como o mercúrio (Costa et al., 2008; Ventura et al., 2005; Rodrigues et al., 2007;) e solventes orgânicos (Lacerda et al., 2012) e os efeitos de patologias oculares, fisiológicas e neuropsiquiátricas sobre a percepção visual, como por exemplo, a ambliopia (Dobson, Miller, Harvey \& Mohan, 2003); a catarata congênita (Maurer, Lewis, Brent \& Levin, 1999), a retinopatia da prematuridade (VanderVeen et. al, 2006), a prematuridade (Oliveira et al., 2004), o baixo peso ao nascimento (Mirabella, Kjaer, Norcia, Good \& Madan, 2006; O'Connor et al., 2004; SanGiovanni et al., 2000a; Tornqvist \& Källén, 2004), a desnutrição (Alencar \& Santos, 2012; Santos \& Alencar, 2010); a Síndrome de Down (John, Bromham, Woodhouse \& Candy, 2004); paralisia cerebral (Costa, Salomão, Berezovsky, Haro \& Ventura, 2004; Costa \& Ventura, 2012); a hidrocefalia (Costa, Haro, Salomão \& Ventura, 2008; Pereira \& Costa, 2012), a distrofia muscular de Duchenne (Costa, Barboni \& Ventura, 2011), dentre outras. 


\section{I.6. O Potencial Visual Evocado de Varredura}

O Potencial Visual Evocado (PVE) é uma resposta cortical proveniente de estimulação visual por flashes de luz ou por estímulos compostos por padrões específicos (quadriculados ou grades), registrada por eletrodos de EEG posicionados na região occipital (Odom et al., 2004).

O PVE é uma técnica não-invasiva que permite a avaliação da integridade funcional do sistema visual de recém-nascidos e indivíduos não-verbais acometidos por doenças que afetem o sistema visual (Almoqbel, Leat \& Irving, 2008; Costa \& Ventura, 2012; Good, Hou \& Norcia, 2012; Norcia et al., 1991; Norcia, Hamer, Jampolsky \& OrelBixler, 1995; Oliveira et al., 2004; Ridder III, 2004; Salomão et al., 2008).

Para a medição da acuidade visual pelo PVE, utilizam-se estímulos compostos por padrão (quadriculados ou grades) que podem ser apresentados com taxas de repetição diferentes. Para estímulos apresentados com taxa de repetição rápida (freqüência temporal alta), denomina-se o PVE em estado estável, por exemplo, o PVE de varredura (Odom et al., 2004). Já para estímulos com taxa de repetição baixa (freqüência temporal baixa) denomina-se PVE transiente, como por exemplo, o PVE por reversão de padrão e o PVE on-off (Odom et al., 2004).

O PVE por reversão de padrões. Os estímulos consistem em tabuleiros de xadrez ou grades que mudam de fase em 180 graus (do branco para o preto e do preto para o branco) abruptamente e repetidamente em um número específico de vezes por segundo com a luminância média da tela constante. Os estímulos são definidos em termos de ângulo visual para os tabuleiros de xadrez e em frequiências espaciais para grades (Odom et al., 2004).

O PVE por padrão aparece-desaparece (on-off). Um padrão (tabuleiro de xadrez ou grade) é apresentado de 100 a $200 \mathrm{~ms}$ e abruptamente trocado por um fundo difuso 
eqüiluminante por cerca de $400 \mathrm{~ms}$, a luminância média da tela permanece constante durante todo exame (Odom et al., 2004).

$O$ PVE de varredura (PVEv). A estimulação consiste, habitualmente, em uma série de grades de padrão reverso que variam em uma dimensão (freqüência espacial, por exemplo), durante um período relativamente curto de apresentação. Para as medidas de acuidade visual, utilizamos uma apresentação sucessiva de grades senoidais com diferentes frequiências espaciais em um período de testagem de 10 segundos.

No presente estudo utilizamos a técnica do PVE de varredura que foi proposta por Regan (1973) e aplicada, primeiramente, por Tyler, Apkarian, Levi e Nakayama (1979) a fim de fornecer uma avaliação rápida da acuidade visual de resolução de grades, uma vez que o tempo requerido para avaliação pelas técnicas clássicas de PVE transiente era longo e se tornava uma desvantagem para a avaliação clínica (Tyler et al., 1979).

No método do PVEv ocorrem mudanças sistemáticas (varreduras) para uma determinada dimensão do estímulo visual apresentado, tal como a freqüência espacial para as medidas de acuidade visual, numa seqüência de passos com duração relativamente curta (p. ex., 1 segundo) chamada "bins". A varredura completa consiste de $\mathrm{N}$ bins, usualmente dez, para um tempo total de dez segundos que constitui uma única tentativa de PVEv. Na medida de acuidade visual, por exemplo, cada bin apresenta uma freqüência espacial diferente da grade em reversão de fase para a frequiência temporal de $6 \mathrm{~Hz}$.

A idéia geral do PVEv é aplicar a análise de frequiência para extrair do potencial evocado os componentes correlacionados com as mudanças temporais (p.ex., reversão de fase a $6 \mathrm{~Hz}$ ) do estímulo visual. O protocolo do PVEv também calcula o ruído local em cada bin ordenadamente para distinguir entre o sinal real (respostas evocadas por estímulos) e o ruído (componentes do EEG ou artefatos não associados com o estímulo visual). O resultado é a medida, para cada bin, de (1) amplitude do PVE (em $\mu \mathrm{V}$ ) em uma ou mais freqüências temporais específicas harmonicamente relacionada à frequiência 
temporal do estímulo, (2) a fase daquele harmônico (a fase relacionada às mudanças periódicas no estímulo), e (3) o ruído local. Para mais detalhes consulte a seção Métodos.

O ruído corresponde à atividade neuronal não relacionada ao estímulo visual. Existem outras fontes de ruído, por exemplo, a atividade elétrica de músculos, movimentação dos eletrodos, campos elétricos radiados de equipamentos eletrônicos, etc. A amplitude de ruído é considerada como a amplitude do sinal em uma frequiência temporal próxima à freqüência temporal de análise, como por exemplo, 11 e $13 \mathrm{~Hz}$ para o componente de resposta em $12 \mathrm{~Hz}$ (Norcia \& Tyler, 1985a).

A fase corresponde à medida da relação temporal entre a freqüência temporal de análise do PVEv e a frequiência de estimulação. Períodos de fase constante (ou estáveis) são consistentes com a atividade cortical provocada pelos estímulos e inconsistentes com o EEG espontâneo (ruído). Em outras palavras, quando a fase é estável indica que a atividade cortical está sincronizada com a freqüência de teste. A fase pode ser convertida em latência aparente da resposta, ou seja, a fase pode indicar em quanto tempo a informação visual atravessa os meios ópticos e é processada pela retina e pela via geniculo-estriada. $\mathrm{Na}$ mensuração da acuidade visual, normalmente ocorre um aumento gradual das latências em função do aumento da freqüência espacial (Norcia \& Tyler, 1985a).

A acuidade visual medida com estímulos de grade senoidal pelo PVEv refere-se ao menor tamanho do estímulo visual capaz de gerar uma resposta neuronal. Estima-se a acuidade visual, considerando-se a amplitude da resposta eletrofisiológica em função da frequiência espacial de uma grade. Como a amplitude diminui com o aumento da frequiência espacial (próximo ao limiar de acuidade), Norcia e Tyler (1985a) consideram que a amplitude de zero microvolts representa a cessação da atividade neuronal relacionada ao estímulo visual e, portanto, pode ser adotada como indicativa do limiar de acuidade visual. Este limiar é estimado no PVEv pela intersecção da reta de regressão traçada entre o pico da amplitude do sinal e o ponto em que a amplitude do sinal se iguala ou é menor que a amplitude do ruído e que interpola a amplitude zero, em função da frequiência espacial com a abscissa. A freqüência espacial a qual a linha de regressão cruza zero microvolts é considerada como a estimativa da acuidade visual. Para uma medida de 
acuidade visual confiável considera-se a amplitude significativamente maior do que a média do ruído (razão 3:1). Este critério foi determinado empiricamente e pode proporcionar um total de no máximo $0,3 \%$ de respostas falso-positivas (Norcia \& Tyler, 1985a).

Norcia e Tyler (1985) avaliaram o desenvolvimento da acuidade visual em 215 recém-nascidos na faixa etária de 1 a 13 meses lunares. Os autores observaram que durante o primeiro ano de vida a acuidade visual aumenta de 4,5 cpg no primeiro mês para cerca de $20 \mathrm{cpg}$ no final do primeiro ano. A partir dos 8 meses de vida a acuidade visual aproximase do valor adulto de $24,3 \mathrm{cpg}$ (Figura 1).

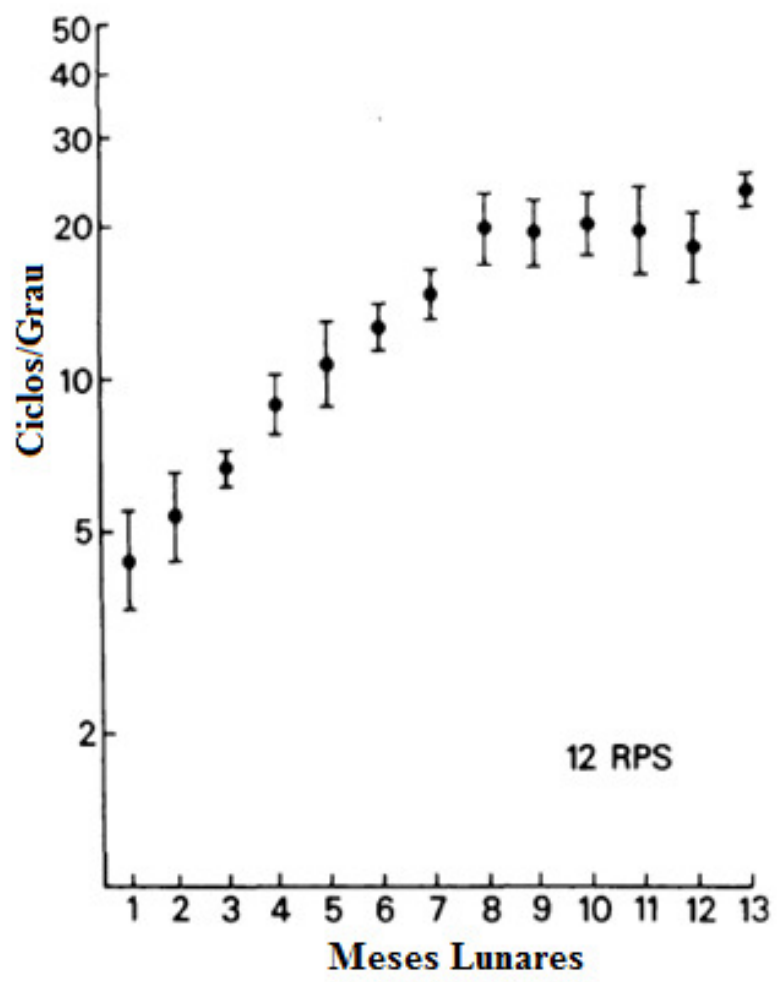

Figura 1. A média da acuidade visual em função da idade (meses lunares) pelo PVEv para a freqüência temporal de $6 \mathrm{~Hz}$. Barras mostram valores de desvio de $95 \%$ de confiança (Norcia \& Tyler, 1985a).

Norcia (2004) comparou o desenvolvimento da acuidade visual de resolução de grades de seis estudos (Norcia e Tyler, 1985; Norcia et al., 1990b; Allen et al., 1996; Sokol 
et al., 1992; Auestad et al. 1997; Birch et al., 1998) e observou que em cada estudo a acuidade visual encontrava-se em torno de $5 \mathrm{cpg}$ em um mês de vida e em torno de 15 a 20 cpg aos 8 meses de idade (Figura 2).

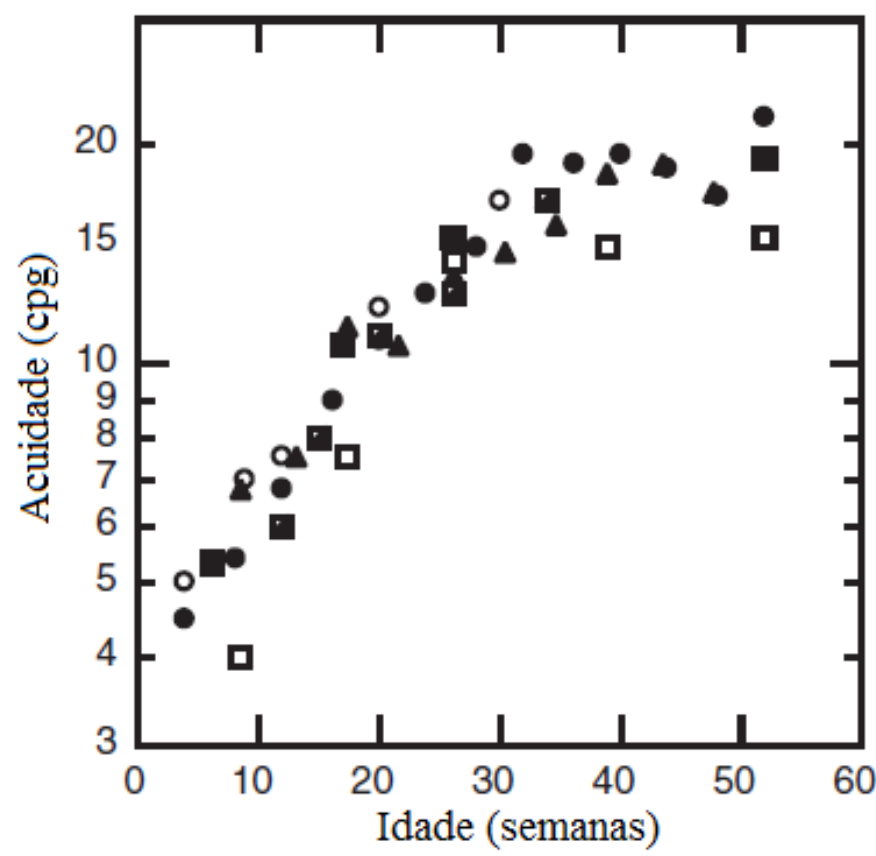

Figura 2. Desenvolvimento da acuidade visual de resolução de grades pelo Potencial visual evocado de varredura para estímulos em reversão de padrão de 5 a 10 Hz. Dados de Norcia e Tyler, 1985 (círculos cheios); Norcia et al., 1990b (círculos vazios), Allen et al., 1996 (quadrados cheios pela metade); Sokol et al., 1992 (triângulos); Auestad et al. 1997 (quadrados vazios); Birch et al., 1998 (quadrados cheios). Redesenhados de Norcia e Manny, 2003. Fonte: Norcia (2004).

Salomão, Ejzenbaum, Berezovsky, Sacai e Pereira (2008) mediram a acuidade visual de resolução de grades monocular de 67 recém-nascidos saudáveis de 1 a 36 meses de idade com o PVEv. Os autores relataram que a média da acuidade visual no primeiro mês de vida é 4,8 cpg (0,80 logMar), aumentando para 30 cpg (0,06 logMar) aos 36 meses de vida (Figura 3).

A acuidade visual média de recém-nascidos é diferente quando medida pelas técnicas comportamental e eletrofisiológica. Por exemplo, a comparação entre a acuidade visual média de recém-nascidos, com idades entre duas semanas e 14 meses, considerando 
as normas de Salomão e Ventura (1995) para os Cartões de Acuidade de Teller (CAT), técnica comportamental, e Norcia e Tyler (1985a) para o PVEv mostrou que a AV média é 1,9 vezes (0,93 oitavas) mais alta para o PVEv do que para os CAT. Para os adultos, a AV média também é ligeiramente diferente quando medida pelas técnicas comportamental, 30 cpg e eletrofisiológica, 24,3 cpg (Norcia \& Tyler, 1985a).

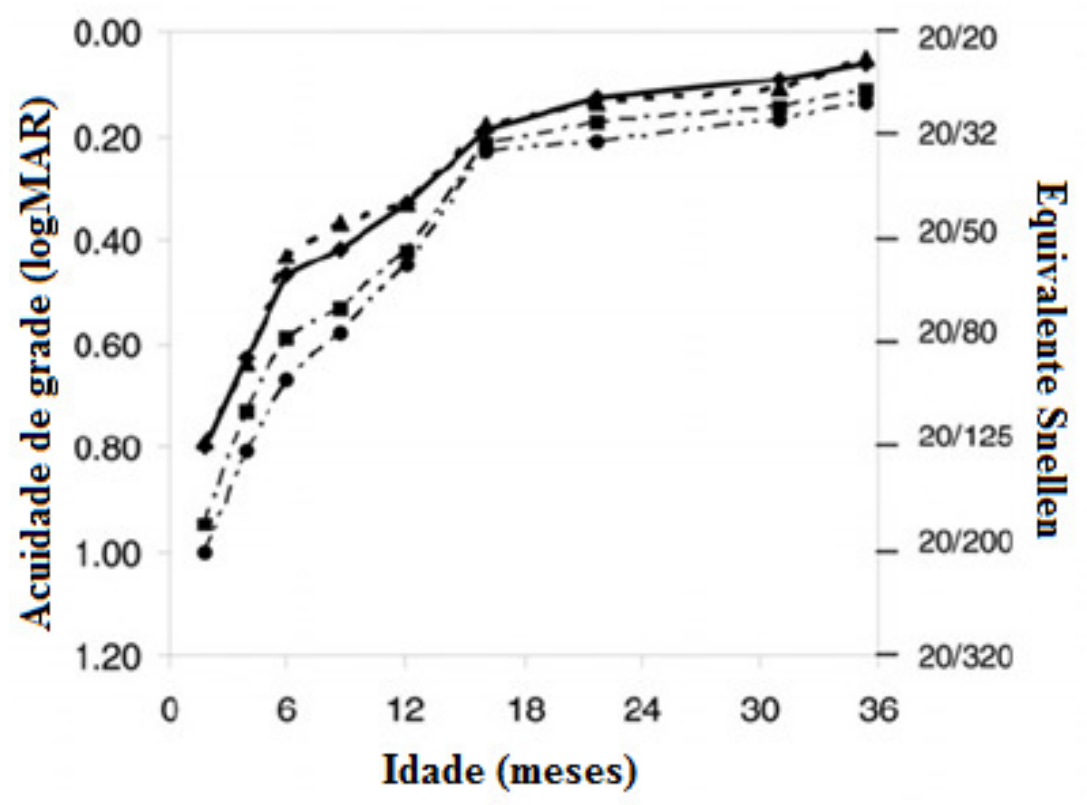

Figura 3. Desenvolvimento da acuidade de resolução de grades nos primeiros 36 meses de vida medido pelo PVEv (Salomão, Ejzenbaum, Berezovsky, Sacai \& Pereira, 2008). Legenda: média $(\bullet)$, mediana (triângulo), Percentil 95 (๘) e limite inferior $(\diamond)$.

As diferenças nos valores de AV entre as técnicas comportamentais e eletrofisiológicas podem ser atribuídas às condições experimentais, equipamentos, luminância, apresentação dos estímulos, critérios de respostas, dentre outras (Dobson \& Teller, 1978). Além disso, essas técnicas avaliam o processamento do estímulo visual para diferentes áreas do sistema nervoso central.

De acordo com o exposto anteriormente, o sistema visual do recém-nascido humano é imaturo do ponto de vista funcional. Banks e Bennett (1988) relataram que essa imaturidade funcional deve-se, em parte, a causas anatômicas e fisiológicas. Os autores 
mostraram que os segmentos internos dos cones em recém-nascidos são largos e curtos, já nos adultos são finos e compridos. Adicionalmente, mostraram que os segmentos externos dos cones são mais curtos em recém-nascidos do que em adultos. O fato de o segmento interno ser mais largo e curto do que o segmento externo, em recém-nascidos, faz com que os raios de luz que refletem nas paredes do segmento interno tenham ângulos agudos e não possam alcançar o segmento externo, o que diminui a absorção de energia eletromagnética e reduz a acuidade visual (Banks \& Bennett, 1988).

Norcia, Tyler e Hamer (1990) avaliaram o desenvolvimento da função de sensibilidade ao contraste utilizando o PVEv e mostraram que a SC para as freqüências espaciais mais baixas se desenvolve rapidamente nas primeiras 10 semanas após o nascimento, diferentemente das freqüências espaciais mais altas, que continuam seu desenvolvimento até cerca de 30 semanas de vida, alcançando os limiares de um adulto saudável (Figuras 4 e 5).
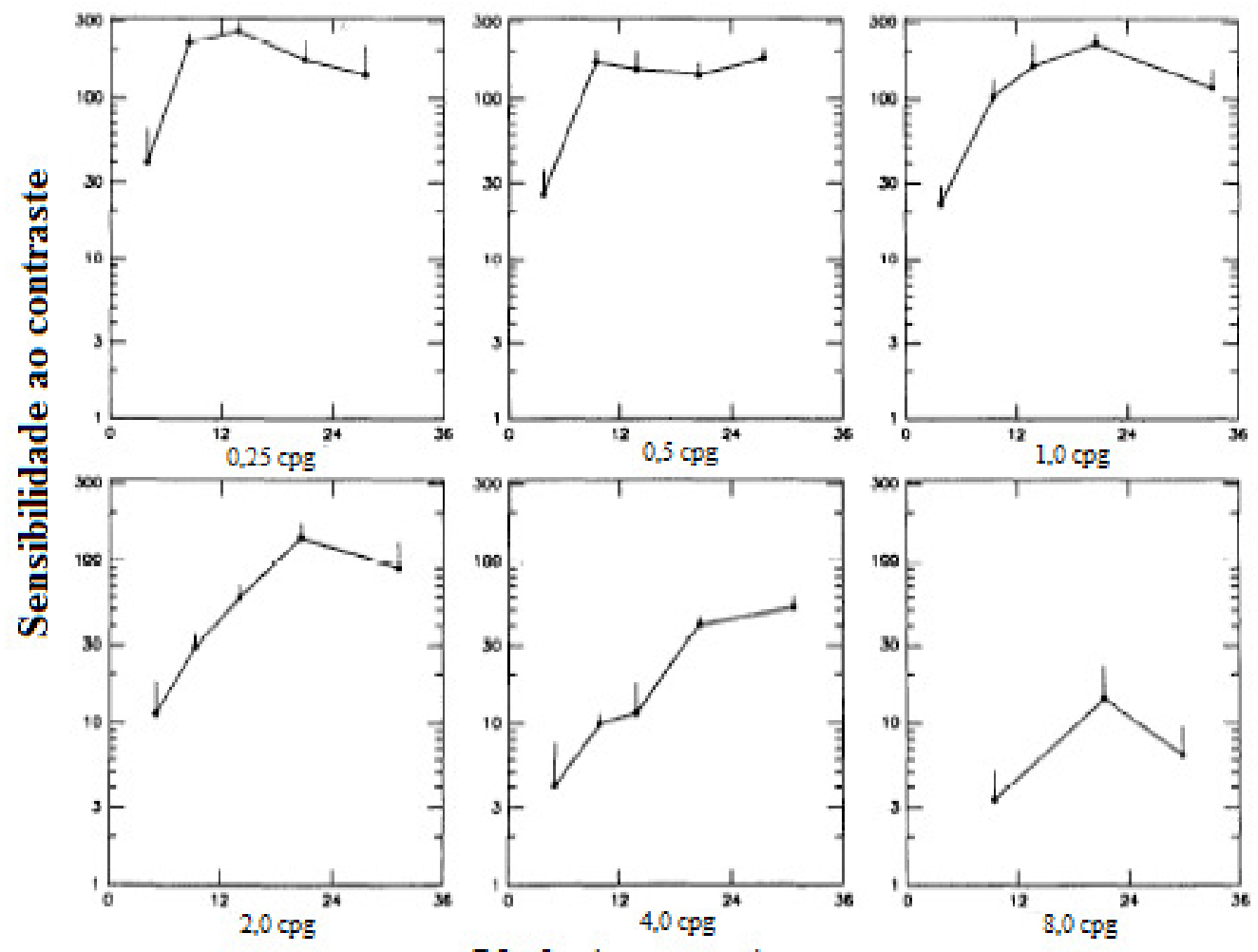

Idade (semanas)

Figura 4. Sensibilidade ao contraste em função da idade para freqüências espaciais de 0,$25 ; 0,5 ; 1,0 ; 2,0 ; 4,0$ e 8,0 cpg (Norcia, Tyler \& Hamer, 1990). 
Norcia, Tyler e Hamer (1990) realizaram um estudo transversal com 38 crianças até 30 semanas de idade e mostraram o desenvolvimento da sensibilidade ao contraste para as freqüências espaciais baixas de 0,25;0,5 e 1,0 cpg. Para as análises, considerou-se apenas a frequiência espacial que apresentou a SC mais alta. Os autores observaram que a sensibilidade ao contraste para as frequiências espaciais baixas parece atingir uma assíntota em torno de 200 de contraste por volta de 10 semanas de vida (Figura 5).

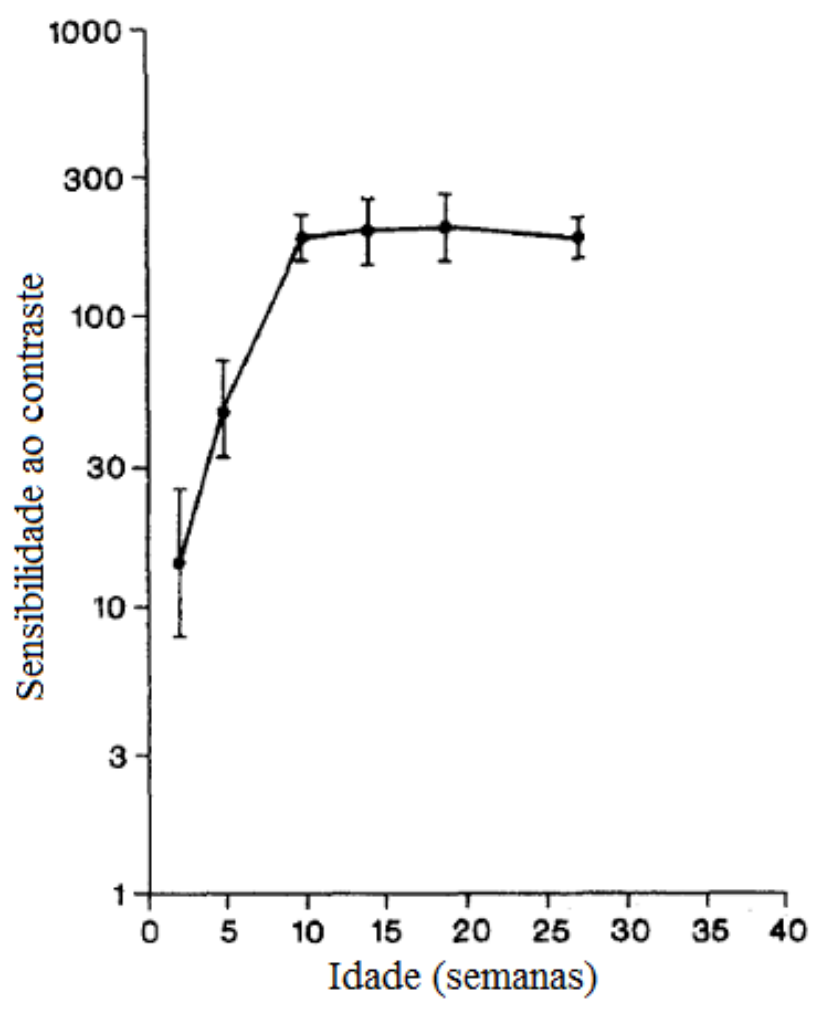

Figura 5. Estudo transversal do desenvolvimento da sensibilidade ao contraste para as baixas freqüências espaciais. Cada símbolo representa a média da sensibilidade ao contraste como uma função da idade, com o erro barra indicando um erro padrão.

\section{I.7. Ácidos Graxos versus Desenvolvimento do Sistema Visual}

Estudos mostram a importância da nutrição adequada nos períodos intrauterino e pós-natal para o desenvolvimento visual normal. Dentre estes, encontram-se os estudos desenvolvidos para investigar a função dos ácidos graxos no desenvolvimento visual 
(Birch et al., 2005; Hoffman et al., 2000; Hoffman et al., 2004). Os ácidos graxos são cadeias retas de hidrocarbono terminando em um grupo carboxila em uma terminação e um grupo metil na outra (Mahan \& Escott-Stump, 2002).

O leite materno é fonte de ácido linoléico e ácido $\alpha$-linolênico, além de ácido araquidônico (ARA), eicosapentaenóico (EPA) e docosaexaenóico (DHA) (Innis, 2007). Diferentemente, os leites de fórmulas contêm apenas o ácido linoléico e ácido $\alpha$-linolênico (Makrides et al., 1995). Os ácidos graxos essenciais na dieta são o ácido linoléico e o ácido $\alpha$-linolênico. $O$ ácido linoléico, através da ação das enzimas desaturase, pode ser convertido em ácido gama-linoléico e ARA. Já o ácido $\alpha$-linolênico pode ser convertido em EPA e deste convertido para o ácido DHA. O termo "essencial" significa que são necessários na dieta e não podem ser sintetizados pelo corpo humano (Innis, 2007).

Alguns estudos mostram que a concentração plasmática de DHA é menor em crianças desnutridas do que em crianças bem nutridas (Inbal Savion \& Igal Savion, 2007; Leichsenring et al., 1995; Smit, Oelen, Seerat, Muskiet \& Boersma, 2000). Smit, Muskiet e Boersma (2004) afirmaram que a baixa ingestão de ácidos graxos essenciais explica em parte a redução de ácidos graxos em crianças desnutridas, pois a digestão, a absorção e o transporte de nutrientes também se encontram prejudicados em conseqüência da desnutrição. Além disso, a dessaturação de ácidos graxos essenciais está reduzida e ocorre um alto consumo de ácidos graxos pela ß-oxidação e peroxidação.

Estudos que envolveram recém-nascidos pequenos para a idade gestacional (PIG) de termo e pré-termo mostraram que esses apresentaram baixas concentrações de ácidos graxos essenciais em comparação aos recém-nascidos com peso adequado para a idade gestacional (AIG) de termo e pré-termo (Agostin et al., 2008; Cetin et al., 2002; Felton et al., 1994; Llanos et al., 2005; van Eijsden et al., 2008).

Especificamente, o DHA está presente em alta concentração na retina, e encontrase incorporado primariamente dentro da estrutura glicerofosfolipídios da bicamada de lipídios da membrana celular, sendo particularmente concentrado dentro dos discos da membrana do segmento externo dos bastonetes (Jeffrey, Weisinger, Neuringer \& Mitchell, 2001). 
Evidências do importante papel de tais nutrientes na função visual foram encontradas por estudos que mostraram que uma dieta rica em ácidos graxos melhora a $\mathrm{AV}$ de crianças saudáveis recém-nascidas a termo (Birch et al., 2005; Hoffman et al., 2000; Hoffman et al., 2004) e pré-termo (O’Connor et al., 2001; SanGiovanni et al., 2000b).

Por outro lado, estudos mostram que uma dieta deficiente em DHA pode implicar em prejuízos visuais. Makrides et al. (1995) avaliaram longitudinalmente crianças recémnascidas a termo, saudáveis, nas faixas etárias de 16 e 30 semanas, alimentadas por leite materno ou leite de fórmula com ou sem DHA, utilizando o Potencial Visual Evocado de padrão reverso. Os resultados mostraram que a acuidade visual das crianças alimentadas com leite sem DHA foi reduzida em relação às alimentadas por leite materno. Todavia, a acuidade visual das crianças nutridas por leite enriquecido com DHA foi semelhante à das crianças amamentadas por leite materno, em ambas as idades.

Marín, Rey, Pedersolí, Rodrigo e Alaniz (2000) mostraram que uma dieta pobre em DHA, também, prejudica o desenvolvimento visual de crianças recém-nascidas desnutridas. Os autores mediram o eletrorretinograma de campo total por flash de luz em crianças nascidas a termo com desnutrição protéico-calórica moderada e idades entre 45 e 90 dias, cuja nutrição era leite materno ou leite de fórmulas com ou sem DHA. Os resultados do ERG mostraram aumento significante na latência da onda $b$ apenas para as crianças alimentadas por leite sem DHA quando comparadas as nutridas por leite materno.

Em revisão da literatura, não encontramos estudos que relacionaram os níveis de ácidos graxos e desenvolvimento visual com recém-nascidos PIG, embora alguns estudos tenham mostrado que esses recém-nascidos apresentam baixas concentrações de ácidos graxos essenciais em comparação aos bebês AIG (Agostin et al., 2008; Cetin et al., 2002; Felton et al., 1994; Llanos et al., 2005; van Eijsden et al., 2008).

\section{I.8. Conseqüências da Desnutrição para o Sistema Visual Humano}

Análises morfológicas em células piramidais localizadas nas áreas corticais somestésica, motora e occipital de crianças, com idades de 8 a 24 meses, vítimas da 
desnutrição protéico-calórica severa pós-natal mostraram redução significativa no comprimento dos dendritos apicais e no número de espinhos por dendrito nas três áreas corticais em comparação às crianças bem-nutridas (Benítez-Bribiesca et al., 1999).

Stanley, Fleming e Morgan (1991) avaliaram os efeitos da restrição do crescimento intrauterino no desenvolvimento cortical de recém-nascidos pré-termo, logo após o nascimento e aos nove meses de idade, utilizando o Potencial visual evocado por flashes de luz (PVEf). Os resultados mostraram que o desenvolvimento das latências de duas ondas negativas (N2 e N3) do PVEf encontrava-se atrasado em crianças que sofreram RCIU quando avaliadas logo após o nascimento; e redução na amplitude de $\mathrm{N} 3$ aos nove meses de idade que indicava que o desenvolvimento do PVEf continuava alterado até essa idade em comparação aos recém-nascidos com crescimento adequado. Os autores sugeriram que a RCIU pode afetar o desenvolvimento de atividade secundária no córtex visual estriado.

Hermans, Van Hof-van Duin e Oudesluys-Murpy (1992) mediram a acuidade visual de recém-nascidos PIG e AIG de termo e pré-termo até 7,71 semanas de idade, utilizando o procedimento de Cartão de Acuidade. Os autores não observaram diferenças significativas nas médias de acuidade visual entre os subgrupos AIG pré-termo, PIG prétermo, AIG de termo e PIG de termo. Esses resultados não indicam nenhuma influência negativa da RCIU na acuidade visual ou algum benefício na acuidade visual decorrente da prematuridade pelo aumento da experiência visual em comparação ao recém-nascido de termo.

Van Hof-van Duin et al. (1992) verificaram os efeitos da experiência visual extra no campo visual e acuidade visual em crianças de 6 a 52 semanas de idade corrigida e aos 2 anos e 6 meses de vida que nasceram PIG e AIG pré-termo. Os resultados mostraram que o desenvolvimento da visão até dois anos e meio de idade era similar entre os grupos AIG e PIG considerando tanto a idade natal como a corrigida. Os autores concluíram que a experiência visual extra não acelera o desenvolvimento da acuidade visual ou da visão periférica.

Getz, Dobson e Luna (1994) avaliaram (1) a acuidade visual com os Cartões de Acuidade de Teller; (2) o campo visual com o Perímetro Cinético desenvolvido por Mohn e Van Hof-van Duin (1986); e (3) acuidade de reconhecimento com o HOTV letter chart, 
em crianças de zero a 48 meses de vida que nasceram PIG e AIG pré-termo com complicações perinatais, como por exemplo, estágio três de retinopatia da prematuridade, displasia broncopulmonar, asfixia perinatal e desordem de membrana hialina. Os resultados mostraram que a acuidade visual de resolução de grades e o campo visual eram semelhantes entre os grupos PIG e AIG, no entanto o grupo AIG apresentou média mais alta para a acuidade de reconhecimento em comparação ao grupo PIG o que sugere que as crianças que nasceram PIG podem ter risco aumentado para déficit na acuidade de reconhecimento. No entanto, os autores alertaram que a alta proporção de anormalidades oculares (ambliopia estrábica e miopia) na amostra do grupo PIG pode ter contribuído para a baixa acuidade de reconhecimento.

Durmaz, Karagöl, Deda e Zülküfönal (1999) avaliaram os efeitos da desnutrição protéica e energética no desenvolvimento das vias visuais de crianças com idades de 2 a 18 meses utilizando o PVEf. Os resultados não revelaram diferenças significativas nas médias

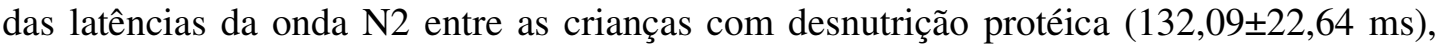
desnutrição energética $(118,80 \pm 11,17 \mathrm{~ms})$ e bem nutridas $(112,50 \pm 13,5 \mathrm{~ms})$. Entretanto, mostraram que as crianças desnutridas apresentaram latências maiores do que as bem nutridas. Estes resultados sugerem ter havido prejuízo no processamento de informações nas vias neurais centrais.

Thordstein et al. (2004) avaliaram o desenvolvimento cerebral de crianças recémnascidas a termo e pré-termo com restrição de crescimento uterino desproporcional (RCUD) ou desnutrição intra-uterina desproporcional utilizando o PVEf durante as idades gestacionais de 40 e 46 semanas. Os resultados mostraram que as crianças com RCUD apresentaram latências significativamente mais longas nas ondas $\mathrm{P}$ e $\mathrm{N}$ do que as crianças com crescimento adequado, durante as duas idades gestacionais. Os autores concluíram que há um atraso no desenvolvimento do sistema visual de crianças com RCUD estimados em três semanas. Além disso, mostraram que as crianças com RCUD não obtiveram benefícios no PVEf com a reabilitação nutricional até a idade gestacional de 46 semanas.

Dantas, Brandt e Leal (2005) investigaram possíveis alterações oftalmológicas em 91 crianças entre 2 e 11 anos de idade que tiveram desnutrição grave durante os seis primeiros meses de vida utilizando os Cartões de Acuidade de Teller (CAT), testes de 
motilidade aocular, biomicroscopia, refração e fundoscopia. Os resultados mostraram que houve uma maior freqüência (em \% de olhos) de crianças desnutridas com valores de acuidade visual de 0,3 a $0,1(7,7 \%)$ e menor que $0,1(3,8 \%)$ em comparação as crianças eutróficas. Observou-se ainda, uma maior freqüência de astigmatismo (51,6\%), miopia $(1,6 \%)$ e alterações fundoscópicas, tais como palidez de papila $(2,2 \%)$, aumento da escavação papilar (4,4\%), aumento da tortuosidade vascular $(6,6 \%)$, alteração da cor da retina $(13,2 \%)$ e atrofia do epitélio pigmentar da retina $(12,0 \%)$ nas crianças que tiveram desnutrição. Os autores concluíram que a desnutrição precoce efetivamente interfere na função visual e na saúde ocular dos indivíduos.

McDonald, Joffe, Barnet e Flinn (2007) mediram o PVEf em crianças com desnutrição protéico-calórica durante a admissão e alta hospitalar, respectivamente aos $199 \pm 28$ dias e aos $326 \pm 22$ dias de vida. Os resultados mostraram que no período de admissão, as latências das ondas N3 (220 ms), P3 (480 ms) e P4 (810 ms) foram significativamente mais longas para as crianças com desnutrição do que para as bem nutridas. No período de alta hospitalar, as crianças desnutridas, apresentavam amplitudes anormalmente maiores na onda P3 (620 ms) em comparação as bem nutridas. Esses resultados sugerem que existem déficits em áreas corticais responsáveis pelo processamento visual de ordem mais alta em crianças desnutridas e que a reabilitação nutricional não elimina completamente as anormalidades no PVEf dessas crianças, possivelmente devido a alteração do desenvolvimento normal da inibição GABAérgica.

Nilsson, Dahlgren, Karlsson e Grönlund (2011) investigaram se as crianças nascidas PIG pré-termo apresentavam alterações no PVE por reversão de padrões na idade pré-escolar, quando comparadas ao grupo AIG pré-termo. Os resultados mostraram que não houve diferença estatística significativa entre os grupos na avaliação monocular e binocular para as latências do componente de alta amplitude positivo ao redor dos $100 \mathrm{~ms}$ (P100). Não houve diferença significativa na latência do PVE entre as crianças nascidas PIG classificadas como simétrico (102,2 ms) e assimétrico $(99,5 \mathrm{~ms})$. Os autores relataram que o presente estudo corrobora o achado de outros autores que sugerem que os recémnascidos PIG apresentam uma aceleração na maturação neurofisiológica após o nascimento levando a normalização das latências do PVE aos 12 meses de vida. 
Os estudos anteriores sugerem que a desnutrição altera a estrutura e o funcionamento do sistema visual humano o que fornece um forte indício para possíveis alterações no desenvolvimento da acuidade visual e da sensibilidade ao contraste. Entretanto, os efeitos da desnutrição no sistema visual humano ainda são pouco explorados. Encontramos apenas 13 estudos, dentre estes dois morfológicos, cinco eletrofisiológicos (PVE) e seis psicofísicos. No entanto, quatro estudos mediram a AV de recém-nascidos PIG apenas com teste psicofísico e não localizamos estudos envolvendo a avaliação da SC de recém-nascidos PIG. Dessa forma, o presente estudo visa contribuir com informações referentes ao desenvolvimento da AV e SC de recém-nascidos PIG nos primeiros meses de vida utilizando o PVEv.

Adicionalmente, consideramos para avaliação do sistema visual dos recém-nascidos PIG outros registros obtidos pelo PVEv (fase, amplitude, inclinação da reta de regressão linear, ruído e razão sinal ruído - SNR), pois podem evidenciar alterações no sistema visual de recém-nascidos PIG independente de existirem alterações ou não nos limiares de AV e SC (Mirabella et al., 2006). Estudos apontam para alterações na velocidade das respostas visuais e amplitude em recém-nascidos pequenos para a idade gestacional (Durmaz et al.,1999; McDonald et al., 2007; Stanley et al.,1991; Thordstein et al., 2004) o que justifica a importância da avaliação destas medidas no presente estudo. 


\section{OBJETIVOS}

\section{II.1. Objetivo Geral}

Avaliar o desenvolvimento da Acuidade Visual (AV) de resolução de grades e a Sensibilidade ao Contraste (SC) de recém-nascidos de termo pequenos para a idade gestacional (PIG).

\section{II.2. Objetivos Específicos}

Verificar as possíveis alterações nos registros do Potencial Visual Evocado de Varredura (limiar, inclinação da reta, fase, amplitude máxima, ruído médio e SNR) de recém-nascidos de termo pequenos para a idade gestacional em comparação aos recémnascidos com peso adequado para a idade gestacional. 


\section{METODOLOGIA}

\section{III.1. Situação ou Contexto:}

O presente estudo foi desenvolvido no Laboratório de Psicofisiologia Sensorial do Instituto de Psicologia da Universidade de São Paulo.

\section{III.2. Participantes:}

Participaram 53 recém-nascidos de termo pequenos para a idade gestacional - PIG, Grupo Experimental - GE, (Média de Idade = 9,24 \pm 3,77 semanas) e 73 recém-nascidos de termo com o peso adequado para a idade gestacional - AIG, Grupo Controle, GC, (Média de Idade $=11,27 \pm 4,34$ semanas). Dentre estes, 12 PIG e 18 AIG realizaram os testes visuais duas vezes com idades diferentes. Adicionamos ainda os resultados de alguns recém-nascidos avaliados durante o mestrado da aluna a fim de proporcionar uma melhor observação e avaliação dos resultados.

Os recém-nascidos foram selecionados previamente pela pesquisadora e profissionais do ambulatório de puericultura do HU/USP (Hospital Universitário da Universidade de São Paulo) e encaminhados ao laboratório da Visão no Instituto de Psicologia - USP. A participação na pesquisa ocorreu mediante a assinatura de termo de consentimento livre e esclarecido pelos responsáveis (Anexo A).

O presente estudo foi aprovado pelo Comitê de Ética em Pesquisa do HU-USP (registro 736/07A) (Anexo B).

Os critérios de inclusão para os GC e GE foram: idade $\geq 37$ semanas completas, exame oftalmológico com fundo de olho normal e ausência de doenças neurológicas ou sistêmicas. 
Excluiu-se do GE recém-nascidos pequenos para a idade gestacional que apresentavam anormalidades cromossômicas, anormalidades congênitas, infecções congênitas e desordens genéticas. Também foram excluídos de ambos os grupos, recémnascidos cujas mães apresentavam desordens renais, infecções e uso e abuso de drogas, tais como álcool e cigarro.

Os profissionais da Unidade Neonatal do HU/USP, rotineiramente, seis horas após o nascimento mediram o peso, comprimento e circunferência craniana dos recém-nascidos. Os recém-nascidos foram classificados como pequenos para a idade gestacional (PIG) ou adequados para a idade gestacional (AIG) a partir das curvas de crescimento intrauterino produzidas por Alexander, Himes, Kaufman, Mor e Kogan (1996) nos Estados Unidos da América, conforme mostra a Figura 6. Os recém-nascidos que apresentavam peso ao nascer correspondente ao percentil menor que 10 foram classificados como PIG e com o peso ao nascer entre os percentis 10 e 90 foram classificados como AIG.

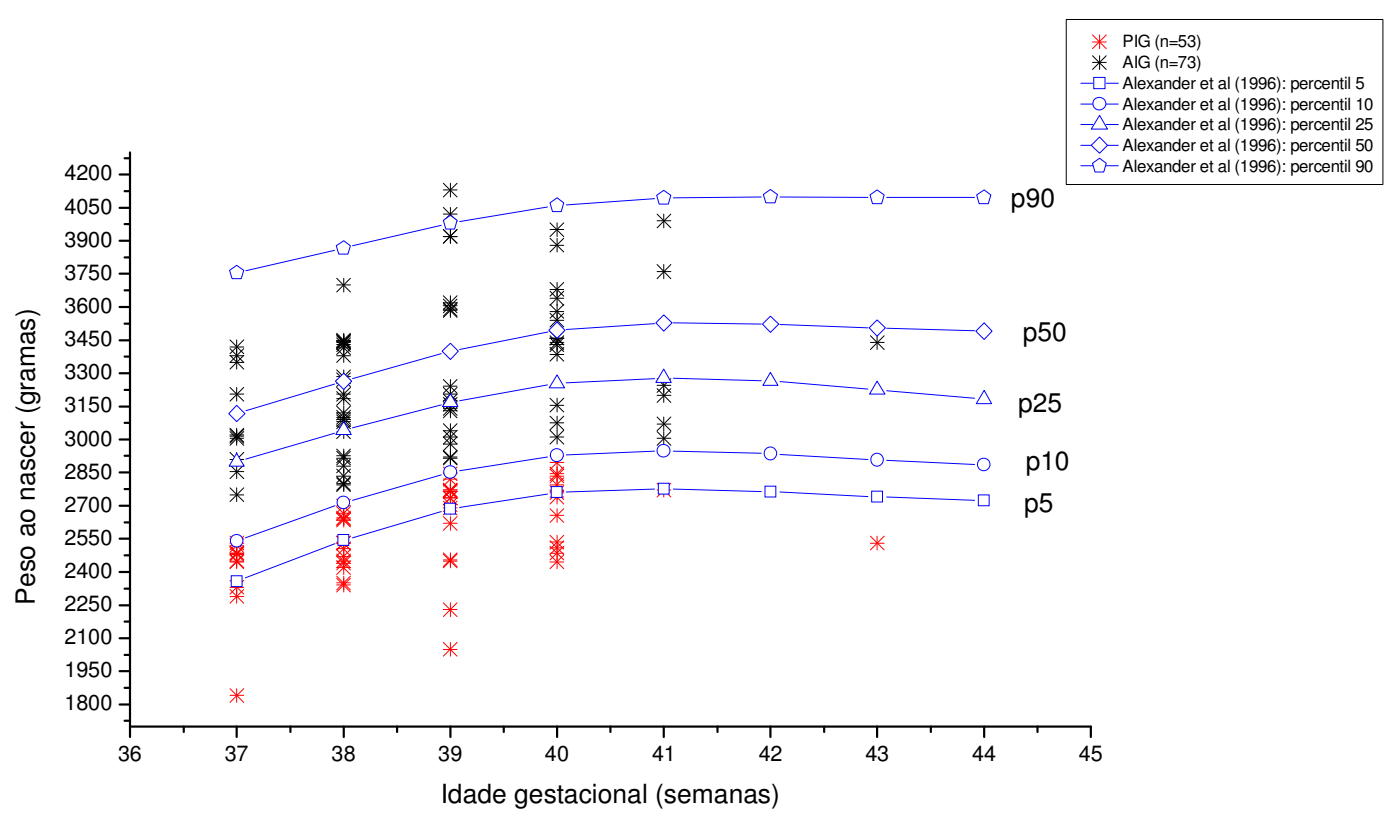

Figura 6. O peso ao nascimento de acordo com a idade gestacional para os recémnascidos PIG $(\times)$ e AIG $(*)$, segundo as curvas de crescimento intrauterino de Alexander et al (1996). 
A idade gestacional foi definida, conforme rotina da Unidade Neonatal do HU/USP, a partir dos seguintes critérios, por ordem de prioridade: (1) Informação materna sobre a data da última menstruação, segundo a Regra de Naegele que considera o tempo normal de 280 dias, quando esta diferia em menos de duas semanas da idade gestacional fornecida pela ultrasonografia fetal realizada antes da $20^{\mathrm{a}}$ semana de gestação; (2) ultrasonografia precoce, realizada com menos de 20 semanas de gestação, nos casos em que a idade gestacional não foi considerada confiável ou a diferença entre as idades calculadas pelos métodos ultrasonográficos e por métodos pós-natais (Método de Capurro e New Ballard) foi inferior a duas semanas; e (3) idade gestacional pós-natal calculada através do Método de Capurro para os recém-nascidos de termo e o Método de New Ballard para os recém-nascidos pré-termo, quando esta diferia em mais de duas semanas das idades gestacionais materna e ultrasonográfica (Capurro et al., 1978; Ballard et al., 1991).

O Índice ponderal (IP) de Rhorer $\{$ IP $=$ peso em gramas $\times 100 /($ comprimento em $\left.\mathrm{cm})^{3}\right\}$ foi calculado pela pesquisadora a fim de avaliar o peso em relação ao comprimento, isto é a proporcionalidade corporal de todos os recém-nascidos. Utilizaram-se os percentis de Índice Ponderal segundo a idade gestacional registrados por Ramos (1983) para classificar os recém-nascidos como assimétrico ou com baixo peso para estatura (percentil menor que 10) e simétrico ou pesado para a estatura (percentil maior que 10). As curvas de Ramos (1983) foram construídas a partir dos dados dos recém-nascidos vivos da Maternidade do Hospital das Clínicas da Faculdade de Medicina da Universidade de São Paulo.

A Figura 7 mostra a distribuição dos recém-nascidos PIG e AIG para o Índice Ponderal de Rohrer de acordo com a idade gestacional, segundo as curvas de Ramos (1983). A proporcionalidade corporal distribui-se diferentemente entre os recém-nascidos PIG e AIG. Há um maior número de recém-nascidos PIG assimétricos, isto é com baixo peso para estatura $(n=14)$ em comparação ao grupo AIG $(n=4)$. Para ambos os grupos o número de recém-nascidos simétricos (PIG n= 36; AIG n=68) foi maior do que os recémnascidos assimétricos. 


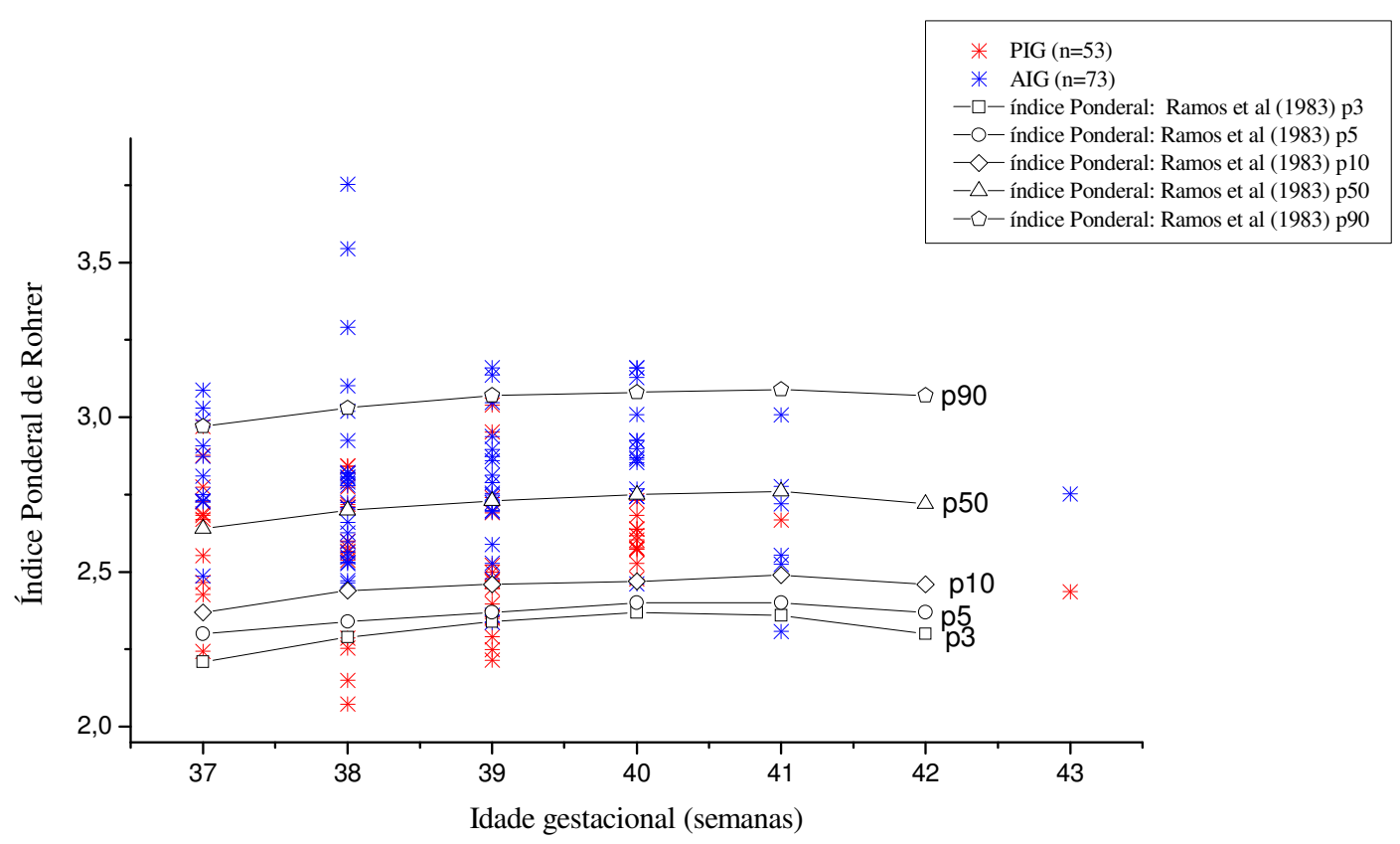

Figura 7. O índice ponderal de Rohrer de acordo com a idade gestacional para os recémnascidos PIG e AIG, segundo as curvas de Ramos (1983).

A Tabela 1 apresenta as informações demográficas (Média e Desvio-Padrão) dos recém-nascidos PIG e AIG.

Tabela 1. Informações Demográficas (Média e Desvio-Padrão) ao nascimento dos recémnascidos PIG e AIG.

\begin{tabular}{lcc}
\hline & $\begin{array}{c}\text { Recém-nascidos PIG (n=53) } \\
\text { Média (DP) }\end{array}$ & $\begin{array}{c}\text { Recém-nascidos AIG (n=73) } \\
\text { Média (DP) }\end{array}$ \\
\hline Gênero (M:F) (n) & $(13: 40)(53)$ & $(41: 32)(73)$ \\
\hline Idade gestacional & $38,95(1,28)$ & $39,23(1,26)$ \\
\hline Apgar 1' & $8,66(1,33)$ & $8,97(1,15)$ \\
Apgar 5' & $9,60(0,65)$ & $9,70(0,69)$ \\
\hline Peso (g) & $2554,14(205,34)$ & $3299,11(331,43)$ \\
\hline Comprimento (cm) & $46,38(1,64)$ & $49,01(1,73)$ \\
\hline Crânio (cm) & $32,78(0,86)$ & $34,29(1,13)$ \\
\hline Índice Ponderal (IP) & $2,56(0,21)$ & $2,81(0,26)$
\end{tabular}


Após os exames visuais mediu-se o peso, comprimento e circunferência craniana dos recém-nascidos PIG e AIG. A partir dos dados de peso obtidos no dia dos testes visuais foi possível classificar o estado nutricional dos recém-nascidos PIG e AIG, segundo a classificação de Gomez modificada por Bengoa que se baseia no índice de peso para idade e sexo (P/I). No qual P/I corresponde ao peso observado dividido pelo peso esperado para a idade e sexo (p50) multiplicado por 100. O p50 é definido como o percentil 50 do padrão de referência (NCHS, 2006).

A Tabela 2 mostra a classificação do estado nutricional dos recém-nascidos PIG e AIG no dia dos testes visuais, segundo critério de Gomez, modificado por Bengoa. Observa-se que a metade dos recém-nascidos PIG encontrava-se com o peso adequado para a idade no dia dos testes visuais e a maioria dos recém-nascidos AIG apresentava o estado nutricional saudável, no entanto nove deles foram considerados com grau leve de desnutrição.

Tabela 2. Classificação do estado nutricional dos recém-nascidos PIG e AIG no dia dos testes visuais, segundo critério de Gomez, modificado por Bengoa.

\begin{tabular}{lcc}
\multicolumn{1}{c}{ Estado de Nutrição } & $\begin{array}{c}\text { Recém-nascidos PIG } \\
(\mathbf{n = 5 3 )}\end{array}$ & $\begin{array}{c}\text { Recém-nascidos } \\
\text { AIG }(\mathbf{n = 7 3 )}\end{array}$ \\
\hline Eutrofia & 17 & 46 \\
\hline Desnutrição leve ou de $1^{\mathbf{o}}$ grau & 21 & 14 \\
\hline Desnutrição moderada ou de $2^{\mathbf{o}}$ grau & 09 & 01 \\
\hline Desnutrição grave ou de $3^{\mathbf{0}}$ grau & 0 & 0 \\
\hline Sem dados de peso nos testes visuais & 6 & 12 \\
\hline
\end{tabular}

Realizou-se anamnese nutricional com as mães a fim de (1) identificar-se a etiologia do nascimento PIG e (2) obter informações sobre a nutrição materna durante a gestação e amamentação, assim como a nutrição do bebê nos períodos neonatal e pós-natal. 


\section{III.3. Equipamentos e Estímulos Visuais:}

Utilizamos o sistema PowerDiva (Digital Infant Visual Assessment) para o registro do PVEv, desenvolvido por Norcia e Tyler (1985), constituído por um programa de comando de estimulação e análise de dados digitalizados.

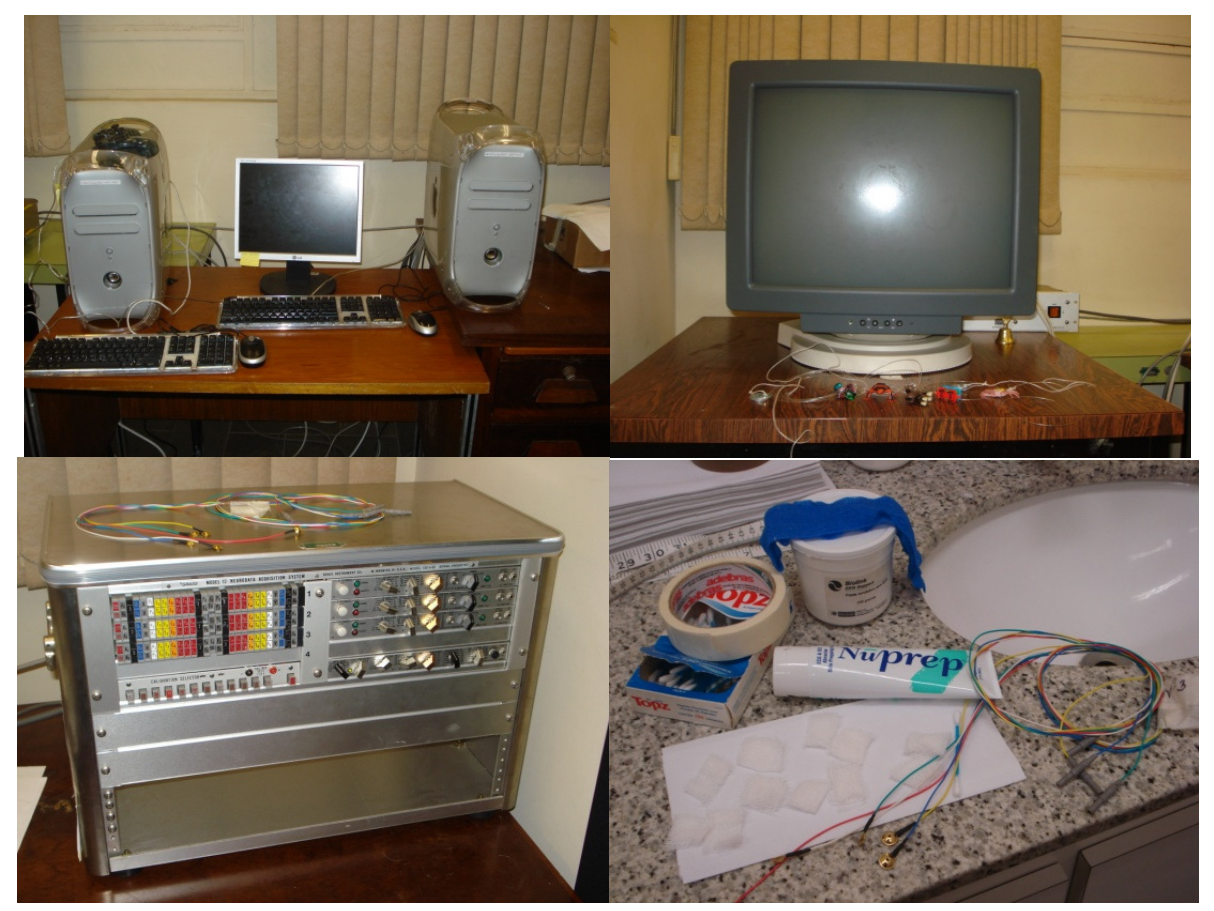

Figura 8. Equipamentos de registro do Potencial Visual Evocado de Varredura. Um microcomputador Power Macintosh modelo G4 (à esquerda acima), um amplificador Neurodata Grass (à esquerda abaixo), um monitor de vídeo FIMI Modelo MD0709BRM (à direita acima), eletrodos e materiais para a sua fixação (à direita abaixo).

O programa funcionou em um Power Macintosh modelo G4 no qual uma interface A/D executou a aquisição de dados. Para avaliação da AV e FSC, os estímulos eram compostos de grades de ondas verticais senoidais apresentadas em um monitor de vídeo monocromático de 21 polegadas e com alta resolução (FIMI Model MD0709BRM - MGD 403) compreendendo 34 graus de ângulo visual a $65 \mathrm{~cm}, 17$ graus de ângulo visual a 131 $\mathrm{cm}$ e 14 graus de ângulo visual a $165 \mathrm{~cm}$. Os testes iniciais foram realizados com a 
luminância média do monitor de vídeo com $161,13 \mathrm{~cd} / \mathrm{m}^{2}$, mas o nível de luminância média diminuiu com o passar do tempo e finalizamos as análises com 135,25 cd/ $/ \mathrm{m}^{2}$.

Durante a sessão de teste de AV, uma seqüência de dez freqüências espaciais, designada varredura, era apresentada na razão de uma freqüência por segundo. As freqüências espaciais foram apresentadas com padrão de reversão temporal de $6 \mathrm{~Hz}$. O contraste era mantido fixo com o valor de $80 \%$.

A faixa de varredura utilizada foi selecionada de acordo com a faixa etária dos participantes e consistiu em valores que abrangiam e ultrapassavam a faixa de valores de resolução de grades que o participante em teste poderia resolver, estimada baseada nas normas de Norcia e Tyler (1985). Sendo assim, as faixas de varredura utilizadas para os recém-nascidos de 5-10 semanas, 10-16 semanas e 16-28 semanas de vida foram, respectivamente, 0,8 a $8,5 \mathrm{cpg} ; 1,0$ a $16 \mathrm{cpg}$ e 2,0 a $25 \mathrm{cpg}$.

A seleção das faixas etárias dos participantes, também, baseou-se nas normas de Norcia e Tyler (1985) que mostraram diferenças significativas no limiar de AV entre essas faixas etárias. Por exemplo, a AV média para as idades de 5-10 semanas, 10-16 semanas e 16-28 semanas foram, respectivamente, $5,6 \mathrm{cpg}$; 7,0 cpg e $12,0 \mathrm{cpg}$.

Durante o teste de SC, uma varredura de contrastes era constituída por uma sequiência de dez níveis de contraste que foram apresentados numa razão de um quadro por segundo, com dez padrões de reversão em cada contraste. A frequiência espacial era mantida fixa em cada sessão de teste. A freqüência temporal das reversões foi $6 \mathrm{~Hz}$.

A sensibilidade ao contraste foi medida apenas para a freqüência espacial de 0,5 cpg, cuja faixa de varredura utilizada foi 0,3 a $25 \%$ de contraste para todas as faixas etárias avaliadas no presente estudo, estimada baseada nos estudos de Norcia et al (1990).

As medidas de PVEv foram obtidas através de eletrodos de EEG (Grass Gold Disc Electrodes - E6GH) fixados no escalpo com um creme eletrolítico (Biolink EEG) e com algodão (Webril II). O escalpo era limpo com uma solução apropriada para testes eletrofisiológicos (Nuprep). Uma faixa elástica (3M Coban Self-Adherent Wrap 1581) foi utilizada para manter os eletrodos aderidos ao local. 


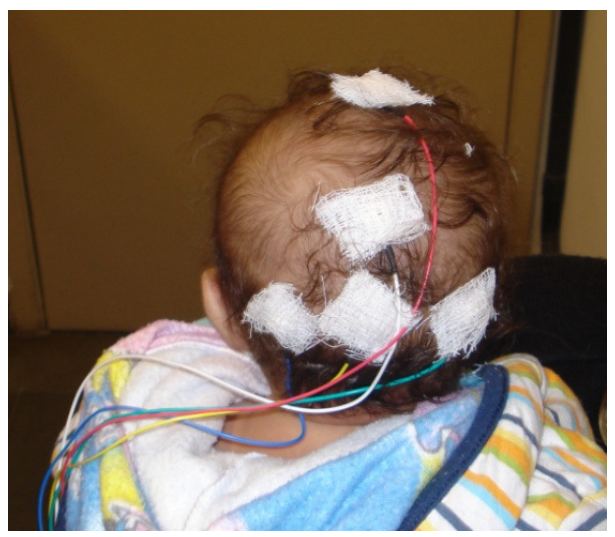

Figura 9. Posição dos eletrodos de registro do Potencial Visual Evocado de Varredura sobre o córtex occipital.

O eletroencefalograma foi obtido a partir de três arranjos unipolares de eletrodos: O1 versus $\mathrm{Cz}$ (Canal 1 - hemisfério esquerdo), Oz versus $\mathrm{Cz}$ (Canal 2 - linha média) e O2 versus $\mathrm{Cz}$ (Canal 3 - hemisfério direito). Os eletrodos ativos $\mathrm{O} 1$ e $\mathrm{O} 2$ localizavam-se, respectivamente, a $2 \mathrm{~cm}$ para a direita e para a esquerda do eletrodo ativo $\mathrm{Oz}$ o qual por sua vez será fixado $1 \mathrm{~cm}$ acima do ínion na linha média. Já, o eletrodo de referência $(\mathrm{Cz})$ estava localizado no vertex. Um eletrodo terra foi fixado $4 \mathrm{~cm}$ acima de $\mathrm{Oz} . \mathrm{O}$ eletroencefalograma foi amplificado por um amplificador Neurodata Grass (12C-4-23 ganho = 20.000; atenuação de -3db entre 0,3 e 100 Hz) (Norcia \& Tyler, 1985).

\section{III.4. Procedimento Experimental:}

O PVEv foi utilizado para medir o limiar de acuidade visual e a sensibilidade ao contraste para cada conjunto de estímulos. As medidas de AV e SC eram realizadas no mesmo dia. $\mathrm{O}$ experimentador ativava a varredura das freqüências espaciais quando a criança estava em alerta e observando atentamente o monitor de vídeo. O EEG era captado simultaneamente dos três canais e filtrado em tempo real (taxa de amostragem $=601 \mathrm{~Hz}$ ) para isolar o PVE e uma análise espectral foi aplicada com o método de filtragem dos Mínimos Quadrados Adaptativo e Recursivo ("Recursive Least Squares" - RLS) para calcular a amplitude e a fase para o segundo harmônico da freqüência de estimulação de 6 $\mathrm{Hz}$ que corresponde a $12 \mathrm{~Hz}$ (Tang \& Norcia, 1995). É possível extrair respostas em 
teoricamente qualquer harmônico da freqüência temporal fundamental (aquela usada para apresentação do estímulo). Este método de análise dos dados substitui a transformada discreta de Fourier usada nas versões antigas do software, pois garante uma relação sinal por ruído maior em $10 \mathrm{~dB}$ (Tang \& Norcia, 1993). As medidas eram digitalizadas e uma transformada discreta de Fourier foi aplicada para medir a amplitude e a fase sobre a faixa de $1 \mathrm{~Hz}$ de banda centralizada no segundo harmônico $(12 \mathrm{~Hz})$ da frequiência de estimulação visual $(6 \mathrm{~Hz})$.

A frequiência de ruído era $\pm 1 \mathrm{~Hz}$ em torno da frequiência temporal de análise. A amplitude e a fase foram apresentadas em um gráfico em tempo real, em função da frequiência espacial (cpg) nos testes de AV e em função do contraste nos testes de SC. Os testes foram realizados binocularmente em uma sala escura. A apresentação de cada estímulo por 1 segundo precedeu o início de cada varredura, em cada freqüência temporal avaliada. Durante os testes, pequenos brinquedos eram apresentados em frente ao monitor de vídeo e movimentados pelo experimentador para chamar a atenção da criança e manter sua fixação próxima ao centro da tela.

\section{Análise dos Registros do PVEv:}

Os limiares de AV e SC foram estimados usando um algoritmo automatizado. No caso da AV, este algoritmo traçou um ajuste linear dos dados de amplitude do segundo harmônico em função da freqüência espacial, e no caso da SC, em função do contraste. Os limiares de acuidade visual e SC foram obtidos pela extrapolação para amplitude zero dessa função de ajuste linear. A estimativa final da AV foi expressa em ciclos por grau (cpg) de ângulo visual e para a SC foi expressa em porcentagem de contraste. 

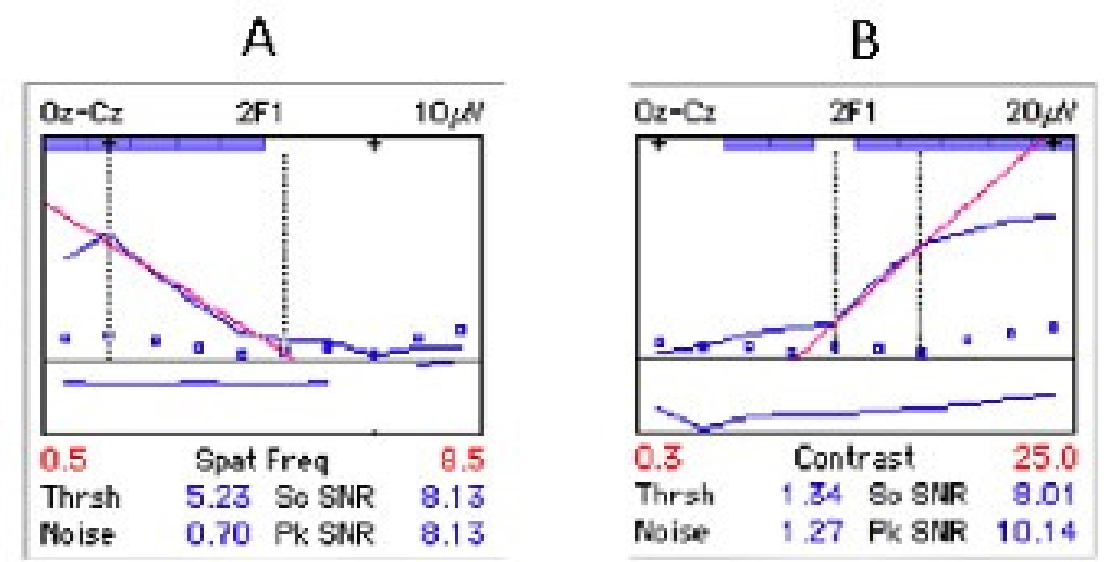

Figura 10. Exemplo de registro da acuidade visual (A) e sensibilidade ao contraste (B) com o PVEv para frequiência de estimulação a $6 \mathrm{~Hz}$. Determinamos a acuidade visual e a sensibilidade ao contraste pela extrapolação da resposta à amplitude zero através da regressão linear. Os pontos azuis representam o ruído neural, isto é frequiências temporais $1 \mathrm{~Hz}$ acima e abaixo da freqüência de resposta a $12 \mathrm{~Hz}$ (segundo harmônico). A linha azul no quadro superior representa a resposta visual ou sinal. A linha azul no quadro inferior indica a fase que varia entre $-\pi \mathrm{a}+\pi$. $\mathrm{O}$ ponto azul onde a linha vermelha toca a abscissa é considerado o limiar de acuidade. Os retângulos azuis na borda superior correspondem à estatística t-circ que mostra se uma dada amplitude é significativamente diferente da amplitude zero considerando as respostas de amplitude e fase consistentes através das tentativas. Legenda: Thrsh, limiar; Spat Freq., freqüência espacial; Noise, ruído; Sc SNR, razão sinal para o ruído máxima no registro; Pk SNR, razão sinal para o ruído máxima na média de valores usados para determinar o limiar.

Para que uma varredura fosse considerada válida exigiu-se uma razão sinal-ruído de 3:1 no pico da amplitude para médias vetoriais, considerando os resultados do melhor canal de registro. Realizaram-se, no mínimo, cinco varreduras com boa razão sinal/ruído e fase constante que compõe a média, assim estimou-se o limiar com confiança. Além disso, o software quantificou automaticamente a significância estatística para cada bin (registro por segundo) usando valores de $p$ derivados de uma estatística circular $\mathrm{T}$ ( $\mathrm{T}^{2}$ circ) que mostrava se uma dada amplitude de resposta era significativamente diferente da amplitude zero considerando-se ambas as respostas de amplitude e fase consistentes através das tentativas (Victor \& Mast, 1991). 


\section{III.5. Análises dos Dados:}

Os limiares de AV (cpg) obtidos pelo PVEv foram convertidos em Log e os limiares de contraste foram convertidos em valores de SC. Analisamos outros registros do PVEv, além dos limiares de AV e SC. Para tanto, selecionamos os registros do PVEv para o bin com amplitude máxima, SNR máxima e fase máxima. Para o registro de ruído, consideramos a média de ruído para todos os bins.

Calculamos ainda o valor de inclinação da reta de regressão linear gerada pelo sistema Powerdiva (Figura 10) para ambas as funções visuais:

Para acuidade visual: Inclinação da reta $(\mathrm{m})=\mathrm{y}-\mathrm{y} 0 / \mathrm{x}-\mathrm{x} 0$, onde y é igual a zero, pois corresponde a amplitude em zero microvolts; y0 é igual ao valor de amplitude máxima escolhida correspondente ao bin esquerdo nesse caso; $\mathrm{x}$ corresponde ao valor de limiar de acuidade visual, isto é, o valor resultante da interceptação da reta no eixo x; x0 corresponde ao valor da frequência espacial correspondente ao bin esquerdo. Os valores do eixo x ou freqüência espacial encontravam-se em escala linear.

Para a sensibilidade ao contraste: Inclinação da reta $(\mathrm{m})=\mathrm{y}-\mathrm{y} 0 / \log \mathrm{x}-\log \mathrm{x} 0$, onde y é igual ao valor da amplitude máxima escolhida correspondente ao bin direito nesse caso; y0 é igual a zero, pois corresponde a amplitude em zero microvolts; $\mathrm{x}$ é igual ao valor de contraste correspondente ao bin direito; $x 0$ corresponde ao valor de limiar de contraste, isto é, o valor resultante da interceptação da reta no eixo x. Os valores do eixo x foram convertidos em escala logarítmica.

A análise estatística foi feita com o programa Statistica (StatSoft Inc, Tulsa, Ok, USA, versão 6.0). Aplicou-se a ANOVA de um fator nas comparações entre os grupos para as medidas antropométricas (peso, comprimento e circunferência craniana). A ANOVA fatorial para as comparações entre os limiares de acuidade visual e sensibilidade ao contraste, amplitude máxima, SNR, ruído médio e valor de inclinação da reta dos grupos PIG e AIG. A ANOVA fatorial na comparação intragrupos para os parâmetros dos testes de acuidade visual e sensibilidade ao contraste entre duas faixas etárias. Utilizou-se a análise de regressão linear para calcular as taxas de desenvolvimento de fase dos grupos PIG e AIG. 
Realizou-se também a "normalização" dos nossos dados, para isso calculou-se a média dos limiares de acuidade visual e sensibilidade ao contraste para os recém-nascidos AIG que apresentavam o peso ao nascimento igual ou acima do percentil $50(\mathrm{P} \geq 50)$ considerando-se a idade gestacional, de acordo com as curvas de crescimento intrauterino de Alexander et al. (1996). Os recém-nascidos AIG foram agrupados em duas faixas etárias: 5-9 semanas de idade e 10-24 semanas. Dividiu-se o valor de acuidade visual e sensibilidade ao contraste de cada recém-nascido PIG pela média obtida para o grupo AIG (P50), considerando-se a faixa etária. Em seguida, calculou-se a freqüência de recémnascidos PIG acima e abaixo dos dados do grupo AIG. A aplicou-se o teste Qui-Quadrado com a correção de Yates para as freqüências observadas.

Aplicou-se a correlação de Spearman para os dados de peso ao nascimento e as medidas de acuidade visual e sensibilidade ao contraste. E a comparação entre os coeficientes de correlação para os resultados de sensibilidade ao contraste do grupo AIG e PIG que foram calculados com base numa estatística de diferença, onde os dados são submetidos a uma transformação Z de Fisher, podendo-se calcular o desvio padrão. Desta forma, os dois coeficientes podem ser comparados e, com base no número de sujeitos de cada grupo, uma estatística p é calculada para dar significância à diferença de coeficientes.

Realizou-se uma análise de test- $T$ de amostra única, com o objetivo de analisar se a média da diferença entre o $\log$ AV AIG e $\log$ AV PIG era similar ou diferente de valores teóricos de igual variância.

Como uma forma alternativa de buscar uma evidência de redução de função visual nos recém-nascidos PIG, realizou-se uma distribuição por percentis somente para o grupo AIG cujo valor de peso ao nascimento estava acima de 50\% das curvas antropométricas (P.50). Analisamos, assim, as frequiências de recém-nascidos PIG nas seguintes faixas: $<5 \%, 6-25 \%, 26-50 \%, 51-75 \%, 76-95 \%,>95 \%$ para os valores do grupo AIG P $>50$. 


\section{RESULTADOS}

Avaliamos os limiares de acuidade visual e sensibilidade ao contraste de luminância para 53 recém-nascidos de termo pequenos para a idade gestacional (PIG) e 73 recémnascidos de termo com o peso adequado para a idade gestacional (AIG).

Adicionalmente, avaliamos os registros de fase, inclinação da reta, amplitude máxima, ruído e razão sinal-ruído para os testes de acuidade visual e sensibilidade ao contraste de luminância para a freqüência espacial de $0,5 \mathrm{cpg}$ e freqüência temporal de 6 $\mathrm{Hz}$.

Realizaram-se as análises estatísticas para os recém-nascidos PIG e AIG agrupados em duas faixas etárias: 5-9 semanas e 10-24 semanas. O agrupamento por idade baseou-se na maior concentração de recém-nascidos nessas faixas etárias e no desenvolvimento da acuidade visual e sensibilidade ao contraste. Uma vez que o grupo AIG é formado por um grande número de recém-nascidos com o peso ao nascimento entre o percentil 10 e 50 $(n=42)$, dentre esses alguns recém-nascidos com o peso ao nascimento muito próximo ao percentil 10 (P10), ou seja, entre o P10 e P20 (n=17), a fim de realizar-se uma análise mais refinada dos resultados subdividiu-se o grupo AIG pelo percentil de peso ao nascimento: menor que 50 (AIG $\mathrm{P}<50, \mathrm{n}=42$ ) e maior ou igual a 50 (AIG $\mathrm{P} \geq 50, \mathrm{n}=31$ ).

A ANOVA com um fator para as comparações entre as medidas antropométricas dos grupos PIG e AIG aferidas no dia do nascimento mostrou que os PIG apresentaram redução significativa no peso $[\mathrm{F}(1,104)=162,48 ; \mathrm{p}=0,001]$, comprimento $[\mathrm{F}(1,104)=$ $60,55 ; \mathrm{p}=0,00001]$, crânio $[\mathrm{F}(1,104)=63,9 ; \mathrm{p}=0,00001]$ e no índice ponderal $[\mathrm{F}(1,104)$ = 20,99; $\mathrm{p}=0,00001]$ quando comparados aos AIG.

A ANOVA com um fator para as comparações entre as medidas antropométricas aferidas no dia dos testes visuais mostraram que os PIG apresentavam redução significativa no peso $[\mathrm{F}(1,104)=26,58 ; \mathrm{p}=0,00001]$, comprimento $[\mathrm{F}(1,104)=9,96$; $\mathrm{p}=0,002]$ e circunferência craniana $[\mathrm{F}(1,104)=12,27 ; \mathrm{p}=0,0007]$ quando comparados aos AIG. Essas análises devem ser avaliadas considerando-se a diferença entre as médias das idades dos grupos PIG (9,24 $\pm 3,77$ semanas) e AIG (11,27 $\pm 4,34$ semanas). 


\section{IV.1. Acuidade Visual e Sensibilidade ao Contraste de Luminância}

A Tabela 3 abaixo mostra as médias dos limiares de Acuidade Visual, em unidade logarítmica, e Sensibilidade ao Contraste para a freqüência espacial de 0,5 cpg dos recémnascidos PIG e AIG divididos em duas faixas etárias: 5-9 semanas e 10-24 semanas, cujos dados foram analisados por testes estatísticos. O grupo AIG foi subdividido por percentil de peso ao nascimento: menor que $50(\mathrm{P}<50)$ e maior ou igual a $50(\mathrm{P} \geq 50)$.

Tabela 3 - Mostra a média e o desvio-padrão dos limiares de acuidade visual, em unidade logarítmica, e sensibilidade ao contraste para a freqüência espacial de $0,5 \mathrm{cpg}$ dos recémnascidos PIG e AIG em duas faixas etárias. O grupo AIG foi subdividido por percentil de peso ao nascimento $(50 \leq \mathrm{P}<50)$.

\begin{tabular}{|c|c|c|}
\hline Grupos & $\begin{array}{c}\text { Acuidade Visual } \\
\text { (Log) }\end{array}$ & $\begin{array}{c}\text { Sensibilidade ao } \\
\text { contraste }\end{array}$ \\
\hline $\begin{array}{c}\text { AIG }<10 \text { semanas } \\
(P \geq 50)\end{array}$ & $0,69 \pm 0,13(n=18)$ & $58,48 \pm 24,16(n=14)$ \\
\hline 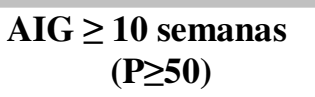 & $1,09 \pm 0,12(n=13)$ & $189,00 \pm 114,71(n=13)$ \\
\hline $\begin{array}{c}\text { AIG }<10 \text { semanas } \\
(P<50)\end{array}$ & $0,79 \pm 0,18(n=17)$ & $99,75 \pm 102,12(n=14)$ \\
\hline $\begin{array}{c}\mathrm{AIG} \geq \underset{(\mathrm{P}<\mathbf{5 0})}{10} \text { semanas } \\
\text { (I) }\end{array}$ & $1,01 \pm 0,13(n=25)$ & $152,27 \pm 114,56(n=23)$ \\
\hline PIG < 10 semanas & $0,73 \pm 0,14(n=33)$ & $96,34 \pm 117,11(n=26)$ \\
\hline PIG $\geq 10$ semanas & $1,02 \pm 0,12(n=20)$ & $124,95 \pm 85,99(n=19)$ \\
\hline
\end{tabular}

A ANOVA fatorial não mostrou diferença significativa entre os grupos de recémnascidos PIG, AIG $\mathrm{P} \geq 50$ e AIG $\mathrm{P}<50$ para os valores de acuidade visual em nenhuma das faixas etárias $[\mathrm{F}(1,124)=0,92 ; \mathrm{p}=0,40]$, conforme mostra a Tabela 3. No entanto, observaram-se diferenças significativas intragrupos para os valores de acuidade visual considerando-se as faixas etárias $[\mathrm{F}(1,124)=120,61 ; \mathrm{p}=0,00001]$. O teste post hoc de Fisher LSD (Least Significant difference) mostrou que a acuidade visual encontrava-se significativamente mais alta para os recém-nascidos PIG ( $p=0,00001)$, AIG P $\geq 50$ ( $p=0$, 00001) e AIG $\mathrm{P}<50(\mathrm{p}=0,00001)$ na faixa etária de 10 a 24 semanas em comparação aos recém-nascidos abaixo de 10 semanas de idade para seus respectivos grupos, conforme mostra a literatura (Norcia \& Tyler, 1985; Salomão et al., 2008). 


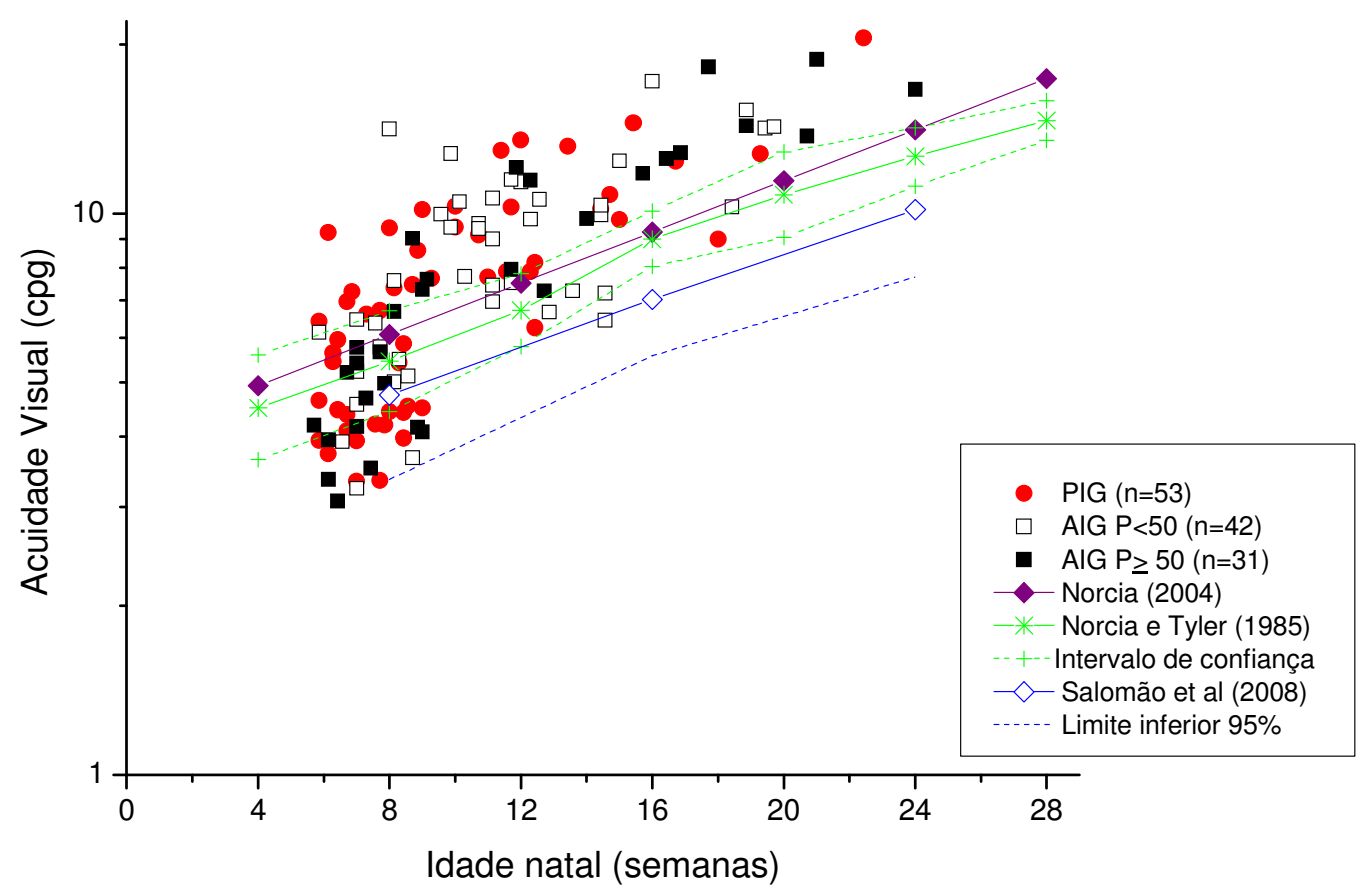

Figura 11. Desenvolvimento da acuidade visual medido pelo PVEv com a frequiência temporal de $6 \mathrm{~Hz}$ para os recém-nascidos PIG (•), AIG P<50 (口) e AIG P $\geq 50$ (匹) em comparação aos dados apresentados por Norcia (2004) (-४-), Norcia e Tyler (1985) (*) e Salomão et al (2008) (-৩-).

A Figura 11 acima mostra o desenvolvimento da acuidade visual, em unidade Logcpg, medido pelo PVEv com a freqüência temporal de $6 \mathrm{~Hz}$ para os recém-nascidos PIG e AIG em comparação aos dados de Salomão et al (2008), Norcia e Tyler (1985) e Norcia (2004) que é constituída pelos dados de Norcia e Tyler (1985) e de outros autores.

Observa-se na Figura 11 que a acuidade visual dos PIG e AIG desenvolve-se com a idade, assim como mostraram as normas de Norcia e Tyler (1985) e Salomão et al (2008). Uma parcela dos recém-nascidos PIG e AIG menores que 10 semanas de idade apresentou a acuidade visual mais baixa do que os valores observados por Norcia e Tyler (1985). No entanto, entre 10 e 24 semanas de idade, a acuidade visual dos grupos PIG e AIG encontrava-se mais alta do que as normas de Norcia e Tyler (1985) e Salomão et al (2008). No total foram 29 AIG e 21 PIG com valores de acuidade visual mais baixos (ou piores) que os dados de Norcia (2004); e 44 AIG e 32 PIG com valores de acuidade visual mais altos (ou melhores) que os dados de Norcia (2004). 
A fim de responder a esta pergunta: "a acuidade visual e a sensibilidade ao contraste dos recém-nascidos são afetadas pelo seu peso ao nascer, independentemente de sua idade no dia da medição?" fez-se a correlação do peso ao nascimento com os valores de acuidade visual e sensibilidade ao contraste considerando-se que essas funções visuais desenvolvemse ou aumentam com a idade. Para tanto os valores de acuidade visual e sensibilidade ao contraste dos recém-nascidos PIG e AIG foram "ajustados" para se tornarem comparáveis em todas as idades, uma vez que avaliamos os recém-nascidos em diferentes idades. Optou-se por utilizar as curvas de desenvolvimento de acuidade visual de seis estudos apresentados por Norcia (2004) (Figura 2) e a curva de desenvolvimento da sensibilidade ao contraste de Norcia, Tyler e Hamer (1990).

Para a acuidade visual, o procedimento utilizado para "ajustar" os valores de acuidade visual consistiu em fazer o ajuste linear dos dados apresentados por Norcia (2004), que está representado pelos dados na cor violeta (-४) na Figura 11, e obter a equação linear $\left(\log A V=Y=0,0228^{*} X+0,6020\right)$. Então, calcularam-se os valores de acuidade visual (Log) adicionando-se as idades dos recém-nascidos PIG e AIG no X dessa equação linear. Logo após, subtraiu-se o LogAV PIG (ou LogAV AIG) pelo LogAV obtido pela equação linear. Denominou-se como acuidade visual "ajustada" o resultado dessa subtração.

Correlacionou-se o peso ao nascimento e os valores de acuidade visual "ajustados", no entanto a correlação de Spearman não foi significante para os recém-nascidos AIG (r= $0,166 ; p=0,112)$ e PIG $(r=-0,131 ; p=0,141)$.

Realizou-se a análise da diferença entre os valores de acuidade visual (Log) dos recém-nascidos PIG e AIG, para tanto se fez o ajuste exponencial para os dados do grupo

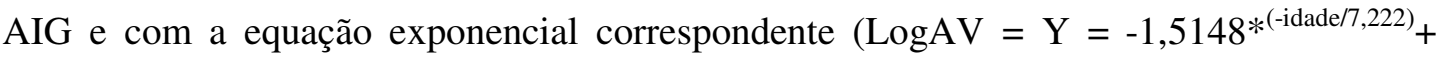
$1,2667)$ calcularam-se os valores de acuidade visual ( $\log )$ referentes às idades dos recémnascidos PIG, conforme mostra a Figura 12a. Dessa forma foi possível realizar a subtração entre o LogAV (Log acuidade visual) PIG e LogAV AIG obtido a partir da equação exponencial, conforme consta na Figura 12b. Aplicou-se o test- $T$ para média única, no entanto não encontramos diferenças significativas para a média da diferença de LogAV entre AIG e PIG $(t=0,433 ; p=0,667)$. 
A Figura 12 mostra a comparação da acuidade visual (log) entre os grupos PIG e AIG a partir do ajuste exponencial dos dados do grupo AIG.

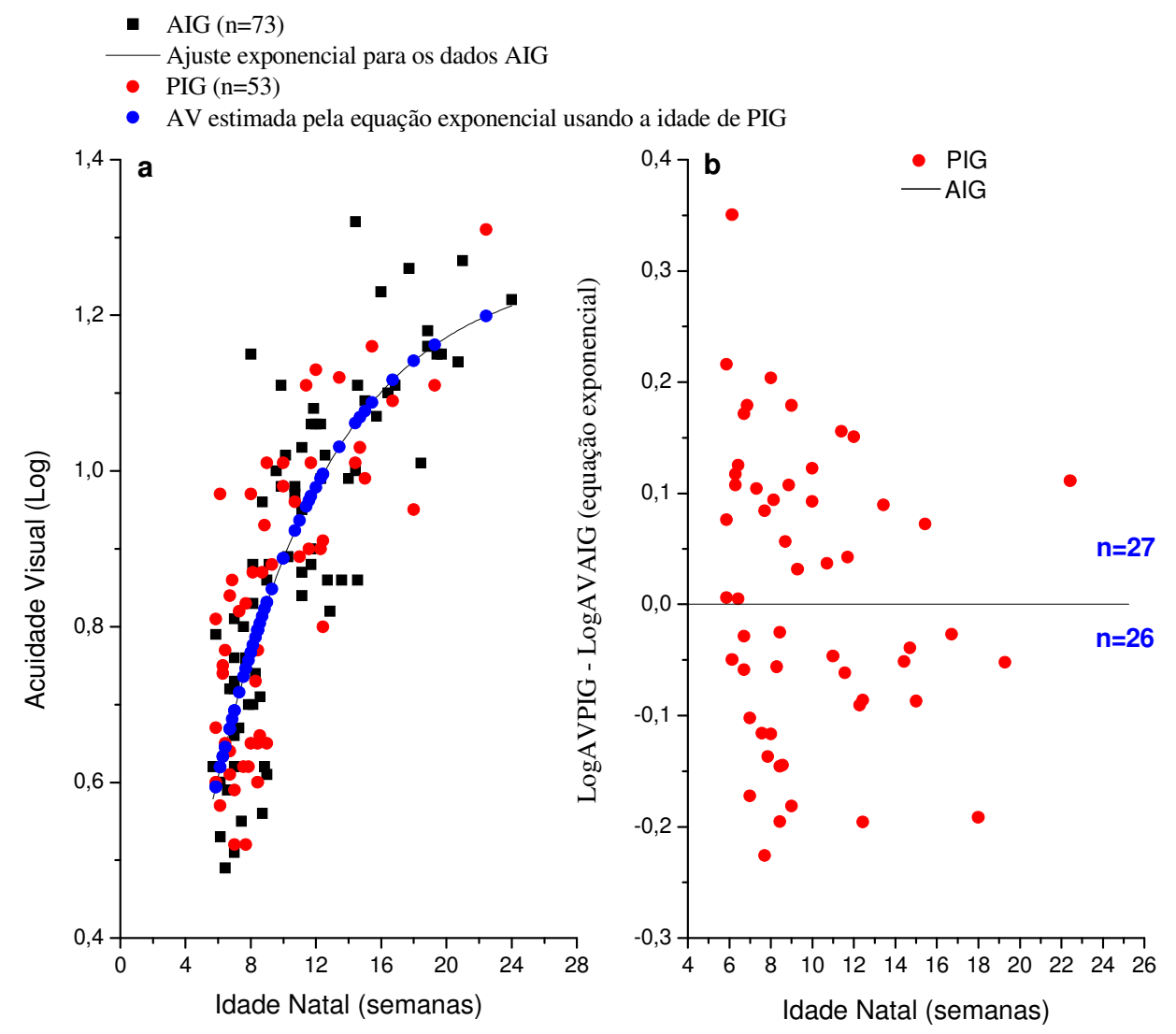

Figura 12. Comparação da acuidade visual $(\log )$ entre os grupos PIG (•) e AIG (ロ) a partir do ajuste exponencial dos dados do grupo AIG (•) (Figura a). A Figura $b$ mostra a diferença entre o LogAV PIG e LogAV AIG. A linha horizontal representa o grupo AIG e $n$ o número de recém-nascidos PIG.

Observa-se na Figura 12b que 26 recém-nascidos PIG apresentaram valores de acuidade visual menores do que a média do grupo AIG e 27 PIG apresentaram valores de acuidade visual mais altos do que a média do grupo AIG. A análise estatística não mostrou diferença significativa na proporção de recém-nascidos PIG com valores de acuidade visual abaixo ou acima do grupo $\mathrm{AIG}\left[\mathrm{x}^{2}=0,00 ; \mathrm{p}=0,94\right]$.

A Figura 13 mostra a distribuição dos dados de acuidade visual dos recémnascidos PIG até 9 semanas de idade em comparação aos percentis dos dados de acuidade 
visual do grupo AIG $\mathrm{P} \geq 50$. Observa-se que 61,29\% dos recém-nascidos PIG apresentaram valores de acuidade visual abaixo do percentil 50 da acuidade visual do grupo AIG $\mathrm{P} \geq 50\left[\mathrm{x}^{2}=7,28 ; \mathrm{p}=0,02\right]$.

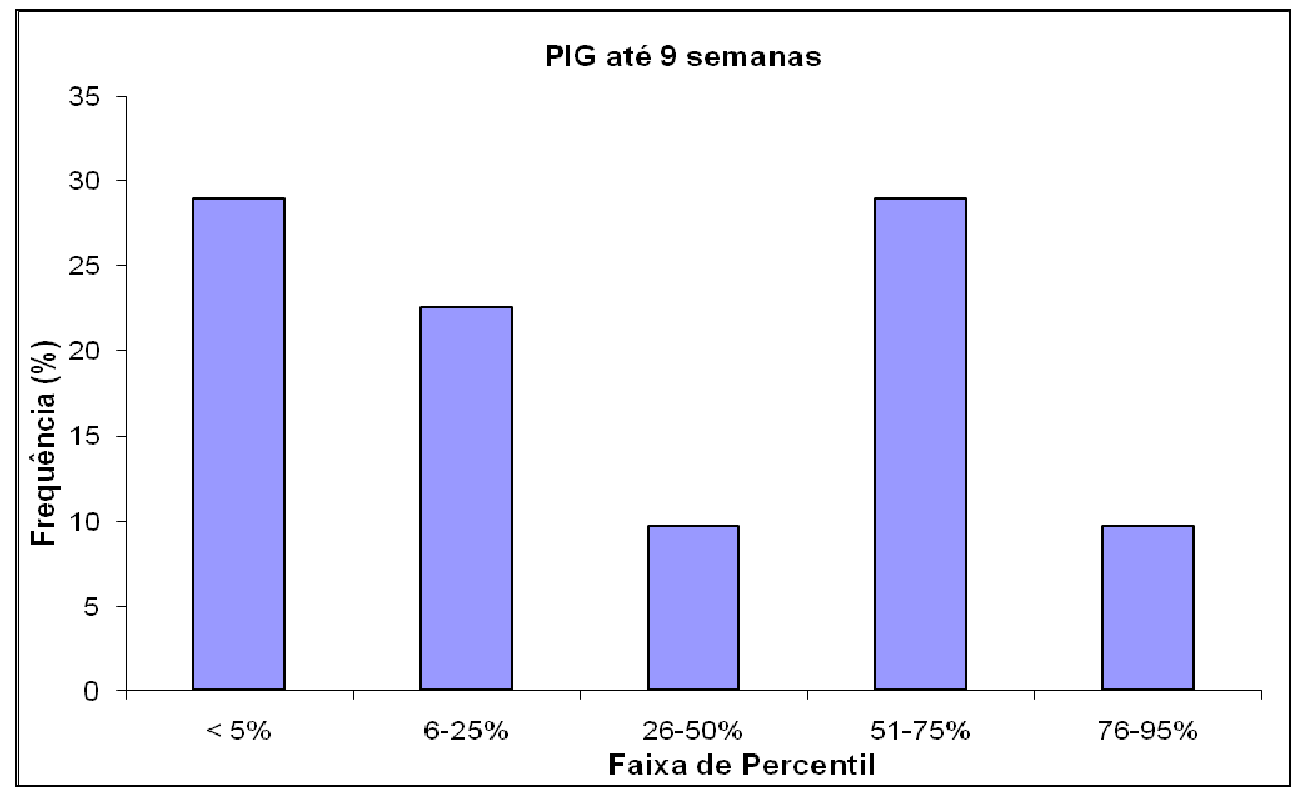

Figura 13. Distribuição dos dados de acuidade visual dos recém-nascidos PIG até 9 semanas de idade em comparação aos percentis dos dados AIG $\mathrm{P} \geq 50$.

A Figura 14 mostra a distribuição dos dados de acuidade visual dos recémnascidos PIG acima de 9 semanas de idade em comparação aos percentis dos dados de acuidade visual dos AIG $\mathrm{P} \geq 50$. Observa-se que apenas 36,84\% dos recém-nascidos PIG apresentaram valores de acuidade visual abaixo do percentil 50 da acuidade visual do grupo AIG $\mathrm{P} \geq 50$. Não foram observadas diferenças significativas entre os grupos. 


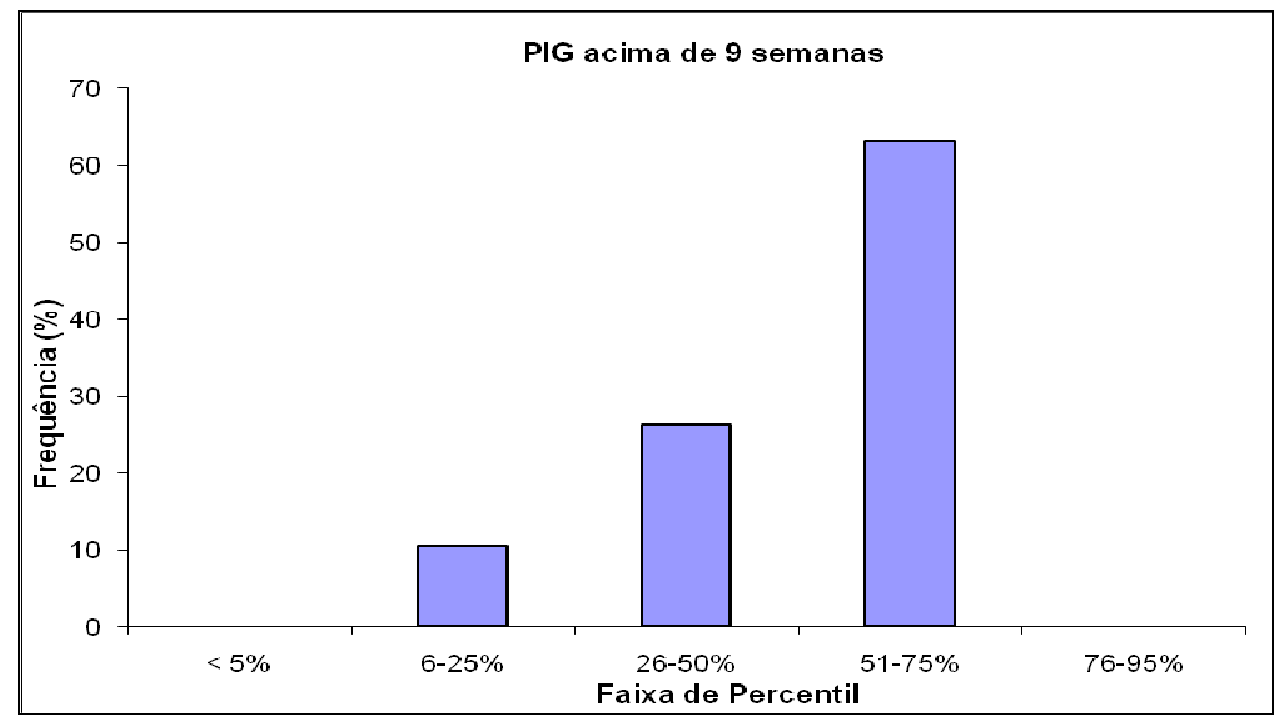

Figura 14. Distribuição dos dados de acuidade visual dos recém-nascidos PIG acima de 9 semanas de idade em comparação aos percentis dos dados AIG $\mathrm{P} \geq 50$.

A Figura 15 a seguir mostra o desenvolvimento da acuidade visual para os recémnascidos PIG e AIG. As Figuras 15a e 15b mostram o desenvolvimento da acuidade visual para cada recém-nascido e a Figura 15c mostra o desenvolvimento da acuidade visual para os grupos PIG e AIG em duas faixas etárias. Observa-se que a acuidade visual desenvolvese com a idade para ambos os grupos PIG e AIG e que os valores de acuidade visual são semelhantes entre os grupos para as duas faixas etárias.

A ANOVA fatorial para os dados longitudinais não mostrou diferenças significativas entre os grupos PIG e AIG para as medidas de acuidade visual em nenhuma das faixas etárias $\mathrm{F}(1,52)=0,28 ; \mathrm{p}=0,60]$, conforme se observa na Figura 15 . O teste post hoc de Fisher LSD mostrou diferença significativa intragrupos considerando-se a acuidade visual em duas faixas etárias, isto é os recém-nascidos na faixa etária de 10 a 24 semanas apresentaram valores de acuidade visual mais altos em comparação aos recém-nascidos menores que 10 semanas de idade para ambos os grupos $[F(1,52)=84,10 ; p=0,0001]$. 

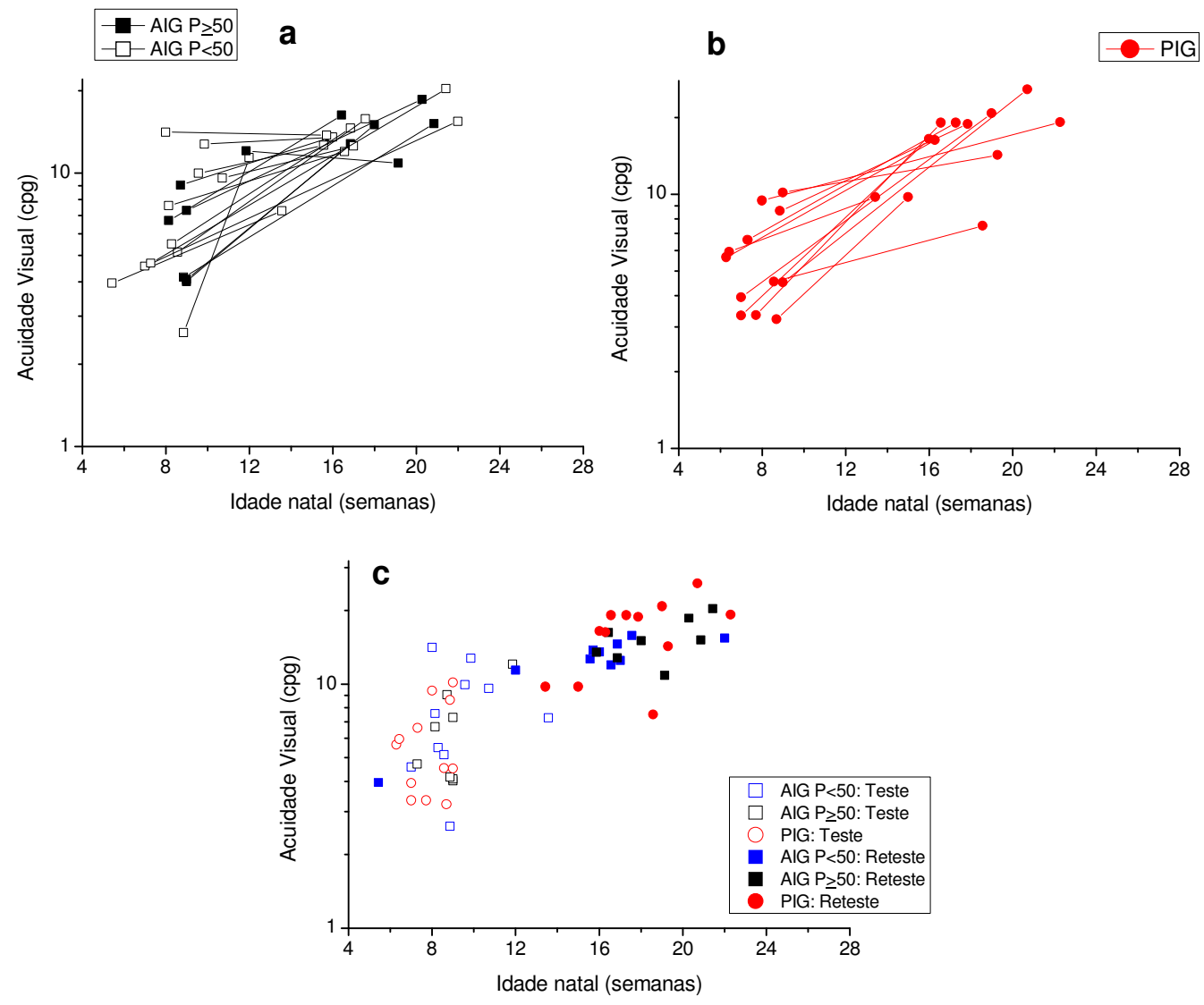

Figura 15. Desenvolvimento da acuidade visual para os recém-nascidos PIG e AIG. Figura a, cada linha representa os dados obtidos para um recém-nascido AIG ( $\mathrm{P} \geq 50 \mathrm{e}$ $\square \mathrm{P}<50$ ) e na Figura b para um recém-nascido PIG ( $\circ$ PIG). Na Figura c, os símbolos abertos representam o teste ( $\circ$ PIG, $\square$ AIG $\mathrm{P}<50$ e $\square$ AIG $\mathrm{P} \geq 50$ ) e símbolos fechados o reteste $(\bullet \mathrm{PIG}, \square \mathrm{AIG} \mathrm{P}<50$ e $\square \mathrm{AIG} \mathrm{P} \geq 50)$.

A Figura 16 mostra o desenvolvimento da sensibilidade ao contraste de luminância para os recém-nascidos PIG e AIG avaliados com a frequiência temporal de $6 \mathrm{~Hz}$ e a frequiência espacial de $0,5 \mathrm{cpg}$ e a sensibilidade ao contraste para as frequências espaciais de 0,25; 0,5 e 1,0 cpg de acordo com Norcia, Tyler e Hamer (1990). 


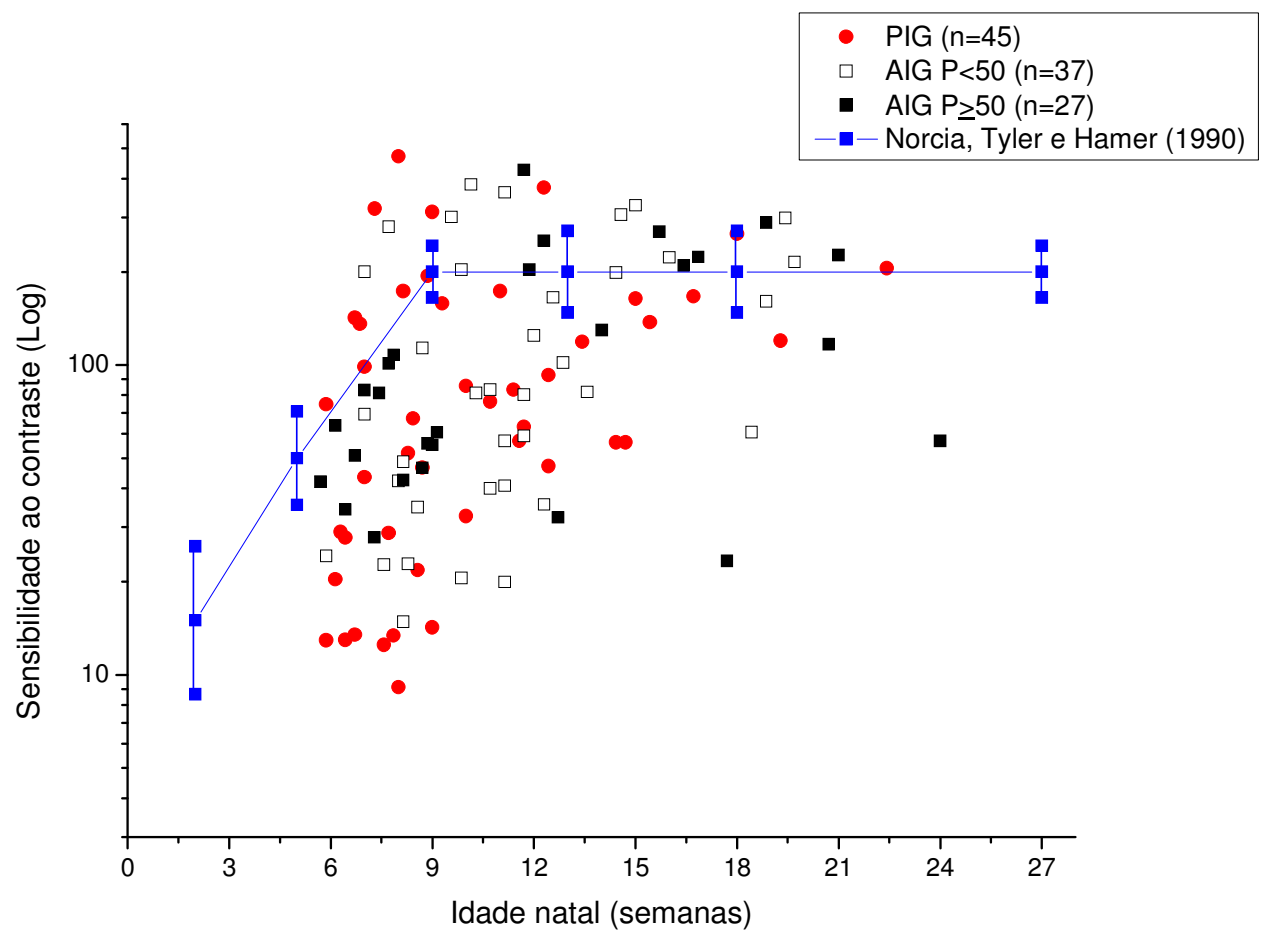

Figura 16. Sensibilidade ao contraste medida pelo PVEv com a freqüência espacial de $0,5 \mathrm{cpg}$ e freqüência temporal de $6 \mathrm{~Hz}$ para os recém-nascidos PIG $(\bullet)$, AIG P<50 (口) e AIG P $\geq 50$ (匹) em comparação às médias de sensibilidade ao contraste de Norcia, Tyler e Hamer (1990) (-ø-) com as barras de erro indicando um erro padrão da média.

A Figura 16 mostra que a sensibilidade ao contraste de luminância para a freqüência espacial de $0,5 \mathrm{cpg}$ aumenta rapidamente até as dez primeiras semanas de vida para ambos os grupos, após essa idade o desenvolvimento da sensibilidade ao contraste é pequeno, conforme os resultados obtidos por Norcia, Tyler e Hamer (1990). Norcia, Tyler e Hamer (1990) relataram que a sensibilidade ao contraste para as frequências espaciais baixas parece atingir uma assíntota em torno de 200 de contraste por volta de 10 semanas de vida. No entanto, uma pequena parcela dos nossos dados encontra-se entre 200 e 400 de contraste para recém-nascidos entre 7 e 22 semanas de idade. Esses valores encontram-se muito próximos aos esperados para os adultos, de acordo com os autores citados. Por outro lado há uma grande concentração de dados entre 6 e 12 semanas de idade abaixo dos valores encontrados por Norcia, Tyler e Hamer (1990). 
Uma comparação mais precisa entre os grupos PIG, AIG e os dados de Norcia, Tyler e Hamer (1990) mostra que para a faixa etária de 5 a 9 semanas, 17 PIG e 22 AIG apresentaram valores de sensibilidade ao contraste mais baixos do que Norcia, Tyler e Hamer (1990) e 08 PIG e 02 AIG apresentaram valores de sensibilidade ao contraste mais altos do que Norcia, Tyler e Hamer (1990). Na faixa etária de 10 a 24 semanas, 17 PIG e 20 AIG apresentaram valores de sensibilidade menores do que encontraram Norcia, Tyler e Hamer (1990) e 03 PIG e 17 AIG apresentaram a sensibilidade ao contraste mais alta do que os recém-nascidos do estudo de Norcia, Tyler e Hamer (1990).

A ANOVA fatorial não mostrou diferenças significativas entre os grupos PIG, AIG $\mathrm{P} \geq 50$ e AIG $\mathrm{P}<50$ para os valores de sensibilidade ao contraste em nenhuma das faixas etárias $[\mathrm{F}(1,107)=2,06 ; \mathrm{p}=0,13]$. Entretanto, a Tabela 3 mostra que a sensibilidade ao contraste encontrava-se mais alta para os recém-nascidos AIG $\mathrm{P} \geq 50$ $(189,00 \pm 114,71)$ em comparação aos AIG P<50 $(152,27 \pm 114,56)$ e PIG $(124,95 \pm 85,99)$ na faixa etária de 10 a 24 semanas.

Observaram-se diferenças estatísticas significativas intragrupos para os valores de sensibilidade ao contraste entre as faixas etárias $[F(1,107)=12,24 ; p=0,001]$. O teste post hoc de Fisher LSD mostrou que a sensibilidade ao contraste encontrava-se significativamente mais alta para os recém-nascidos AIG $\mathrm{P} \geq 50$ de 10 a 24 semanas de idade em comparação aos recém-nascidos menores que 10 semanas de idade de seu respectivo grupo $(\mathrm{p}=0,001)$. No entanto, não foram encontradas diferenças significativas nos valores de sensibilidade ao contraste entre as faixas etárias para os grupos PIG $(\mathrm{p}=0,35)$ e AIG $\mathrm{P}<50(\mathrm{p}=0,11)$. A Tabela 3 mostra que para os três grupos a sensibilidade ao contraste encontrava-se mais alta para os recém-nascidos de 10 a 24 semanas de idade em comparação aos menores de 10 semanas.

A fim de responder a pergunta: "A sensibilidade ao contraste dos recém-nascidos é afetada pelo seu peso ao nascer, independentemente de sua idade no dia da medição?" utilizamos o procedimento adotado para responder a mesma pergunta para a acuidade visual (página 40), no caso da sensibilidade ao contraste realizou-se o ajuste linear dos dados de Norcia, Tyler e Hamer (1990) representados pela linha azul na Figura 16, e obteve-se a equação linear $(\operatorname{LogSC}=\mathrm{Y}=0,955+0,1496 * \mathrm{X})$ referente aos dados das crianças até 9 semanas de idade. Então, calcularam-se os valores de sensibilidade ao contraste (Log) 
adicionando-se as idades dos recém-nascidos PIG e AIG no X dessa equação linear. Para as crianças acima de 9 semanas de idade, a equação foi $(\operatorname{LogSC}=\mathrm{Y}=2,30)$, pois o slope é igual a zero a partir dessa faixa etária. Logo após, subtraiu-se o LogSC PIG (ou LogSC AIG) pelo LogSC obtido pelas equações lineares para ambas as faixas etárias. Denominouse como sensibilidade ao contraste "ajustada" o resultado dessa subtração.

A análise de correlação de Spearman foi realizada utilizando-se os valores de sensibilidade ao contraste "ajustados" e o peso ao nascimento para os recém-nascidos PIG e AIG, mas não mostraram diferenças estatísticas.

A Figura 17 a seguir mostra a comparação da sensibilidade ao contraste entre os grupos PIG e AIG (representado pela linha horizontal). Observa-se uma maior concentração de recém-nascidos PIG abaixo do grupo AIG. No total, 31 recém-nascidos PIG encontravam-se abaixo da média do grupo AIG e 14 recém-nascidos acima da média do grupo AIG. A análise estatística mostrou diferença significativa na proporção de recémnascidos PIG com valores de sensibilidade ao contraste abaixo do grupo AIG P $\geq 50\left[\mathrm{x}^{2}=\right.$ $6,44 ; \mathrm{p}=0,01]$.

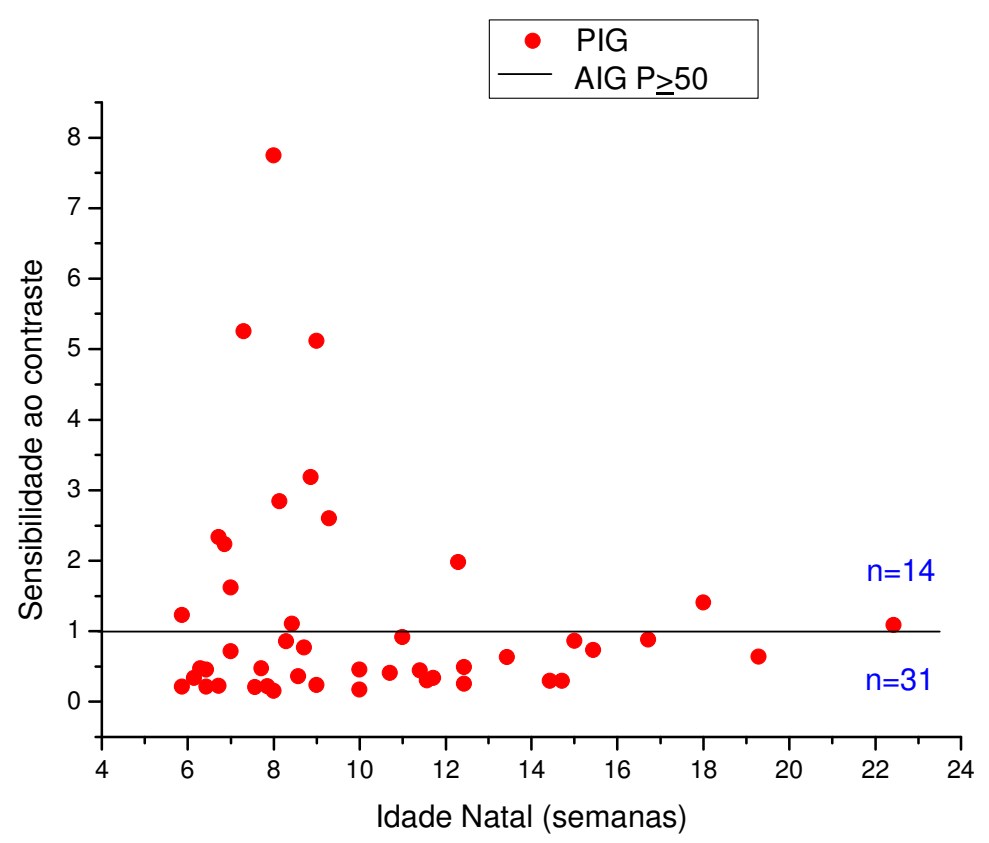

Figura 17. Comparação da sensibilidade ao contraste entre os grupos PIG $(\bullet)$ e AIG P $\geq 50(-)$. 
A Figura 18 mostra a distribuição dos dados de sensibilidade ao contraste dos recém-nascidos PIG até 9 semanas de idade em comparação aos percentis dos dados de acuidade visual do grupo AIG $\mathrm{P} \geq 50$. Observa-se que 76,92\% dos recém-nascidos PIG apresentaram valores de sensibilidade ao contraste abaixo do percentil 50 da sensibilidade ao contraste do grupo AIG $\mathrm{P} \geq 50\left[\mathrm{x}^{2}=12,86 ; \mathrm{p}=0,01\right]$.

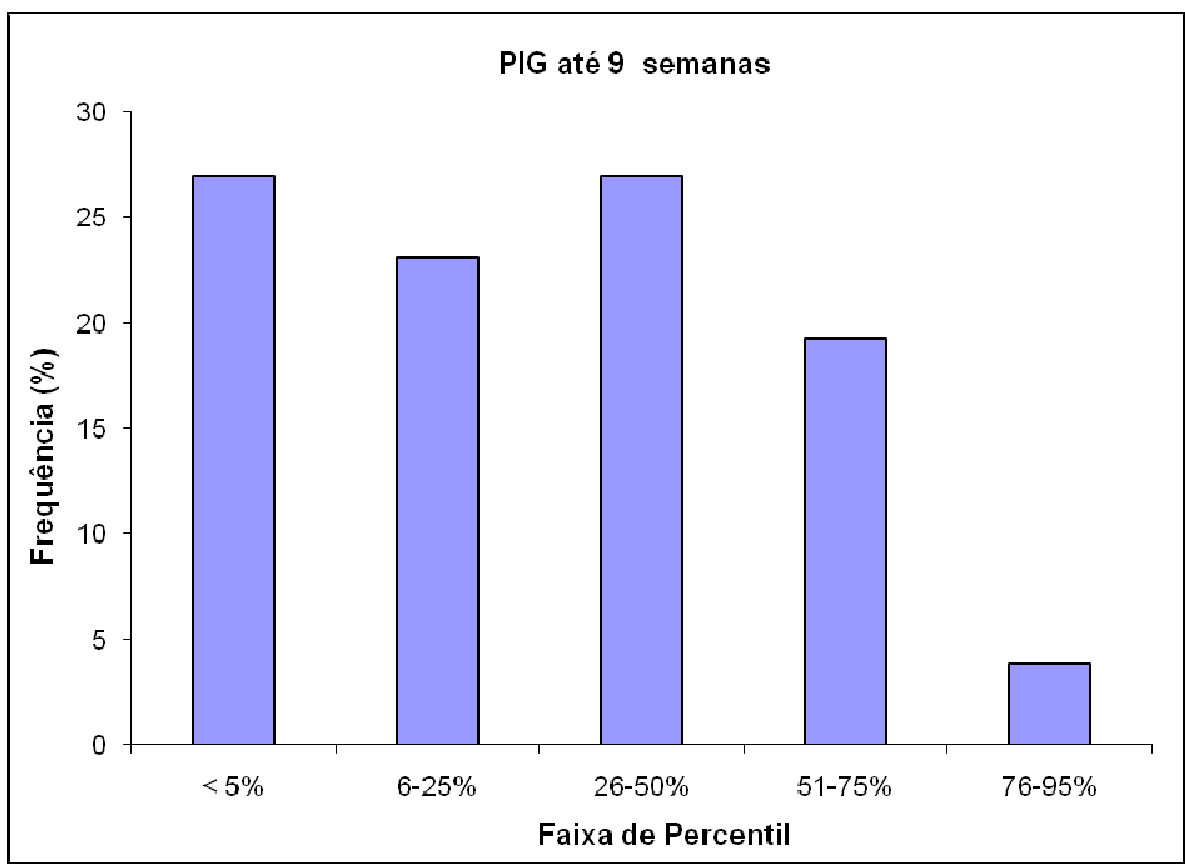

Figura 18. Distribuição dos dados de sensibilidade ao contraste dos recém- nascidos PIG até 9 semanas de idade em comparação aos percentis dos dados AIG P $\geq 50$.

A Figura 19 mostra a distribuição dos dados de sensibilidade ao contraste dos recém-nascidos PIG acima de 9 semanas de idade em comparação aos percentis dos dados de sensibilidade ao contraste do grupo AIG $\mathrm{P} \geq 50$. Observa-se que apenas 52,63\% dos recém-nascidos PIG apresentaram valores de sensibilidade ao contraste abaixo do percentil 50 de sensibilidade ao contraste do grupo AIG $\mathrm{P} \geq 50$. Não foram observadas diferenças significativas entre os grupos. 


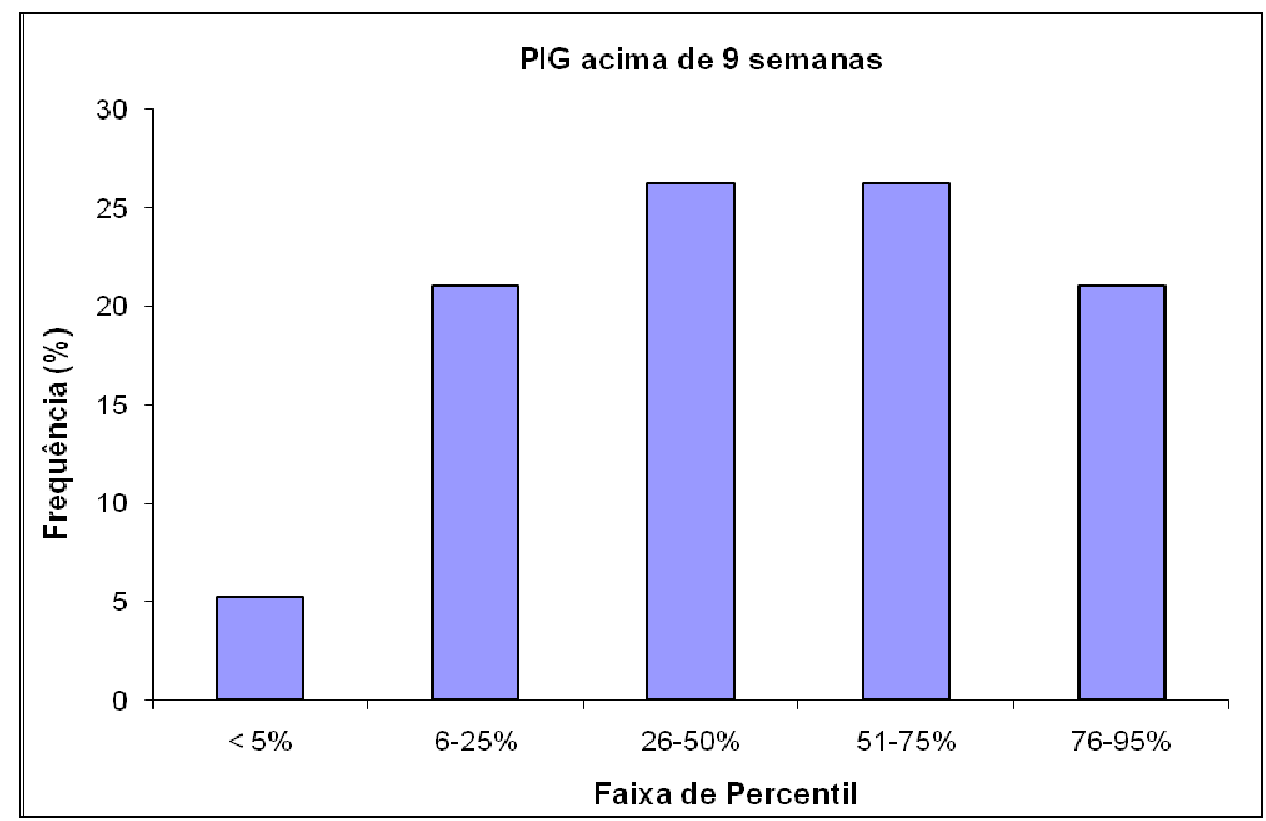

Figura 19. Distribuição dos dados de sensibilidade ao contraste dos recém- nascidos PIG acima de 9 semanas de idade em comparação aos percentis dos dados do grupo AIG $P \geq 50$.

A Figura 20 a seguir mostra o desenvolvimento da sensibilidade ao contraste para os recém-nascidos PIG e AIG. As Figuras 20a e 20b mostram o desenvolvimento da sensibilidade ao contraste para cada recém-nascido e a Figura 20c mostra o desenvolvimento da sensibilidade ao contraste para ambos os grupos em duas faixas etárias. De forma geral, observa-se que a sensibilidade ao contraste aumenta com a idade e que os valores de sensibilidade ao contraste são semelhantes entre os grupos PIG e AIG em ambas as faixas etárias.

A ANOVA fatorial para os dados longitudinais não mostrou diferenças significativas entre os grupos PIG e AIG para os valores de sensibilidade ao contraste em nenhuma das medidas (teste ou reteste) $[\mathrm{F}(1,44)=0,70 ; \mathrm{p}=0,41]$. Não foram encontradas diferenças estatísticas significativas intragrupos para os valores de sensibilidade ao contraste entre as duas faixas etárias ou medidas (teste ou reteste) $[\mathrm{F}(1,44)=3,12$; $\mathrm{p}=0,08]$. 


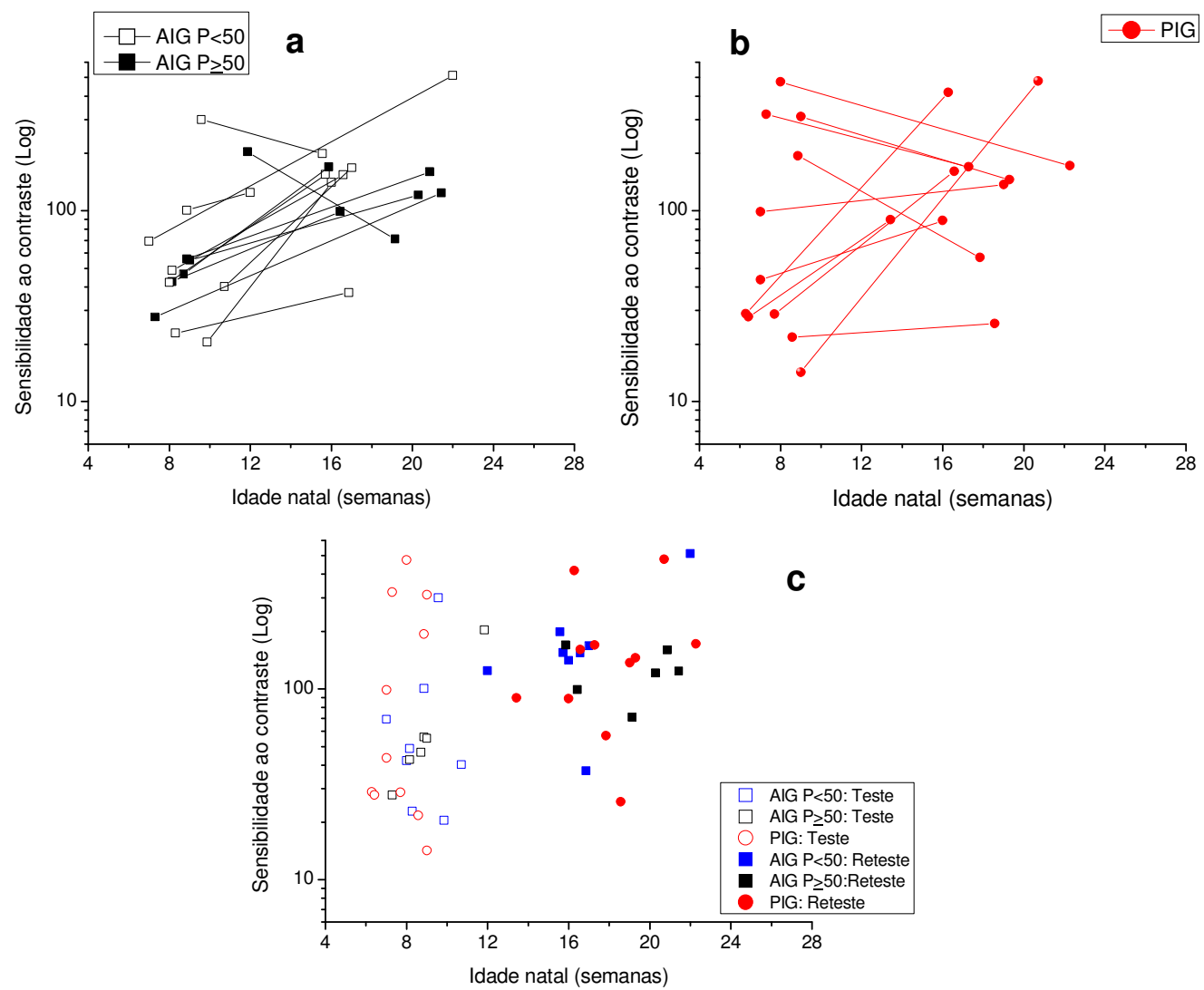

Figura 20. Desenvolvimento da sensibilidade ao contraste para os recém-nascidos PIG e AIG. Figura a, cada linha representa os dados obtidos para um recém-nascido AIG ( $\mathrm{P} \geq 50$ e $\square \mathrm{P}<50$ ) e Figura b para um recém-nascido PIG $(0)$. Na Figura c, os símbolos abertos representam o teste ( $\circ \mathrm{PIG}, \square \mathrm{AIG} \mathrm{P}<50$ e $\square \mathrm{AIG} \mathrm{P} \geq 50)$ e símbolos fechados o reteste $(\bullet \mathrm{PIG}, \square \mathrm{AIG} \mathrm{P}<50$ e AIG $\mathrm{P} \geq 50$ ). 


\section{IV.2. Análises estatísticas dos registros de fase, inclinação da reta, amplitude máxima, ruído médio e SNR durante os testes de Acuidade Visual e Sensibilidade ao Contraste de Luminância}

\section{Análises da Fase}

Os registros de fase expostos no presente estudo correspondem a valores relativos de fases, pois (1): Adicionamos 180 graus para tornar os valores de fase comparáveis aos valores de Hamer e Norcia (1994); (2) não corrigimos o tempo de atraso do equipamento, conforme fizeram Hamer e Norcia (1994); (3) realizamos o procedimento "phasewrapping. Entretanto, a análise da fase relativa é válida mesmo que não calcule o atraso específico no sistema visual, as mudanças na fase com a idade são válidas, assim como todas as comparações entre os grupos.

De acordo com Hamer e Norcia (1994), os valores de fase em idades iniciais são altos e diminuem rapidamente durante as primeiras 20 semanas de idade. Uma vez que o PVEv não pode distinguir entre 2 ciclos de fase, por exemplo 20 graus é indistinguível de 380 graus e assumindo-se que as respostas de fase para os recém-nascidos com idades maiores que 20 semanas teriam um avanço maior que 360 graus em relação aos bebês mais jovens utilizamos o procedimento denominado "phase-wrapping" baseado em Hamer e Norcia (1994). Portanto, em nosso estudo, adicionamos 360 graus às respostas de fase dos RN com idade até 11 semanas e fases menores que 90 graus; e subtraímos 360 graus das respostas de fase dos RN com idade maior que 11 semanas e respostas de fase maiores que 270 graus.

O procedimento "phase-wrapping" foi utilizado para os registros de fase obtidos durante o teste de acuidade visual. No total modificaram-se os valores de fase para seis recém-nascidos do grupo AIG e cinco recém-nascidos do grupo PIG com idades até 11 semanas. Para os recém-nascidos com idades maiores que 11 semanas, modificaram-se os valores de fase para dois recém-nascidos PIG e AIG, conforme mostra a Figura 21. 

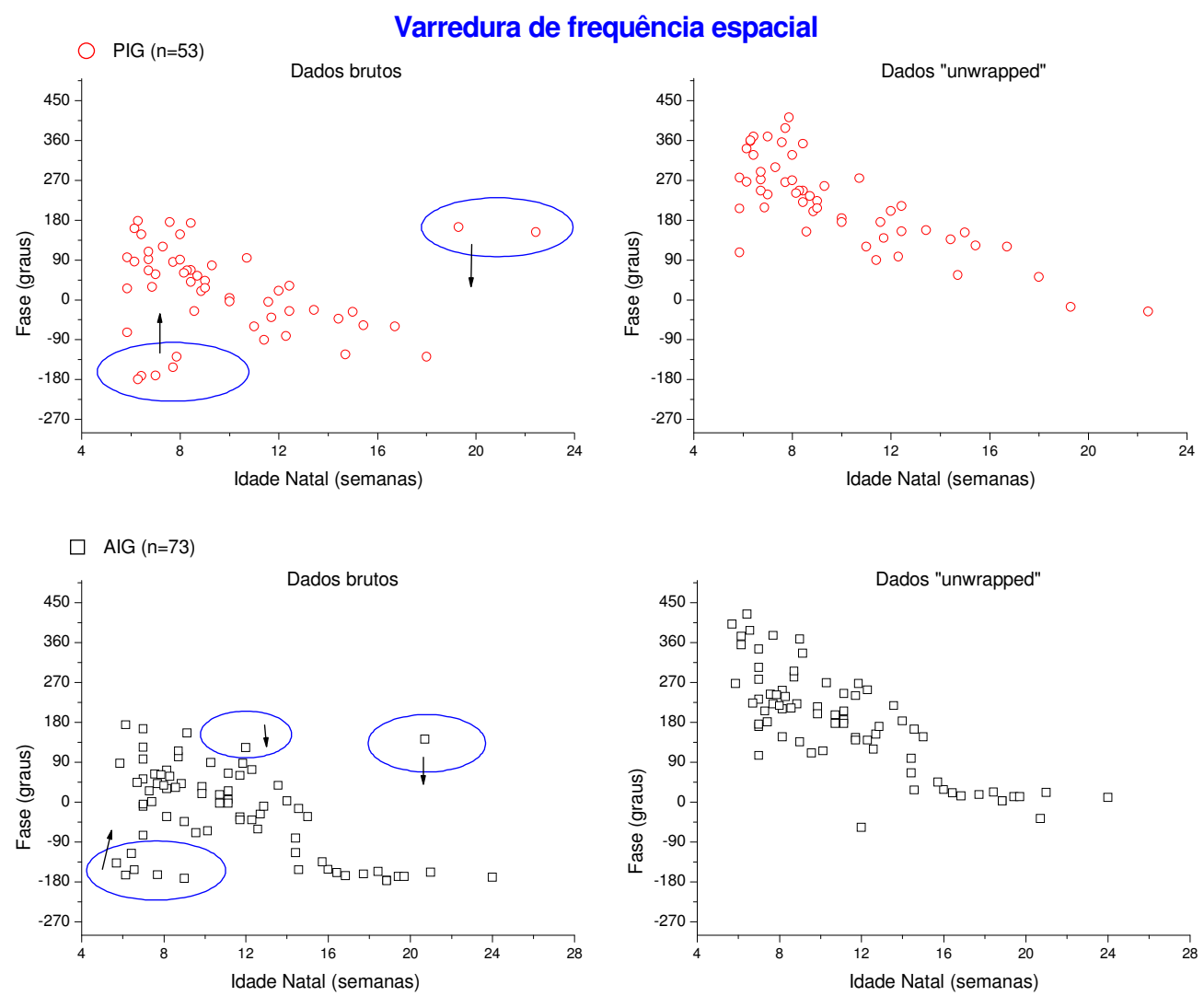

Figura 21. Valores de fases brutos (sem tratamento) e "unwrapped" (com tratamento "phase-wrapping"), obtidos durante o teste de acuidade visual para os recém-nascidos PIG (०) e AIG (口).

Aplicou-se ainda o procedimento de "phase-wrapping" para os registros de fase obtidos durante o teste de sensibilidade ao contraste para oito recém-nascidos PIG e seis recém-nascidos AIG até 11 semanas de idade. Três recém-nascidos PIG e onze recémnascidos AIG acima de 11 semanas de idade também tiveram seus valores de fase modificados pelo procedimento "phase-wrapping", conforme mostra a Figura 22. 

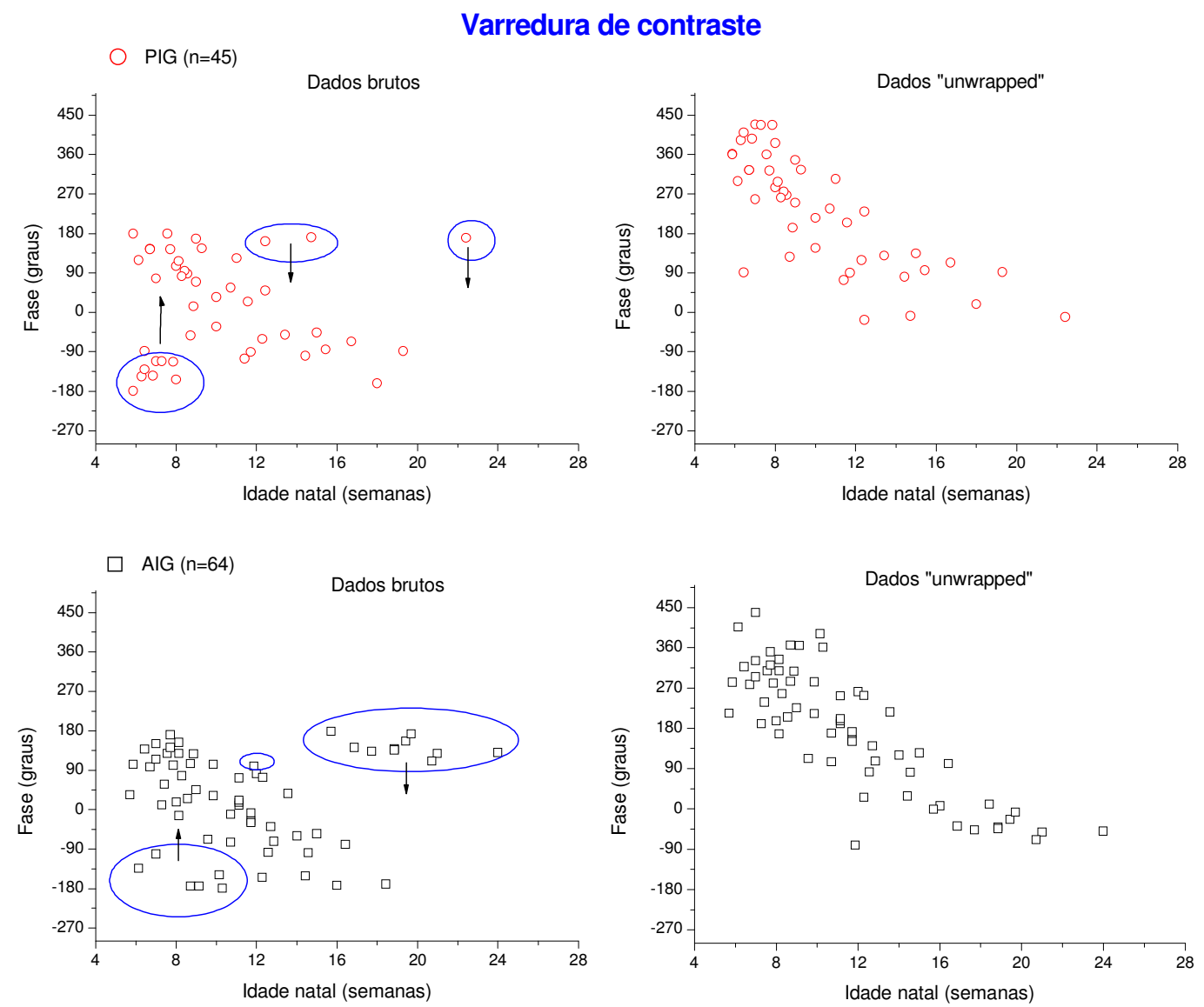

Figura 22. Valores de fases brutos (sem tratamento) e "unwrapped" (com tratamento "phasewrapping"), obtidos durante o teste de sensibilidade ao contraste para os recém-nascidos PIG (०) e AIG (口).

A Figura 23 a seguir mostra o desenvolvimento de fase (graus) para os recémnascidos AIG e PIG com os registros obtidos nos testes de acuidade visual (Figura 23a) e sensibilidade ao contraste (Figura 23b) em comparação aos registros de fase de Hamer e Norcia (1994) referentes ao teste de sensibilidade ao contraste.

Realizou-se o ajuste exponencial com os dados do grupo AIG até 24 semanas de idade e incluíram-se os dados do estudo de Hamer e Norcia (1994) a partir de 25 até 56 semanas de idade. Essa inclusão justifica-se uma vez que os nossos dados até 24 semanas de idade e os dados de Hamer e Norcia (1994) assemelham-se, sendo assim podem 
representar uma previsão do desenvolvimento de fase para o grupo AIG em idades posteriores. Além disso, permitiu um melhor ajuste dos dados do grupo AIG.

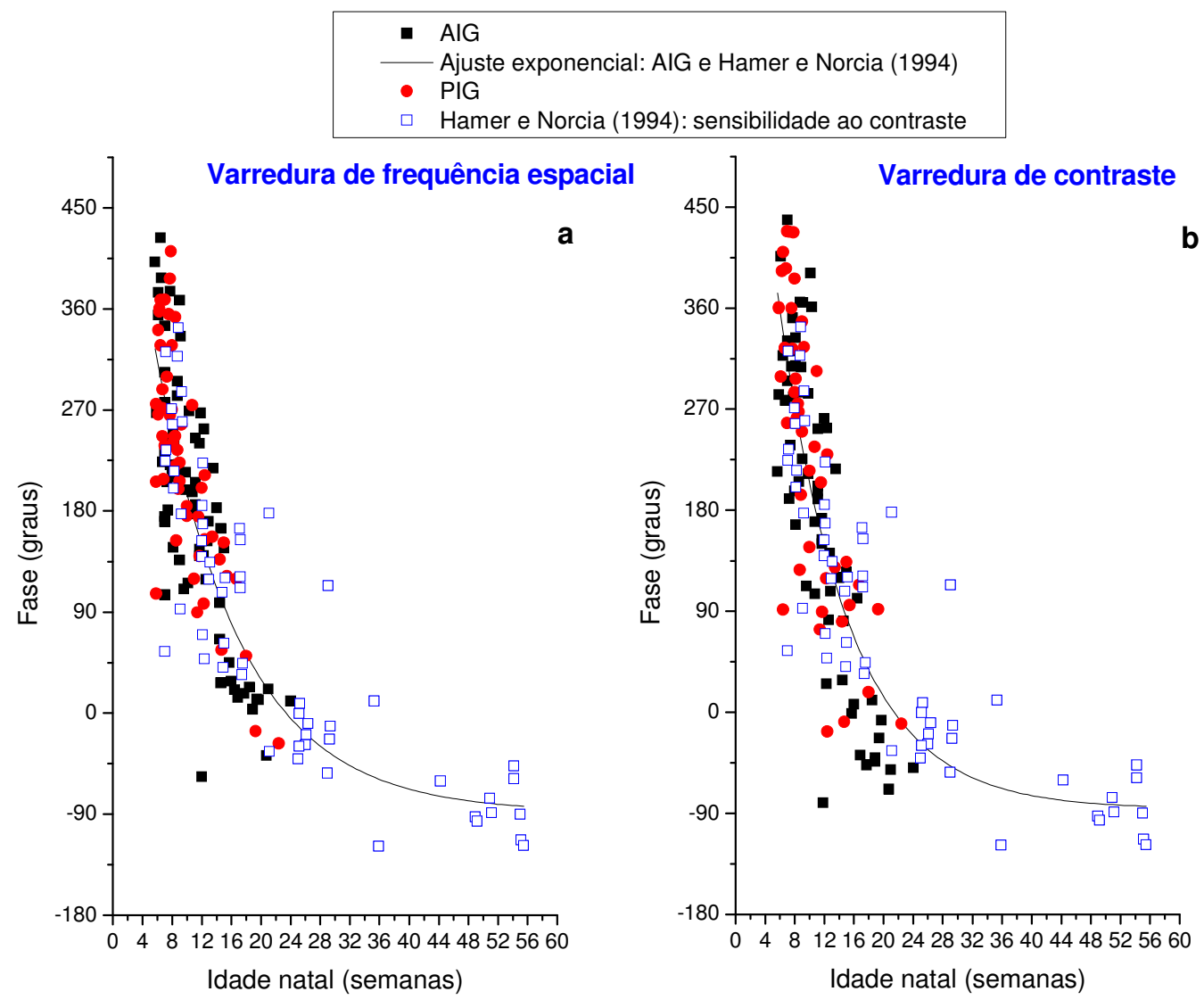

Figura 23. Registros de fase "unwrapped" para a freqüência temporal de $6 \mathrm{~Hz}$ durante os testes de acuidade visual (a) e sensibilidade ao contraste (b) para os recém-nascidos PIG (•) e AIG (ロ) em comparação aos registros de Hamer e Norcia (1994) ( $\square$ ).

Convém mencionar que valores de fases maiores correspondem a respostas visuais mais lentas e valores de fases menores correspondem a respostas visuais mais rápidas. Para os testes de acuidade visual e sensibilidade ao contraste, observa-se que entre 6 e 18 semanas as respostas de fase diminuem rapidamente, respectivamente, aproximadamente 253,08 e 370,80 graus para o grupo PIG; e 280,68 e 361,92 graus para o grupo AIG, correspondendo, respectivamente, a uma diminuição na latência aparente de 4,88 e 7,15 ms/semana para os recém-nascidos PIG; e 5,41 e 6,98 ms/semana para os recém-nascidos 
AIG. As taxas de desenvolvimento de fase foram semelhantes entre os grupos PIG e AIG para ambas as funções visuais, no entanto ambos os grupos apresentaram taxas de desenvolvimento de fase mais altas para a sensibilidade ao contraste em comparação às taxas de acuidade visual.

Hamer e Norcia (1994) encontraram uma taxa no desenvolvimento de fase em torno de 6,3 ms por semana para o segundo harmônico da freqüência de estimulação em $6 \mathrm{~Hz}$. As taxas de desenvolvimento de fase dos AIG e PIG aproximaram-se dos dados de Hamer e Norcia (1994).

A conversão de graus para milissegundos foi feita a partir de uma regra de três simples que considerou as respostas de fase obtidas para o segundo harmônico da freqüência de estimulação. Por exemplo, considerando o segundo harmônico correspondente a $6 \mathrm{~Hz}$, isto é $12 \mathrm{~Hz}$, um ciclo (360 graus) corresponde a 83,3 ms $(1000 / 12 \mathrm{~Hz})$. Portanto, uma taxa de 27,27 graus/semana $[(27,27 / 360) \times$ x 83,3] corresponde a $6,3 \mathrm{~ms}$.

A Tabela 4 a seguir mostra os resultados da análise de regressão linear das respostas de fase "unwrapped" para os recém-nascidos PIG e AIG registrados durante os testes de acuidade visual e sensibilidade ao contraste. O grupo AIG foi subdividido por percentil de peso ao nascimento: menor que $50(\mathrm{P}<50)$ e maior ou igual a $50(\mathrm{P} \geq 50)$.

Tabela 4. Resultados da análise de regressão linear das respostas de fase "unwrapped" para os recém-nascidos PIG e AIG de 6 a 18 semanas de idade para a frequiência temporal de 6 $\mathrm{Hz}$.

\begin{tabular}{ccccccc}
\hline $\begin{array}{c}\text { Função } \\
\text { Visual }\end{array}$ & Grupos & $\begin{array}{c}\text { Intercepto } \\
\text { (graus) }\end{array}$ & $\begin{array}{c}\text { Taxa } \\
\text { (graus/ } \\
\text { semana) }\end{array}$ & $\begin{array}{c}\text { Taxa } \\
\text { (ms/semanas) }\end{array}$ & $\begin{array}{c}\text { Coeficiente } \\
\text { de } \\
\text { correlação } \\
\text { de Pearson }\end{array}$ & $\begin{array}{c}\text { Nível de } \\
\text { significância } \\
\text { do } \\
\text { coeficiente }\end{array}$ \\
\hline AV & PIG & $\begin{array}{c}428,31 \\
\pm 28,81\end{array}$ & $-21,09 \pm 2,92$ & 4,88 & $\mathrm{r}=-0,72$ & $\mathrm{p}=, 000001$ \\
& & & & & \\
$\mathrm{AV}$ & AIG & $\begin{array}{l}440,03 \\
\pm 30,89\end{array}$ & $-23,39 \pm 2,90$ & 5,41 & $\mathrm{r}=-0,71$ & $\mathrm{p}=0,00001$ \\
& & & & & \\
$\mathrm{SC}$ & $\mathrm{PIG}$ & 540,86 & $-30,90 \pm 23,96$ & 7,15 & $\mathrm{r}=-0,77$ & $\mathrm{p}=0,00001$ \\
& & $\pm 40,43$ & & & & \\
$\mathrm{SC}$ & AIG & 521,29 & $-30,16 \pm 3,49$ & 6,98 & $\mathrm{r}=-0,76$ & $\mathrm{p}=0,00001$ \\
& & $\pm 37,86$ & & & & \\
\hline
\end{tabular}


O valor de intercepto da análise de regressão linear corresponde ao valor presumido da fase no dia do nascimento. Compararam-se os valores de intercepto dos grupos PIG e AIG para a acuidade visual e sensibilidade ao contraste e observou-se que a diferença entre os grupos foi pequena. No entanto, para a acuidade visual, o valor presumido da fase para o dia do nascimento é menor para os PIG em comparação aos AIG. Essa projeção das respostas de fase sugere que os PIG apresentaram um processamento do estímulo visual mais rápido em comparação aos AIG. Resultado diferente foi encontrado para o teste de sensibilidade ao contraste, uma vez que os PIG apresentaram o valor de fase maior do que os recém-nascidos AIG que sugere processamento do estímulo visual mais lento ao nascimento.

\section{Análise da Inclinação da Reta}

A Tabela 5 mostra a média e o desvio-padrão para os valores de inclinação da reta dos registros de acuidade visual e sensibilidade ao contraste para a freqüência espacial de 0,5 cpg dos recém-nascidos PIG e AIG em duas faixas etárias: 5-9 semanas e 10-24 semanas. O grupo AIG foi subdividido por percentil de peso ao nascimento $(50 \leq \mathrm{P}<50)$.

Tabela 5. Mostra a Média e o desvio-padrão dos valores de inclinação da reta para os registros de acuidade visual e sensibilidade ao contraste para a freqüência espacial de 0,5 cpg dos recém-nascidos PIG e AIG em duas faixas etárias. O grupo AIG foi subdividido por percentil de peso ao nascimento $(50 \leq \mathrm{P}<50)$.

\begin{tabular}{clc}
\hline \multicolumn{1}{c}{ Grupos } & Inclinação da reta AV & $\begin{array}{c}\text { Inclinação da reta } \\
\text { SC }\end{array}$ \\
\hline $\begin{array}{c}\text { AIG }<\mathbf{1 0} \text { semanas } \\
(\mathbf{P} \geq \mathbf{5 0})\end{array}$ & $-0,72 \pm 0,56(\mathrm{n}=18)$ & $2,14 \pm 0,96(\mathrm{n}=14)$ \\
$\mathbf{A I G} \geq \mathbf{1 0}$ semanas \\
$\begin{array}{c}(\mathbf{P} \geq \mathbf{5 0}) \\
\mathbf{A I G}<\mathbf{1 0} \text { semanas } \\
(\mathbf{P}<\mathbf{5 0})\end{array}$ & $-0,64 \pm 0,37(\mathrm{n}=13)$ & $3,28 \pm 2,95(\mathrm{n}=13)$ \\
$\mathbf{A I G} \geq \mathbf{1 0}$ semanas & $-0,52 \pm 0,30(\mathrm{n}=17)$ & $2,16 \pm 1,29(\mathrm{n}=14)$ \\
$\mathbf{( P < \mathbf { 5 0 } )}$ & $-0,83 \pm 0,65(\mathrm{n}=25)$ & $3,04 \pm 1,49(\mathrm{n}=23)$ \\
$\mathbf{P I G}<\mathbf{1 0}$ semanas & $-0,54 \pm 0,34(\mathrm{n}=33)$ & $2,08 \pm 1,34(\mathrm{n}=26)$ \\
$\mathbf{P I G} \geq \mathbf{1 0}$ semanas & $-0,75 \pm 0,43(\mathrm{n}=20)$ & $3,53 \pm 2,04(\mathrm{n}=19)$ \\
\hline
\end{tabular}


A ANOVA fatorial não mostrou diferenças significativas entre os grupos PIG, AIG $\mathrm{P} \geq 50$ e AIG $\mathrm{P}<50$ para os valores de inclinação da reta registrados durante o teste de acuidade visual em nenhuma das faixas etárias $[\mathrm{F}(1,124)=1,10 ; \mathrm{p}=0,34]$. No entanto, a Tabela 5 mostra que os recém-nascidos AIG $\mathrm{P} \geq 50$ na faixa etária de 5 a 9 semanas apresentaram valores de inclinação da reta maiores que os recém-nascidos do grupo AIG P<50 e PIG na mesma faixa etária. Observa-se ainda que para esse registro os grupos PIG e AIG P<50 assemelham-se.

As análises estatísticas intragrupos não mostraram diferenças significativas entre as faixas etárias para a inclinação da reta registrada durante o teste de acuidade visual [F (1, 124) $=2,59 ; \mathrm{p}=0,11$ ], entretanto a Tabela 5 mostra que os três grupos apresentavam valores diferentes para a inclinação da reta entre as faixas etárias, isto é os recém-nascidos AIG P<50 e PIG na faixa etária de 5 a 9 semanas apresentavam valores de inclinação da reta menores em comparação a faixa etária de 10 a 24 semanas. A exceção foi o grupo AIG $\mathrm{P} \geq 50$ que apresentou resultado inverso, ou seja, valores de inclinação da reta maiores para os recém-nascidos de 5 a 9 semanas de idade em comparação aos recém-nascidos na faixa etária de 10 a 24 semanas.

A Figura 24 mostra os valores da inclinação da reta dos recém-nascidos PIG e AIG durante o teste de acuidade visual (Figura a) e sensibilidade ao contraste (Figura b) pelo PVEv. As Figuras 24a e 24b mostram que a maior parte dos dados dos recém-nascidos PIG e AIG se sobrepõe. Observa-se na Figura 24a que a maior parte dos dados concentra-se entre $-0,12$ e $-1,0$ microvolts/cpg e na Figura 24 b que a maior parte dos dados concentra-se entre 0,61 e 5,0 microvolts/logcontraste.

A ANOVA não mostrou diferenças significativas entre os grupos PIG, AIG P $\geq 50$ e AIG $\mathrm{P}<50$ para os valores de inclinação da reta registrados durante o teste de sensibilidade ao contraste em nenhuma das faixas etárias $[\mathrm{F}(1,107)=0,20 ; \mathrm{p}=0,81]$, conforme mostra a Tabela 5 .

As análises estatísticas mostraram diferenças significativas intragrupos para os valores de inclinação da reta entre as duas faixas etárias $[\mathrm{F}(1,107)=11,70 ; \mathrm{p}=0,001]$. O teste post hoc de Fisher LSD mostrou que o valor de inclinação da reta encontrava-se mais alto para os recém-nascidos PIG de 10 a 24 semanas de idade em comparação aos recém- 
nascidos PIG menores que essa faixa etária $(\mathrm{p}=0,006)$. Não houve diferença significativa nos valores de inclinação da reta entre as faixas etárias para os recém-nascidos AIG P<50 $(\mathrm{p}=0,09)$ e $\mathrm{AIG} P \geq 50(\mathrm{p}=0,11)$.

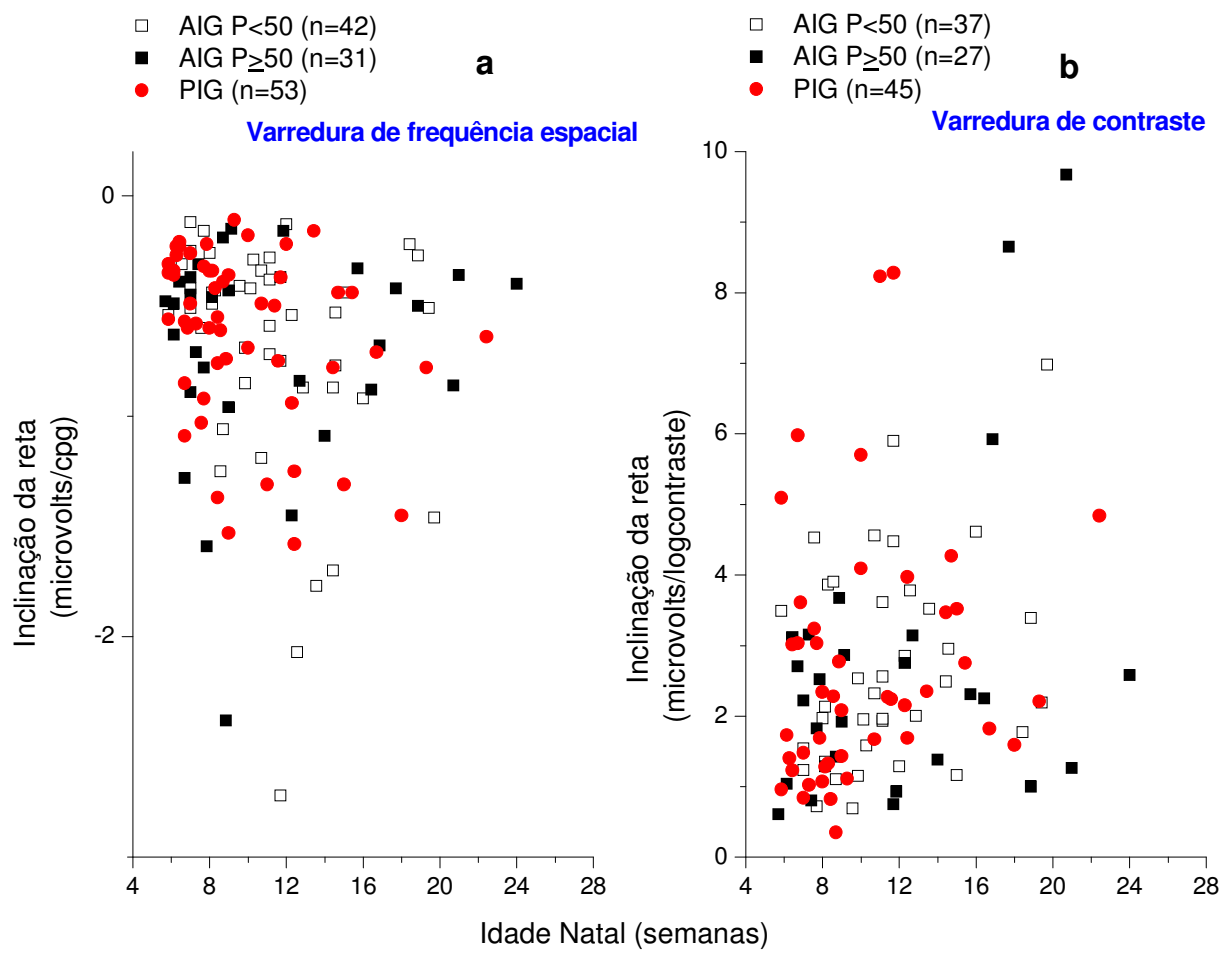

Figura 24. Registro da inclinação da reta dos recém-nascidos PIG (•), AIG P<50 ( $\square$ ) e AIG P $\geq 50$ ( $\square$ ) durante os testes de acuidade visual (a) e sensibilidade ao contraste (b) pelo PVEv utilizando a freqüência temporal de $6 \mathrm{~Hz}$.

A Figura 25 a seguir mostra a comparação dos valores de inclinação da reta entre o grupo PIG e AIG obtidos a partir do registro dos testes de acuidade visual e sensibilidade ao contraste. Na Figura 25a, observa-se que a maioria dos dados do grupo PIG encontra-se abaixo dos dados do grupo AIG $\mathrm{P} \geq 50$, no total são 34 recém-nascidos abaixo e 19 acima da média do grupo AIG $\mathrm{P} \geq 50$ para o teste de acuidade visual. No entanto, a análise estatística não mostrou diferença significativa na proporção de recém-nascidos PIG com valores de inclinação da reta abaixo ou acima da média do grupo AIG $\mathrm{P} \geq 50$ para o teste de acuidade visual $\left[\mathrm{x}^{2}=3,78 ; \mathrm{p}=0,05\right]$. Pode-se falar apenas em tendência a maior proporção 
de recém-nascidos PIG com valores de inclinação da reta mais baixos do que a média do grupo AIG $\mathrm{P} \geq 50$.

$\mathrm{Na}$ Figura 25b, observa-se que a maioria dos dados do grupo PIG encontra-se abaixo dos dados do grupo AIG $\mathrm{P} \geq 50$. No total são 26 recém-nascidos PIG abaixo e 19 acima da média do grupo AIG $\mathrm{P} \geq 50$ para o teste de sensibilidade ao contraste. No entanto, a análise estatística não mostrou diferença significativa na proporção de recém-nascidos PIG com valores de inclinação da reta abaixo ou acima da média do grupo AIG $\mathrm{P} \geq 50$ para o teste de sensibilidade ao contraste $\left[\mathrm{x}^{2}=0,86 ; \mathrm{p}=0,35\right]$.

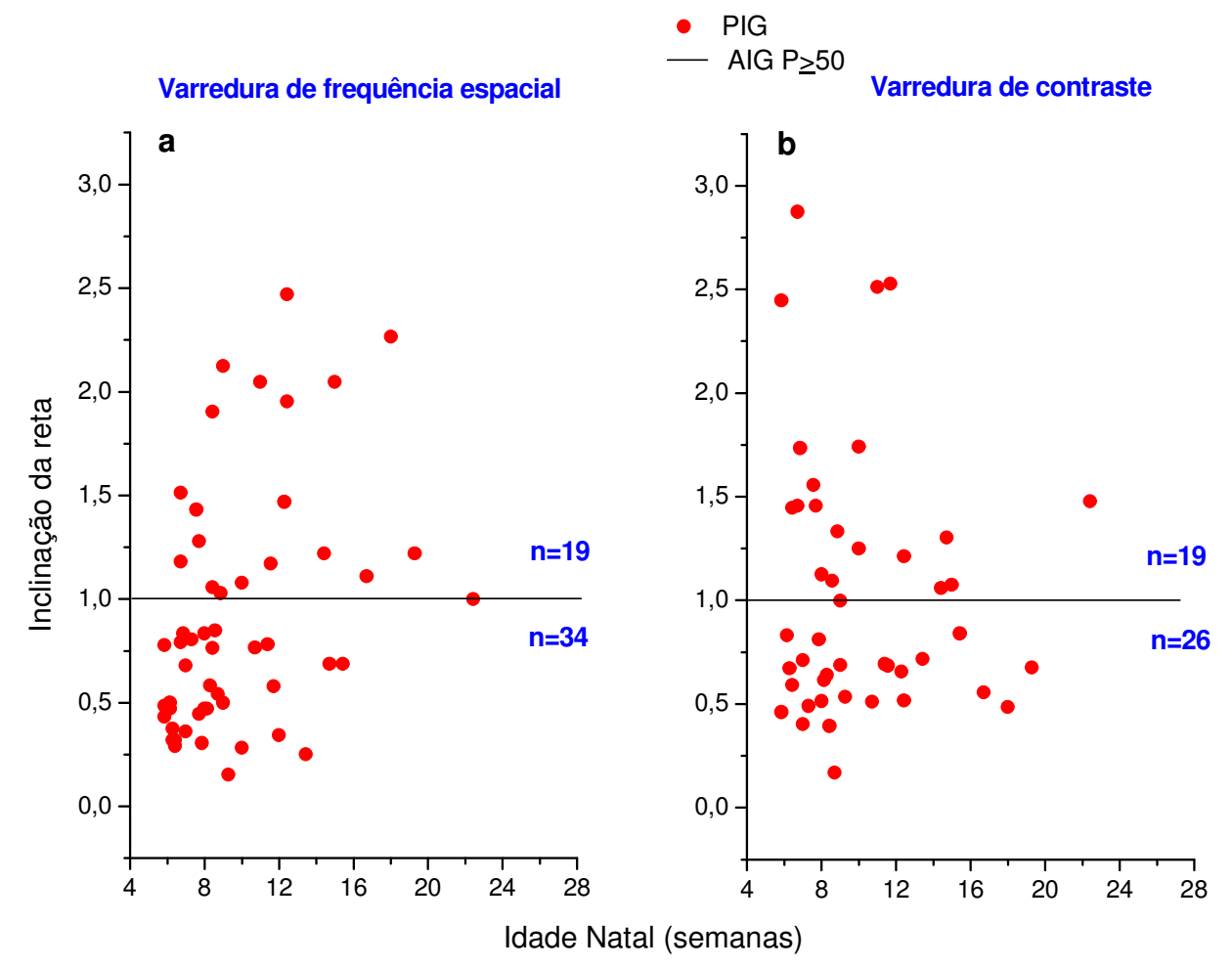

Figura 25. Comparação dos valores de inclinação da reta entre o grupo PIG (•) e os dados AIG P $\geq 50$ ( - ) obtidos a partir dos testes de acuidade visual (a) e sensibilidade ao contraste (b).

A ANOVA fatorial para os dados longitudinais não mostrou diferenças significativas entre os grupos PIG e AIG para os valores de inclinação da reta obtidos a partir do teste de acuidade visual em nenhuma das medidas (teste ou reteste) $[\mathrm{F}(1,52)=0,09 ; \mathrm{p}=0,77]$. Não 
houve diferença significativa intragrupos para os valores de inclinação da reta entre as medidas (teste e reteste) $[\mathrm{F}(1,52)=0,77 ; \mathrm{p}=0,38]$, conforme mostra a Figura 26.

A Figura 26 a seguir mostra a inclinação da reta para os recém-nascidos PIG e AIG obtidos do registro do teste de acuidade visual. As Figuras 26a e 26b mostram os valores de inclinação da reta para cada recém-nascido AIG ou PIG e a Figura 26c mostra os valores de inclinação da reta para ambos os grupos em duas faixas etárias diferentes (ou medidas).
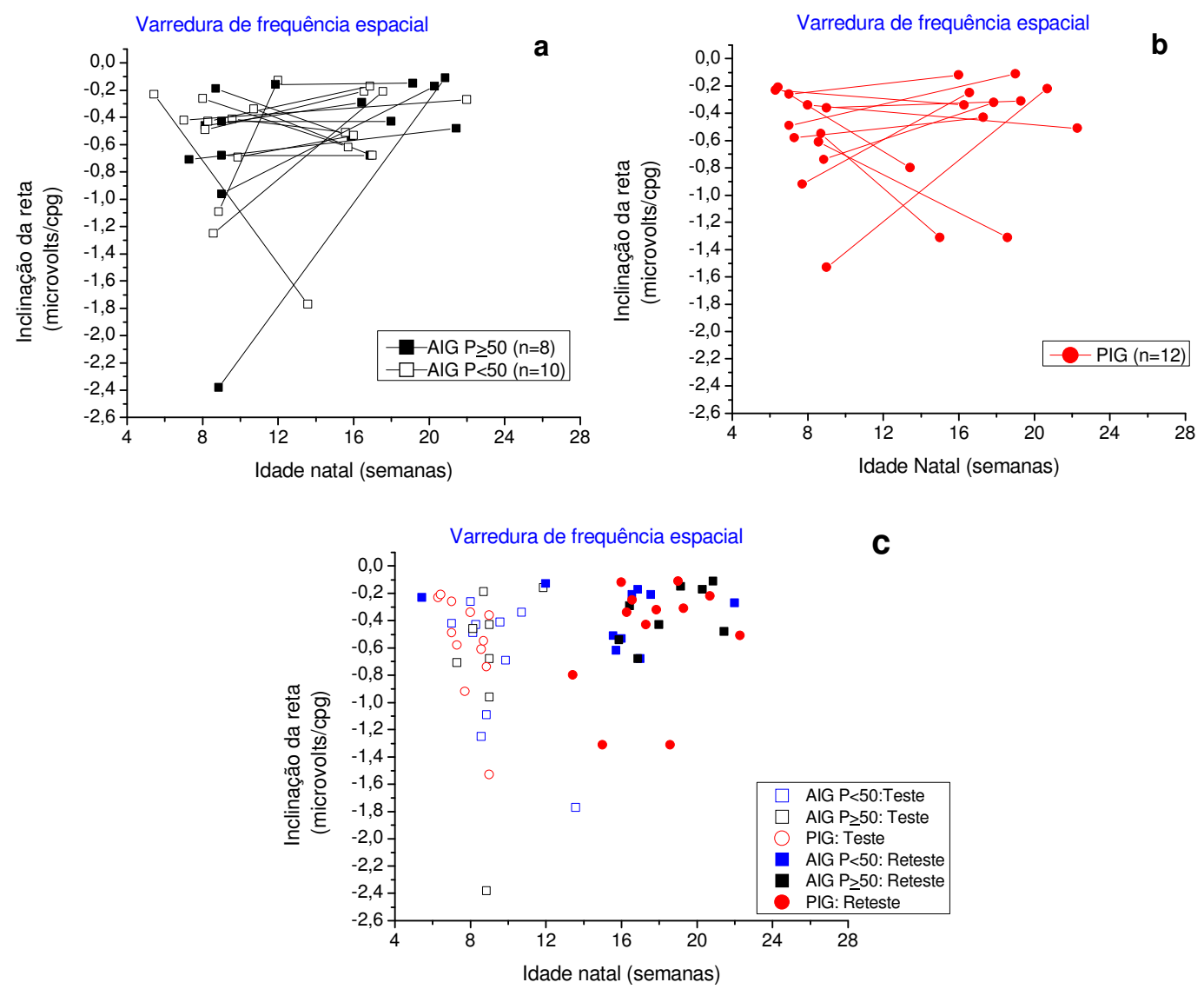

Figura 26. Valores de inclinação da reta (microvolts/cpg) para os recém-nascidos PIG e AIG obtidos do registro do teste de acuidade visual. Figura a, cada linha representa os dados obtidos para um recém-nascido AIG $(\backsim \mathrm{P} \geq 50$ e $\square \mathrm{P}<50$ ) e na Figura b ( $\circ$ PIG) para um recémnascido PIG. Na Figura c, os símbolos abertos representam o teste ( $\circ$ PIG, $\square$ AIG P $<50$ e $\square$ AIG $\mathrm{P} \geq 50)$ e símbolos fechados o reteste ( $\bullet \mathrm{PIG}$, $\mathrm{AIG} \mathrm{P}<50$ e $\square$ AIG $\mathrm{P} \geq 50$ ). 
A Figura 27 a seguir mostra a inclinação da reta para os recém-nascidos PIG e AIG obtidos do registro do teste de sensibilidade ao contraste. As Figuras 27a e 27b mostram os valores de inclinação da reta para cada recém-nascido AIG ou PIG e a Figura 27c mostra os valores de inclinação da reta para ambos os grupos em duas faixas etárias diferentes (ou medidas).
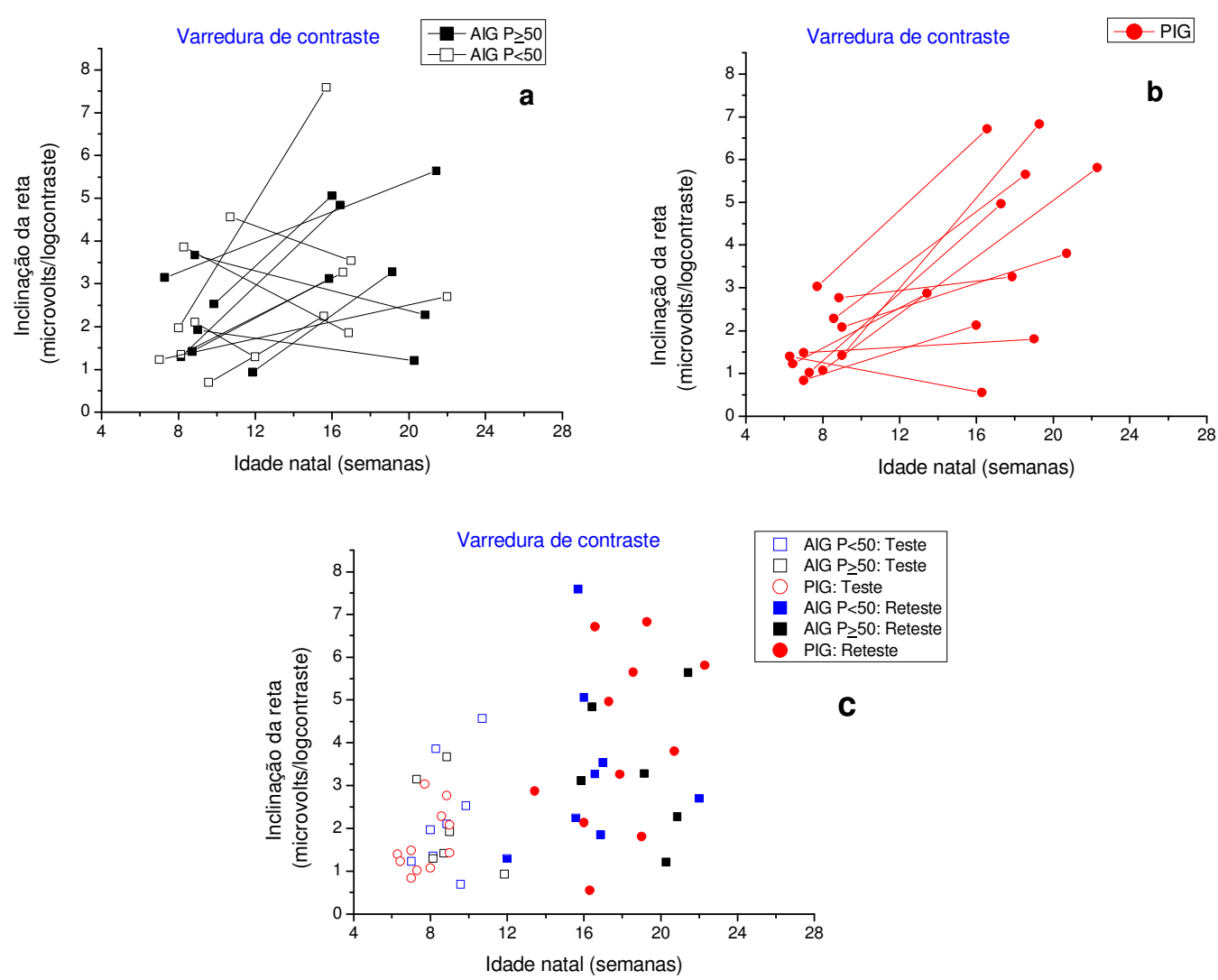

Figura 27. Valores de inclinação da reta (microvolts/logcontraste) para os recém-nascidos PIG e AIG obtidos do registro do teste de sensibilidade ao contraste. Figura a, cada linha representa os dados obtidos para um recém-nascido AIG ( P $\geq 50$ e $\square \mathrm{P}<50)$ e na Figura $b$ ( $\circ$ PIG) para um recém-nascido PIG. Na Figura c, os símbolos abertos representam o teste $(\circ \mathrm{PIG}, \square \mathrm{AIG} \mathrm{P}<50$ e $\square$ AIG $\mathrm{P} \geq 50$ ) e símbolos fechados o reteste $(\bullet \mathrm{PIG}, \square \mathrm{AIG} \mathrm{P}<50$ e AIG $\mathrm{P} \geq 50$ ).

A ANOVA fatorial para os dados longitudinais não mostrou diferenças significativas entre os grupos PIG e AIG para os valores de inclinação da reta obtidos a partir do teste de sensibilidade ao contraste em nenhuma das medidas (teste ou reteste) $[\mathrm{F}(1,44)=1,20$; 
$\mathrm{p}=0,28]$. No entanto, houve diferença significativa intragrupos para os valores de inclinação da reta entre as medidas (teste e reteste) $[\mathrm{F}(1,44)=15,67 ; \mathrm{p}=0,0003]$. O teste post hoc de Fisher LSD mostrou que os valores de inclinação da reta apresentavam-se significativamente mais altos no reteste (recém-nascidos mais velhos) em comparação ao teste (recém-nascidos mais jovens) para ambos os grupos PIG ( $\mathrm{p}=0,001)$ e AIG $(\mathrm{p}=0,04)$.

\section{Análises da Amplitude Máxima}

A Tabela 6 mostra a média e o desvio-padrão para a amplitude máxima durante os testes de acuidade visual e sensibilidade ao contraste para a freqüência espacial de 0,5 cpg dos recém-nascidos PIG e AIG em duas faixas etárias: 5-9 semanas e 10-24 semanas. O grupo AIG foi subdividido por percentil de peso ao nascimento $(50 \leq \mathrm{P}<50)$.

Tabela 6. Mostra a média e o desvio-padrão da amplitude máxima durante os testes de acuidade visual e sensibilidade ao contraste para a freqüência espacial de $0,5 \mathrm{cpg}$ dos recém-nascidos PIG e AIG em duas faixas etárias. O grupo AIG foi subdividido por percentil de peso ao nascimento $(50 \leq \mathrm{P}<50)$.

\begin{tabular}{|c|c|c|}
\hline Grupos & $\begin{array}{c}\text { Amplitude de AV } \\
\text { (microvolts) }\end{array}$ & $\begin{array}{c}\text { Amplitude de SC } \\
\text { (microvolts) }\end{array}$ \\
\hline $\begin{array}{c}\text { AIG }<10 \text { semanas } \\
(P \geq 50)\end{array}$ & $3,98 \pm 3,15(n=18)$ & $2,26 \pm 1,23(n=14)$ \\
\hline AIG $\geq \underset{(P \geq 50)}{10 \text { semanas }}$ & $10,70 \pm 6,78(n=13)$ & $4,67 \pm 4,30(n=13)$ \\
\hline $\begin{array}{c}\text { AIG }<\underset{\text { 10 semanas }}{\mathrm{P}<50} \\
\text { (50 }\end{array}$ & $4,71 \pm 4,06(n=17)$ & $1,91 \pm 0,68(n=14)$ \\
\hline 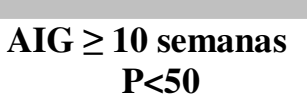 & $9,34 \pm 6,27(n=25)$ & $4,70 \pm 3,47(n=23)$ \\
\hline PIG $<10$ semanas & $2,97 \pm 1,84(n=33)$ & $1,76 \pm 1,12(n=26)$ \\
\hline PIG $\geq 10$ semanas & $9,49 \pm 5,16(n=20)$ & $4,60 \pm 2,20(\mathrm{n}=19)$ \\
\hline
\end{tabular}

A ANOVA fatorial não mostrou diferença significativa entre os grupos PIG, AIG $\mathrm{P} \geq 50$ e AIG $\mathrm{P}<50$ para os valores de amplitude máxima registrados durante o teste de acuidade visual em nenhuma das duas faixas etárias $[\mathrm{F}(1,124)=0,30 ; \mathrm{p}=0,74]$. 
Encontramos diferenças significativas intragrupos para os valores de amplitude máxima entre as faixas etárias $[\mathrm{F}(1,124)=40,39 ; \mathrm{p}=0,00001]$. $\mathrm{O}$ teste post hoc de Fisher LSD mostrou que a amplitude máxima encontrava-se significativamente mais alta para os recém-nascidos PIG (p=0, 00001), AIG P $\geq 50(\mathrm{p}=0,01)$ e AIG $\mathrm{P}<50(\mathrm{p}=0,0003)$ de 10 a 24 semanas de idade em comparação aos recém-nascidos abaixo de 10 semanas de idade para seus respectivos grupos.

A ANOVA fatorial não mostrou diferença significativa entre os grupos PIG, AIG $\mathrm{P} \geq 50$ e AIG $\mathrm{P}<50$ para os valores de amplitude máxima registrados durante o teste de sensibilidade ao contraste em nenhuma das faixas etárias $[\mathrm{F}(1,107)=0,07 ; \mathrm{p}=0,93]$. Observaram-se diferenças estatísticas significativas intragrupos para os valores de amplitude máxima entre as faixas etárias $[\mathrm{F}(1,107)=30,20 ; \mathrm{p}=0,00001]$. O teste post hoc de Fisher LSD mostrou que a amplitude máxima encontrava-se mais alta para os recémnascidos PIG ( $p=0,0002)$, AIG P $\geq 50(p=0,014)$ e AIG $P<50(p=0,0008)$ na faixa etária de 10 a 24 semanas em comparação aos recém-nascidos abaixo de 10 semanas de idade para seus respectivos grupos.

A Figura 28 apresenta os valores de amplitude máxima para os recém-nascidos PIG e AIG registrados durante o teste de acuidade visual e sensibilidade ao contraste pelo PVEv utilizando a freqüência temporal de $6 \mathrm{~Hz}$ e a freqüência espacial de 0,5 cpg. Observa-se que os dados de amplitude máxima dos recém-nascidos PIG e AIG encontramse justapostos para todas as idades tanto para os dados obtidos a partir do registro de acuidade visual (Figura 28a) como para os dados do registro de sensibilidade ao contraste (Figura 28b). No geral, observa-se que a maior parte dos dados está concentrada entre 0,73 e 10 microvolts (Figuras 28ab). 


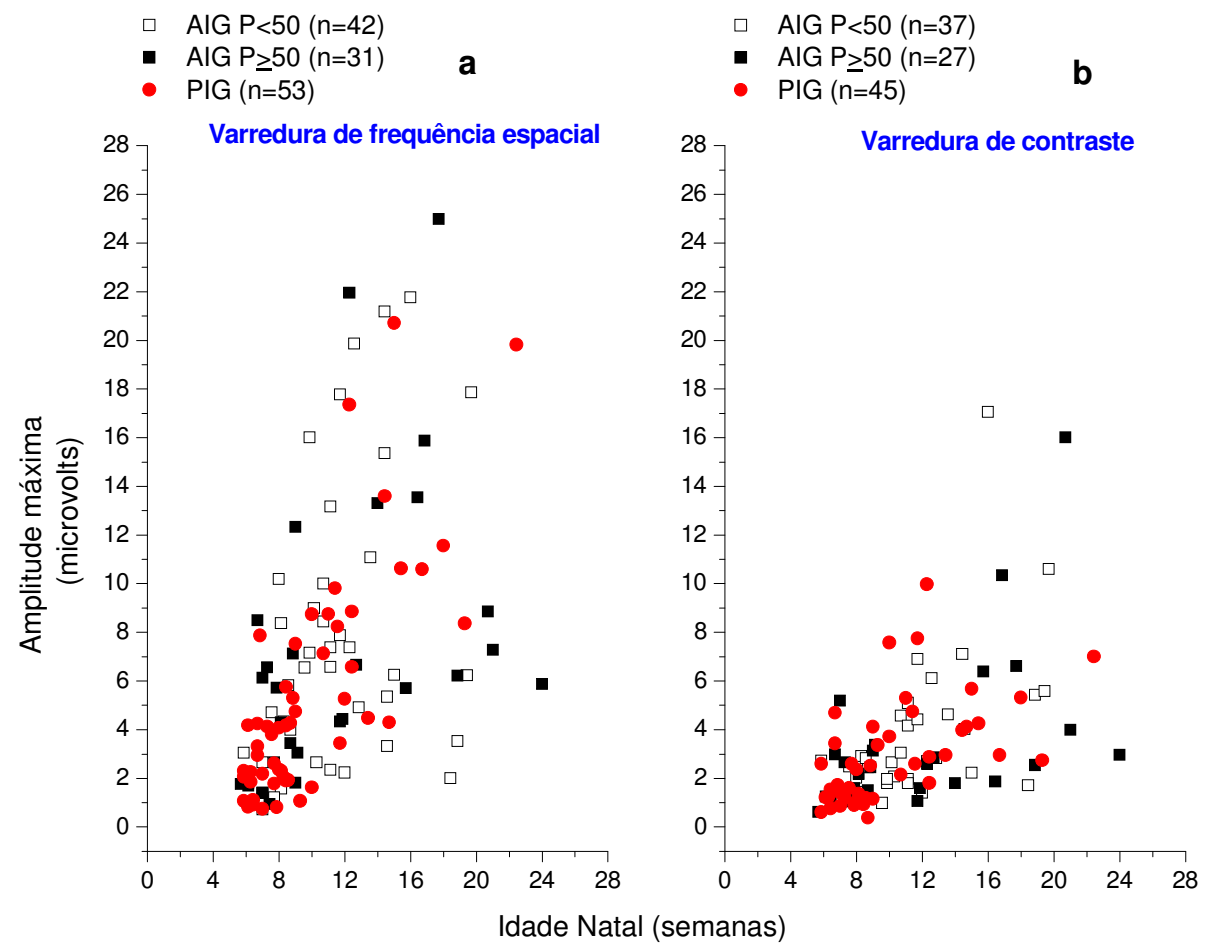

Figura 28. Registro de amplitude máxima para os recém-nascidos PIG $(\bullet)$, AIG $\mathrm{P}<50$ ( $\square$ ) e AIG $\mathrm{P} \geq 50$ (ロ) durante os testes de acuidade visual (a) e sensibilidade ao contraste (b) pelo PVEv utilizando a freqüência temporal de $6 \mathrm{~Hz}$ e a freqüência espacial de $0,5 \mathrm{cpg}$.

A Figura 29 a seguir apresenta a comparação entre os grupos PIG e AIG P $\geq 50$ para a amplitude máxima registrada durante os testes de acuidade visual e sensibilidade ao contraste. Observa-se na Figura 29a que 37 recém-nascidos PIG encontravam-se abaixo e 16 recém-nascidos encontravam-se acima da média do grupo AIG para a amplitude máxima registrada durante o teste de acuidade visual. A análise estatística mostrou diferença significativa na proporção de recém-nascidos PIG com valores de amplitude máxima abaixo da média do grupo AIG $\mathrm{P} \geq 50\left[\mathrm{x}^{2}=7,23 ; \mathrm{p}=0,007\right]$ para o registro de acuidade visual. 


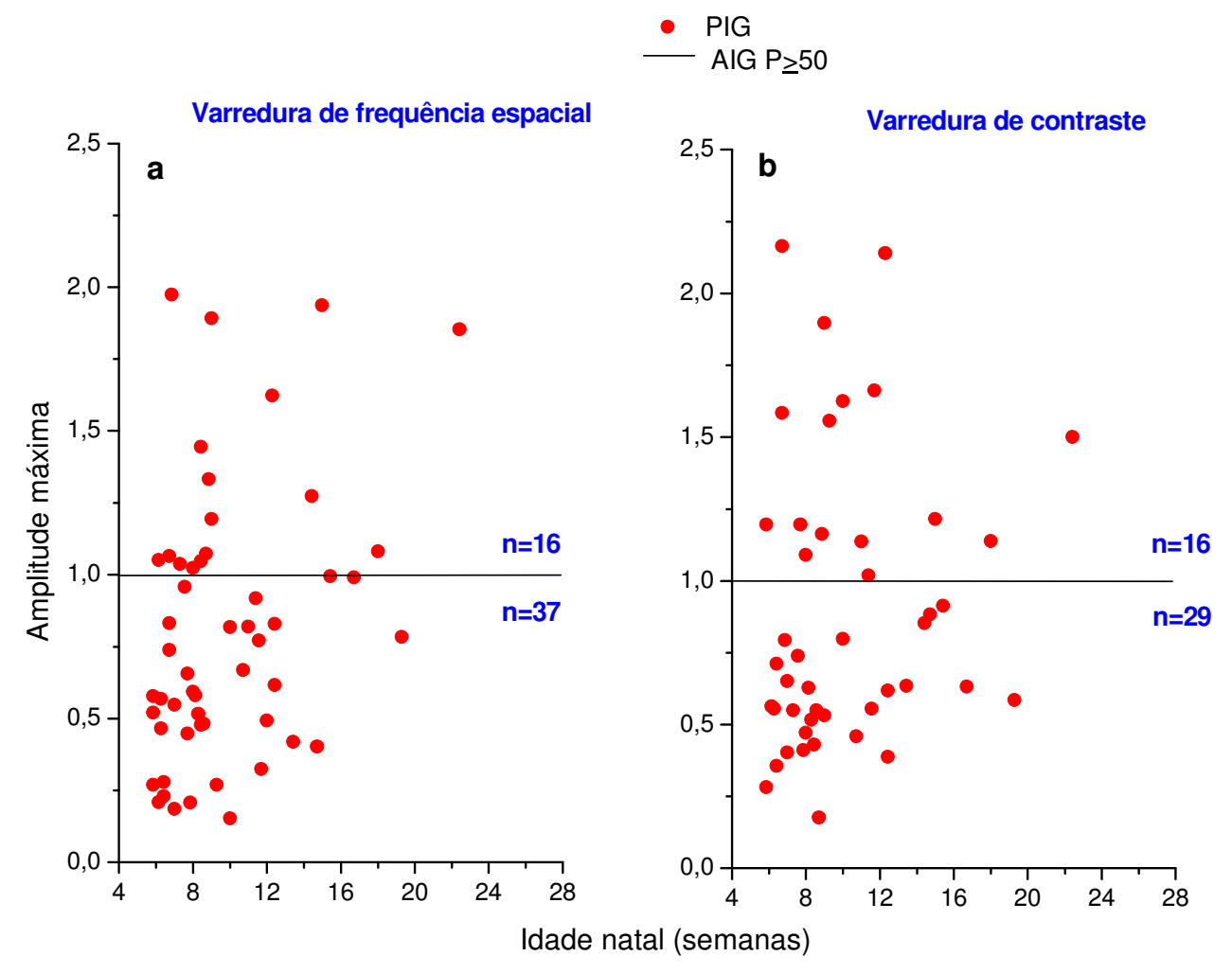

Figura 29. Comparação da amplitude máxima registrada durante os testes de acuidade visual (a) e sensibilidade ao contraste (b) entre o grupo PIG ( $\bullet$ ) e os dados AIG P $\geq 50$ $(-)$.

A Figura 29b mostra que 29 recém-nascidos PIG encontravam-se abaixo da média do grupo AIG $\mathrm{P} \geq 50$ e 16 recém-nascidos encontravam-se acima da média do grupo AIG $\mathrm{P} \geq 50$ para a amplitude máxima registrada durante o teste de sensibilidade ao contraste. A análise estatística não mostrou diferença significativa na proporção de recém-nascidos PIG com valores de amplitude máxima abaixo ou acima da média do grupo AIG $\mathrm{P} \geq 50\left[\mathrm{x}^{2}=\right.$ $3,78 ; \mathrm{p}=0,05]$ para o registro de sensibilidade ao contraste. Pode-se falar apenas em tendência a uma maior proporção de recém-nascidos PIG com valores de amplitude máxima menores do que a média do grupo AIG $\mathrm{P} \geq 50$.

A Figura 30 mostra os valores de amplitude máxima para os recém-nascidos PIG e AIG obtidos a partir do registro do teste de acuidade visual. As Figuras 30a e 30b mostram os valores de amplitude máxima para cada recém-nascido AIG ou PIG e a Figura 30c 
mostra os valores de amplitude máxima para ambos os grupos em duas faixas etárias diferentes (ou medidas).

A ANOVA fatorial para os dados longitudinais não mostrou diferenças significativas entre os grupos PIG e AIG para os valores de amplitude máxima obtidos a partir do teste de acuidade visual em nenhuma das medidas (teste ou reteste) $[\mathrm{F}(1,52)$ $=1,76 ; \mathrm{p}=0,19]$. As análises intragrupos não mostraram diferença significativa para os valores de amplitude máxima entre as medidas (teste e reteste) $[\mathrm{F}(1,52)=0,36 ; \mathrm{p}=0,55]$.

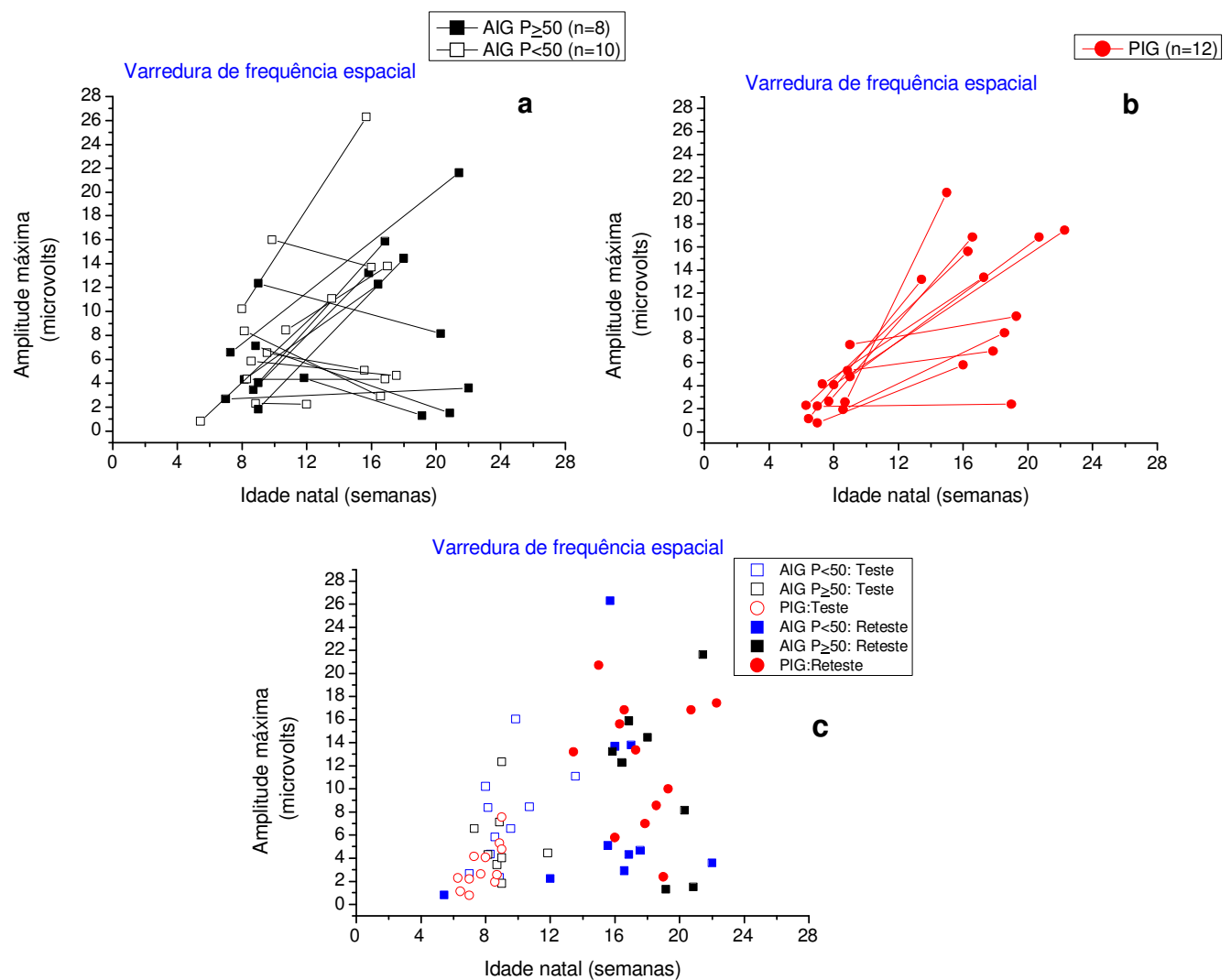

Figura 30. Valores de amplitude máxima (microvolts) para os recém-nascidos PIG e AIG obtidos do registro do teste de acuidade visual. Figura a, cada linha representa os dados obtidos para um recém-nascido AIG $(\square \mathrm{P} \geq 50$ e $\square \mathrm{P}<50)$ e na Figura $\mathrm{b}$ para um recémnascido PIG ( $\circ$ PIG). Na Figura c, os símbolos abertos representam o teste ( $\circ$ PIG, $\square$ AIG $\mathrm{P}<50$ e $\square$ AIG $\mathrm{P} \geq 50$ ) e símbolos fechados o reteste ( $\bullet \mathrm{PIG}$, AIG $\mathrm{P}<50$ e - AIG $\mathrm{P} \geq 50$ ). 
A Figura 31 mostra os valores de amplitude máxima para os recém-nascidos PIG e AIG obtidos a partir do registro do teste de sensibilidade ao contraste. As Figuras 31a e $31 \mathrm{~b}$ mostram os valores de amplitude máxima para cada recém-nascido AIG ou PIG e a Figura 31c mostra os valores de amplitude máxima para ambos os grupos em duas faixas etárias diferentes (ou medidas).
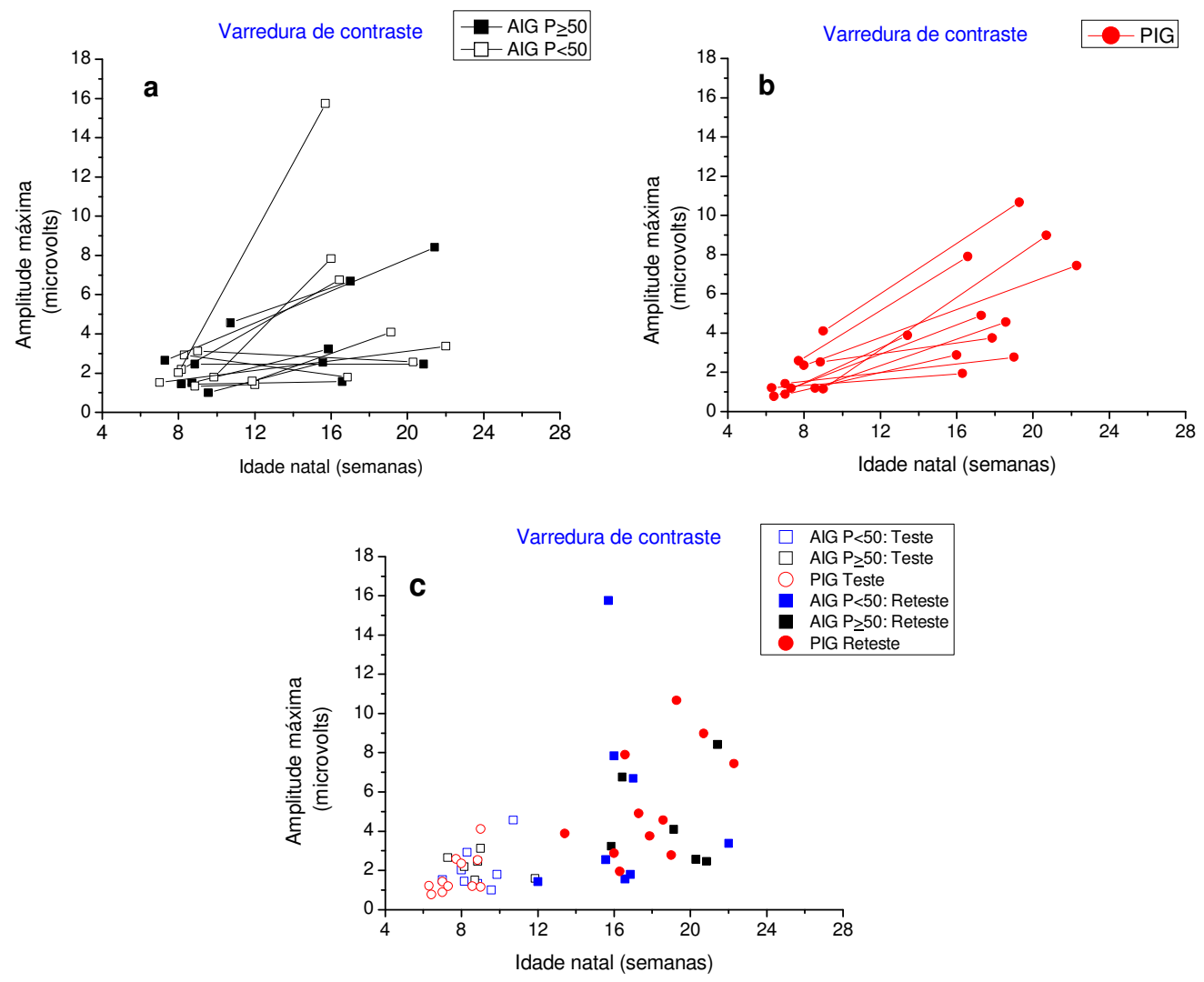

Figura 31. Valores de amplitude máxima (microvolts) para os recém-nascidos PIG e AIG obtidos do registro do teste de sensibilidade ao contraste. Figura a, cada linha representa os dados obtidos para um recém-nascido AIG ( $\bullet \mathrm{P} \geq 50$ e $\square \mathrm{P}<50)$ e na Figura b para um recém-nascido PIG ( $\circ$ PIG). Na Figura c, os símbolos abertos representam o teste ( $\circ$ PIG, $\square$ AIG $\mathrm{P}<50$ e $\square$ AIG $\mathrm{P} \geq 50)$ e símbolos fechados o reteste $(\bullet \mathrm{PIG}$, AIG $\mathrm{P}<50$ e - AIG $\mathrm{P} \geq 50$ ).

A ANOVA fatorial para os dados longitudinais não mostrou diferenças significativas entre os grupos PIG e AIG para os valores de amplitude máxima obtidos a partir do teste de sensibilidade ao contraste em nenhuma das medidas (teste ou reteste) $[\mathrm{F}(1,44)=0,29 ; \mathrm{p}=0,59]$. As análises intragrupos mostraram diferença significativa para os 
valores de amplitude máxima entre as medidas (teste e reteste) $[\mathrm{F}(1,44)=17,14 ; \mathrm{p}=0$, 0002]. O teste post hoc de Fisher LSD mostrou que os recém-nascidos PIG ( $p=0,002)$ e AIG $(\mathrm{p}=0,01)$ na faixa etária de 10 a 24 semanas apresentaram valores de amplitude máxima significativamente mais altos em comparação aos recém-nascidos de 5 a 9 semanas de idade para seus respectivos grupos.

\section{Análises do Ruído Médio}

A Tabela 7 mostra a média e o desvio-padrão para o ruído médio durante os testes de acuidade visual e sensibilidade ao contraste para a frequiência espacial de $0,5 \mathrm{cpg}$ dos recém-nascidos PIG e AIG em duas faixas etárias: 5-9 semanas e 10-24 semanas. O grupo AIG foi subdividido por percentil de peso ao nascimento $(50 \leq \mathrm{P}<50)$.

Tabela 7. Mostra a média e o desvio-padrão para o ruído médio durante os testes de acuidade visual e sensibilidade ao contraste para a freqüência espacial de $0,5 \mathrm{cpg}$ dos recém-nascidos PIG e AIG em duas faixas etárias. O grupo AIG foi subdividido por percentil de peso ao nascimento $(50 \leq \mathrm{P}<50)$.

\begin{tabular}{|c|c|c|}
\hline Grupos & $\begin{array}{c}\text { Ruído Médio de AV } \\
\text { (microvolts) }\end{array}$ & $\begin{array}{l}\text { Ruído Médio de } \\
\text { SC (microvolts) }\end{array}$ \\
\hline $\begin{array}{c}\text { AIG }<10 \text { semanas } \\
(P \geq 50)\end{array}$ & $0,41 \pm 0,16(n=18)$ & $0,35 \pm 0,10(n=14)$ \\
\hline $\begin{array}{c}A I G \geq \underset{(P \geq 50)}{10} \text { semanas } \\
(P=50\end{array}$ & $0,69 \pm 0,26(n=13)$ & $0,51 \pm 0,16(n=13)$ \\
\hline $\begin{array}{c}\text { AIG }<\mathbf{1 0} \text { semanas } \\
\text { P }<50\end{array}$ & $0,36 \pm 0,15(n=17)$ & $0,32 \pm 0,11(n=14)$ \\
\hline $\begin{array}{c}\mathrm{AIG} \geq \mathbf{1 0} \text { semanas } \\
\mathbf{P}<\mathbf{5 0}\end{array}$ & $0,69 \pm 0,30(n=25)$ & $0,58 \pm 0,28(n=23)$ \\
\hline PIG $<10$ semanas & $0,37 \pm 0,14(n=33)$ & $0,30 \pm 0,11(n=26)$ \\
\hline PIG $\geq 10$ semanas & $0,60 \pm 0,19(n=20)$ & $0,49 \pm 0,16(n=19)$ \\
\hline
\end{tabular}

A ANOVA fatorial não mostrou diferença significativa entre os grupos PIG, AIG $\mathrm{P} \geq 50$ e AIG $\mathrm{P}<50$ para os valores de ruído médio registrados durante o teste de acuidade visual em nenhuma das faixas etárias $[\mathrm{F}(1,124)=1,24 ; \mathrm{p}=0,29]$. 
Para as análises estatísticas intragrupos observaram-se diferenças significativas para os valores de ruído médio entre as faixas etárias $[\mathrm{F}(1,124)=47,69 ; \mathrm{p}=0,00001]$. $\mathrm{O}$ teste post hoc de Fisher LSD mostrou que o ruído médio encontrava-se significativamente mais alto para os recém-nascidos PIG ( $\mathrm{p}=0,0001)$, AIG $\mathrm{P} \geq 50(\mathrm{p}=0,01)$ e AIG $\mathrm{P}<50$ $(\mathrm{p}=0,001)$ na faixa etária de 10 a 24 semanas em comparação aos recém-nascidos abaixo de 10 semanas de idade de seus respectivos grupos, conforme mostra a Tabela 7.

A ANOVA fatorial não mostrou diferença significativa entre os grupos PIG, AIG $\mathrm{P} \geq 50$ e $\mathrm{AIG} \mathrm{P}<50$ para os valores de ruído médio registrados durante o teste de sensibilidade ao contraste em nenhuma das faixas etárias $[\mathrm{F}(1,107)=0,53 ; \mathrm{p}=0,59]$. No entanto, mostrou diferenças significativas intragrupos para os valores de ruído médio entre as faixas etárias $[\mathrm{F}(1,107)=36,68 ; \mathrm{p}=0,00001]$. O teste post hoc de Fisher LSD mostrou que os valores de ruído médio encontravam-se significativamente mais altos para os recém-nascidos PIG ( $\mathrm{p}=0,0004)$, AIG $\mathrm{P} \geq 50(\mathrm{p}=0,01)$ e AIG $\mathrm{P}<50(\mathrm{p}=0,00002)$ na faixa etária de 10 a 24 semanas em comparação aos recém-nascidos abaixo de 10 semanas de seus respectivos grupos, conforme mostra a Tabela 7.

A Figura 32 apresenta o registro de ruído médio para os recém-nascidos PIG e AIG durante os testes de acuidade visual e sensibilidade ao contraste. De forma geral, observase uma sobreposição nos valores de ruído médio dos recém-nascidos PIG e AIG registrados a partir dos testes de acuidade visual (Figura 32a) e sensibilidade ao contraste (Figura 32b).

A comparação entre as médias do ruído médio para as funções visuais mostra que as médias encontram-se um pouco mais altas para os registros do teste de acuidade visual para os três grupos de recém-nascidos, conforme mostra a Tabela 7 e a Figura 32ab. 


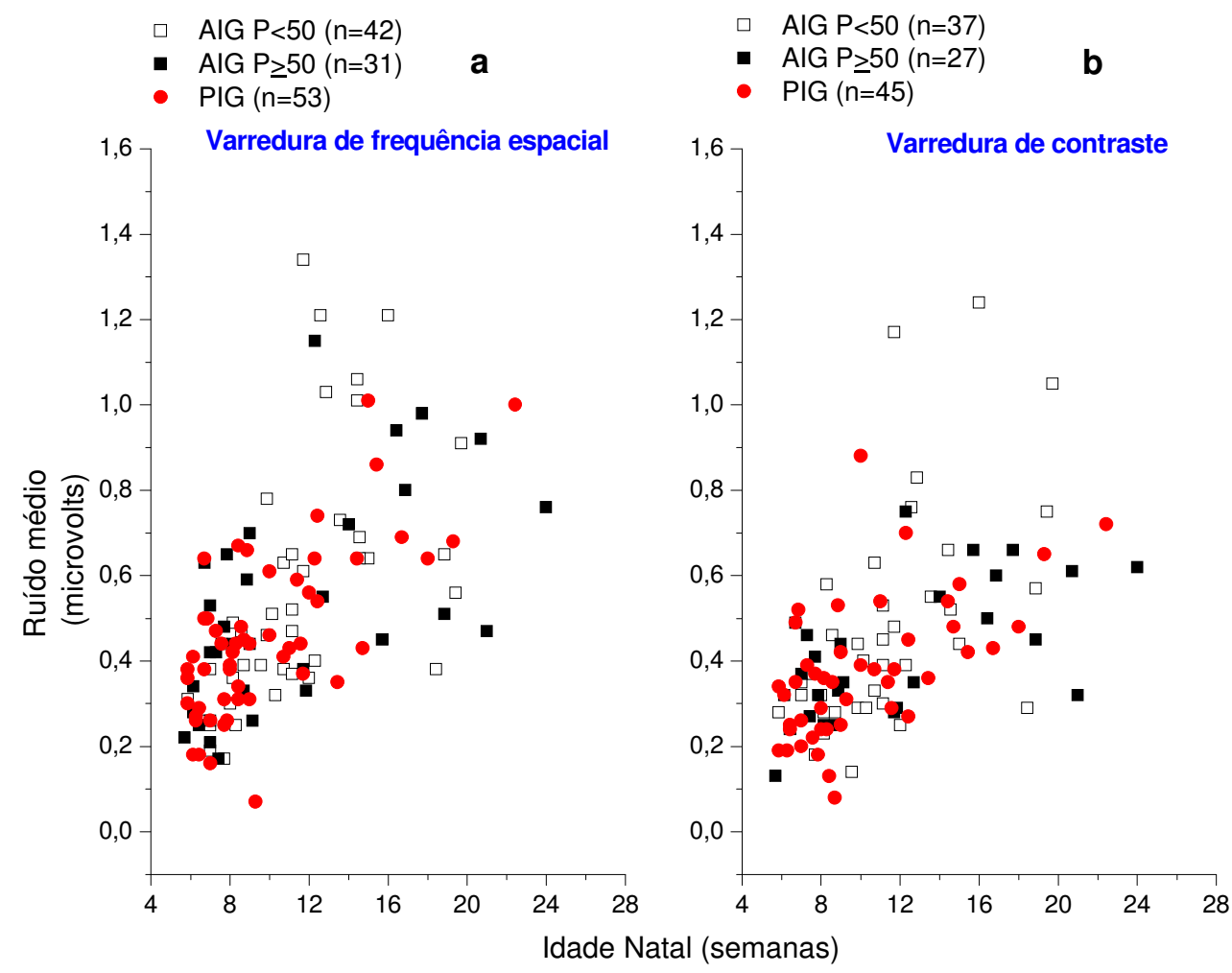

Figura 32. Registro de ruído médio para os recém-nascidos PIG ( $\bullet$ ), AIG P<50 ( $\square$ ) e AIG P $\geq 50$ ( $\square$ ) durante os testes de acuidade visual (a) e sensibilidade ao contraste (b) pelo PVEv utilizando a freqüência temporal de $6 \mathrm{~Hz}$ e a frequência espacial de $0,5 \mathrm{cpg}$.

A Figura 33 a seguir apresenta a comparação entre o grupo PIG e AIG P $\geq 50$ para o ruído médio registrado durante os testes de acuidade visual e sensibilidade ao contraste. Observa-se na Figura 33a que 36 recém-nascidos PIG apresentavam os valores de ruído médio menores do que a média do grupo AIG $\mathrm{P} \geq 50$ e 17 recém-nascidos com valores de ruído médio maiores do que a média do grupo $\mathrm{AIG} P \geq 50$. A análise estatística mostrou diferença significativa na proporção de recém-nascidos PIG com valores de ruído médio abaixo da média do grupo AIG $\mathrm{P} \geq 50$ para o registro de acuidade visual $\left[\mathrm{x}^{2}=5,71\right.$; $\mathrm{p}=0,017]$. 


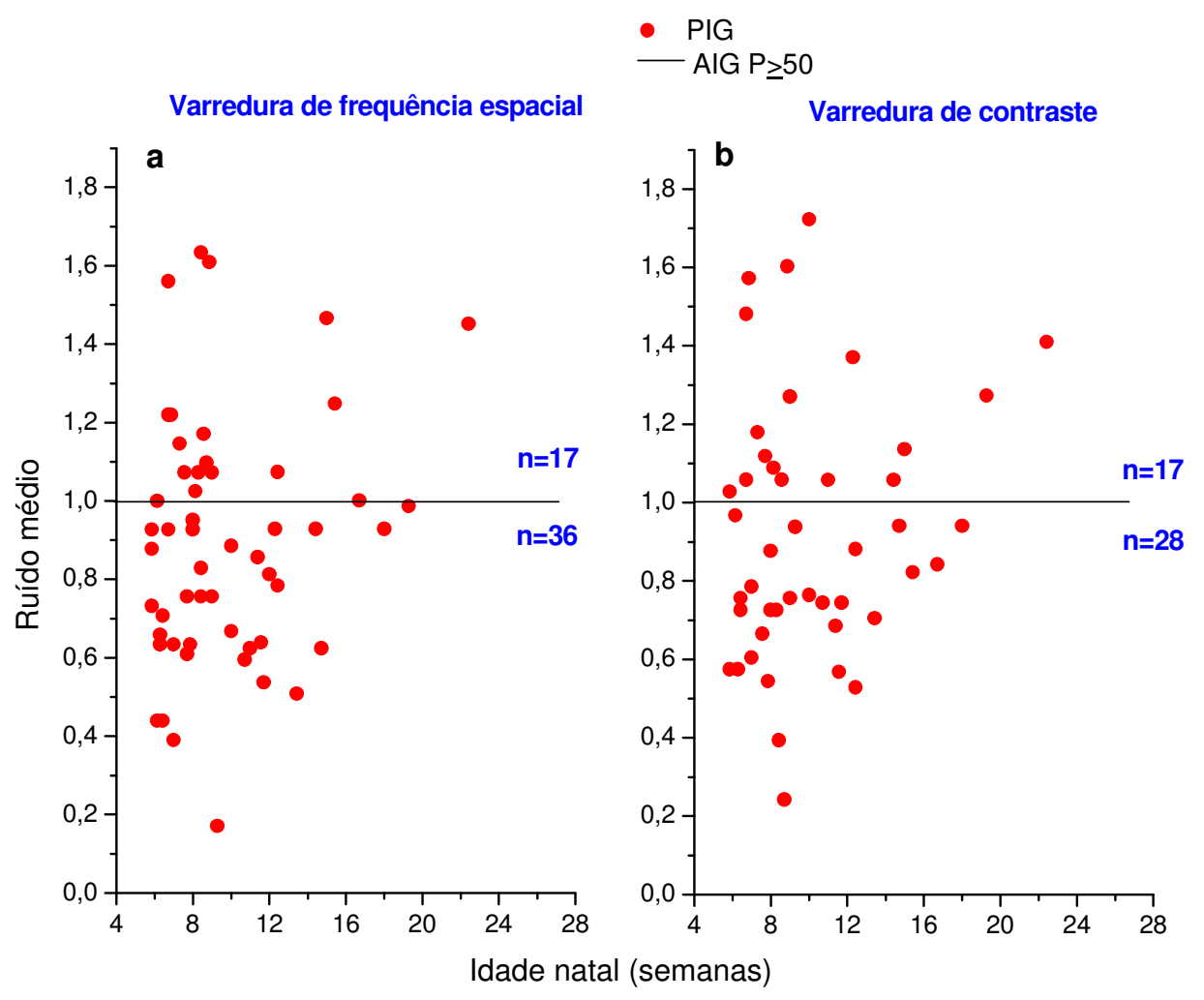

Figura 33. Comparação do ruído médio registrado durante os testes de acuidade visual (a) e sensibilidade ao contraste (b) entre o grupo PIG $(\bullet$ e os dados AIG P $\geq 50(-)$.

A Figura 33b mostra que 28 recém-nascidos PIG apresentavam valores de ruído médio abaixo da média do grupo AIG P $\geq 50$ e 17 recém nascidos PIG acima da média do grupo AIG $P \geq 50$. A análise estatística não mostrou diferença significativa na proporção de recém-nascidos PIG com valores de ruído médio abaixo ou acima da média do grupo AIG $\mathrm{P} \geq 50$ para o registro de sensibilidade ao contraste $\left[\mathrm{x}^{2}=2,73 ; \mathrm{p}=0,098\right]$.

A ANOVA fatorial para os dados longitudinais não mostrou diferença significativa entre os grupos PIG e AIG para os valores de ruído médio obtidos a partir do teste de acuidade visual em nenhuma das faixas etárias ou medidas (teste e reteste) $[\mathrm{F}(1,52)=1,29$; $\mathrm{p}=0,26]$. No entanto, as análises intragrupos mostraram diferenças significativas para os valores de ruído médio entre as medidas $[\mathrm{F}(1,52)=24,06 ; \mathrm{p}=0,00001]$. O teste post hoc de Fisher LSD mostrou que os recém-nascidos PIG $(p=0,001)$ e AIG $(p=0,02)$ na faixa etária de 10 a 24 semanas apresentaram valores de ruído médio significativamente mais 
altos em comparação aos recém-nascidos de 5 a 9 semanas de idade para seus respectivos grupos.

A Figura 34 mostra os valores de ruído médio para os recém-nascidos PIG e AIG obtidos a partir do registro do teste de acuidade visual. As Figuras 34a e 34b mostram os valores de ruído médio para cada recém-nascido AIG ou PIG e a Figura 34c mostra os valores de ruído médio para ambos os grupos em duas faixas etárias diferentes (ou medidas).
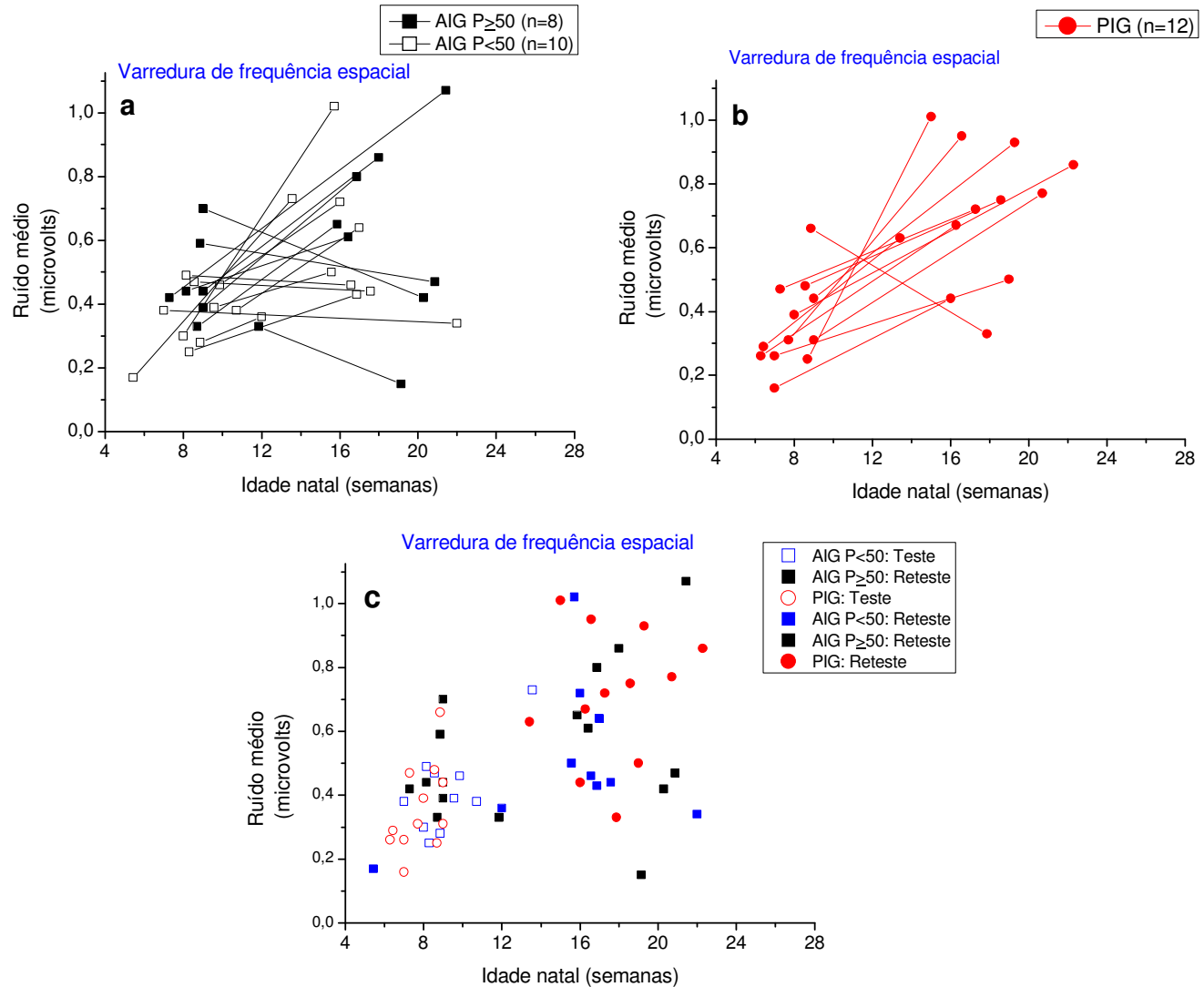

Figura 34. Valores de ruído médio (microvolts) para os recém-nascidos PIG e AIG obtidos do registro do teste de acuidade visual. Figura a, cada linha representa os dados obtidos para um recém-nascido AIG $(\square \mathrm{P} \geq 50$ e $\square \mathrm{P}<50)$ e na Figura b para um recémnascido PIG (०). Na Figura c, os símbolos abertos representam o teste ( $\circ$ PIG, $\square$ AIG $\mathrm{P}<50$ e $\square$ AIG $\mathrm{P} \geq 50$ ) e símbolos fechados o reteste ( $\bullet \mathrm{PIG}$, AIG $\mathrm{P}<50$ e $\square$ AIG $\mathrm{P} \geq 50$ ). 
A Figura 35 mostra os valores de ruído médio para os recém-nascidos PIG e AIG obtidos a partir do registro do teste de sensibilidade ao contraste. As Figuras 35a e 35b mostram os valores de ruído médio para cada recém-nascido AIG ou PIG e a Figura 35c mostra os valores de ruído médio para ambos os grupos em duas faixas etárias diferentes (ou medidas).

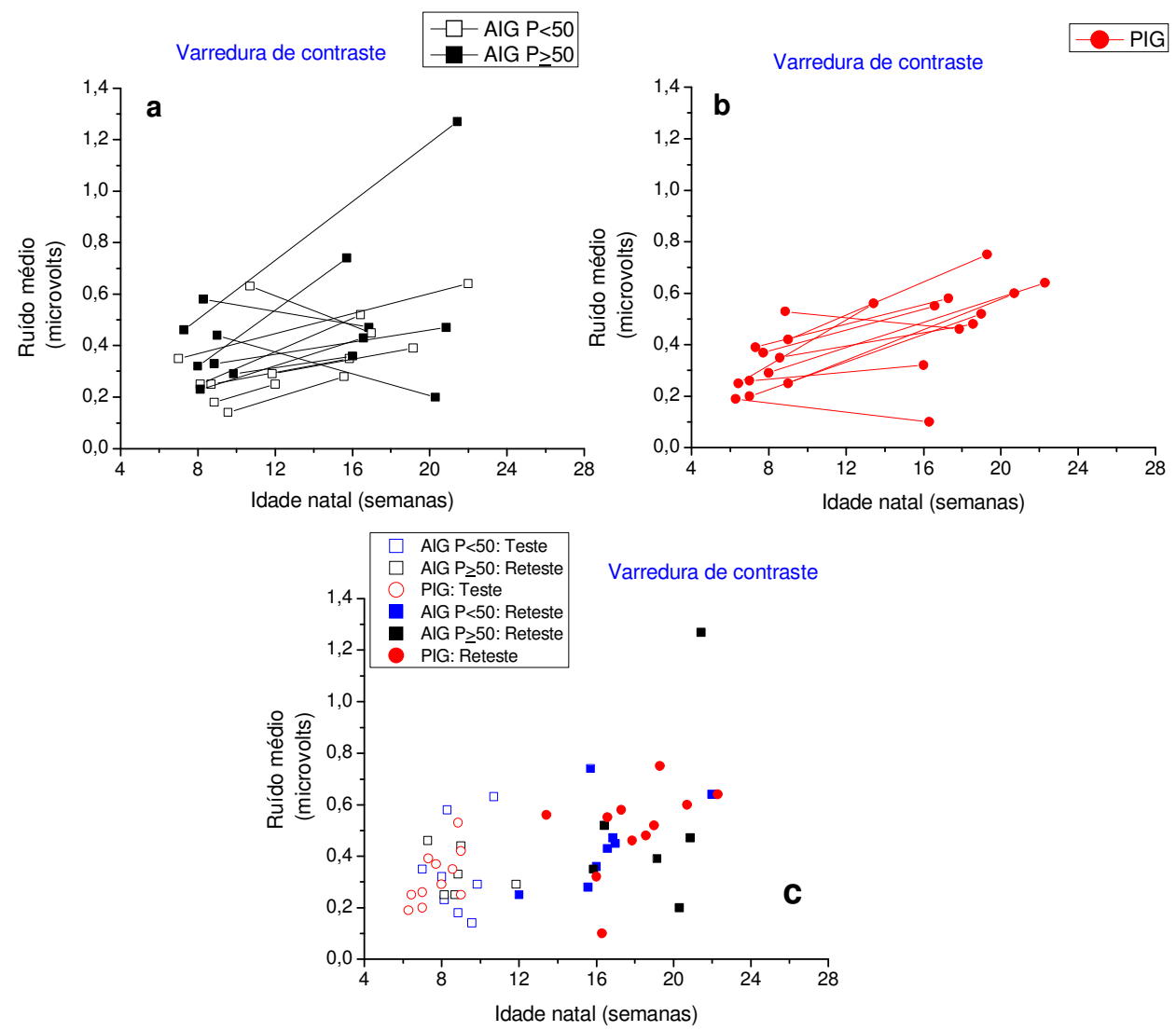

Figura 35. Valores de ruído médio (microvolts) para os recém-nascidos PIG e AIG obtidos do registro do teste de sensibilidade ao contraste. Figura a, cada linha representa os dados obtidos para um recém-nascido AIG ( $\mathrm{P} \geq 50$ e $\square \mathrm{P}<50)$ e na Figura b para um recém-nascido PIG ( $\circ$ ). Na Figura c, os símbolos abertos representam o teste ( $\circ \mathrm{PIG}, \square \mathrm{AIG} \mathrm{P}<50$ e $\square$ AIG P $\geq 50)$ e símbolos fechados o reteste $(\bullet \mathrm{PIG}$, —AIG $\mathrm{P}<50$ e $\square \mathrm{AIG} \mathrm{P} \geq 50)$.

A ANOVA fatorial para os dados longitudinais não mostrou diferença significativa entre os grupos PIG e AIG para os valores de ruído médio obtidos a partir do teste de 
sensibilidade ao contraste em nenhuma das faixas etárias ou medidas (teste e reteste) $[\mathrm{F}(1,44)=0,004 ; \mathrm{p}=0,95]$.

As análises intragrupos mostraram diferenças significativas para os valores de ruído médio entre as medidas $[\mathrm{F}(1,44)=10,83 ; \mathrm{p}=0,002]$. O teste de post hoc de Fisher LSD mostrou que os recém-nascidos PIG $(\mathrm{p}=0,02)$ e $\mathrm{AIG}(\mathrm{p}=0,02)$ na faixa etária de 10 a 24 semanas apresentaram valores de ruído médio significativamente mais altos em comparação aos recém-nascidos de 5 a 9 semanas de idade para seus respectivos grupos.

\section{Análises da Razão Sinal-Ruído}

A Tabela 8 mostra a média e o desvio-padrão da razão sinal-ruído durante os testes de acuidade visual e sensibilidade ao contraste para a freqüência espacial de $0,5 \mathrm{cpg}$ dos recém-nascidos PIG e AIG em duas faixas etárias: 5-9 semanas e 10-24 semanas. O grupo AIG foi subdividido por percentil de peso ao nascimento $(50 \leq \mathrm{P}<50)$.

Tabela 8. Mostra a média e o desvio-padrão da razão sinal-ruído durante os testes de acuidade visual e sensibilidade ao contraste para a freqüência espacial de $0,5 \mathrm{cpg}$ dos recém-nascidos PIG e AIG em duas faixas etárias. O grupo AIG foi subdividido por percentil de peso ao nascimento $(50 \leq \mathrm{P}<50)$.

\begin{tabular}{ccc}
\hline \multicolumn{1}{c}{ Grupos } & SNR de AV & SNR de SC \\
\hline $\begin{array}{c}\text { AIG }<\mathbf{1 0} \text { semanas } \\
(\mathbf{P} \geq \mathbf{5 0})\end{array}$ & $8,91 \pm 4,21(\mathrm{n}=18)$ & $6,40 \pm 2,88(\mathrm{n}=14)$ \\
$\mathbf{A I G} \geq \mathbf{1 0}$ semanas \\
$\begin{array}{c}\mathbf{P} \geq \mathbf{5 0}) \\
\text { AIG }<\mathbf{1 0} \text { semanas } \\
\mathbf{P}<\mathbf{5 0}\end{array}$ & $14,80 \pm 4,85(\mathrm{n}=13)$ & $8,78 \pm 6,71(\mathrm{n}=13)$ \\
$\mathbf{\text { AIG }} \geq \mathbf{1 0}$ semanas & $12,33 \pm 9,49(\mathrm{n}=17)$ & $6,10 \pm 1,77(\mathrm{n}=14)$ \\
$\mathbf{P}<\mathbf{5 0}$ & $12,93 \pm 5,60(\mathrm{n}=25)$ & $7,76 \pm 2,38(\mathrm{n}=23)$ \\
$\mathbf{P I G}<\mathbf{1 0}$ semanas & $8,04 \pm 3,98(\mathrm{n}=33)$ & $5,90 \pm 2,63(\mathrm{n}=26)$ \\
$\mathbf{P I G} \geq \mathbf{1 0}$ semanas & $15,13 \pm 5,37(\mathrm{n}=20)$ & $9,47 \pm 3,67(\mathrm{n}=19)$ \\
\hline
\end{tabular}


A ANOVA fatorial não mostrou diferença significativa entre os grupos PIG e AIG para os valores de SNR obtidos durante o teste de acuidade visual em nenhuma das faixas etárias $[\mathrm{F}(1,124)=2,74 ; \mathrm{p}=0,07]$.

As análises estatísticas intragrupos mostraram diferenças significativas para os valores de SNR entre as faixas etárias $[\mathrm{F}(1,124)=15,76 ; \mathrm{p}=0,0001]$. O teste post hoc de Fisher LSD mostrou que os recém-nascidos PIG ( $\mathrm{p}=0$, 00002) e AIG P $\geq 50 \quad(\mathrm{p}=0,04)$ na faixa etária de 10 a 24 semanas apresentaram valores de SNR significativamente mais altos do que os recém-nascidos na faixa etária de 5 a 9 semanas para seus respectivos grupos. No entanto, não foram observadas diferenças estatísticas significativas nos valores de SNR para o grupo AIG $\mathrm{P}<50(\mathrm{p}=0,43)$ entre as faixas etárias.

A ANOVA fatorial não mostrou diferença significativa entre os grupos PIG, AIG $\mathrm{P} \geq 50$ e AIG $\mathrm{P}<50$ para os valores de $\mathrm{SNR}$ obtidos durante o teste de sensibilidade ao contraste em nenhuma das faixas etárias $[\mathrm{F}(1,107)=0,71 ; \mathrm{p}=0,49]$. Observaram-se diferenças significativas intragrupos para os valores de SNR entre as faixas etárias [F (1, 107) $=13,55 ; \mathrm{p}=0,0004]$. O teste post hoc de Fisher LSD mostrou que os recém-nascidos PIG na faixa etária de 10 a 24 semanas apresentaram valores de SNR mais altos do que os recém-nascidos PIG na faixa etária de 5 a 9 semanas $(\mathrm{p}=0,001)$. No entanto, não houve diferença significativa para os valores de SNR entre as faixas etárias para os grupos AIG $\mathrm{P} \geq 50(\mathrm{p}=0,11)$ e AIG $\mathrm{P}<50(\mathrm{p}=0,12)$.

A Figura 36 mostra o registro da razão sinal-ruído para os recém-nascidos PIG e AIG durante o teste de acuidade visual (Figura 36a) e sensibilidade ao contraste (Figura 36b). De forma geral, observa-se que os valores de SNR dos grupos PIG e AIG encontramse sobrepostos, sendo que a distribuição dos dados mostra-se diferente para os registros obtidos pelos testes de acuidade visual e sensibilidade ao contraste. Há uma maior concentração de dados entre os valores de SNR 3 e 20 para o registro de acuidade visual e uma maior concentração de dados entre os valores de SNR 3 e 10 para o registro de sensibilidade ao contraste. 


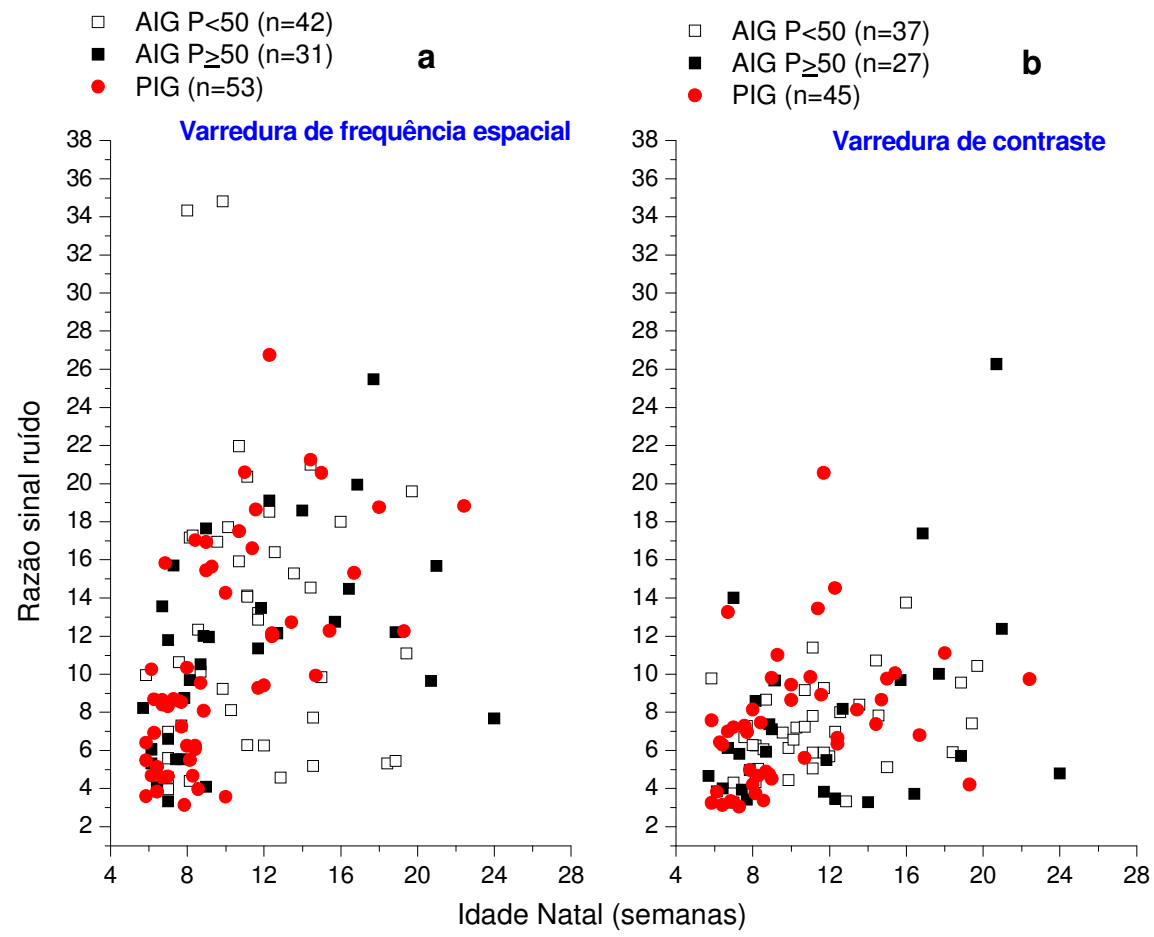

Figura 36. Registro da razão sinal-ruído para os recém-nascidos PIG (•), AIG P<50 () e AIG P $\geq 50$ (ロ) durante os testes de acuidade visual (a) e sensibilidade ao contraste (b) pelo PVEv utilizando a frequiência temporal de $6 \mathrm{~Hz}$.

A Figura 37 mostra a comparação entre os grupos PIG e AIG P $\geq 50$ para a razão sinal ruído registrada durante os testes de acuidade visual (Figura 37a) e sensibilidade ao contraste (Figura37b).

A Figura 37a mostra que 35 recém-nascidos PIG apresentavam valores de SNR abaixo da média do grupo AIG $\mathrm{P} \geq 50$ e 18 recém-nascidos PIG acima da média do grupo AIG P $\geq 50$. A análise estatística mostrou diferença significativa na proporção de recémnascidos PIG com valores de SNR abaixo da média do grupo AIG $\mathrm{P} \geq 50$ para o registro de acuidade visual $\left[\mathrm{x}^{2}=5,02 ; \mathrm{p}=0,02\right]$. 


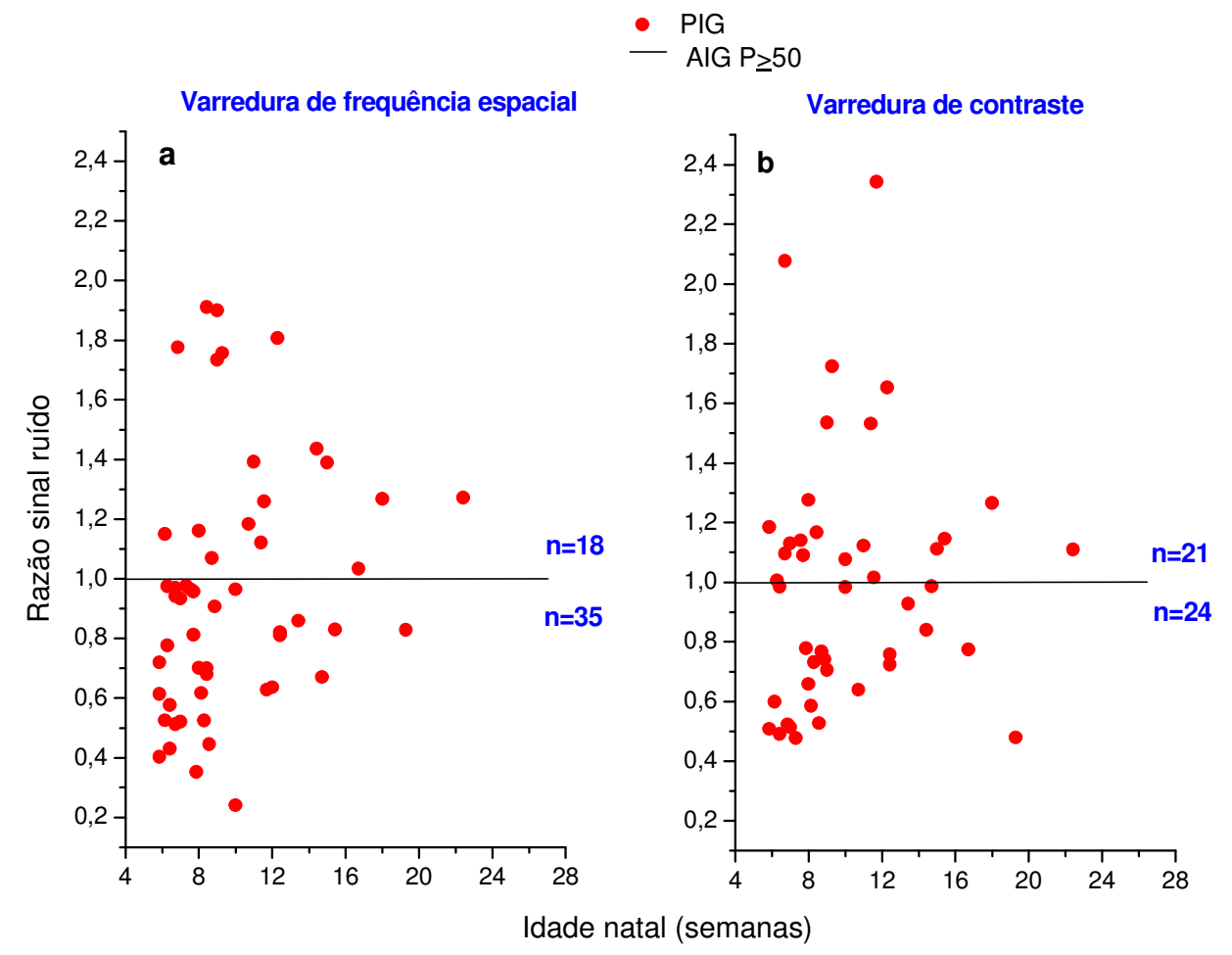

Figura 37. Comparação da razão sinal ruído registrada durante os testes de acuidade visual (a) e sensibilidade ao contraste (b) entre o grupo PIG ( $\bullet$ ) e os dados AIG P $\geq 50$ $(-)$.

Observa-se na Figura 37b que 24 recém-nascidos PIG encontravam-se abaixo da média do grupo AIG $\mathrm{P} \geq 50$ e 21 recém-nascidos PIG acima da média do grupo AIG P $\geq 50$. Não houve diferença significativa na proporção de recém-nascidos PIG abaixo ou acima da média do grupo AIG $\mathrm{P} \geq 50$ para o registro de sensibilidade ao contraste $\left[\mathrm{x}^{2}=0,13 ; \mathrm{p}=0,72\right]$.

A ANOVA fatorial para os dados longitudinais não mostrou diferença significativa entre os grupos PIG e AIG para os valores de SNR obtidos a partir do teste de acuidade visual em nenhuma das faixas etárias ou medidas (teste e reteste) $[\mathrm{F}(1,52)=0,09 ; \mathrm{p}=0,93]$. As análises intragrupos também não mostraram diferenças significativas para os valores de SNR entre as medidas $[\mathrm{F}(1,52)=0,22 ; \mathrm{p}=0,64]$. 
A Figura 38 mostra os valores de SNR máximo para os recém-nascidos PIG e AIG obtidos a partir do registro do teste de acuidade visual. As Figuras 38a e 38b mostram os valores de SNR máximo para cada recém-nascido AIG ou PIG e a Figura 38c mostra os valores de SNR máximo para ambos os grupos em duas faixas etárias diferentes (ou medidas).

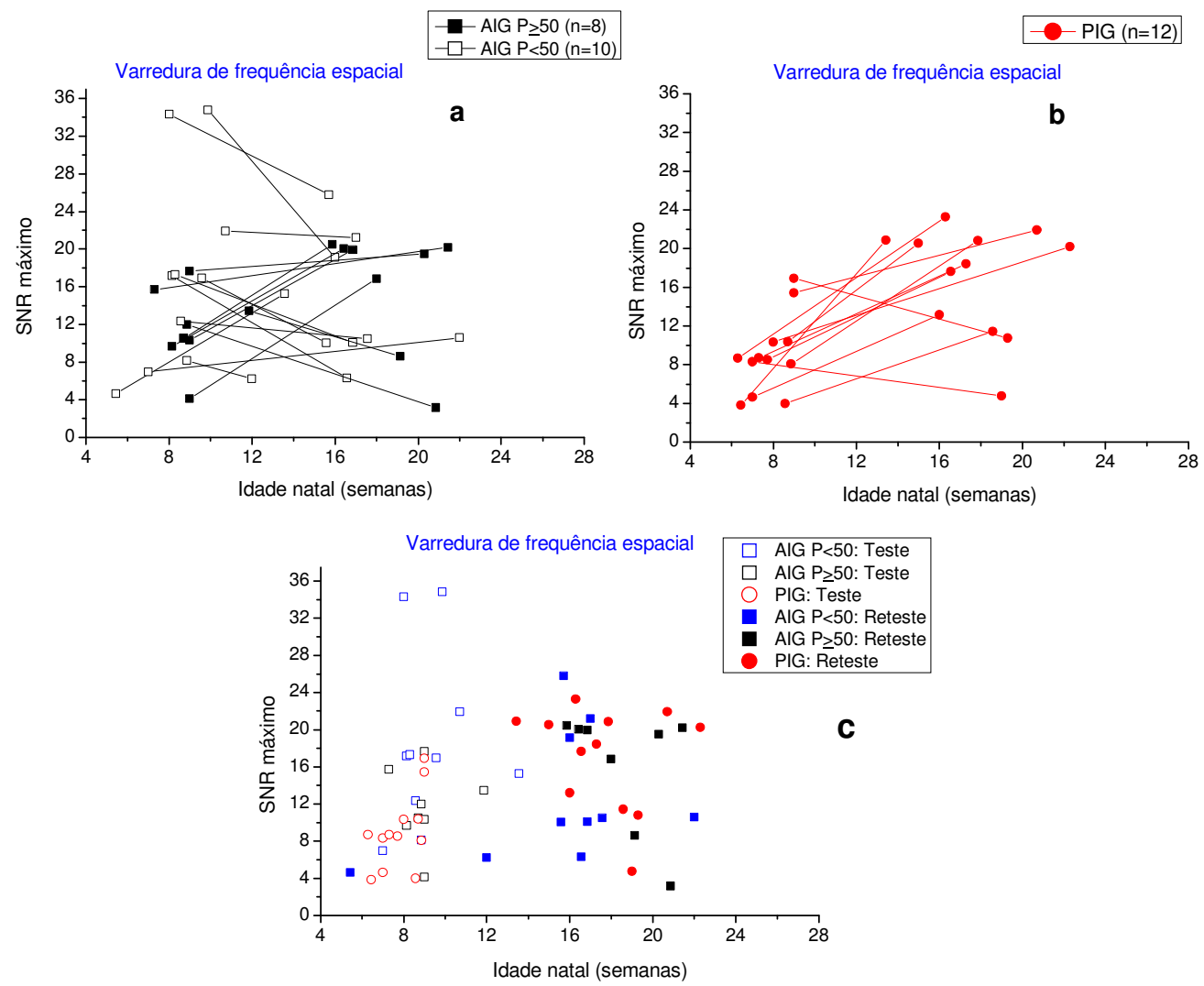

Figura 38. Valores de SNR máximo para os recém-nascidos PIG e AIG obtidos do registro do teste de acuidade visual. Figura a, cada linha representa os dados obtidos para um recém-nascido AIG ( $\mathrm{P} \geq 50$ e $\square \mathrm{P}<50)$ e na Figura b para um recém-nascido PIG ( $\circ$ ). Na Figura c, os símbolos abertos representam o teste ( $\circ$ PIG, $\square$ AIG P $<50$ e $\square$ AIG $\mathrm{P} \geq 50)$ e símbolos fechados o reteste ( $\bullet \mathrm{PIG}$, A AIG $\mathrm{P}<50$ e $\square \mathrm{AIG} \mathrm{P} \geq 50$ ).

A ANOVA fatorial para os dados longitudinais não mostrou diferença significativa entre os grupos PIG e AIG para os valores de SNR obtidos a partir do teste de 
sensibilidade ao contraste em nenhuma das faixas etárias ou medidas (teste e reteste) $[\mathrm{F}(1,44)=0,0001 ; \mathrm{p}=0,99]$. As análises intragrupos também não mostraram diferenças significativas para os valores de SNR entre as medidas $[\mathrm{F}(1,44)=1,77 ; \mathrm{p}=0,19]$.

A Figura 39 mostra os valores de SNR máximo para os recém-nascidos PIG e AIG obtidos a partir do registro do teste de sensibilidade ao contraste. As Figuras 39a e 39b mostram os valores de SNR para cada recém-nascido AIG ou PIG e a Figura 39c mostra os valores de SNR para ambos os grupos em duas faixas etárias diferentes (ou medidas).
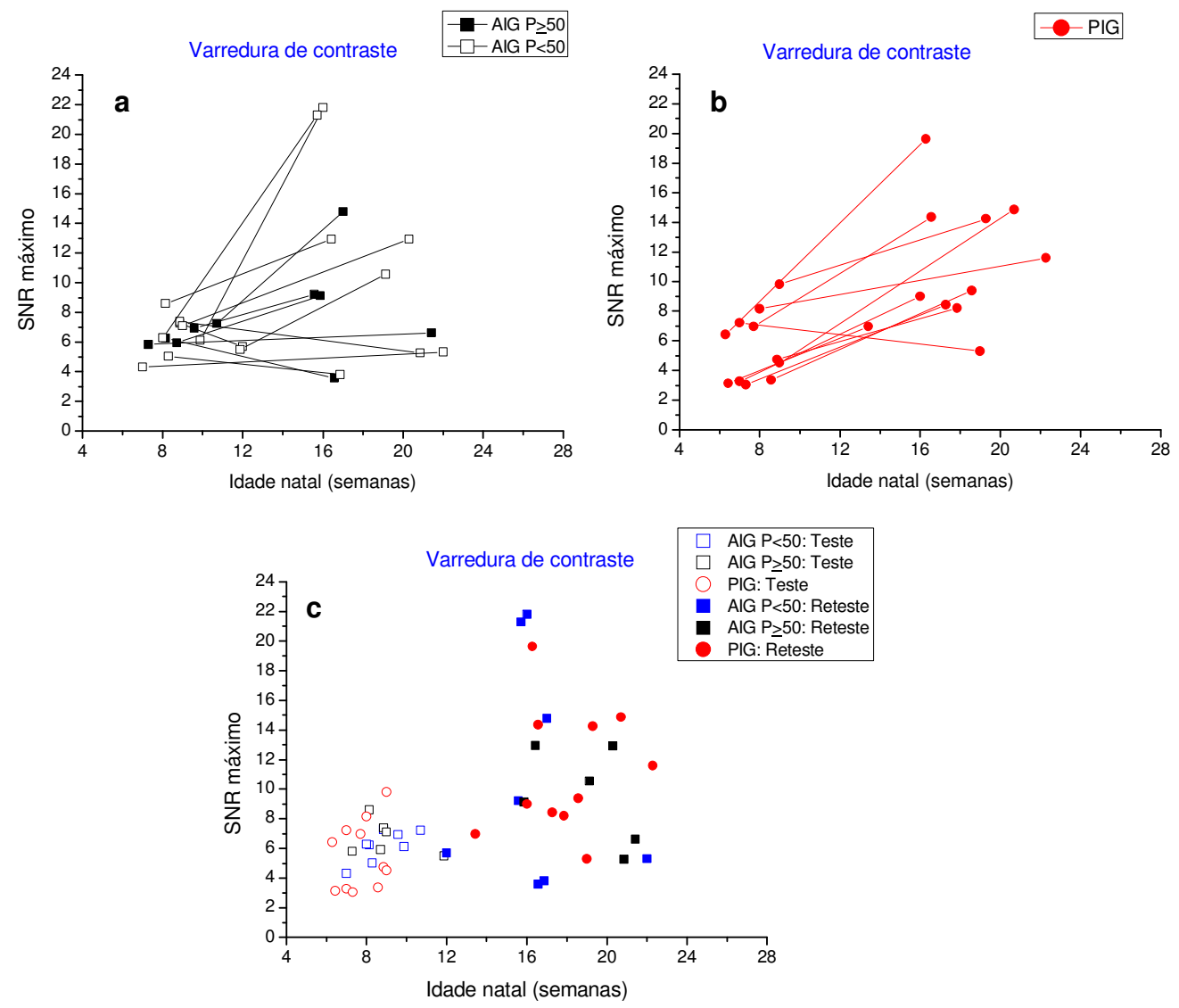

Figura 39. Valores de SNR máximo para os recém-nascidos PIG e AIG obtidos do registro do teste de sensibilidade ao contraste. Figura a, cada linha representa os dados obtidos para um recém-nascido AIG $(\backsim \mathrm{P} \geq 50$ e $\square \mathrm{P}<50)$ e na Figura b para um recémnascido PIG ( $\circ$ ). Na Figura c, os símbolos abertos representam o teste ( $\circ$ PIG, $\square$ AIG $\mathrm{P}<50$ e $\square \mathrm{AIG} \mathrm{P} \geq 50$ ) e símbolos fechados o reteste ( $\bullet \mathrm{PIG}$, AIG $\mathrm{P}<50$ e - AIG $\mathrm{P} \geq 50$ ). 
A ANOVA de um fator foi aplicada para as comparações entre os grupos PIG e AIG em duas faixas etárias (5-9 semanas e 10-24 semanas), sem a distinção de percentil de peso ao nascimento para o grupo AIG. No entanto, não foram encontradas diferenças significativas entre os grupos para nenhum dos parâmetros analisados (acuidade visual, sensibilidade ao contraste, inclinação da reta, amplitude máxima, ruído médio e SNR). 


\section{DISCUSSÃO}

\section{V.1. Acuidade Visual}

No presente estudo, aplicaram-se os testes estatísticos paramétricos e não paramétricos para os resultados de acuidade visual a fim de extrair-se o maior número de informações possíveis.

O teste paramétrico (ANOVA fatorial) não mostrou diferenças significativas entre os limiares de acuidade visual de resolução de grades para os grupos PIG e AIG de 5 a 24 semanas de idade utilizando a técnica do PVEv.

Estudos realizados com recém-nascidos PIG e AIG de termo e pré-termo com o procedimento do olhar preferencial de escolha-forçada mostraram resultados semelhantes aos nossos (Getz, Dobson \& Luna, 1994; Hermans, Van Hof-van Duin \& OudesluysMurpy, 1992; Van Hof-van Duin et al., 1992) quando utilizaram os testes paramétricos.

Van Hof-van Duin et al. (1992) observaram que os recém-nascidos PIG apresentavam uma tendência a valores mais baixos de acuidade visual, além de uma maior variabilidade nos resultados. Os autores aplicaram apenas os testes paramétricos, mesmo diante dessa observação. Diferentemente desses autores, aplicamos testes estatísticos nãoparamétricos (Qui-quadrado) que revelaram que uma proporção significativa de recémnascidos PIG menores de 9 semanas de idade apresentavam valores de acuidade visual abaixo do percentil 50 da acuidade visual do grupo AIG $\mathrm{P} \geq 50$ (percentil maior ou igual a $50)$.

A ANOVA fatorial revelou que a acuidade visual encontrava-se significativamente mais alta para os recém-nascidos PIG, AIG P $\geq 50$ e AIG $P<50$ na faixa etária de 10 a 24 semanas em comparação aos recém-nascidos abaixo de 10 semanas de idade de seus respectivos grupos. Esse resultado está de acordo com a literatura (Norcia e Tyler, 1985; Salomão et al., 2008) e reflete a maturação do sistema visual. 
As diferenças encontradas entre os limiares das funções visuais (acuidade visual e sensibilidade ao contraste) dos recém-nascidos AIG, obtidos no presente estudo, com as normas de Norcia e Tyler (1985) e Norcia, Tyler e Hamer (1990) podem refletir as mudanças no poder de análise dos registros do PVEv para a nova versão do software "PowerDiva" utilizado no presente estudo.

O sistema PowerDiva avalia a estatística $t^{2}$-circ que aumenta significativamente a validade estatística do sinal medido em cada segundo (bin) de análise quando a informação naquele tempo é o resultado de uma média vetorial de $n$ tentativas. As tentativas mais usadas, o SNR mais baixo que pode ser considerado estatisticamente significante com um dado nível de significância. Além disso, o nosso sistema usa um novo método de filtragem, o "Recursive Least Squares" (RLS) que demonstrou melhorar a razão sinal-ruído (SNR) em 10 decibéis em relação à análise tradicional pela "Transformada Discreta de Fourier" (TDF) (Tang e Norcia, 1995) usada em estudos anteriores (Norcia e Tyler, 1985; Norcia, Tyler e Hamer, 1990). Esse novo método de filtragem permite a medição de limiares que o antigo método falharia em registrar uma resposta significante do PVEv.

\section{V.2. Sensibilidade ao Contraste de Luminância}

O teste de Qui-quadrado mostrou diferença significativa na proporção de recémnascidos PIG com valores de sensibilidade ao contraste menores que os recém-nascidos AIG P $\geq 50$ de acordo com as curvas de Alexander et al. (1996). Não encontramos estudos na literatura que avaliaram a sensibilidade ao contraste de recém-nascidos PIG.

Não observamos diferenças significativas entre as médias de sensibilidade ao contraste para os grupos PIG e AIG na faixa etária de 5 a 24 semanas com o teste paramétrico (ANOVA fatorial).

O desenvolvimento da sensibilidade ao contraste foi semelhante para os recémnascidos PIG e AIG e confirma os estudos de Norcia, Tyler e Hamer (1990) que relataram que sensibilidade ao contraste de luminância para as frequiências espaciais 
baixas aumenta rapidamente até as dez primeiras semanas de vida. Os autores relataram ainda que a sensibilidade ao contraste para as freqüências espaciais baixas parece atingir uma assíntota em torno de 200 de contraste por volta de 10 semanas de vida, no entanto observamos um grande número de recém-nascidos entre 6 e 22 semanas de idade com valores de sensibilidade ao contraste entre 200 e 400. Por outro lado, observamos também um grande número de recém-nascidos entre 6 e 12 semanas de idade abaixo dos valores encontrados por Norcia, Tyler e Hamer (1990).

Observou-se que a sensibilidade ao contraste encontrava-se mais alta para os recém-nascidos de 10 a 24 semanas de idade em comparação aos recém-nascidos de 5 a 9 semanas de idade para os grupos PIG e AIG, resultado já esperado de acordo com a literatura (Norcia, Tyler e Hamer, 1990), devido à maturação do sistema visual.

\section{V.3. Avaliação das respostas de fase, amplitude máxima, ruído médio, SNR e inclinação da reta.}

Registro da Fase. A resposta de fase (latência) pelo PVEv é um indicador do desenvolvimento das vias visuais, da retina ao córtex visual primário, portanto alterações nas respostas de fase indicam problemas na maturação do sistema visual.

No presente estudo, observou-se que as respostas de fase dos recém-nascidos PIG e AIG diminuíram rapidamente entre 6 e 18 semanas de idade, tanto para as respostas de fase obtidas durante o teste de acuidade visual $(\mathrm{PIG}=253,1$ graus e $\mathrm{AIG}=280,7$ graus $)$ como para o teste de sensibilidade ao contraste ( $\mathrm{PIG}=370,8$ graus; $\mathrm{AIG}=361,9$ graus). Correspondendo a uma diminuição na latência aparente de 4,88 ms/semana (Acuidade Visual) e 7,15 ms/semana (Sensibilidade ao contraste) para os recém-nascidos PIG; e para os recém-nascidos AIG de 5,41 ms/semana (Acuidade Visual) e 6,98 ms/semana (Sensibilidade ao contraste). Os nossos dados são comparáveis aos dados de Hamer e Norcia (2004) e mostram uma extraordinária diminuição na latência neuronal durante os primeiros meses de vida. 
Observaram-se semelhanças nas taxas de desenvolvimento de fase entre os grupos PIG e AIG de 6 a 18 semanas, para os registros obtidos durante o teste de sensibilidade ao contraste e acuidade visual. Diferentemente dos nossos resultados de fase (latência), alguns estudos (Stanley et al.,1991; Scherjon et al., 1996; Thordstein et al., 2004) que utilizaram o potencial visual evocado por flashes de luz mostraram que os recém-nascidos PIG apresentavam latências mais longas do que os recém-nascidos AIG.

No presente estudo analisamos alguns registros do PVEv que foram pouco explorados pela literatura, tais como amplitude máxima, fase, ruído médio, inclinação da reta e SNR. As análises desses registros são importantes uma vez que podem evidenciar alterações no sistema visual de recém-nascidos independente de existirem alterações ou não nos limiares de $\mathrm{AV}$ e SC, uma vez que esses registros são referentes à estimulação supralimiar, exceto o ruído médio. Por exemplo, Mirabella et al. (2006) observaram que as amplitudes máximas dos grupos de recém-nascidos com muito baixo peso ao nascimento ( $<1500$ gramas) encontravam-se mais altas em comparação aos recém-nascidos de termo, no entanto os limiares de acuidade visual, a sensibilidade ao contraste e acuidade de Vernier, assim como as respostas de fase mostraram-se semelhantes entre os grupos.

Os nossos resultados mostraram que para as medidas de acuidade visual, uma proporção significativa de recém-nascidos PIG de 5 a 24 semanas de idade apresentava valores de amplitude máxima, ruído médio e SNR máximo significativamente menores do que a média do grupo AIG $\mathrm{P} \geq 50$. Além disso, observou-se que os valores desses registros aumentaram com a idade para ambos os grupos.

\section{V.4. Avaliação de ácidos graxos em recém-nascidos de termo pequenos para a idade gestacional}

O estado nutricional dos recém-nascidos do presente estudo foi classificado de acordo com as medidas antropométricas de peso, comprimento e circunferência craniana ao nascimento e no dia dos testes visuais. Com o objetivo de explorar um pouco mais a relação entre a nutrição do recém-nascido PIG e o seu desenvolvimento visual, optou-se por realizar as análises bioquímicas dos ácidos graxos uma vez que a literatura mostra que 
os recém-nascidos PIG de termo e pré-termo apresentam baixas concentrações de ácidos graxos essenciais em comparação aos bebês AIG (Agostin et al., 2008; Cetin et al., 2002; Felton et al., 1994; Llanos et al., 2005; van Eijsden et al., 2008). Alguns estudos relataram que a dieta deficiente em ácido graxo DHA pode implicar em prejuízos visuais (Makrides et al., 1995; Marín, Rey, Pedersolí, Rodrigo \& Alaniz, 2000) e a dieta rica em ácidos graxos melhora a AV de crianças saudáveis recém-nascidas a termo (Birch et al., 2005; Birch et al., 1998; Hoffman et al., 1999; Morale et al., 2005) e pré-termo (Birch et al., 1992; O’Connor et al., 2001; SanGiovanni et al., 2000). Não foram encontrados estudos envolvendo a correlação entre as medidas de acuidade visual e os ácidos graxos para os recém-nascidos PIG.

Iniciou-se um trabalho inédito no Brasil em colaboração com o Prof. Dr. Fabio Augusto e o Dr. Stanislau Bogusz Junior, ambos do Laboratório de Cromatografia Gasosa, Instituto de Química, Universidade Estadual de Campinas - São Paulo, cujo objetivo era realizar as análises dos ácidos graxos das células da mucosa bucal dos recém-nascidos PIG e AIG e correlacioná-las às medidas de acuidade visual e sensibilidade ao contraste. A análise dos ácidos graxos das células da mucosa bucal é ideal para avaliações clínicas e pesquisas com recém-nascidos ou pessoas com saúde muito comprometida, pois a coleta desse material é feita de forma indolor, não-invasiva e sem desconforto para o indivíduo. Além disso, estudos mostraram que os ácidos graxos das células da boca podem servir como um marcador do conteúdo de ácidos graxos essenciais, assim como o plasma e as células vermelhas do sangue (Connor et al., 2000; Hoffman et al., 1999; Koletzko et al., 1999).

As coletas foram iniciadas no Hospital Universitário da USP, no entanto por dificuldades técnicas não foi possível dar seguimento ao estudo. O número de dados coletados não foi suficiente para a realização das correlações entre as medidas das concentrações de ácidos graxos e os valores de acuidade visual. No entanto, o trabalho em colaboração com o Prof. Dr. Fabio Augusto e Dr. Stanislau Bogusz Junior resultou na simplificação da metodologia convencional, tornando-a mais simples e rápida para a análise de ácidos graxos, conforme consta detalhadamente no artigo anexo na página 104. 


\section{V.5. Pesquisas Futuras:}

No futuro seria importante avaliar os recém-nascidos PIG acima de 24 semanas de idade a fim de investigar se os limiares de acuidade visual e contraste permaneceriam nos níveis alcançados em 24 semanas ou se esses recém-nascidos atingiriam níveis iguais aos estabelecidos em estudos normativos. Embora a literatura não apresente os valores normativos para o ruído médio, amplitude máxima, inclinação da reta ou SNRmáximo, observou-se a importância das suas análises no presente estudo, uma vez que as mesmas podem revelar aspectos diferentes da maturação do sistema visual. Portanto, seria importante continuar analisando estas medidas com os recém-nascidos PIG acima de 24 semanas de idade.

As próximas pesquisas também poderiam correlacionar as concentrações de ácidos graxos com os vários parâmetros do PVEv medidos nesse estudo, uma vez que a literatura mostra que os recém-nascidos PIG apresentam baixas concentrações de ácidos graxos essenciais e o importante papel dos ácidos graxos, principalmente o docosaexaenóico (DHA), para o desenvolvimento das funções visuais. 


\section{V.6. Conclusão}

Acredita-se que as alterações na acuidade visual, sensibilidade ao contraste, ruído médio e respostas supralimiares (amplitude máxima e SNR) encontradas no grupo PIG de termo são decorrentes da sua condição de nascimento, uma vez que os mesmos não apresentaram intercorrências perinatais ou pós-natais e no dia dos testes visuais, 39,6\% dos recém-nascidos PIG apresentavam desnutrição leve ( $1^{\circ}$ grau), 32\% apresentavam o peso adequado para a idade e apenas uma pequena parcela apresentava a desnutrição moderada (17\%). Excluíram-se os recém-nascidos cujas mães usaram drogas recreativas lícitas (p.ex., cigarro, álcool etc) ou ilícitas (p.ex., maconha etc) durante ou após a gravidez uma vez que a literatura mostra ser fator de risco para os prejuízos visuais (Ribeiro et al., 2007; Strömland, 1992). 


\section{REFERÊNCIAS $\mathbf{S}^{1}$}

Agostoni, C., Marangoni, F., Stival, G., Gatelli, I., Pinto, F., Risé, P., Giovannini, M., Galli, C. \& Riva, E. (2008).Whole Blood Fatty Acid Composition Differs in Term Versus Mildly Preterm Infants: Small Versus Matched Appropriate for Gestational Age. Pediatric Research, 64, 298-302.

Alencar, C. C. G \& Santos, N. A. (2012). Early malnutrition decreases contrast sensitivity to circular concentric gratings. Psychology Neuroscience, 5 (1): 3-9.

Alexander, G. R., Himes, J. H., Kaufman, R. B., Mor, J. \& Kogan, M. (1996). A United States national reference for fetal growth. Obstet Gynecol., 87(2):163-8.

Almeida, S. S. \& De Araújo, M. (2001). Postnatal protein malnutrition affects play behavior and other social interactions in juvenile rats. Physiology \& Behavior, 74 (1-2), 45-51.

Almeida, S. S., Tonkiss, J. \& Galler, J.R. (1996). Malnutrition and reactivity to drugs acting in the central nervous system. Neuroscience Biobehavioral Reviews, 20(3), 389402.

Almeida, M. F. L., Silveira, A. C. D., Guedes, R. C. A., Hokoç, J. N., \& Martinez, A. M. B. (2005). Quantitative ultrastructural evidence of myelin malformation in optic nerves of rats submitted to a multideficient diet. Nutritional Neuroscience, 8(2), 91-99.

Almoqbel, F., Leat, S. J. \& Irving, E. (2008). The technique, validity and clinical use of the sweep VEP. Ophthal. Physiol. Opt., 28, 393- 403.

Atkinson, J. \& Braddick, O. (1989). Development of Basic Visual Fuctions. In A. Slater \& G. Bremner (Eds.), Infant Development (Lawrence Erlbaum Associates).

Ballard, J. L, Khoury, J. C, Wedig, K., Wang, L., Eilers-Walsman, B. L. \& Lipp, R. (1991). New Ballard Score, expanded to include extremely premature infants. J Pediatr., 119(3): 417-23.

Bandstra, E. S., Morrow, C. E., Anthony, J. C., Churchill, S. S., Chitwood, D. C., Steele, B. W., Ofir, A. Y \& Xue, L. (2001). Intrauterine Growth of Full-Term Infants: Impact of Prenatal Cocaine Exposure. Pediatrics, 108, 1309-1319.

Banks, M. B. \& Bennett, P. J. (1988). Optical and photoreceptor immaturities limit the spatial and chromatic vision of human neonates. Journal of the Optical Society of America A: Optics, Image Science \& Vision, 5, (12), 2059-2079.

\footnotetext{
${ }^{1}$ De acordo com o estilo APA - American Psychological Association.
} 
Benítez-Bribiesca, L., Rosa-Alvarez, Irma De la \& Mansilla-Olivares, A. (1999). Dendritic Spine Pathology in Infants with Severe Protein-Calorie Malnutrition. Pediatrics, 104 (2), 1-6.

Blowey, D. L. \& Warady, B. A. (2007). Outcome of infants born to women with chronic kidney disease. Advances in Chronic Kidney Disease, 14(2), 199-205.

Brandt, I., Sticker, E. J. \& Lentze, M. J. (2003). Catch-Up Growth of Head Circumference of Very Low Birth Weight, Small for Gestational age Preterm Infants and Mental Development to Adulthood. J Pediatr., 142, 463-468.

Brosnahan, D., Norcia, A. M., Schor, C. M. \& Taylor, D.G. (1998). OKN, perceptual and VEP direction biases in strabismus. Vision Research, 38, 2833-2840.

Birch, E. E., Birch, D. G., Hoffman, D. R. \& Uauy, R. (1992). Dietary Essential Fatty Acids Supply and Visual Acuity Development. Investigative Ophtalmology \& Visual Science, 33 (1), 3242-3253.

Birch, E. E., Hoffman, D. R., Uauy, R., Birch, D. G. \& Prestidge, C. (1998). Visual acuity and the essentiality of docosahexaenoic acid and arachidonic acid in the diet of term infants. Pediatric Research, 44(2), 201-209.

Birch, E. E., Castañeda, Y. S., Wheaton, D. H., Birch, D. G., Uauy, R. D. \& Hoffman, D. R. (2005). Visual maturation of term infants fed long-chain polyunsaturated fatty acidsupplemented or control formula for 12 mo. The American Journal of Clinical Nutrition, 81 (4), 871-879.

Birch, E. E., Carlson, S. E., Hoffman, D. R., Fitzgerald-Gustafson, K. M., Fu, V. L., Drover, J. R., Castañeda, Y. S., Minns, L., Wheaton, D. K., Mundy, D., Marunycz, J. \& Diersen-Schade, D. A. (2010). The DIAMOND (DHA Intake And Measurement Of Neural Development) Study: a double-masked, randomized controlled clinical trial of the maturation of infant visual acuity as a function of the dietary level of docosahexaenoic acid. Am J Clin Nutr., 91(4):848-59.

Chase, H.P., Welch, N.N., Dabiere, C.S., Vasan, N.S. \& Butterfield, L. J. (1972). Alterations in human brain biochemistry following intrauterine growth retardation. Pediatrics, 50 (3): 403-411.

Camargo, L. M. M \& Almeida, S. S. (2005). Early postnatal protein malnutrition changes the development of social play in rats. Physiology \& Behavior, 85 (3), 246-251.

Capurro, M. D. (1978). A simplified method for diagnosis of gestational age in the newborn infant. Journal of Pediatric, 93, 120-122.

Catov, J. M., Nohr, E. A. \& Ness, R. B. (2008). Chronic hypertension related to risk for preterm and term small for gestational age births. Obstetrics and Gynecology, 112 (2 Pt1), 290-296. 
Cetin, I., Giovannini, N., Alvino, G., Agostoni,C., Riva, E., Giovannini, M. \& Pardi, G. (2002). Intrauterine Growth Restriction Is Associated with Changes in Polyunsaturated Fatty Acid Fetal-Maternal Relationships. Pediatr. Res., 52, 750-755.

Centers for Disease Control and Prevention and National Center for Health Statistics (2002). 2000 CDC growth charts for the United States: Methods and development. National Center for Health Statistics. Vital Health Stat 11(246): 01-190. Recuperado em 04 fev. de 2006: http://www.cdc.gov/growthcharts.

Chiaffarino, F., Parazzini1, F., Chatenoud, L., Ricci, E., Sandretti, F., Cipriani, S., Caserta, D. \& Fedele, L. (2006). Alcohol drinking and risk of small for gestational age birth. European Journal of Clinical Nutrition, 60, 1062-1066.

Connor, S. L., Zhu, N., Anderson, G. J., Hamill, D., Jaffe, E., Carlson,J. \& Connor, W. E. (2000). Cheek cell phospholipids in human infants: a marker of docosahexaenoic and arachidonic acids in the diet, plasma, and red blood cells. Am J Clin Nutr., 71, 21-27.

Cornsweet, T. N. (1970). Vision perception. New York: Academic Press.

Costa, M. F. \& Ventura, D. F. (2012).Visual impairment in children with spastic cerebral palsy measured by psychophysical and electrophysiological grating acuity tests. Developmental Neurorehabilitation, 15 (6): 414-424.

Costa, M. F, Barboni, M. T. S. \& Ventura, D. F. (2011). Psychophysical measurements of luminance and chromatic spatial and temporal contrast sensitivity in Duchenne muscular dystrophy. Psychology \& Neuroscience, 4 (1): 67-74.

Costa, M. F., Tomaz, S., Souza, J. M., Silveira, L. C. L. \& Ventura, D. F. (2008). Electrophysiological evidence for impairment of contrast sensitivity in mercury vapor occupational intoxication. Environmental Research, 107 (1): 132-138.

Costa, M. F., De Haro, F. B. Salomão, S. R. \& Ventura, D. F. (2008). Acuidade Visual para padrões espaciais periódicos medida pelos potenciais visuais evocados de Varredura em Crianças com hidrocefalia. Neurociências (Rio De Janeiro), 4 (2), 87-92.

Costa, M. F., Salomão, S. R., Berezovsky, A., Haro, F. M \& Ventura, D. F. (2004). Relationship between vision and motor impairment in children with spastic cerebral palsy: new evidence from electrophysiology. Behavioural Brain Research, 149 (2), $145-150$.

Dantas, A. P., Brandt, C. T. \& Leal, D. N. B. (2005). Manifestações Oculares em pacientes que tiveram desnutrição nos primeiros seis meses de vida. Arquivos Brasileiros de Oftalmologia, 68 (6), 753-756.

Darendeliler, F., Çoban,, A., Baş, F., Bundak, R., Dişçi, R., Şükür, M., et al., (2008). Catch-up growth in appropriate- or small-for-gestational age preterm infants. The Turkish Journal of Pediatrics, 50, 207-213. 
Dobson, V. \& Teller, D. Y. (1978). Visual Acuity in Human Infants: A Review and Comparison of Behavioral and Electrophysiological Studies. Vision Research, 18 (11), 1469-1483.

Dobson, V., Miller, J. M., Harvey, E. M. \& Mohan, K. M. (2003). Amblyopia in astigmatic preschool children. Vision Research, 43 (9), 1081-1090.

Durmaz, L., Karagöl, U., Deda, G. \& Zülküfönal, M. (1999). Brainstem auditory and visual evoked potentials in children with protein-energy malnutrition. Pediatrics International, 41 (6), 615-619.

Falcão, M. C. (2000). Avaliação nutricional do recém-nascido. Pediatria, 22 (3), 233-239.

Fantz, R. L. (1958). Pattern vision in young infants. Psychological Record, 8 (2), 43-47.

Feldman, R. \& Eidelman, A. (2006). Neonatal State Organization, Neuromaturation, Mother-Infant Interaction, and Cognitive Development in Small-for-Gestational-Age Premature Infants. Pediatrics, 118, e869-e878.

Felton, C. V., Chang, T. C., Crook, D., Marsh, M., Robson,S. C., Spencer, J. A. D (1994).Umbilical vessel wall fatty acids after normal and retarded fetal growth. Archives of Disease in Childhood, 70, F36-F39.

Frederick, I. O., Williams, M. A., Sales, A. E., Martin, D. P, \& Killien, M. (2008). Prepregnancy Body Mass Index, Gestational Weight Gain, and Other Maternal Characteristics in Relation to Infant Birth Weight. Matern Child Health J., 12, $557-$ 567.

Fewtrell, M. S., Morley, R., Abbott, R. A., Singhal, A., Stephenson, T., MacFadyen, U. M., Clements, H. \& Lucas, A (2001). Catch-up growth in small-for-gestational-age term infants:a randomized Trial. Am J Clin Nutr., 74, 516-23.

Fiorentini, A. \& Trimarchi, C. (1992). Development of Temporal Properties of Pattern Electroretinogram and Visual Evoked Potentials in Infants. Vision Research, 32 (9), 1609-1621.

Fundo das Nações Unidas para a Infância - UNICEF (2005). Situação da Infância Brasileira 2006: Crianças de até 6 anos. O Direito à Sobrevivência e ao Desenvolvimento. Recuperado em 18 ago. de 2006: http://www.unicef.org/brazil/

Galler, J. R., Shumsky, J. S. \& Morgane, P. J. (1996). Malnutrition and Brain Development. In: Walker, W.A and Watkins., eds. Nutrition in Pediatrics. $2^{\text {nd }}$ edition, Neuilly su-Sein, France; Plenm Press, pp. 194-210.

Georgieff, M. K. (2007). Nutrition and the developing brain: nutrient priorities and Measurement. Am J Clin Nutr, 85(suppl), 614S - 620S.

Guedes, R. C. A., Rocha-de-Melo, A. P. \& Teodósio, N. R. (2004). Nutrição Adequada: A Base do Funcionamento Cerebral. Ciência e Cultura, 56 (1), 32-35. 
Guesry, P. (1998). The Role of Nutrition in Brain Development. Preventive Medicine, 27, 189 - 194.

Getz, L., Dobson, V. \& Luna, B. (1994). Development of grating acuity, letter acuity and visual fields in small- for- gestational-age preterm infants. Early Human Development, 40: 59-71.

Good, W.V., Hou, C. \& Norcia, A. M. (2012). Spatial contrast sensitivity vision loss in children with cortical visual impairment. Investigative Ophthalmology and Visual Science, 53(12): 7730-7734.

Goto, M. M. F., Gonçalves, V. M. G., Netto, A. A., Morcillo, A. M. \& Moura-Ribeiro, M. V. L. (2005). Neurodesenvolvimento de lactentes nascidos a termo pequenos para a Idade Gestacional no segundo mês de vida. Arq Neuropsiquiatr., 63(1): 75- 82.

Habib, N. A., Daltveit, A. K., Bergsjø, P., Shao, J., Oneko, O. \& Lie, R. T. (2008). Maternal HIV status and pregnancy outcomes in northeastern Tanzania: a registrybased study. BJOG., 115(5), 616-24.

Haeri, S., Khoury, J., Kovilam, O. \& Miodovnik, M. (2008). The association of intrauterine growth abnormalities in women with type 1 diabetes mellitus complicated by vasculopathy. American Journal of Obstetrics and Gynecology, 199, 278.e1-278.e5.

Hamer, R. D., Norcia, A. M., Tyler, C. W., Hsu-Winges, C. (1989). The development of monocular and binocular VEP acuity. Vision Research, 29(4), 397-408.

Hamer, R. D. \& Norcia, A. M. (1994). The Development of Motion Sensitivity during the First Year of Life. Vision Research, 34 (18), 2387-2402.

Hatch, E. E \& Bracken, M. B .(1986). Effect of marijuana use in pregnancy on fetal growth. Am J Epidemiol., 124(6), 986-93.

Hazin, A.N., Alves, J. G. \& Falbo, A. (2007). The myelination process in severely malnourished children: MRI findings. The International journal of neuroscience, 117 (8), 1209-1214.

Hermans, A. J. M., Van Hof-van Duin, J. \& Oudesluys-Murpy. (1992). Visual acuity in low birth weight (1500-2500 g) neonates. Early Human Development, 28: 155-167.

Hoffman, D. R., Birch, E.E., Birch, D.G. \& Uauy, R. (1999). Fatty Acid Profile of Buccal Cheek Cell Phospholipids as an Index for Dietary Intake of Docosahexaenoic Acid in Preterm Infants. Lipids, 34, 337-342.

Hoffman, D. R., Birch, E. E., Birch, D. G.,Uauy, R., Castañeda, Y. S., Lapus, M. G. et al. (2000). Impact of Early Dietary Intake and Blood Lipid Composition of Long-Chain Polyunsaturated Fatty Acids on Later Visual Development. Journal of Pediatric Gastroenterology and Nutrition, 31 (5), 540-553.

Hoffman, D. R., Theuer, R. C., Castañeda, Y. S., Wheaton, D. H., Bosworth, R. G., O'Connor, A. R. et al. (2004). Maturation of Visual Acuity Is Accelerated in Breast- 
Fed Term Infants Fed Baby Food Containing DHA-Enriched Egg Yolk. The Journal of Nutrition, 134 (9), 2307-2313.

Hvas, C. L, Henriksen, T. B,, Ostergaard, J. R,, Dam, M. (2000). Epilepsy and pregnancy: effect of antiepileptic drugs and lifestyle on birthweight. Journal of obstetrics and gynaecology, 107(7), 896-902.

Innis, S. M. (2007). Human milk: maternal dietary lipids and infant development. Proceedings of the Nutrition Society, 66 (3), 397-404.

Instituto Brasileiro de Geografia e Estatística - IBGE (2010). Pesquisa de Orçamentos Familiares 2008-2009: Avaliação nutricional da disponibilidade domiciliar de alimentos no Brasil. Recuperado em 26 de fev. de 2012: http://www.ibge.com.br/home/estatistica/populacao/condicaodevida/pof/2008_2009_en caa/default.shtm

Ivanovic, D. M. (1996). Does Undernutrition During Infancy Inhibit Brain Growth and Subsequent Intellectual Development? Nutrition, 12 (7-8), 569-571.

Ivanovic, D. M., Leiva, B. P., Perez, H. T., Inzunza, N. B., Almagia, A. F., Toro, T. D. et al. (2000). Long-Term Effects of Severe Undernutrition During the First Year of Life on Brain Development and Learning in Chilean High-School Graduates. Nutrition, 16 (11-12), 1056-1063.

Jeffrey, B. G., Weisinger, H. S., Neuringer, M. \& Mitchell, D. C. (2001). The Role of Docosahexaenoic Acid in Retinal Function. Lipids, 36 (9), 859-871.

John, F. M., Bromham, N. R., Woodhouse, J. M. \& Candy, T. R. (2004). Spatial Vision Deficits in Infants and Children with Down Syndrome. Investigative Ophthalmology and Visual Science, 45 (5), 1566-1572.

Kaplan, E. \& Shapley, R. M. (1986). The primate retina contains two types of ganglion cells, with high and low contrast sensitivity. Proc Natl Acad Sci U S A., 83(8): 27552757.

Kar, B. R., Rao, S. L. \& Chandramouli, B. A. (2008). Cognitive development in children with chronic protein energy malnutrition. Behavioral and Brain Functions, 4, 1-31.

Karatekin, G., Kutan, A. F. \& Nuhoğlu, A. (2002). Catch-up growth in fetal malnourished term infants. Journal of Perinatal Medicine, 30, 411 - 415.

Koletzko, B, Knoppke, B., von Schenck, U., Demmelmair, H. \& Damli, A. (1999). Noninvasive Assessment of Essential Fatty Acid Status in Preterm Infants by Buccal Mucosal Cell Phospholipid Analysis. Journal of Pediatric Gastroenterology \& Nutrition, 29(4), 467-474.

Kim, So-Young \& Lee, Jung-Hyun (2008). Prognosis of Neonates in Pregnant Women with Systemic Lupus Erythematosus. Yonsei Medical Journal, 49(4), 515 - 520. 
Lacerda, E. M. C. B., Lima, M. G., Rodrigues, A. R., Teixeira, C. E. C., De Lima, L. J. B., Ventura, D. F. \& Silveira, L. C. L. (2012). Psychophysical Evaluation of Achromatic and Chromatic Vision of Workers Chronically Exposed to Organic Solvents. Journal of Environmental and Public Health, 1-7.

Llanos, A., Li, Y., Mena, P., Salem Jr, N., \& Uauy, R. (2005). Infants with Intrauterine Growth Restriction Have Impaired Formation of Docosahexaenoic Acid in Early Neonatal Life: A Stable Isotope Study. Pediatr Res., 58, 735-740.

Lee, P. A., Chernauseck, S. D., Hokken-Koelega, A. C. S. \& Czernichow, P. (2003). International Small for Gestational Age Advisory Board Consensus Development Conference Statement: Management of Short Children Born Small for Gestational Age, April 24 - October 1, 2001. Pediatrics, 111 (6 Pt 1), 1253-1261.

Leichsenring, M., Sutterlin, N., Less, S., Baumann, K., Anninos, A \& Becker, K. (1995). Polyunsaturated fatty acids in erythrocyte and plasma lipids of children with severe protein-energy malnutrition. Acta Paediatrica, 84 (5): 516-520.

Levitsky, D. A \& Strupp, B. J. (1995). Malnutrition and the Brain: Changing Concepts, Changing Concerns. Journal of Nutrition, 125 (8 Suppl), 2212S-2220S.

Liu, J., Raine, A., Venables, P. H., Dalais, C., Mednick, S.A. (2003). Malnutrition at age 3 years and Lower Cognitive Ability at age 11 years. Arch Pediatr Adolesc Med., 157,593-600.

Liu, J., Raine, A., Venables, P. H., \& Mednick, S. A. (2004). Malnutrition at age 3 years and externalizing behavior problems at ages 8,11 \& 17 years. Am $J$ Psychiatry, 161(11), 2005-2013.

Lubchenco, L. O, Hansman, C. \& Boyd, E. (1966). Intrauterine growth in length and head circumference as estimated from live births at gestational ages from 26 to 42 weeks. Pediatrics, 37 (3), 403-408.

Mahan, L. K. \& Escott-Stump, S. (2002). Alimentos, nutrição e dietoterapia. 10. ed. São Paulo: Roca.

Mahajan S. D., Singh, S., Shah, P., Gupta, N. \& Kochupillai, N. (2004). Effect of maternal malnutrition and anemia on the endocrine regulation of fetal growth. Endocr Res. 30(2), 189-203.

Makrides, M., Neuman, M., Simmer, K., Pater, J. \& Gibson, R. (1995). Are longchain polyunsaturated fatty acids essential nutrients in infancy? Lancet, 345 (8963), 1463 1468.

Marín, M. C., Rey, G. E., Pedersolí, L. C., Rodrigo, M. A., Alaniz, M. J. T. (2000). Dietary long-chain fatty acids and visual response in malnourished nursing infants. Prostaglandins, Leukotrienes and Essential Fatty Acids, 63(6), 385-390.

Maulik, D. (2006a). Fetal Growth Compromise: Definitions, Standards, And Classification. Clinical Obstetrics and Gynecology, 49 (2), 214-218. 
Maulik, D. (2006b). Fetal Growth Restriction: The Etiology. Clinical Obstetrics and Gynecology, 49(2), 228-235.

Maurer, D., Lewis, T. R., Brent, H. P. \& Levin, A.V. (1999). Rapid Improvement in the Acuity of Infants After Visual Input. Science, 286 (5437), 108-110.

McCulloch, D. L. \& Skarf, B. (1991). Development of the human visual system: monocular and binocular pattern VEP latency. Invest Ophtalmol Vis Sci, 32 (8), 23722381.

McDonald, C. G., Joffe, C. L., Barnet, A. B. \& Flinn, J. M. (2007). Abnormal flash visual evoked potentials in malnourished infants: An evaluation using principal component analysis. Clinical Neurophysiology, 118 (4), 896-900.

Mcllwain, J. T. (1996). An Introduction to the Biology of Vision. Cambridge U. Press.

Mello, B. B. A., Gonçalves, V. M. G. \& Souza, E. A. P. (2004). Comportamento de lactentes nascidos a termo pequenos para a idade gestacional no primeiro trimestre de vida. Arq Neuropsiquiatr., 62 (4): 1046-1051.

Meuris, S., Piko, B.B., Eerens, P., Vanbellinghen, Anne-Marie, Dramaix, M. \& Hennart, P. (1993). Gestational Malaria: Assessment of its Consequences on Fetal Growth. The American Society of Tropical Medicine and Hygiene, 48(5), 603-609.

Mohn, G. \& Van Hof-van Duin, J. (1986). Development of the binocular and monocular visual fields of human infants during the first year of life. Clin. Vis. Sci., 1: 51-64.

Mirabella, G., Kjaer, P. K., Norcia, A. M., Good, W. V. \& Madan, A. (2006). Visual Development in Very Low Birth Weight Infants. Pediatric Research, 60 (4), 435-439.

Morgane, P. J., Austin-LaFrance, R., Bronzino, J., Tonkiss, J., Dáiz-Cintra, S., Cintra, L. et al. (1993). Prenatal Malnutrition and Development of the Brain. Neuroscience and Biobehavioral Reviews, 17 (1), 91-128.

Morrone, M. C., Fiorentini, A. \& Burr, D. C. (1996). Development of the Temporal Properties of Visual Evoked Potentials in Infants to Luminance and Colour Contrast in Infants. Vision Research, 36 (19), 3141-3155.

Ness, Zhang, Bass \& Klebanoff, (2008). Interactions between smoking and weight in pregnancies complicated by preeclampsia and small-for-gestational-age birth. Am J Epidemiol., 168 (4), 427-33.

Newham, J. J., Thomas, S. H., MacRitchie, K., McElhatton, P. R., McAllister-Williams, R. H. (2008). Birth weight of infants after maternal exposure to typical and atypical antipsychotics: prospective comparison study. Br J Psychiatry, 192(5), 333-337.

Nóbrega, F. J. (1998). Distúrbios da Nutrição. Rio de Janeiro: Revinter Ltda. 
Nilsson, J., Dahlgren, J., Karlsson, A. \& Grönlund, M. A. (2011). Normal visual evoked potentials in preschool children born small for gestational age. Acta Paediatrica, 100: 1092-1096.

Norcia, A. M. \& Tyler, C. W. (1985a). Spatial frequency sweep VEP: visual acuity during the first year of life. Vision Research, 25 (10), 1399-1408.

Norcia, A. M. e Tyler, C.W. (1985b). Infant VEP acuity measurements: Analysis of individual differences in measurement error. Electroencephalogr Clih Neurophysiol, 61, 359-369.

Norcia, A. M., Tyler, C. W. \& Hamer, R. D. \& Wesemann, W. (1989). Measurement of Spatial Contrast Sensitivity with the Swept Contrast VEP. Vision Research, 29(5), 627637.

Norcia, A. M., Tyler, C. W. \& Hamer, R. D. (1990). Development of contrast sensitivity in the human infant. Vision Research, 30(10), 1475-1486.

Norcia, A. M., Garcia, H., Humphry, R., Holmes, A., Hamer, R. D. \& Orel-Bixler, D. (1991). Anomalous motion VEPs in infants and in infantile esotropia. Invest Ophthalmol Vis Sci., 32(2), 436 - 439.

Norcia, A. M., Hamer, R. D, Jampolsky, A. \& Orel-Bixler, D. (1995). Plasticity of human motion processing mechanisms following surgery for infantile esotropia. Vision Research, 35(23-24): 3279-3296.

Norcia, A. M. (1999). PowerDiva Manual. Smith-Kettlewell Eye Research Institute, San Francisco.

Norcia, A.M. (2004). Development of spatial selectivity and response timing in humans. In Chalupa, L. M. \& John S. Werner (Org.). The Visual Neurosciences. Volume 1. (pp.174-188). Estados Unidos da América: MIT Press.

O’Connor, D. L., Hall, R., Adamkin, D., Auestad, N., Castillo, M., Connor, W. E. et al. (2001). Growth and Development in Preterm Infants Fed Long-Chain Polyunsaturated Fatty Acids: A Prospective, Randomized Controlled Trial. Pediatrics, 108(2), 359- 371

O’Connor, A. R., Stephenson, T. J., Johnson, A., Tobin, M. J. Ratib, S., Moseley, M. et al. (2004). Visual Function in low birthweight children. British Journal of Ophthalmology, 88 (9), 1149-1153.

Odom, J. V.., Bach, M., Barber, C., Brigell, M., Marmor, M. F., Tormene, A. P., Holder, G. E., \& Vaegan (2004). Visual evoked potentials standard (2004). Documenta Ophthalmologica, 108: 115-123.

Oliveira, A. G. F., Costa, M. F., Souza, J. M. \& Ventura, D. F. (2004). Contrast sensitivity threshold measured by sweep-visual evoked potential in term and preterm infants at 3 and 10 months of age. Brazilian Journal of Medical and Biological Research, 37 (9), 1389-1396. 
Özdemir, O. M., Ergin, H. \& Şahiner, T. (2009). Electrophysiological assessment of the brain function in term SGA infants. Brain Research, 1270: 33- 38.

Pedroso, M. P., Godoy, L. A. F., Fidélis, C. H. V., Ferreira, E. C., Poppi, R. J. \& Augusto, F. (2009). Cromatografia gasosa bidimensional abrangente $(\mathrm{GC} \times \mathrm{GC})$. Quím. Nova, 32 (2): 421- 430.

Pereira, S. A. \& Costa, M. F. (2012). Visual acuity evaluation in children with hydrocephalus: An electrophysiological study with sweep visual evoked potential. World Journal of Neuroscience, 02: 36-43.

Ramos, J. L. A., Leone, C. R. et al. (1986). O recém-nascido de baixo peso. Monografias Médicas. Série Pediatria, v. 28. São Paulo: Sarvier.

Ramos J. L. A. (1983). Avaliação do crescimento intra-uterino por medidas antropométricas do recém-nascido. Tese de Doutorado, Faculdade de Medicina, Universidade de São Paulo, São Paulo.

Ranade, S. C., Rose, A., Rao, M., Gallego, J., Gressens, P. \& Mani, S. (2008). Different types of nutritional deficiencies affect different domains of spatial memory function checked in a radial arm maze. Neuroscience, 152, 859 - 866.

Rasmussen, S. \& Irgens, L. M. (2008). History of fetal growth restriction is more strongly associated with severe rather than milder pregnancy-induced hypertension. Hypertension, 51, 1231-1238.

Regan, D. (1973). Rapid objective refraction using evoked brain potentials. Inves. Ophthalmol, 12, 669-703.

Ribeiro, I. M., Vale, P. J., Tenedorio, P. A, Rodrigues, P. A., Bilhoto, M. A \& Pereira, H. C. (2007). Ocular manifestations in fetal alcohol syndrome. Eur J Ophthalmol.,17(1): 104-109.

Ridder III, W. H. (2004). Methods of visual acuity determination with the spatial frequency sweep visual evoked potential. Documenta Ophthalmologica, 109, 239 247.

Rodrigues, A. R., Souza, C. R. B., Braga, A. M., Rodrigues, P. S. S., Silveira, A. T., Damin, E. T. B., Cortes, M. I. T., Castro, A. J. O., Mello, G. A., Vieira, J. L. F., Pinheiro, M. C. N., Ventura, D. F. \& Silveira, L. C. L. (2007). Mercury toxicity in the Amazon: contrast sensitivity and color discrimination of subjects exposed to mercury. Brazilian Journal of Medical and Biological Research, 40 (3), 415-424.

Rotta, L. N., Leszczinski, D. N., Brusque, A. M., Pereira, P., Brum, L. F. S., Nogueira, C. W., Frizzo, M. E. S., Perry, M. L. S. \& Souza, D. O. (2008). Effects of undernutrition on glutamatergic parameters in the cerebral cortex of young rats. Physiology \& Behavior, 94, 580-585.

Save The Children. A life free from hunger: tackling child malnutrition. London,UK, 2012. 
Sharma, V., Katz, J., Mullany, L.C.,, Khatry S.K., LeClerq, S.C., Shrestha, S.R., Darmstadt, G.L., Tielsch, J.M. (2008). Young maternal age and the risk of neonatal mortality in rural Nepal. Arch Pediatr Adolesc Med., 162(9), 828-835.

Salomão, S. R. \& Ventura, D. F. (1995). Large Sample Population Age Norms for Visual Acuities Obtained With Vistech-Teller Acuity Cards. Investigate Ophthalmology \& Visual Science, 36 (3), 657-670.

Salomão, S. R., Ejzenbaum, F., Berezovsky, A., Sacai, P. Y. \& Pereira, J. M. (2008). Age norms for monocular grating acuity measured by sweep-VEP in the first three years of age. Arq Bras Oftalmol., 71(4), 475 - 479.

SanGiovanni, J. P., Allred, E. N., Mayer, D. L., Stewart, J. E., Herrera, M. G. \& Leviton, A. (2000a). Reduced visual resolution acuity and cerebral white matter damage in verylow-birthweight infants. Developmental Medicine \& Child Neurology, 42 (12), 809815.

SanGiovanni, J. P., Parra-Cabrera, S., Colditz, G. A., Berkey, C. S., \& Dwyer, J. T. (2000b). Infants Fatty Acids as They Relate to Visual Resolution Acuity in Healthy Preterm Meta-analysis of Dietary Essential Fatty Acids and Long-Chain Polyunsaturated. Pediatrics, 105 (6), 1292-1298.

Santos, N. A \& Alencar, C. C. G. (2010). Early malnutrition diffusely affects children contrast sensitivity to sine-wave gratings of different spatial frequencies. Nutritional Neuroscience, 13 (4): 1-6.

Sauer, P. J. J. (2007). Can extrauterine growth approximate intrauterine growth Should it? Am J Clin Nutr., 85(suppl), 608S - 613S.

Savion, I. \& Savion, I. (2007). Nursing of malnourished children with emphasis on polyunsaturated fatty acids. Applied Nursing Research, 20 (3): 140-145.

Schwartz, S. H. (2004). Visual perception: a clinical orientation.(3ed.). McGraw-Hill Companies.

Scrimshaw, N. S. (1998). Malnutrition, Brain Development, Learning and Behavior. Nutrition Research, 18 (2), 351-379.

Shiffman, H. R. (2005). Sensation \& perception: an integrated approach. (5th ed.).

Sigulem, D. M., Devincenzi, M. U \& Lessa, A. C. (2000). Diagnóstico do estado nutricional da criança e do adolescente. Jornal de Pediatria, 76 (Suplemento 3): S275S284.

Silveira, A. C. D., Gardino, P. F., Bevilaqua, M. C. N., \& Hokoç, J. N. (2007). Neurogenesis of GABAergic cells in the retina of malnourished rats. International Journal of Developmental Neuroscience, 25, 325-333.

Skoczenski, A. M. \& Norcia, A. M. (1999). Development of VEP Vernier Acuity and Grating Acuity in Human Infants. Investigative Ophthalmology and Visual Science, 40 (10), 2411-2417. 
Smit, E. N., Muskiet, F. A. J. \& Boersma, E. R. (2004). The possible role of essential fatty acids in the pathophysiology of malnutrition: a review. Prostaglandins, Leukotrienes and Essential Fatty Acids, 71 (4), 241-250.

Smit, E. N., Oelen, E. A., Seerat, E., Muskiet, F. A. J. \& Boersma, E. R. (2000). Breast milk docosahexaenoic acid (DHA) correlates with DHA status of malnourished infants. Archives of Disease in Childhood, 82 (6), 493-494.

Stanley, O.H., Fleming, M.H. \& Morgan, M.H. (1991). Development of visual evoked potentials following intrauterine growth retardation. Early Human Development, 27: 79-91.

Sokol, S., Moskowitz, A. \& McCormack, G. (1992). Infant VEP and Preferential Looking Acuity Measured with Phase Alternating Gratings. Investigative Ophthalmology \& Visual Science, 33 (11), 3156 - 3161.

Soto-Moyano, R., Hernández, A., Pérez, H., Ruiz, S., Carreño, P. \& Belmar, J. (1993). Functional Alterations Induced by Prenatal Malnutrition in Callosal Connections and Interhemispheric Asymmetry as Revealed by Transcallosal and Visual Evoked Responses in the Rat. Experimental Neurology, 119 (1), 07-112.

Soto-Moyano, R., Valladares, L., Sierralta, W., Pérez, H., Mondaca, M., Fernández, V. et al. (2005). Mild prenatal protein malnutrition increases a 2C-adrenoceptor density in the cerebral cortex during postnatal life and impairs neocortical long-term potentiation and visuo-spatial performance in rats. Journal of Neurochemistry, 93 (5), 1099-1109.

Souza, G. S., Gomes, B. D., Saito, C. A., Silva Filho, M. \& Silveira, L. C. (2007). Spatial Luminance Contrast Sensitivity Measured with Transient VEP: Comparison with Psychophysics and Evidence of Multiple Mechanisms. Investigative Ophthalmology \& Visual Science, 48 (7): 3396-404.

Souza, G.S., Gomes, B.D., Lacerda, E.M., Saito, C.A., Silva Filho, M. \& Silveira, L.C. (2008). Amplitude of the transient visual evoked potential (tVEP) as a function of achromatic and chromatic contrast: contribution of different visual pathways. Vis Neurosci., 25(3): 317-325.

Sistema de Vigilância Alimentar e Nutricional - SISVAN (2011). http://nutricao.saude.gov.br/sisvan.php - consultar "Módulo gerador de relatórios".

Stratton, R. J. (2007). Malnutrition: another health inequality? Proceedings of the Nutrition Society, 66 (4), 522-529.

Strömland, K. (1992). Alcohol during pregnancy damages eye and vision development. Nordisc Medicinin, 107(12):313-315.

Suzuki, K., Tanaka, T., Kondo, N., Minai, J., Sato, M., \& Yamagata, Z. (2008). Is Maternal Smoking during Early Pregnancy a Risk Factor for All Low Birth Weight Infants? J Epidemiol, 18(3), 89-96. 
Yu, Tang \& Norcia, A. M. (1995). An Adaptive Filter for Steady-state Evoked Potentials. Electroencephalogr Clin Neurophysiol., 96 (3), 268-277.

Teller, D. Y., Dobson, V. \& Mayer, D. L. (2005). Teller Acuity Cards II Handbook. Copyright Stereo Optical Company Inc, Chicago.

Thordstein, C. M., Sultan, B. L., Wennergren, M. M., Törnqvist, E., Lindecrantz, K. G. \& Kjellmer, I. (2004). Visual Evoked Potentials in Disproportionately Growth-Retarded Human Neonates. Pediatric Neurology, 30 (4), 262-270.

Tornqvist, K. \& Källén, B. (2004). Risk factors in term children for visual impairment without a known prenatal or postnatal cause. Paediatric and Perinatal Epidemiology, 18 (6), 425-430.

Tsukamoto, H., Fukuoka, H., Koyasu, M., Nagai, Y. \& Takimoto, H. (2007). Risk factors for small for gestational age.Pediatrics International, 49, 985 - 990.

Tyler, C. W., Apkarian, P., Levi, D. M. \& Nakayama, K. (1979). Rapid assessment of visual function: an electronic sweep technique for the pattern visual evoked potential. Invest. Ophthalmol. Visual Sci., 18 (7), 703 - 713.

VanderVeen, D. K., Coats, D. K., Dobson, V., Fredrick, D., Gordon, R. A., Hardy, R. J. et al. (2006). Prevalence and Course of Strabismus in the First Year of Life for Infants with Prethreshold Retinopathy of Prematurity. Archives of Ophthalmology, 124 (6), 766-773.

van Eijsden, M., Hornstra, G., van der Wal, M. F., Vrijkotte, T. G. M. \& Bonsel, G. J. (2008). Maternal $n \_3$, n_6, and trans fatty acid profile early in pregnancy and term birth weight: a prospective cohort study. Am J Clin Nutr, 87, 887-895.

Van Hof-van Duin, J., Heersema, D.J. Groenendaal, F., Baerts ,W. \& Fetter, W.P.F. (1992). Visual field and grating acuity development in low-risk preterm infants during the first $2 \frac{1}{2} 2$ years after term. Behavioural Brain Research, 49: 115-122.

Vargas, V., Vargas, R., Marquez, G., Vonasek, E., Mateu, L., Luzzati, V., \& Borges, J. (2000). Malnutrition and myelin structure: an X-ray scattering study of rat sciatic and optic nerves. European Biophysics Journal, 29, 481 - 486.

Ventura, D. F., Simões, A. L. A. C., Tomaz, S., Costa, M. F., Lago, M., Costa, M. T. V., Canto-Pereira, L. H. M., Souza, J. M., Faria, M. A. M. \& Silveira, L. C. L. (2005). Colour vision and contrast sensitivity losses of mercury intoxicated industry workers in Brazil. Environmental Toxicology and Pharmacology, 19 (3): 523-529.

Victor, J. D. \& Mast, J. (1991). A new statistic for steady-state evoked potentials. Electroencephalography and Clinical Neurophysiology, 78(5): 378-88.

Victora, C. G., Barros, F. C., Horta, B. L. \& Martorell, R. (2001). Short-term benefits of catch up growth for small- for- gestational-age infants. International Journal of Epidemiology, 30, 1325- 1330. 
ANEXOS

- Termo de consentimento

- Aprovação do comitê de ética

- Artigo sobre metodologia bioquímica 


\section{TERMO DE CONSENTIMENTO LIVRE E ESCLARECIDO \\ FACULDADE DE PSICOLOGIA DA UNIVERSIDADE DE SÃO PAULO \\ DEPARTAMENTO DE PSICOLOGIA EXPERIMENTAL. SETOR DE PSICOFÍSICA VISUAL CLÍNICA}

\section{Desenvolvimento da Acuidade Visual e Sensibilidade ao Contraste em Recém-Nascidos Pequenos para a Idade Gestacional medido por Potenciais Visuais Evocados de Varredura}

Pesquisadores: Me. Valtenice de Cássia Rodrigues de Matos França; Dr. Stanislau Bogusz Junior; Prof. Dr. Marcelo F. Costa; Prof. Dr. Russell D. Hamer; Prof. Dr. Fabio Augusto; Prof ${ }^{a}$. Dra Dora F. Ventura.

Seu(ua) filho(a) está sendo convidado(a) a participar de um estudo que está sendo desenvolvido na Clínica de Psicofísica e Eletrofisiologia Visual. A proposta deste estudo é avaliar o desenvolvimento da visão de detalhes (acuidade visual) e sensibilidade ao contraste em recém-nascidos pequenos para a idade gestacional (PIG) e adequados para a idade gestacional (AIG) com a técnica dos Potenciais visuais evocados de varredura. O Potencial Visual Evocado de Varredura consiste no registro de sinais elétricos gerados na região posterior da cabeça (região occipital) onde se localiza a parte do cérebro que processa as informações visuais. Para a execução deste teste, serão colocados pequenos discos metálicos (eletrodos) sobre o couro cabeludo de seu(ua) filho(a) com um creme especial anti-alérgico. Durante o exame, seu(ua) filho(a) poderá permanecer sentado em seu colo enquanto observa um monitor de computador onde listras brancas e pretas serão apresentadas. Essas listras brancas e pretas variarão de tamanho e nível de contraste (cor cinza). No final do teste estarão disponíveis as medidas de acuidade visual e sensibilidade ao contraste. Pretende-se realizar esse teste visual com o seu filho por três vezes em diferentes idades, especificamente entre 6-8 semanas, 14-16 semanas e 30-40 semanas de idade. O benefício dado por este teste é a avaliação da visão espacial de seu filho. Este teste não causa nenhum desconforto ou risco para o seu filho. Os dados serão sigilosos e os nomes dos participantes não serão divulgados. Caso ocorra detecção de qualquer problema oftalmológico será feito encaminhamento para o tratamento necessário.

Pretendemos avaliar também a relação entre os valores dessas medidas visuais e o estado nutricional do seu filho. Para isso, serão investigados os ácidos graxos presentes nas células da parte interna das bochechas do seu filho, da seguinte forma: o pesquisador utilizará um swab ("espécie de cotonete") esterilizado e individual que será delicadamente passado nas partes internas das bochechas do seu filho. Esse procedimento é indolor, não-invasivo e não causará desconforto. Além disso, pretendemos também verificar a relação entre a concentração dos ácidos graxos existentes no leite materno e nas células das bochechas do recém-nascido. Para isso será necessário apenas que a mãe do recém-nascido limpe as próprias mamas com soro fisiológico e colete o leite materno num recipiente esterilizado fornecido pelo pesquisador.

Você pode esclarecer suas dúvidas sobre qualquer aspecto deste estudo bem como desistir a qualquer momento em que desejar. A participação no exame é totalmente voluntária. Sua assinatura neste termo de consentimento indica que você concorda na utilização dos resultados deste exame para pesquisa, após ter lido a informação descrita acima (ou alguém ter lido para você). O presente documento será assinado em duas vias, sendo que uma ficará de posse do pesquisador e a outra do responsável pelo recém-nascido.

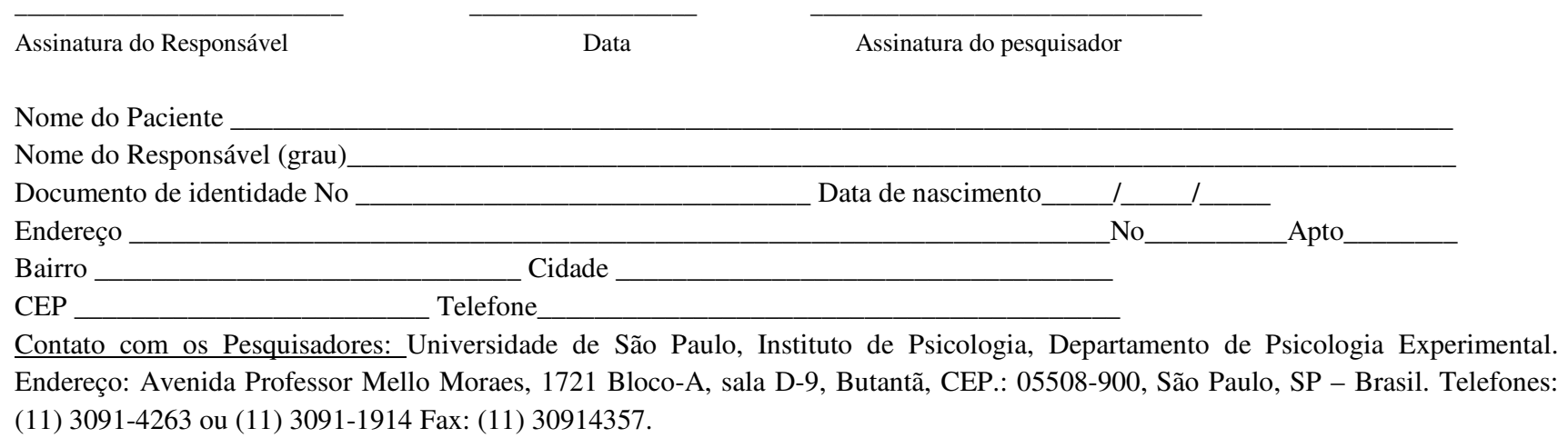




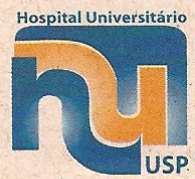

São Paulo, 24 de maio de 2010.

$I^{m o} \cdot S^{r}$

Prof. Dr. Marcelo Fernandes da Costa

Departamento de Psicologia Experimental

Instituto de Psicologia

UNIVERSIDADE DE SÃO PAULO

REFERENTE: Sub-Projeto de Pesquisa "Desenvolvimento da acuidade visual e sensibilidade ao contraste em recém-nascidos pequenos para a idade gestacional medido por potenciais evocados dé varredura" - Registro CEP-HU/USP: 736/07A Registro SISNEP CAAE: --.

Prezado Professor

O Comitê de Ética em Pesquisa do Hospital Universitário da Universidade de São Paulo, em reunião ordinária realizada no dia 21 de maio de 2010, analisou e APROVOU a solicitação feita por V.Sa. através de documento datado de 6 de maio de 2010, referente a nova versão do Súb-projeto acima citado, assim como do seu Termo de Consentimento Livre e Esclarecido, incluindo a análise bioquímica na Metodologia do Estudo.

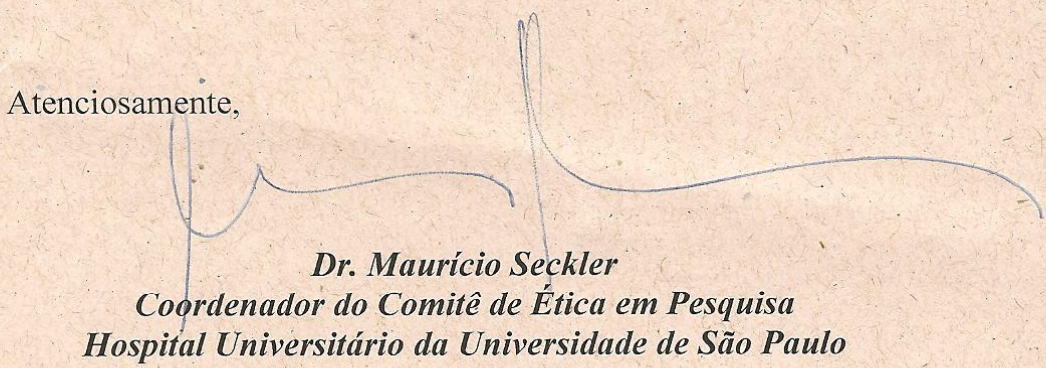

COMITE DE ÉTICA EM PESQUISA DO HOSPITAL UNIVERSITARIO DA USP Avenida Professor Lineu Prestes, 2565 - Cidade Universitária - 05508-000 São Paulo - SP Tel.: 3091-9457 - Fax: 3091-9452 - Email: cep@hu.usp.br 


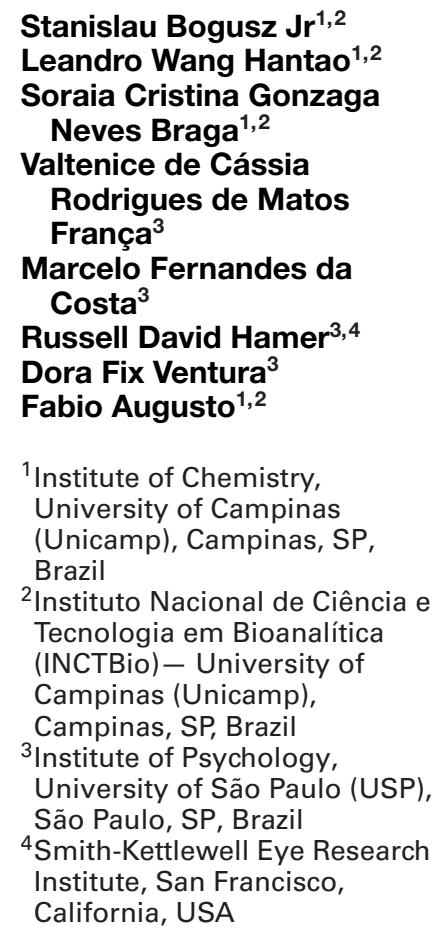

Received March 8, 2012

Revised June 15, 2012

Accepted June 15, 2012

\section{Research Article \\ Solid-phase microextraction combined with comprehensive two-dimensional gas chromatography for fatty acid profiling of cell wall phospholipids}

\begin{abstract}
The combination of solid-phase microextraction (SPME) with comprehensive twodimensional gas chromatography is evaluated here for fatty acid (FA) profiling of the glycerophospholipid fraction from human buccal mucosal cells. A base-catalyzed derivatization reaction selective for polar lipids such as glycerophospholipid was adopted. SPME is compared to a miniaturized liquid-liquid extraction procedure for the isolation of FA methyl esters produced in the derivatization step. The limits of detection and limits of quantitation were calculated for each sample preparation method. Because of its lower values of limits of detection and quantitation, SPME was adopted. The extracted analytes were separated, detected, and quantified by comprehensive two-dimensional gas chromatography with flame ionization detection (FID). The combination of SPME and comprehensive two-dimensional gas chromatography with FID, using a selective derivatization reaction in the preliminary steps, proved to be a simple and fast procedure for FA profiling, and was successfully applied to the analysis of adult human buccal mucosal cells.
\end{abstract}

Keywords: Comprehensive two-dimensional gas chromatography / Fatty acid methyl ester / Human buccal mucosal cells / Lipidomics / Selective methanolysis / Solid-phase microextraction DOI 10.1002/jssc.201200256

\section{Introduction}

The term lipidomics refers to the study of the cellular lipids the lipidome. Although lipidomics is a recent discipline in the study of biological systems, the number of studies in this new area has undergone an exponential growth [1-5]. In this context, lipidomics focuses on the investigation of the structures, functions, interactions, and dynamics of the cellular lipids, on their localization and their dynamics within cellular compartments, and on the dynamic changes that occur during normal physiological processes or in the presence of pathophysiological disturbances [1].

One of the most relevant applications of lipidomics is the investigation of the constitution of cellular phospholipids (PL). Glycerophospholipids (GPL) are major components of biological membranes, and their composition, in terms of the polyunsaturated fatty acids (PUFA), affects the chemical and

Correspondence: Prof. Fabio Augusto, Institute of Chemistry, University of Campinas (Unicamp), CP 6154-13084-971 Campinas, SP, Brazil

E-mail: augusto@iqm.unicamp.br

Fax: $+55193521-3023$

Abbreviations: GPL, Glycerophospholipids; FA, fatty acids; FAME, fatty acid methyl esters; FID, flame ionization detection; LLE, liquid-liquid extraction; PL, phospholipids; PUFA, polyunsaturated fatty acids; $\mathbf{R C F}$, relative centrifugal force; SPME, solid-phase microextraction physical properties of the biological membranes (selectivity and fluidity) [6]. Additionally, the composition and balance of the polyunsaturated n-6/n-3 fatty acids (FA) in red blood cells and other parts of the body is directly related to human health [7]. For example, the FA of the GPL of red blood cells reflects previous food habits integrated over a period of weeks to months, and thus, may serve as an objective gauge of one's nutritional state and health [8-10].

Hence, the analysis of the FA content in GPL can be a valuable tool to help quantify the nutritional status of clinical patients and in research populations where nutrition is a highly relevant factor. One salient example is the assessment of sensory and neurological development of human infants who have had inadequate intake of essential FA, either during gestation, or after full-term, or premature birth. It has been well established that inadequate intake of long-chain PUFA during infancy can compromise normal neurological, cognitive, and sensory development, which is manifested in a range of tasks including tasks as basic as visual acuity [11-15].

Studies have shown that the FA in buccal mucosal cells can be used as biomarkers for the content of FA, as an alternative for sampling plasma and red blood cells [16]. Typically, sampling of red blood cells are obtained from the antecubital vain or by heel stick [15], which can be painful and traumatic for the subject, especially for infants, thus the analysis of buccal cell provides a noninvasive and painless for the patient $[17,18]$. 
The conventional method for FA profiling in buccal mucosal cell consists of essentially three steps: lipid isolation, derivatization, and gas chromatographic (GC) analysis. Lipid isolation requires the extraction of the lipids from the matrix by the use of organic solvents, such as chloroform and methanol. After extraction, the GPL are separated from the total lipids by using either thin-layer chromatography (TLC) or solid-phase extraction (SPE) [19]. Consequently, these steps are necessary to ensure, mainly, the selectivity of the method and sample cleanup, since the conventional approaches do not provide the necessary peak capacity for these analyses. In the derivatization step, the GPL fraction is converted into their respective fatty acid methyl esters (FAMEs) through hydrolysis followed by condensation. However, hydrolysis followed by a condensation reaction or acid-catalyzed solvolysis, usually requires heating of the reaction medium for an extended period of time (tens of minutes). Consequently, the use of antioxidants for these derivatization procedures is usually a means to reduce sample degradation. In addition, base-catalyzed solvolysis is commonly carried out at ambient temperature for a few minutes, although most base-catalyzed reactions are not selective toward GPL. Even more, because of their low concentration, a preconcentration step is necessary which, commonly, consists of the evaporation of the solvent prior analysis. As for the identification and quantitation, the conventionally adopted technique is GC [16-18].

The present steps for the analysis of the FA content in cheek cells require much manipulation of the sample and, hence, are very laborious. Consequently, the automation of these procedures is difficult and the general method is time consuming, thus reducing the total sample processing capacity. In this context, more improvements must be performed in the analytical method regarding sample isolation and derivatization. In addition the occurrence of peak overlap will affect peak integration results and, thus, quantitation.

The use of the selective methanolysis, with $\mathrm{KOH} 70 \%$ (v/v) in aqueous methanol [10], and extraction technologies for sampling and preconcentration such as miniaturized liquid-liquid extraction (LLE) and solid-phase microextraction (SPME) are alternatives that can be employed to reduce the amount of steps during sample preparation, by increasing the selectivity toward GPL and detectability of the overall method $[20,21]$. However, the use of this combination for profiling GPL in human cheek cells is still in developmental stages for application in clinical analyses.

Considering the great complexity and diversity of the saturated and PUFA present in the buccal mucosal cells, and their small amount upon collection, it becomes evident the need for an analytical method with increased sensitivity and detectability to determine analytes occurring in trace concentrations, such as arachidonic acid (C20:4n-3), eicosapentaenoic acid (C22:5n-3), and eicosahexaenoic acid (C22:6n-3, DHA). These FAs are typically used as markers of many pathological processes or of the nutritional state in humans $[9,11-15,18]$. Hence, comprehensive two-dimensional gas chromatography (GC $\times \mathrm{GC})$ is a valuable analytical tool since it provides increased peak capacity, and it has already been applied to solve many complex separation problems [22-25].

The aim of this study was to simplify and improve the conventional methodology for lipidomic profiling to adapt it for analysis of FA in human buccal mucosal cells. The approach was to combine selective methanolysis, followed by SPME, to ensure selectivity of the derivatization while providing high detectability, and to GC $\times$ GC, allowing for the elimination of sample cleanup by SPE/TLC. The selectivity of the derivatization was evaluated for this type of biological sample (buccal mucosal cells). Then, after ensuring selectivity, the comparison between SPME and LLE was performed, independently, with the use of FAME analytical standards. Lastly, the combined methodology was applied for the lipidomic profiling of buccal mucosal cells in seven test subjects.

\section{Experimental section}

\subsection{Materials and chemicals}

Analytical grade solvents such as n-hexane, methanol, chloroform, and iso-octane were purchased from Synth (São Paulo, Brazil). The SPME fibers coated with poly(dimethylsiloxane) (PDMS) of 7 and $100 \mu \mathrm{m}$ thickness and other extraction apparatus, such as $200-\mu \mathrm{L}$ extraction vials, PTFE-silicone coated septa and caps, were purchased from Supelco (Bellefonte, PA, USA). The fibers were conditioned prior to use according to the instruction from the supplier. The SPE Florisil cartridges and extraction apparatus was also supplied by Supelco. Additionally, the analytical standards used for the identification were the FAME mixture of C8 to C24, PUFA from marine source and animal source, and DHA (Fluka, Steinheim, Germany). For the determination of the extraction profile and linear detection range, the analytical standards of C8 to C24 and DHA were used. The standard solution of $n$-alkanes used for the determination of the van den Dool retention indexes was C7-C30 (Fluka).

The GC $\times$ GC-FID (where FID is flame ionization detection) prototype was used for the optimization processes and sample analyses. The GC $\times$ GC-FID consisted of a commercial Agilent 6890 N GC-FID (Agilent Technologies, Wilmington, CA, USA) fitted with a laboratory designed and made two-stage cryogenic modulator. The cryogenic fluid was $\mathrm{N}_{2}$ cooled in liquid nitrogen $\left(\mathrm{LN}_{2}\right)$. The $\mathrm{N}_{2}$ flow was toggled by two three-way Asco solenoid valves (Florham Park, NJ, USA). The command to these valves was controlled by a low-cost 8-bit Arduino Duemilanove microcontroller (Ivrea, Italy).

The GC $\times$ GC-qMS (qMS, mass spectrometer with a fast quadrupole mass analyzer) prototype was used for the identification of the analytes. The GC $\times$ GC-qMS consisted of a commercial GC-qMS QP2010 Plus (Shimadzu, Kyoto, Japan) fitted with a two-stage cryogenic modulator. The cryogenic fluid and valve controllers were the same as for the GC $\times$ GC-FID system.

In both $\mathrm{GC} \times \mathrm{GC}$ system, the column set used consisted of a nonpolar HP-5 $(30 \mathrm{~m}$, i.d. $0.25 \mathrm{~mm}, 0.25-\mu \mathrm{m}$ film 
thickness) serially connected by a SilTite metallic connector (SGE, San Diego, CA, USA) to a polar column (1.0 m, i.d. $0.10 \mathrm{~mm}, 0.10-\mu \mathrm{m}$ film thickness). The modulation period used was $6 \mathrm{~s}$. In both systems, the carrier gas was hydrogen at $0.7 \mathrm{~mL} / \mathrm{min}\left(170^{\circ} \mathrm{C}\right)$. The injection temperatures were $270^{\circ} \mathrm{C}$. The FID detector operated at $270^{\circ} \mathrm{C}$. For the GC $\times$ GC-qMS system both the transfer line and the ion source operated at $250^{\circ} \mathrm{C}$; the electron multiplier operated at $0.9 \mathrm{kV}$ and electron ionization was used for ionization technique; the reduced scan range was operated at 50-393 at acquisition rate of $25 \mathrm{~Hz}$. For SPME injections, the injector operated in splitless mode; while for the LLE injector, a split ratio of 1:20 was used. The chromatographic oven's linear temperature program was set to $170^{\circ} \mathrm{C}$ at $3^{\circ} \mathrm{C} / \mathrm{min}$ until $240^{\circ} \mathrm{C}$, held at $240^{\circ} \mathrm{C}$ for $16.67 \mathrm{~min}$.

The program used in the Arduino microcontroller board was lab-written in a wiring-based language, similar to $\mathrm{C}++$. The input of the modulation parameters was performed by a lab-programmed applet written in Visual Basic. For chromatographic data collected in the GC $\times$ GC-FID equipment, the commercial software ChemStation (Agilent Technologies) was used. While for the collection and digitalization of data from GC $\times$ GC-qMS, the commercial software GCMS solution (Shimadzu Corporation, Tokyo, Japan) was employed. For the interpretation of the bidimensional data, the commercial software GCImage (Zoex Coorporation, Houston, TX, USA) was used.

\subsection{Selectivity of the reaction}

\subsubsection{Synthetic mixture}

To ensure the selectivity of the derivatization two studies were performed, independently of the SPME procedure. Firstly, a mixture containing neutral lipids and phospholipids was prepared. The neutral lipids consisted of a solution of soy oil in $n$-hexane $(100 \mathrm{mg} / \mathrm{mL})$, which was purified to remove any traces of GPL. The polar GPL consisted of a standard solution of egg yolk phosphatidylcholine $(34 \mathrm{mg} / \mathrm{mL})$. The mixture was prepared with $500 \mu \mathrm{L}$ of each sample. The second set consisted of the buccal mucosal cells collected from volunteers.

To evaluate the selectivity, the neutral lipids were separated from the polar GPL by SPE. The commercial SPE cartridge was filled with Florisil. This cartridge was acidified with $5 \mathrm{~mL}$ of an aqueous solution of $\mathrm{pH} 2.6$ followed by $5 \mathrm{~mL}$ of methanol. Then, the cartridge was dried by allowing a flow of air through it for $20 \mathrm{~min}$. Afterwards, the synthetic mixture was applied to the head of the cartridge. Neutral lipids were eluted with $3 \mathrm{~mL}$ of $n$-hexane and collected for prior analysis. Immediately after, $2 \mathrm{~mL}$ of $0.7 \mathrm{~mol} / \mathrm{L} \mathrm{KOH}_{(\mathrm{MeOH})} / \mathrm{H}_{2} \mathrm{O} 70: 30$ $(\mathrm{v} / \mathrm{v})$ was added to the cartridge, this mixture was allowed to "wet" the florisil content for $2 \mathrm{~min}$. Then, $3 \mathrm{~mL}$ of $n$-hexane was used to eluted the polar fraction, containing the GPL. Additionally, the $n$-hexane layer was immediately transferred to a separate vial. These fractions were reconcentrated by evaporating the solvent under a flow of nitrogen, and transferred to the microvials for complete evaporation of the solvent.

For the derivatization of the neutral fraction, $10 \mu \mathrm{L}$ of iso-octane and $20 \mu \mathrm{L}$ of derivatization solution were added to the vial. The vessel was then stirred for $2 \mathrm{~min}$ and the reaction was ceased with $1.5 \mu \mathrm{L}$ of concentrated acetic acid. The second fraction, containing the GPL, was reconstituted with $10 \mu \mathrm{L}$ of iso-octane. All analyses were performed in a GC $\times$ GC-FID system. These procedures were carried out in duplicate.

\subsubsection{Buccal mucosal cells}

Because of the low content of biological material, four swabs were collected and each buccal swab was extracted with $0.5 \mathrm{~mL}$ of a mixture of 1:1 chloroform/methanol (v/v) under ultrasound for $10 \mathrm{~min}$. All the biological material was transferred to a preconditioned florisil cartridge. The initial solvent was collected along with the eluate of the $3 \mathrm{~mL}$ of $n$-hexane fraction. Finally, the polar lipids were derivatized in the SPE cartridge and eluted with $n$-hexane as described previously. The derivatization of the neutral fraction proceeded as described previously. This procedure was also carried out in duplicate.

\subsection{Comparison of microextraction techniques}

For the selection of the sample preparation technique, SPME was compared to LLE with the use of analytical standards. For the SPME procedure, commercial coatings of PDMS of 7 and $100-\mu \mathrm{m}$ thickness were evaluated (Supelco). The extraction profile of both fibers was evaluated for the time interval of 5 to $40 \mathrm{~min}$. For this purpose, $1 \mu \mathrm{L}$ of a $20 \mathrm{mg} / \mathrm{mL}$ of a standard solution, containing C8-C24 FAME, was added to the $200 \mu \mathrm{L}$ vial and the flask was filled with distilled water. The flask was then agitated for $1 \mathrm{~min}$ followed by SPME fiber exposure. Ideally, the extraction profile is usually obtained with the real sample. However, in this study, the amount of biological material was rather limited, and even if more swabs are collected from the same subject, the material diminishes with each sample collection. Hence, the extraction profile was evaluated with FAME analytical standards and distilled water. Additionally, for the determination of the analytical linear range, five solutions were prepared and exactly $1 \mu \mathrm{L}$ of the individual solution was added to $200 \mu \mathrm{L}$ vial, followed by the addition of $200 \mu \mathrm{L}$ of distilled water. The vial was agitated for $1 \mathrm{~min}$, followed by the exposure of the $7 \mu \mathrm{m}$ PDMS-coated fiber for $20 \mathrm{~min}$. All analyses were carried out in triplicates.

For the determination of the linear detection range by LLE, addition of analytical standards with different concentrations were added to the $200 \mu \mathrm{L}$ vials with $10 \mu \mathrm{L}$ of iso-octane, followed by vortexing for $1 \mathrm{~min}$. Also, proper dilution factors were considered during the determination of the linear range. The linear range was determined in five distinct intervals of concentration and analyses were performed in triplicates. 


\subsection{SPME combined to comprehensive GC}

\subsubsection{Biological samples}

The protocol used throughout the current study was reviewed and approved by the Ethical Committee of the University Hospital of the University of São Paulo. Thus, oral consent of adult volunteers was obtained.

For development of the analytical methods, cheek cell samples were collected from seven adult volunteers. Subjects did not ingest any kind of food. The adults' mouths were rinsed out with water just prior to sample collection. The cells were collected with a cytological brush by scraping, with circular movements, the inside of the cheek (about ten times). The cells were suspended in $1 \mathrm{~mL}$ of sterile saline by introducing the cytological brush into the test tube and rotating it. The same process was performed for samples from the other cheek.

The test tubes containing the samples were centrifuged at 5433 relative centrifugal force (RCF) for $10 \mathrm{~min}$ in order to separate (and eliminate) the saline medium from the cells. Visual inspection of the receptacle should indicate the presence of the cellular mass at the bottom of the receptacle.

\subsubsection{Combined methodology}

The extraction of the lipids from the cellular medium was performed according to an adapted Bligh-Dyer methodology and miniaturized using a ternary mixture of methanol (1000 $\mu \mathrm{L})$, chloroform $(2000 \mu \mathrm{L})$, and distilled water $(800 \mu \mathrm{L})$. This method was applied to the biological material by adding the mixture to the test tube, vortexing for $1 \mathrm{~min}$ to resuspend this material, and then submitting it to ultrasound for $15 \mathrm{~min}$.

Afterwards, $1000 \mu \mathrm{L}$ of 1:1 methanol/chloroform (v/v) were added to the mixture. The suspension was vortexed for another minute and centrifuged for $5 \mathrm{~min}$ at $5433 \mathrm{RCF}$, to achieve full separation of the phases. The organic layer was collected and transferred to $200 \mu \mathrm{L}$ microvials, where the organic solvents were eliminated by applying a small flow of nitrogen gas $\left(\mathrm{N}_{2}\right)$.

The base-catalyzed transesterification reagent used was a solution of $0.7 \mathrm{~mol} / \mathrm{L}$ potassium hydroxide in methanol $\left(\mathrm{KOH}_{(\mathrm{MeoH})}\right) /$ water $\left(\mathrm{H}_{2} \mathrm{O}\right) 70: 30(\mathrm{v} / \mathrm{v})$. The derivatization proceeded as follows: $20 \mu \mathrm{L}$ of $0.7 \mathrm{~mol} / \mathrm{L} \mathrm{KOH}_{(\mathrm{MeOH})} / \mathrm{H}_{2} \mathrm{O} 70: 30$ $(\mathrm{v} / \mathrm{v})$ was added to the microvial, which contained the isolated lipids. After vortexing for $2.0 \mathrm{~min}$, the reaction was ceased by adding $1.5 \mu \mathrm{L}$ of concentrated acetic acid. Then, the solvents were evaporated and the FAMEs were ready for extraction. Immediately afterwards, $200 \mu \mathrm{L}$ of distilled water was added to the vial and the extraction device was exposed to the aqueous medium. Most importantly, there was no headspace present in the extraction vessels.

Then, the SPME fiber was exposed to the aqueous medium for $20 \mathrm{~min}$, followed by thermal desorption in the GC injection port. The SPME fiber was kept in the GC in- jection for $5 \mathrm{~min}$ to avoid a memory effect. Analysis of each subject was carried out in four replicates.

\section{Results and discussion}

\subsection{Derivatization and selectivity of the reaction}

In the conventional methodologies for GC analysis, the buccal mucosal cells were partitioned by TLC before derivatization in order to ensure that only GPL fractions are being analyzed. Thus, in order to evaluate the overall selectivity of the proposed method, a synthetic mixture containing neutral lipids from purified soy oil and egg yolk phosphatidylcholine, and cheek cells were used to evaluate the selectivity of this reaction. The synthetic mixture was partioned by using an acidified florisil cartridge. The neutral lipids were eluted with n-hexane, while the following eluate contained the polar GPL. The difference between retention factors occurs because when the neutral lipids are eluted with $n$-hexane, the GPLs are retained in the acidified florisil due to acid-base interactions between adsorption sites in the florisil and the phosphate group present in the GPL. As illustrated in Fig. 1A, the nonpolar fraction lacks FAME peaks. In Fig. 1B, the presence of the FAME from the GPL can be visualized. This observation implies that the reaction is selective toward GPL.

The same procedure was applied to the pure cheek cell extracts. The chromatographic profiles obtained by the fractionation of the nonpolar and polar lipids were also compared. Major analytes, such as FAME from C16 and C18 groups, were present in the polar fraction (Fig. 1D), while almost no FAMEs were detected in the nonpolar fraction (Fig. 1C). Consequently, this fact, combined with the previous results, is important evidence supporting the selectivity of the methanolysis.

However, DHA and EPA were almost unmeasureable in the polar fraction, as were some other minor analytes, because of the nonquantitative transfers from the SPE cartridge. Hence, considering the results presented here, the overall method may be regarded as selective toward GPL, despite the lack of detectability of the SPE method.

Additionally, the conventional method requires a lot of sample manipulation and nonquantitative transfers, thus resulting in a lower detectability of the overall method. Also, this method is not ideal for automation.

Thus, in the current study, in the lipid isolation step, the solvent partitioning steps, along with fractionation by TLC/SPE, were eliminated, permitting a considerable reduction of the time spent in sample preparation (by a factor of nearly four). Additionally, all analytical steps took place in the same microvial, eliminating nonquantitative transfers and reducing the amount of required sample manipulation.

\subsection{Comparison of microextraction techniques}

Two techniques were evaluated: SPME and LLE. For the SPME method, the influence of the PDMS-coating thickness 

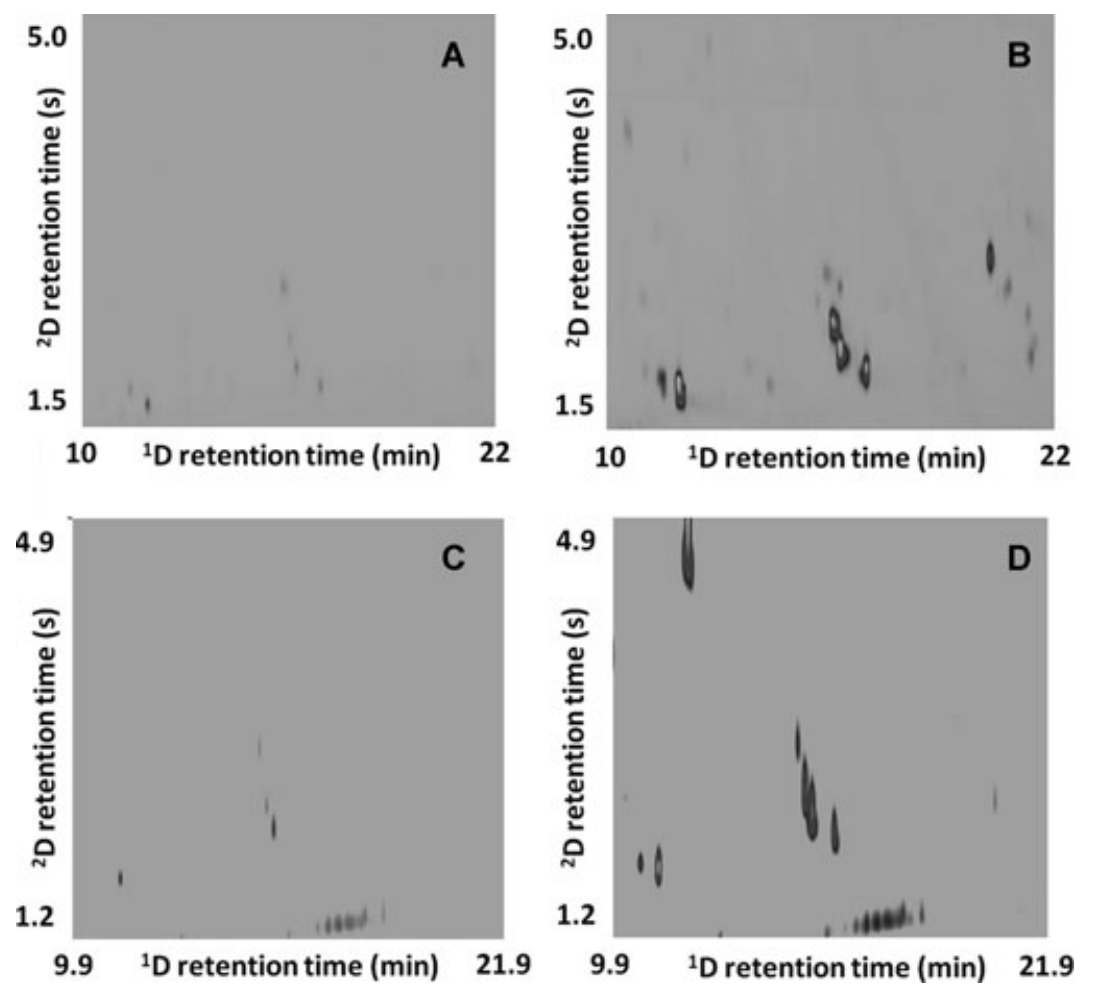

Figure 1. GC $\times$ GC-FID chromatograms of the nonpolar (A) and polar fraction (B) of the synthetic mixture of purified soy oil and egg yolk phosphatidylcholine and the neutral lipids (C) and polar GPL) (D). For operational conditions, see text.

on the extraction profile was evaluated. Then, the linear detection range of both the SPME and LLE method were obtained along with their respective metrics.

It was observed that the amount extracted by the $100-\mu \mathrm{m}$ PDMS coating is higher than the amount extracted by the $7-\mu \mathrm{m}$ thick coating. However, for the $100 \mu \mathrm{m}$ coating, equilibrium was not achieved in the evaluated time interval, while for the 7- $\mu \mathrm{m}$ PDMS coating, equilibrium condition was observed in $20 \mathrm{~min}$. Consequently, since the amount extracted by the 7- $\mu \mathrm{m}$ PDMS coating provided enough sensitivity for the FAME analysis, and had shorter equilibration times, the latter was chosen for the current method.

The evaluation of the linear detection range for FAME was performed by both sample isolation techniques, LLE and SPME, while analyses were performed on the GC $\times$ GCFID. Additionally, for the SPME procedure, the amount of organic modifier in the aqueous phase was minimized and maintained constant throughout the study in order to ensure similar distribution constants in all extractions.

The concentrations evaluated were different for some analytes because of their different response factors, and the assessed concentration intervals were chosen according to the peak areas found in the biological samples. Furthermore, concentration intervals of 0.5 to $16.5 \mathrm{mg} / \mathrm{mL}$ were evaluated for LLE, while intervals ranging from $1.2 \times 10^{-2} \mu \mathrm{g} / \mathrm{mL}$ to $790 \mu \mathrm{g} / \mathrm{mL}$ were used for the SPME method.

From the linear regression equation, the limits of detection (LODs) and quantitation (LOQs) were calculated. The LOD was taken as the 3.3 times the ratio of the error of the linear regression term divided by the angular regression term, while the LOQ was taken as ten times this same ratio. Also, illustrated in Table 1 are the regression coefficients for all the linear detection ranges and their respective LOD and LOQ.

The derived value of LOD for DHA was $11 \mu \mathrm{g} / \mathrm{mL}$ for the LLE method. For the SPME method, the value was found to be $2.40 \times 10^{-2} \mu \mathrm{g} / \mathrm{mL}$. Additionally, an LOQ value of $33 \mu \mathrm{g} / \mathrm{mL}$ was determined for the LLE method, and $7.28 \times 10^{-2} \mu \mathrm{g} / \mathrm{mL}$ was calculated for SPME. Consequently, given the increased of almost 100 times, these results suggest that the use of SPME provides higher detectability than the proposed LLE, essentially because of its favorable phase ratio $(\beta)$. Although LLE combined with $\mathrm{GC} \times \mathrm{GC}$ did provide enough detectability for FA profiling for typical biomarkers, the use of SPME coupled to GC $\times$ GC could potentially increase the detection of minoritary compounds and, hence, the discovery of new biomarkers.

\subsection{Lipidic profiling of buccal mucosal cells}

The selectivity of the derivatization reaction was evaluated with two test mixtures, and its selectivity was proven. Then, independently, the comparison of SPME and LLE was performed. Thus, because of the lower values of LOD and LOQ, SPME was chosen for FAME isolation. Consequently, the final methodology for lipid analysis resulted from the combination of the derivatization followed by isolation of the analytes by SPME and analysis by GC $\times$ GC-FID. A chromatogram is illustrated in Fig. 2.

This method was successfully applied for the evaluation of human buccal mucosal cells. Illustrated in Table 2 are the quantitation results from buccal samples obtained from seven 
Table 1. Linear detection ranges (LR), LOD and LOQ for the SPME and miniaturized LLE) methods combined with GC $\times$ GC-FID demonstrating their applicability for lipidic profiling. It can be noticed the increase detectability of SPME over LLE for the analysis of FAME

\begin{tabular}{|c|c|c|c|c|c|c|c|c|}
\hline \multirow[t]{2}{*}{ FAME } & \multicolumn{4}{|l|}{ SPME } & \multicolumn{4}{|l|}{ LLE } \\
\hline & $\mathrm{LR} / \mathrm{mg} / \mathrm{mL}$ & $\mathrm{R}^{2}$ & $\mathrm{LOD} / \mathrm{mg} / \mathrm{mL}$ & $\mathrm{LOQ} / \mathrm{mg} / \mathrm{mL}$ & $\mathrm{LR} / \mathrm{mg} / \mathrm{mL}$ & $\mathrm{R}^{2}$ & $\mathrm{LOD} / \mathrm{mg} / \mathrm{mL}$ & $\mathrm{LOO} / \mathrm{mg} / \mathrm{mL}$ \\
\hline C12:0 & $5.7 \times 10^{-3}-3.8 \times 10^{-1}$ & 0.993 & $3.7 \times 10^{-2}$ & $1.1 \times 10^{-1}$ & $1.2 \times 10^{-1}-1.2 \times 10^{1}$ & 0.974 & 1.9 & 5.6 \\
\hline C14:0 & $5.7 \times 10^{-3}-5.8 \times 10^{-2}$ & 0.959 & $1.4 \times 10^{-1}$ & $4.3 \times 10^{-1}$ & $1.2 \times 10^{-1}-1.2 \times 10^{1}$ & 0.980 & 1.6 & 4.8 \\
\hline C16:0 & $7.9 \times 10^{-3}-7.9 \times 10^{-1}$ & 0.973 & $1.2 \times 10^{-1}$ & $3.7 \times 10^{-1}$ & $1.7 \times 10^{-1}-1.7 \times 10^{1}$ & 0.965 & 2.9 & 8.9 \\
\hline C16:1n-6 & $3.6 \times 10^{-3}-2.4 \times 10^{-1}$ & 0.988 & $3.0 \times 10^{-2}$ & $9.1 \times 10^{-2}$ & $7.5 \times 10^{-2}-7.5$ & 0.970 & 1.2 & 3.7 \\
\hline C18:0 & $5.7 \times 10^{-3}-5.8 \times 10^{-2}$ & 0.992 & $6.0 \times 10^{-2}$ & $1.8 \times 10^{-1}$ & $1.2 \times 10^{-1}-1.2 \times 10^{1}$ & 0.974 & 2.0 & 6.0 \\
\hline C18:1n-9 & $3.6 \times 10^{-3}-2.4 \times 10^{-1}$ & 0.968 & $4.8 \times 10^{-2}$ & $1.4 \times 10^{-1}$ & $7.5 \times 10^{-2}-7.5$ & 0.976 & 1.2 & 3.6 \\
\hline C18:2n-6 & $3.6 \times 10^{-3}-2.4 \times 10^{-1}$ & 0.978 & $4.0 \times 10^{-2}$ & $1.2 \times 10^{-1}$ & $7.5 \times 10^{-2}-7.5$ & 0.990 & $7.8 \times 10^{-1}$ & 2.4 \\
\hline $\mathrm{C} 20: 0$ & $5.7 \times 10^{-3}-5.8 \times 10^{-2}$ & 0.987 & $6.1 \times 10^{-2}$ & $1.8 \times 10^{-1}$ & $1.2 \times 10^{-1}-1.2 \times 10^{1}$ & 0.995 & 0.9 & 2.7 \\
\hline $\mathrm{C} 22: 0$ & $5.7 \times 10-3-5.8 \times 10^{-2}$ & 0.988 & $5.9 \times 10^{-2}$ & $1.8 \times 10^{-1}$ & $1.2 \times 10^{-1}-1.2 \times 10^{1}$ & 0.995 & 0.9 & 2.6 \\
\hline C22:1n-9 & $3.6 \times 10^{-3}-2.4 \times 10^{-1}$ & 0.887 & $9.4 \times 10^{-2}$ & $2.82 \times 10^{-1}$ & $7.5 \times 10^{-2}-7.5$ & 0.976 & 1.2 & 3.6 \\
\hline$C 22: 6 n-3$ & $1.2 \times 10^{-5}-1.2 \times 10^{-4}$ & 0.969 & $2.4 \times 10^{-5}$ & $7.2 \times 10^{-5}$ & $5.2 \times 10^{-3}-1.1 \times 10^{-1}$ & 0.982 & $1.1 \times 10^{-2}$ & $3.3 \times 10^{-2}$ \\
\hline $\mathrm{C} 24: 0$ & $5.7 \times 10^{-3}-3.8 \times 10^{-1}$ & 0.989 & $4.5 \times 10^{-2}$ & $1.3 \times 10^{-1}$ & $1.2 \times 10^{-1}-1.2 \times 10^{1}$ & 0.796 & 6.0 & $1.8 \times 10^{1}$ \\
\hline
\end{tabular}

adults subjects, performed in quadruplicates. At first glance, it can be seen that most FAME could be successfully quantitated by the present methodology, although C14:0, C20:0, and C22:1n- 6 were detected but found in concentrations below the LOQ value. Additionally, if the same samples were to be quantitated by LLE combined with GC $\times$ GC-FID, probably most FAME would have been detected, but in concentrations below LOQ, jeopardizing the quantitation.

Regarding the relatively high standard deviations of the measured concentrations, relatively high values would be expected due to variability in the amount of biological material collected by each cytological brush, a factor that cannot be controlled with high accuracy. However, the current method will being applied to evaluate the nutritional status of several infants, and preliminary results showed that data preprocessing prior to multiway analysis reduces the influence of variability in the amount of collected biological material.

\section{Conclusions}

The combination of a selective methanolysis reagent and a chromatographic system with increased separation power allowed for the simplification of conventional methodology for the profiling of FAs in biological samples, such as buccal mucosal cells. The elimination of sample fractionation by TLC/SPE was possible by use of GC $\times$ GC and the selective derivatization showing a fourfold reduction of time spent in sample preparation. Additionally, with this approach the sample preparation/sample isolation can be performed in the same vial, thus eliminating sample manipulation and nonquantitative transfers. The extraction profile for the $7-\mu \mathrm{m}$ PDMS fiber presented adequate sensitivity and equilibration time for the proposed method. Even so, SPME provided far superior detection and quantitation limits (about 100 times lower), when compared to LLE. As a consequence, the

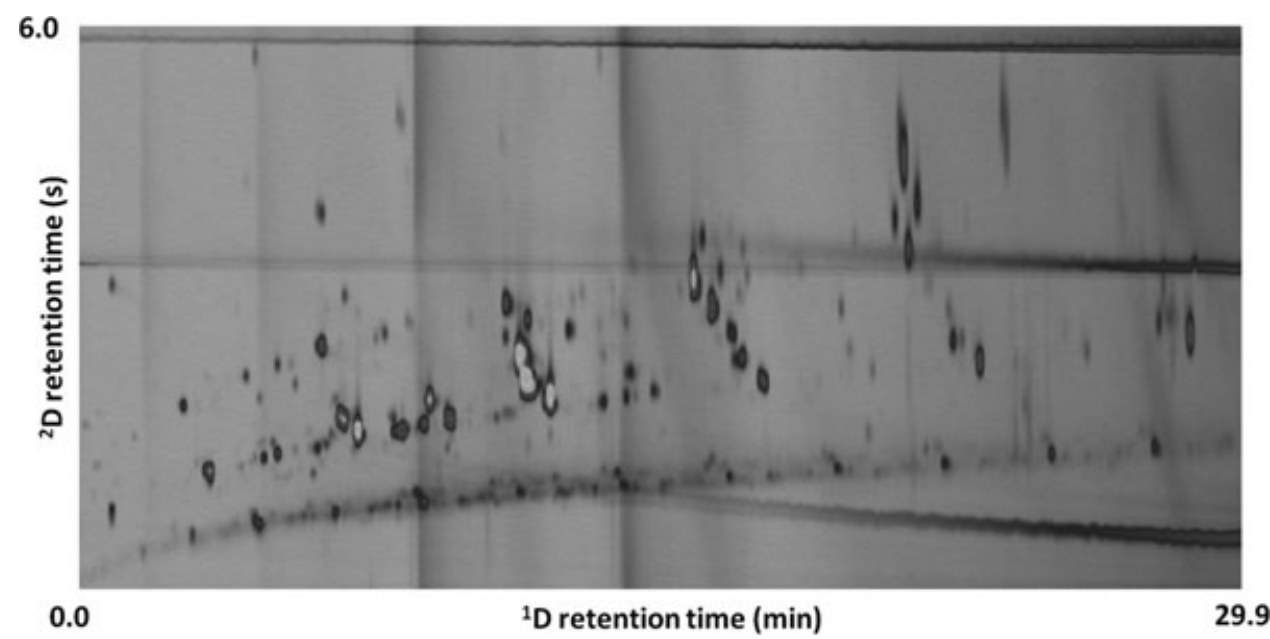

Figure 2. Typical GC $\times$ GC-FID chromatograms of FA profile of buccal mucosal cells. For details, see text. 
Table 2. Quantitation results of the lipidomic profiling of buccal mucosal cells of seven different test subjects by the combined method of SPME and GC $\times$ GC-FID. The units of concentration are $\mathrm{mg} / \mathrm{mL}$, and the four replicates $(N=4)$ for each subject was performed

\begin{tabular}{|c|c|c|c|c|c|c|c|}
\hline Compound & Subject 1 & Subject 2 & Subject 3 & Subject 4 & Subject 5 & Subject 6 & Subject 7 \\
\hline $\mathrm{C} 12: 0$ & $9 \pm 2$ & $2.4 \pm 0.3$ & $2.2 \pm 2$ & $0.90 \pm 0.03$ & $4.05 \pm 0.36$ & $9 \pm 2$ & $4 \pm 1$ \\
\hline C14:0 & $<\mathrm{LOO}$ & $<\mathrm{LOO}$ & $<\mathrm{LOO}$ & $<\mathrm{LOO}$ & $<\mathrm{LOO}$ & $<\mathrm{LOO}$ & $<\mathrm{LOO}$ \\
\hline C16:1n-7 & $0.21 \pm 0.03$ & $1.5 \pm 0.1$ & $1.0 \pm 0.1$ & $0.9 \pm 0.2$ & $0.4 \pm 0.1$ & $0.800 \pm 0.006$ & $1.643 \pm 0.006$ \\
\hline C16:0 & $1.0 \pm 0.1$ & $1.7 \pm 0.5$ & $2.7 \pm 0.3$ & $1.40 \pm 0.07$ & $1.1 \pm 0.1$ & $1.44 \pm 0.07$ & $1.4 \pm 0.4$ \\
\hline C18:2n-6 & $1.1 \pm 0.1$ & $2.4 \pm 0.1$ & $1.11 \pm 0.01$ & $4.4 \pm 0.4$ & $3.84 \pm 0.04$ & $4 \pm 1$ & $3.1 \pm 0.3$ \\
\hline C18:1n-7 & $1.0 \pm 0.1$ & $2.0 \pm 0.2$ & $1.2 \pm 0.3$ & $1.6 \pm 0.2$ & $1.1 \pm 0.1$ & $1.60 \pm 0.01$ & $2.1 \pm 0.5$ \\
\hline C18:0 & $1 \pm 0.1$ & $3.0 \pm 0.3$ & $1.10 \pm 0.05$ & $2.40 \pm 1$ & $1.931 \pm 0.003$ & $2.2 \pm 0.4$ & $2.4 \pm 0.1$ \\
\hline $\mathrm{C} 20: 0$ & $<\mathrm{LOQ}$ & $<\mathrm{LOO}$ & $<\mathrm{LOQ}$ & $<\mathrm{LOQ}$ & $<\mathrm{LO0}$ & $<\mathrm{LOO}$ & $<\mathrm{LOO}$ \\
\hline$C 22: 6 n-3$ & $0.04 \pm 0.01$ & $0.080 \pm 0.001$ & $0.2 \pm 0.1$ & $0.10 \pm 0.01$ & $0.043 \pm 0.002$ & $0.080 \pm 0.001$ & $0.2 \pm 0.1$ \\
\hline C22:1n-6 & $<\mathrm{LOQ}$ & $<\mathrm{LOO}$ & $<\mathrm{LOO}$ & $<\mathrm{LOO}$ & $<\mathrm{LOQ}$ & $<\mathrm{LOO}$ & $<\mathrm{LO0}$ \\
\hline $\mathrm{C} 22: 0$ & $<\mathrm{LOQ}$ & $0.04 \pm 0.004$ & $0.03 \pm 0.001$ & $0.05 \pm 0.004$ & $<\mathrm{LOQ}$ & $0.0200 \pm 0.0004$ & $0.10 \pm 0.01$ \\
\hline
\end{tabular}

feasibility of automation for the SPME procedure is possible. Also, the use of GC $\times$ GC provided superior peak resolution and detectability. Thus, allowing for a higher number of constituents to be determined more accurately. In the light of these results, the currently proposed method has a rather convenient sample throughput and increase detectability for lipidomics studies. The proposed methodology will be used to help quantify the nutritional status of infants.

The authors thank CAPES (Brazilian Ministry of Education Agency for Improvement of Graduate Personnel), FAPESP (Foundation for Research of the State of São Paulo), and the ProReitoria of the University of São Paulo for financial support and fellowships.

The authors have declared no conflict of interest.

\section{References}

[1] Han, X., J. Chromatogr. B 2009, 877, 2663-2663.

[2] Han, X., Gross, R. W., J. Lipid Res. 2003, 44, 1071-1079.

[3] Lagarde, M., Geloen, A., Record, M., Vance, D., Spener, F., Biochim. Biophys. Acta 2004, 1634, 61-61.

[4] Lee, S. H., Williams, M. V., DuBois, R. N., Blair I. A., Rapid Commun. Mass Spectrom. 2003, 17, 2168-2176.

[5] Esch, S. W., Williams, T. D., Biswas, S., Chakrabarty, A., Levine, S. M., Cell. Mol. Biol. 2003, 49, 779-787.

[6] Chow, C. K., Fatty Acid in Foods and Their Health Implications, Marcel Dekker, New York 2000.

[7] Yu, G., Björksten, B., Eur. J. Pediatr. 1998, 157, 298-303.

[8] Guerra, A., Demmelmair, H., Toschke, A. M., Koletzko, B., Ann. Nutr. Metab. 2007, 51, 433-438.

[9] Conquer, J. A., Tierney, M. C., Zecevic, J., Bettger, W. J., Fisher, R. H., Lipids 2000, 35, 1305-1312.

[10] Ichihara, K., Yamaguchi, C., Araya, Y., Sakamoto, A., Yoneda, K., Lipids 2010, 45, 367-374.
[11] Birch, E. E., Hoffman, D. R., Uauy, R., Birch, D. G., Prestidge, C., Pediatr. Res. 1998, 44, 201-209.

[12] Birch, E. E., Garfield, S., Hoffman, D. R., Uauy, R., Birch, D. G., Dev. Med. Child Neurol. 2000, 42, 174-181.

[13] Birch, E. E., Castaneda, Y. S., Wheaton, D. H., Birch, D. G., Uauy, R. D., Hoffman, D. R., Am. J. Clin. Nutr. 2005, 81, 871-879.

[14] Birch, E. E. Garfield, S., Castaneda, Y., HughbanksWheaton, D., Uauy, R., Hoffman, D., Early Hum. Dev. 2007, 83, 279-284.

[15] Birch, E. E., Carlson, S. E., Hoffman, D. R., FitzgeraldGustafson, K. M., Fu, V. L. N., Drover, J. R., Castaneda, Y. S., Minns, L., Wheaton, D. K. H., Mundy, D., Marunycz, J., Diersen-Schade, D. A., Am. J. Clin. Nutr. 2010, 91, 848-859.

[16] Koletzko, B., Knoppke, B., von Schenck, U., Demmelmair, H., Damli, A., J. Pediatr. Gastr. Nutr. 1999, 29, 467-474.

[17] Connor, S. L., Zhu, N., Anderson, G. J., Hamill, D., Jaffe, E., Carlson, J., Connor, W. E., Am. J. Clin. Nutr. 2000, 71, 21-27.

[18] Hoffman, D. R., Birch, E. E., Birch, D. G., Uauy, R., Lipids 1999, 34, 337-342.

[19] Ichihara, K., Yoneda, K., Takahashim, A., Hoshino, N., Matsuda, M., Lipids 2011, 46, 297-306.

[20] Pena-Pereira, F., Lavilla, I., Bendicho, C., Anal. Chim. Acta 2010, 669, 1-16.

[21] Kowalski, C. H., Silva, G. A., Poppi, R. J., Godoy, H. T., Augusto, F., Anal. Chim. Acta 2007, 585, 66-75.

[22] Adahchour, M., Beens, J., Vreuls, R. J. J., Brinkman, U. A. T., Trends Anal. Chem. 2006, 25, 821-840.

[23] Mondello, L., Tranchida, P. Q., Dugo, P., Dugo, G., Mass Spectrom. Rev. 2008, 27, 101- 124.

[24] Pedroso, M. P., Godoy, L. A. F., Ferreira, E. C., Poppi, R. J., Augusto, F., J. Chromatogr. A 2008, 1201, 176182.

[25] Tranchida, P. Q., Costa, R., Donato, P., Sciarrone, D., Ragonese, C., Dugo, P., Dugo, G., Mondello, L., J. Sep. Sci. 2008, 31, 3347-3351. 
APÊNDICE A - Tabelas de acuidade visual 
Recém-nascidos adequados para a idade gestacional

\begin{tabular}{|c|c|c|c|c|c|c|c|c|}
\hline idade semanas & Limiar & LogMar & Log(Limiar) & Amplitude Max & Pendente & Fase & Ruido & Pk SNR \\
\hline 8,71 & 9,02 & 0,52 & 0,96 & 3,44 & $-0,19$ & 102,62 & 0,33 & 10,52 \\
\hline 7,57 & 6,37 & 0,67 & 0,8 & 4,71 & $-0,6$ & 63,1 & 0,44 & 10,64 \\
\hline 8,71 & 3,67 & 0,91 & 0,56 & 4 & $-1,06$ & 115,65 & 0,39 & 10,13 \\
\hline 9,57 & 9,96 & 0,48 & 1 & 6,55 & $-0,41$ & $-69,48$ & 0,39 & 16,94 \\
\hline 9,86 & 12,78 & 0,37 & 1,11 & 16,02 & $-0,69$ & 34,67 & 0,46 & 34,8 \\
\hline 8,14 & 5,01 & 0,78 & 0,7 & 1,58 & $-0,44$ & $-32,43$ & 0,36 & 4,4 \\
\hline 10,14 & 10,48 & 0,46 & 1,02 & 8,98 & $-0,42$ & $-64,17$ & 0,51 & 17,72 \\
\hline 8,14 & 6,69 & 0,65 & 0,83 & 4,29 & $-0,46$ & 72,63 & 0,44 & 9,68 \\
\hline 8,14 & 7,58 & 0,60 & 0,88 & 8,37 & $-0,49$ & 30,23 & 0,49 & 17,16 \\
\hline 8,29 & 5,5 & 0,74 & 0,74 & 4,33 & $-0,43$ & 58,67 & 0,25 & 17,28 \\
\hline 12,00 & 11,38 & 0,42 & 1,06 & 2,23 & $-0,13$ & 123,14 & 0,36 & 6,25 \\
\hline 11,86 & 12,06 & 0,40 & 1,08 & 4,44 & $-0,16$ & 87,37 & 0,33 & 13,46 \\
\hline 9,00 & 4,08 & 0,87 & 0,61 & 1,81 & $-0,43$ & $-172,15$ & 0,44 & 4,09 \\
\hline 10,29 & 7,72 & 0,59 & 0,89 & 2,64 & $-0,29$ & 89,14 & 0,32 & 8,11 \\
\hline 10,71 & 9,59 & 0,50 & 0,98 & 8,44 & $-0,34$ & $-2,63$ & 0,38 & 21,95 \\
\hline 8,86 & 4,16 & 0,86 & 0,62 & 7,11 & $-2,38$ & 41,29 & 0,59 & 11,99 \\
\hline 16,00 & 17,18 & 0,24 & 1,23 & 21,76 & $-0,92$ & $-151,6$ & 1,21 & 17,99 \\
\hline 6,43 & 3,07 & 0,99 & 0,49 & 1 & $-0,39$ & $-116,43$ & 0,25 & 4,05 \\
\hline 7,00 & 5,77 & 0,72 & 0,76 & 1,4 & $-0,45$ & 51,5 & 0,42 & 3,34 \\
\hline 7,86 & 4,98 & 0,78 & 0,7 & 5,72 & $-1,59$ & 62,28 & 0,65 & 8,75 \\
\hline 8,57 & 5,13 & 0,77 & 0,71 & 5,81 & $-1,25$ & 32,52 & 0,47 & 12,32 \\
\hline 6,57 & 3,92 & 0,88 & 0,59 & 1,06 & $-0,31$ & $-152,41$ & 0,26 & 4,04 \\
\hline
\end{tabular}


Recém-nascidos adequados para a idade gestacional

\begin{tabular}{|c|c|c|c|c|c|c|c|c|}
\hline idade semanas & Limiar & LogMar & Log(Limiar) & Amplitude Max & Pendente & Fase & Ruido & Pk SNR \\
\hline 6,14 & 3,95 & 0,88 & 0,6 & 1,69 & $-0,49$ & 174,66 & 0,28 & 6,05 \\
\hline 6,71 & 5,21 & 0,76 & 0,72 & 8,5 & $-1,28$ & 43,73 & 0,63 & 13,56 \\
\hline 6,14 & 3,36 & 0,95 & 0,53 & 1,79 & $-0,63$ & $-165,23$ & 0,34 & 5,31 \\
\hline 7,00 & 5,41 & 0,74 & 0,73 & 6,14 & $-0,89$ & 96,46 & 0,53 & 11,79 \\
\hline 7,00 & 3,24 & 0,97 & 0,51 & 1,39 & $-0,51$ & $-74,72$ & 0,25 & 5,58 \\
\hline 13,57 & 7,28 & 0,61 & 0,86 & 11,09 & $-1,77$ & 38,03 & 0,73 & 15,28 \\
\hline 18,86 & 14,31 & 0,32 & 1,16 & 6,21 & $-0,5$ & $-176,65$ & 0,51 & 12,19 \\
\hline 12,57 & 10,59 & 0,45 & 1,02 & 19,86 & $-2,07$ & $-60,92$ & 1,21 & 16,38 \\
\hline 16,43 & 12,52 & 0,38 & 1,1 & 13,54 & $-0,88$ & $-159,37$ & 0,94 & 14,47 \\
\hline 14,00 & 9,79 & 0,49 & 0,99 & 13,3 & $-1,09$ & 2,9 & 0,72 & 18,58 \\
\hline 18,43 & 10,27 & 0,47 & 1,01 & 2 & $-0,22$ & $-156,91$ & 0,38 & 5,3 \\
\hline 18,86 & 15,26 & 0,29 & 1,18 & 3,52 & $-0,27$ & $-176,7$ & 0,65 & 5,46 \\
\hline 11,14 & 7,44 & 0,61 & 0,87 & 6,57 & $-0,59$ & 5,54 & 0,47 & 14,11 \\
\hline 24,00 & 16,62 & 0,26 & 1,22 & 5,88 & $-0,4$ & $-169,42$ & 0,76 & 7,68 \\
\hline 15,00 & 12,4 & 0,38 & 1,09 & 6,25 & $-0,44$ & $-32,83$ & 0,64 & 9,84 \\
\hline 5,86 & 6,14 & 0,69 & 0,79 & 3,05 & $-0,54$ & 87,6 & 0,31 & 9,94 \\
\hline 11,71 & 7,95 & 0,58 & 0,9 & 4,33 & $-0,37$ & 60,26 & 0,38 & 11,36 \\
\hline 10,71 & 9,39 & 0,50 & 0,97 & 10 & $-1,19$ & 17,09 & 0,63 & 15,91 \\
\hline 9,86 & 9,44 & 0,50 & 0,98 & 7,16 & $-0,85$ & 18,91 & 0,78 & 9,24 \\
\hline 11,71 & 7,53 & 0,60 & 0,88 & 17,77 & $-2,72$ & $-34,07$ & 1,34 & 13,19 \\
\hline 11,71 & 11,48 & 0,42 & 1,06 & 7,88 & $-0,75$ & $-40,21$ & 0,61 & 12,85 \\
\hline 12,71 & 7,28 & 0,61 & 0,86 & 6,67 & $-0,84$ & $-26,95$ & 0,55 & 12,14 \\
\hline
\end{tabular}


Recém-nascidos adequados para a idade gestacional

\begin{tabular}{|c|c|c|c|c|c|c|c|c|}
\hline idade semanas & Limiar & LogMar & Log(Limiar) & Amplitude Max & Pendente & Fase & Ruido & Pk SNR \\
\hline 7,00 & 5,22 & 0,76 & 0,72 & 1,17 & $-0,25$ & $-9,28$ & 0,26 & 4,57 \\
\hline 7,00 & 4,17 & 0,86 & 0,62 & 1,38 & $-0,37$ & $-4,84$ & 0,21 & 6,6 \\
\hline 7,00 & 6,47 & 0,67 & 0,81 & 0,73 & $-0,12$ & 165,11 & 0,19 & 3,96 \\
\hline 12,86 & 6,67 & 0,65 & 0,82 & 4,91 & $-0,87$ & $-9,02$ & 1,03 & 4,56 \\
\hline 19,43 & 14,18 & 0,33 & 1,15 & 6,24 & $-0,51$ & $-167,61$ & 0,56 & 11,09 \\
\hline 19,70 & 14,26 & 0,32 & 1,15 & 17,86 & $-1,46$ & $-168,15$ & 0,91 & 19,59 \\
\hline 11,14 & 9 & 0,52 & 0,95 & 13,17 & $-0,72$ & 25,61 & 0,65 & 20,35 \\
\hline 14,57 & 7,21 & 0,62 & 0,86 & 3,31 & $-0,53$ & $-15,34$ & 0,64 & 5,18 \\
\hline 14,43 & 9,93 & 0,48 & 1 & 21,18 & $-1,7$ & $-81,56$ & 1,01 & 20,99 \\
\hline 21,00 & 18,78 & 0,20 & 1,27 & 7,29 & $-0,36$ & $-158,62$ & 0,47 & 15,68 \\
\hline 14,57 & 6,45 & 0,67 & 1,11 & 5,35 & $-0,77$ & $-153,02$ & 0,69 & 7,73 \\
\hline 7,71 & 5,67 & 0,72 & 0,75 & 2,64 & $-0,78$ & 41,16 & 0,48 & 5,54 \\
\hline 20,71 & 13,73 & 0,34 & 1,14 & 8,86 & $-0,86$ & 142,17 & 0,92 & 9,64 \\
\hline 15,71 & 11,77 & 0,41 & 1,07 & 5,7 & $-0,33$ & $-135,2$ & 0,45 & 12,75 \\
\hline 14,43 & 10,34 & 0,46 & 1,32 & 15,36 & $-0,87$ & $-114,16$ & 1,06 & 14,55 \\
\hline 11,14 & 10,63 & 0,45 & 1,03 & 7,37 & $-0,38$ & $-2,51$ & 0,52 & 14,05 \\
\hline 7,71 & 5,78 & 0,72 & 0,76 & 1,22 & $-0,16$ & $-164,22$ & 0,17 & 7,29 \\
\hline 17,71 & 18,23 & 0,22 & 1,26 & 24,98 & $-0,42$ & $-162,57$ & 0,98 & 25,46 \\
\hline 12,30 & 9,75 & 0,49 & 0,99 & 7,39 & $-0,54$ & 73,05 & 0,4 & 18,53 \\
\hline 11,14 & 6,96 & 0,63 & 0,84 & 2,35 & $-0,28$ & 65,02 & 0,37 & 6,28 \\
\hline 12,29 & 11,45 & 0,42 & 1,06 & 21,96 & $-1,45$ & $-39,99$ & 1,15 & 19,1 \\
\hline 5,70 & 4,19 & 0,85 & 0,62 & 1,77 & $-0,48$ & $-138,04$ & 0,22 & 8,22 \\
\hline
\end{tabular}


Recém-nascidos adequados para a idade gestacional

\begin{tabular}{ccccccccc}
\hline idade semanas & Limiar & LogMar & Log(Limiar) & Amplitude Max & Pendente & Fase & Ruido & Pk SNR \\
\hline 7,00 & 4,57 & 0,82 & 0,66 & 2,66 & $-0,42$ & 123,55 & 0,38 & 6,97 \\
7,29 & 4,69 & 0,81 & 0,67 & 6,56 & $-0,71$ & 25,9 & 0,42 & 15,7 \\
8,00 & 14,13 & 0,33 & 1,15 & 10,2 & $-0,26$ & 37,54 & 0,3 & 34,32 \\
9,00 & 7,31 & 0,61 & 0,86 & 12,34 & $-0,96$ & $-43,58$ & 0,7 & 17,65 \\
9,14 & 7,63 & 0,59 & 0,88 & 3,05 & $-0,15$ & 155,83 & 0,26 & 11,95 \\
16,86 & 12,81 & 0,37 & 1,11 & 15,88 & $-0,68$ & $-166,01$ & 0,8 & 19,94 \\
7,43 & 3,52 & 0,93 & 0,55 & 0,94 & $-0,31$ & 0,83 & 0,17 & 5,54 \\
\hline
\end{tabular}


Recém-nascidos pequenos para a idade gestacional

\begin{tabular}{|c|c|c|c|c|c|c|c|c|}
\hline Idade natal semanas & Limiar & LogMar & Log(Limiar) & Amplitude Max. & Pendente & Fase & Ruido & Pk SNR \\
\hline 8,57 & 4,53 & 0,82 & 0,66 & 1,92 & $-0,61$ & $-26,26$ & 0,48 & 3,97 \\
\hline 8,43 & 4,42 & 0,83 & 0,65 & 4,17 & $-1,37$ & 66,93 & 0,67 & 6,24 \\
\hline 6,86 & 7,25 & 0,62 & 0,86 & 7,86 & $-0,6$ & 28,26 & 0,5 & 15,82 \\
\hline 9,00 & 10,16 & 0,47 & 1,01 & 7,53 & $-0,36$ & 43,14 & 0,44 & 16,93 \\
\hline 8,86 & 8,59 & 0,54 & 0,93 & 5,3 & $-0,74$ & 19,54 & 0,66 & 8,08 \\
\hline 8,43 & 3,98 & 0,88 & 0,6 & 1,9 & $-0,55$ & 172,89 & 0,31 & 6,06 \\
\hline 7,00 & 3,93 & 0,88 & 0,59 & 2,18 & $-0,49$ & $-171,62$ & 0,26 & 8,32 \\
\hline 7,71 & 3,34 & 0,95 & 0,52 & 2,61 & $-0,92$ & 85,22 & 0,31 & 8,53 \\
\hline 7,00 & 3,33 & 0,95 & 0,52 & 0,74 & $-0,26$ & 58,04 & 0,16 & 4,63 \\
\hline 5,86 & 3,94 & 0,88 & 0,6 & 1,07 & $-0,31$ & $-73,66$ & 0,3 & 3,59 \\
\hline 6,29 & 5,64 & 0,73 & 0,75 & 2,26 & $-0,23$ & 177,9 & 0,26 & 8,68 \\
\hline 6,71 & 4,38 & 0,84 & 0,64 & 3,31 & $-0,85$ & 66,58 & 0,38 & 8,64 \\
\hline 5,86 & 6,43 & 0,67 & 0,81 & 2,07 & $-0,35$ & 95,44 & 0,38 & 5,47 \\
\hline 12,43 & 8,18 & 0,56 & 0,91 & 8,86 & $-1,58$ & $-25,41$ & 0,74 & 11,99 \\
\hline 12,00 & 13,5 & 0,35 & 1,13 & 5,26 & $-0,22$ & 20,51 & 0,56 & 9,41 \\
\hline 22,43 & 20,52 & 0,16 & 1,31 & 19,82 & $-0,64$ & 153 & 1 & 18,82 \\
\hline 6,43 & 4,47 & 0,83 & 0,65 & 0,91 & $-0,23$ & $-171,85$ & 0,18 & 5,14 \\
\hline 6,29 & 5,44 & 0,74 & 0,74 & 1,85 & $-0,27$ & $-179,67$ & 0,27 & 6,91 \\
\hline 10,00 & 10,28 & 0,47 & 1,01 & 1,63 & $-0,18$ & 4,26 & 0,46 & 3,57 \\
\hline 6,14 & 3,73 & 0,91 & 0,57 & 0,83 & $-0,36$ & 160,99 & 0,18 & 4,68 \\
\hline 5,86 & 4,64 & 0,81 & 0,67 & 2,3 & $-0,56$ & 26,15 & 0,36 & 6,41 \\
\hline 11,40 & 12,93 & 0,37 & 1,11 & 9,81 & $-0,5$ & $-90,32$ & 0,59 & 16,6 \\
\hline 6,43 & 5,95 & 0,70 & 0,77 & 1,11 & $-0,21$ & 147,55 & 0,29 & 3,84 \\
\hline 6,71 & 4,1 & 0,86 & 0,61 & 2,94 & $-1,09$ & 91,56 & 0,64 & 4,57 \\
\hline 18,00 & 8,99 & 0,52 & 0,95 & 11,56 & $-1,45$ & $-129,19$ & 0,64 & 18,76 \\
\hline 6,71 & 6,96 & 0,63 & 0,84 & 4,24 & $-0,57$ & 108,34 & 0,5 & 8,4 \\
\hline 19,29 & 12,75 & 0,37 & 1,11 & 8,37 & $-0,78$ & 163,83 & 0,68 & 12,26 \\
\hline 7,57 & 4,21 & 0,85 & 0,62 & 3,81 & $-1,03$ & 175,29 & 0,44 & 8,6 \\
\hline 15,00 & 9,74 & 0,49 & 0,99 & 20,71 & $-1,31$ & $-28,09$ & 1,01 & 20,56 \\
\hline
\end{tabular}


Recém-nascidos pequenos para a idade gestacional

\begin{tabular}{|c|c|c|c|c|c|c|c|c|}
\hline Idade natal semanas & Limiar & LogMar & Log(Limiar) & Amplitude Max. & Pendente & Fase & Ruido & Pk SNR \\
\hline 12,29 & 7,87 & 0,58 & 0,9 & 17,36 & $-0,94$ & $-82,58$ & 0,64 & 26,74 \\
\hline 8,00 & 9,42 & 0,50 & 0,97 & 4,07 & $-0,34$ & 147,47 & 0,39 & 10,34 \\
\hline 16,71 & 12,37 & 0,38 & 1,09 & 10,59 & $-0,71$ & $-60,28$ & 0,69 & 15,31 \\
\hline 10,71 & 9,16 & 0,52 & 0,96 & 7,13 & $-0,49$ & 94,43 & 0,41 & 17,51 \\
\hline 8,43 & 5,86 & 0,71 & 0,77 & 5,75 & $-0,76$ & 40,29 & 0,34 & 17,02 \\
\hline 14,43 & 10,19 & 0,47 & 1,01 & 13,6 & $-0,78$ & $-43,18$ & 0,64 & 21,25 \\
\hline 7,71 & 6,71 & 0,65 & 0,83 & 1,78 & $-0,32$ & $-152,92$ & 0,25 & 7,24 \\
\hline 13,43 & 13,16 & 0,36 & 1,12 & 4,47 & $-0,16$ & $-22,94$ & 0,35 & 12,72 \\
\hline 10,00 & 9,45 & 0,50 & 0,98 & 8,74 & $-0,69$ & $-4,45$ & 0,61 & 14,27 \\
\hline 11,00 & 7,69 & 0,59 & 0,89 & 8,75 & $-1,31$ & $-60,32$ & 0,43 & 20,6 \\
\hline 15,43 & 14,5 & 0,32 & 1,16 & 10,62 & $-0,44$ & $-57,88$ & 0,86 & 12,28 \\
\hline 11,57 & 7,87 & 0,58 & 0,9 & 8,24 & $-0,75$ & $-4,93$ & 0,44 & 18,64 \\
\hline 11,71 & 10,25 & 0,47 & 1,01 & 3,45 & $-0,37$ & $-40,11$ & 0,37 & 9,29 \\
\hline 8,00 & 4,43 & 0,83 & 0,65 & 2,36 & $-0,6$ & 90,39 & 0,38 & 6,25 \\
\hline 7,30 & 6,61 & 0,66 & 0,82 & 4,13 & $-0,58$ & 119,51 & 0,47 & 8,7 \\
\hline 9,00 & 4,5 & 0,82 & 0,65 & 4,75 & $-1,53$ & 26,6 & 0,31 & 15,45 \\
\hline 12,43 & 6,25 & 0,68 & 0,8 & 6,58 & $-1,25$ & 31,85 & 0,54 & 12,15 \\
\hline 8,29 & 5,42 & 0,74 & 0,73 & 2,05 & $-0,42$ & 66,2 & 0,44 & 4,67 \\
\hline 6,14 & 9,25 & 0,51 & 0,97 & 4,18 & $-0,34$ & 86,2 & 0,41 & 10,25 \\
\hline 7,86 & 4,2 & 0,85 & 0,62 & 0,82 & $-0,22$ & $-128,72$ & 0,26 & 3,14 \\
\hline 8,14 & 7,36 & 0,61 & 0,87 & 2,31 & $-0,34$ & 60,84 & 0,42 & 5,5 \\
\hline 14,71 & 10,79 & 0,44 & 1,03 & 4,3 & $-0,44$ & $-123,76$ & 0,43 & 9,92 \\
\hline 9,29 & 7,66 & 0,59 & 0,88 & 1,07 & $-0,11$ & 77,08 & 0,07 & 15,65 \\
\hline 8,71 & 7,46 & 0,60 & 0,87 & 4,27 & $-0,39$ & 54,31 & 0,45 & 9,53 \\
\hline
\end{tabular}


APÊNDICE B - Tabelas de Sensibilidade ao contraste 
Recém-nascidos adequados para a idade gestacional

\begin{tabular}{|c|c|c|c|c|c|c|c|}
\hline Idade semanas & Limiar & SC X 100 & Amplitude Max. & Pendente & Fase (graus) & Ruido (microvolts) & Pk SNR \\
\hline 8,71 & 2,15 & 46,54 & 1,51 & 1,42 & 104,92 & 0,25 & 5,93 \\
\hline 7,57 & 4,41 & 22,67 & 2,49 & 4,53 & 128,07 & 0,37 & 6,69 \\
\hline 8,71 & 0,88 & 113,35 & 2,45 & 1,1 & $-174,58$ & 0,28 & 8,66 \\
\hline 9,57 & 0,33 & 300,61 & 0,99 & 0,69 & $-67,64$ & 0,14 & 6,94 \\
\hline 9,86 & 4,87 & 20,52 & 1,79 & 2,53 & 103,81 & 0,29 & 6,11 \\
\hline 8,14 & 6,74 & 14,84 & 1,21 & 2,13 & 153,62 & 0,28 & 4,33 \\
\hline 10,14 & 0,26 & 382,46 & 2,65 & 1,95 & $-148,75$ & 0,4 & 6,56 \\
\hline 8,14 & 2,35 & 42,56 & 2,18 & 1,29 & 128,7 & 0,25 & 8,59 \\
\hline 8,14 & 2,05 & 48,71 & 1,44 & 1,35 & $-12,91$ & 0,23 & 6,24 \\
\hline 8,29 & 4,38 & 22,81 & 2,92 & 3,86 & 76,99 & 0,58 & 5,03 \\
\hline 12,00 & 0,8 & 124,62 & 1,41 & 1,29 & 81,95 & 0,25 & 5,69 \\
\hline 11,86 & 0,49 & 203,46 & 1,59 & 0,93 & 99,58 & 0,29 & 5,49 \\
\hline 10,29 & 1,23 & 81,16 & 2,07 & 1,58 & $-179,04$ & 0,29 & 7,19 \\
\hline 10,71 & 2,5 & 40,02 & 4,56 & 4,56 & $-74,64$ & 0,63 & 7,23 \\
\hline 8,86 & 1,79 & 55,93 & 2,45 & 3,67 & 127,46 & 0,33 & 7,38 \\
\hline 16,00 & 0,45 & 222,78 & 17,06 & 4,61 & $-172,75$ & 1,24 & 13,76 \\
\hline 6,43 & 2,93 & 34,17 & 0,98 & 3,12 & 137,84 & 0,24 & 4,01 \\
\hline 7,86 & 0,93 & 107,83 & 1,59 & 2,52 & 101,15 & 0,32 & 4,96 \\
\hline 8,57 & 2,87 & 34,79 & 2,83 & 3,9 & 25,35 & 0,46 & 6,07 \\
\hline 6,71 & 1,96 & 50,98 & 2,98 & 2,7 & 97,81 & 0,49 & 6,11 \\
\hline 6,14 & 1,57 & 63,86 & 1,25 & 1,04 & $-133,85$ & 0,32 & 3,85 \\
\hline 7,00 & 1,21 & 82,97 & 5,18 & 2,22 & 115,25 & 0,37 & 14 \\
\hline 13,57 & 1,22 & 81,83 & 4,62 & 3,52 & 36,87 & 0,55 & 8,4 \\
\hline
\end{tabular}


Recém-nascidos adequados para a idade gestacional

\begin{tabular}{|c|c|c|c|c|c|c|c|}
\hline Idade semanas & Limiar & SC $\times 100$ & Amplitude Max. & Pendente & Fase & Ruido & Pk SNR \\
\hline 18,86 & 0,35 & 288,01 & 2,54 & 1 & 139,4 & 0,45 & 5,7 \\
\hline 12,57 & 0,6 & 165,33 & 6,11 & 3,78 & $-97,6$ & 0,76 & 8,01 \\
\hline 16,43 & 0,48 & 209,24 & 1,87 & 2,25 & $-78,54$ & 0,5 & 3,71 \\
\hline 14,00 & 0,77 & 129,71 & 1,8 & 1,38 & $-60,13$ & 0,55 & 3,29 \\
\hline 18,43 & 1,65 & 60,71 & 1,71 & 1,77 & $-169,39$ & 0,29 & 5,9 \\
\hline 18,86 & 0,62 & 160,62 & 5,43 & 3,39 & 136,15 & 0,57 & 9,56 \\
\hline 11,14 & 1,76 & 56,92 & 4,16 & 3,61 & 9,87 & 0,53 & 7,81 \\
\hline 24,00 & 1,76 & 56,86 & 2,97 & 2,58 & 130,49 & 0,62 & 4,8 \\
\hline 15,00 & 0,31 & 327,69 & 2,22 & 1,16 & $-55,12$ & 0,44 & 5,11 \\
\hline 5,86 & 4,13 & 24,19 & 2,72 & 3,49 & 103,2 & 0,28 & 9,77 \\
\hline 11,71 & 0,23 & 426,12 & 1,06 & 0,75 & $-26,04$ & 0,28 & 3,82 \\
\hline 10,71 & 1,2 & 83,23 & 3,05 & 2,32 & $-10,35$ & 0,33 & 9,17 \\
\hline 9,86 & 0,49 & 203,51 & 1,96 & 1,15 & 32,4 & 0,44 & 4,44 \\
\hline 11,71 & 1,7 & 58,96 & 6,9 & 5,9 & $-29,83$ & 1,17 & 5,88 \\
\hline 11,71 & 1,25 & 80,25 & 4,43 & 4,48 & $-7,34$ & 0,48 & 9,27 \\
\hline 12,71 & 3,1 & 32,24 & 2,85 & 3,14 & $-38,53$ & 0,35 & 8,16 \\
\hline 7,00 & 0,5 & 199,83 & 1,03 & 1,54 & $-101,39$ & 0,32 & 3,25 \\
\hline 12,86 & 0,98 & 101,74 & 2,82 & 2 & $-72,47$ & 0,83 & 3,34 \\
\hline 19,43 & 0,34 & 298,24 & 5,58 & 2,19 & 156,86 & 0,75 & 7,41 \\
\hline 19,70 & 0,47 & 215,01 & 10,59 & 6,98 & 172,88 & 1,05 & 10,44 \\
\hline 11,14 & 0,28 & 360,18 & 5,09 & 1,93 & 16,91 & 0,45 & 11,39 \\
\hline 14,57 & 0,33 & 305,48 & 4,03 & 2,95 & $-98,69$ & 0,52 & 7,82 \\
\hline 14,43 & 0,5 & 198,72 & 7,1 & 2,49 & $-151,39$ & 0,66 & 10,71 \\
\hline
\end{tabular}


Recém-nascidos adequados para a idade gestacional

\begin{tabular}{|c|c|c|c|c|c|c|c|}
\hline Idade semanas & Limiar & SC X 100 & Amplitude Max. & Pendente & Fase & Ruido & Pk SNR \\
\hline 21,00 & 0,44 & 226,74 & 3,98 & 1,26 & 128,82 & 0,32 & 12,38 \\
\hline 7,71 & 0,99 & 101,08 & 1,38 & 1,82 & 171,21 & 0,41 & 3,41 \\
\hline 20,71 & 0,86 & 116,64 & 16,02 & 9,67 & 111,49 & 0,61 & 26,26 \\
\hline 15,71 & 0,37 & 269,32 & 6,4 & 2,31 & 178,99 & 0,66 & 9,68 \\
\hline 11,14 & 2,45 & 40,78 & 1,97 & 1,96 & 21,25 & 0,39 & 5,04 \\
\hline 7,71 & 0,36 & 279,02 & 1,33 & 0,72 & 141,91 & 0,18 & 7,28 \\
\hline 17,71 & 4,29 & 23,33 & 6,62 & 8,65 & 133,07 & 0,66 & 10,01 \\
\hline 12,30 & 2,82 & 35,46 & 2,71 & 2,85 & 73,16 & 0,39 & 6,96 \\
\hline 11,14 & 5,01 & 19,94 & 1,79 & 2,56 & 72,47 & 0,3 & 5,88 \\
\hline 12,29 & 0,4 & 251,85 & 2,6 & 2,75 & $-154,52$ & 0,75 & 3,46 \\
\hline 5,70 & 2,38 & 42,06 & 0,62 & 0,61 & 34,27 & 0,13 & 4,66 \\
\hline 7,00 & 1,44 & 69,38 & 1,52 & 1,23 & 151,12 & 0,35 & 4,31 \\
\hline 7,29 & 3,6 & 27,77 & 2,65 & 3,15 & 10,36 & 0,46 & 5,82 \\
\hline 8,00 & 2,37 & 42,23 & 2,02 & 1,97 & 17,06 & 0,32 & 6,28 \\
\hline 9,00 & 1,81 & 55,26 & 3,13 & 1,92 & 45,7 & 0,44 & 7,11 \\
\hline 9,14 & 1,65 & 60,57 & 3,38 & 2,86 & $-174,88$ & 0,35 & 9,66 \\
\hline 16,86 & 0,45 & 223,47 & 10,35 & 5,92 & 141,75 & 0,6 & 17,37 \\
\hline 7,43 & 1,23 & 81,12 & 1,05 & 0,8 & 57,92 & 0,27 & 3,95 \\
\hline
\end{tabular}


Recém-nascidos pequenos para a idade gestacional

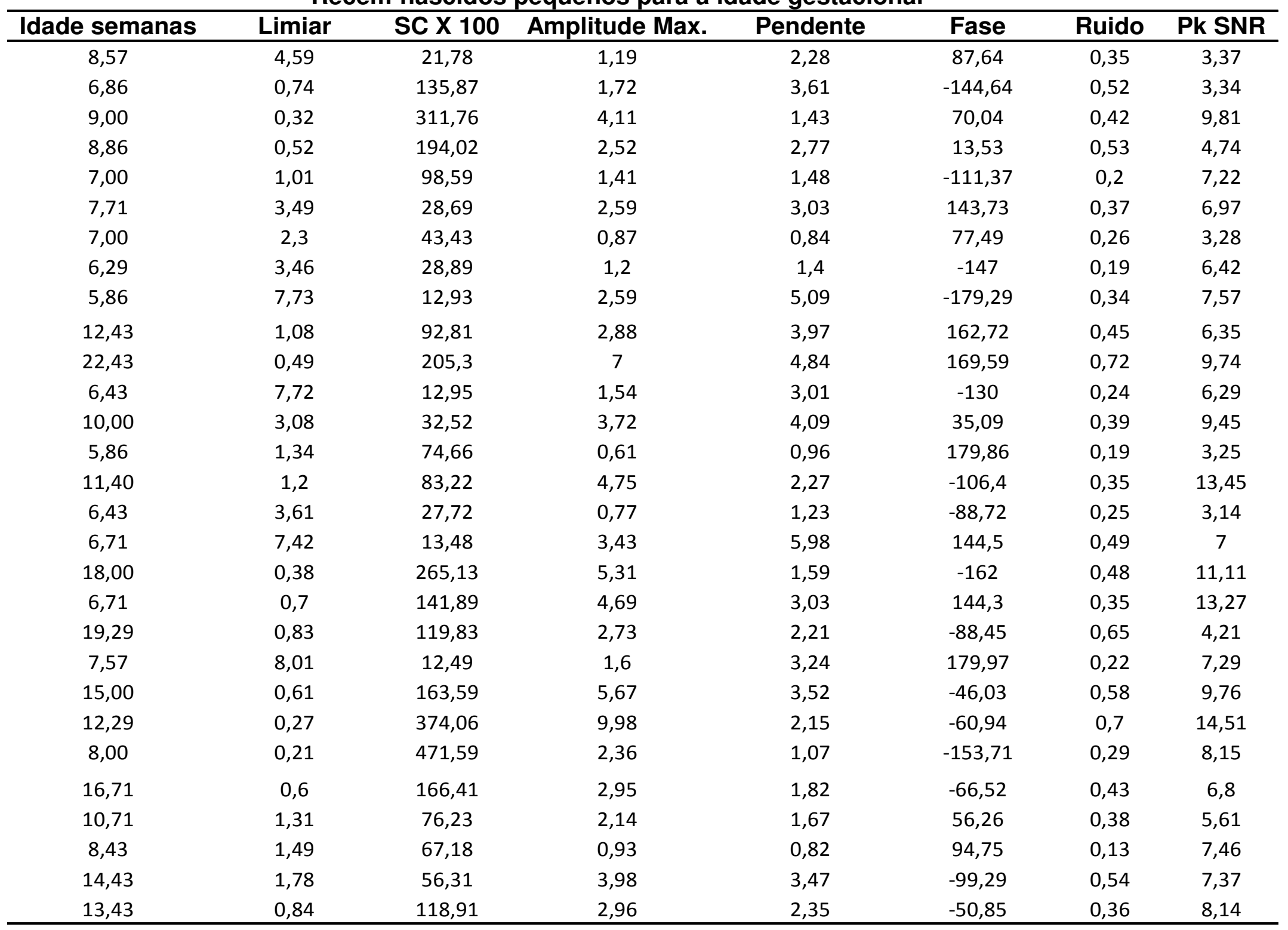


Recém-nascidos pequenos para a idade gestacional

\begin{tabular}{cccccccc}
\hline Idade semanas & Limiar & SC X 100 & Amplitude Max. & Pendente & Fase & Ruido & Pk SNR \\
\hline 10,00 & 1,17 & 85,57 & 7,58 & 5,7 & $-32,89$ & 0,88 & 8,64 \\
11,00 & 0,58 & 173,21 & 5,3 & 8,23 & 123,73 & 0,54 & 9,85 \\
15,43 & 0,73 & 137,53 & 4,26 & 2,75 & $-84,72$ & 0,42 & 10,06 \\
11,57 & 1,76 & 56,91 & 2,59 & 2,24 & 24,64 & 0,29 & 8,92 \\
11,71 & 1,58 & 63,17 & 7,75 & 8,28 & $-90,52$ & 0,38 & 20,56 \\
8,00 & 10,97 & 9,11 & 1,02 & 2,34 & 105,13 & 0,24 & 4,21 \\
7,30 & 0,31 & 319,94 & 1,19 & 1,02 & $-111,99$ & 0,39 & 3,05 \\
9,00 & 7,02 & 14,25 & 1,15 & 2,08 & 167,97 & 0,25 & 4,51 \\
12,43 & 2,12 & 47,13 & 1,81 & 1,69 & 49,69 & 0,27 & 6,65 \\
8,29 & 1,93 & 51,95 & 1,12 & 1,33 & 82,1 & 0,24 & 4,68 \\
6,14 & 4,92 & 20,34 & 1,22 & 1,73 & 119,05 & 0,32 & 3,83 \\
7,86 & 7,48 & 13,37 & 0,89 & 1,69 & $-112,53$ & 0,18 & 4,97 \\
8,14 & 0,58 & 173,15 & 1,36 & 1,28 & 117 & 0,36 & 3,74 \\
14,71 & 1,78 & 56,28 & 4,12 & 4,27 & 171,32 & 0,48 & 8,66 \\
9,29 & 0,63 & 158,13 & 3,37 & 1,11 & 145,42 & 0,31 & 11,01 \\
8,71 & 2,14 & 46,69 & 0,38 & 0,35 & $-53,01$ & 0,08 & 4,9 \\
\hline
\end{tabular}


APÊNDICE C - Tabelas com as medidas antropométricas dos recém nascidos 
Recém-nascidos adequados para a idade gestacional

\begin{tabular}{|c|c|c|c|c|c|c|c|c|c|c|c|c|}
\hline $\begin{array}{l}\text { Código do } \\
\text { bebêe }\end{array}$ & Gênero & $\begin{array}{c}\text { Idade } \\
\text { Gestacio } \\
\text { nal }\end{array}$ & $\begin{array}{c}\text { Idade no } \\
\text { teste } \\
\text { (sem) }\end{array}$ & $\begin{array}{c}\text { APGAR } \\
1^{\prime}\end{array}$ & $\begin{array}{c}\text { APGAR } \\
5^{\prime}\end{array}$ & $\begin{array}{c}\text { Peso ao } \\
\text { nascer } \\
\text { (gramas) }\end{array}$ & $\begin{array}{c}\text { Peso no } \\
\text { teste } \\
\text { (gamas) }\end{array}$ & $\begin{array}{c}\text { Compri } \\
\text { mento ao } \\
\text { nascer } \\
\text { (cm) }\end{array}$ & $\begin{array}{c}\text { Compri } \\
\text { mento no } \\
\text { teste } \\
(\mathrm{cm})\end{array}$ & $\begin{array}{c}\text { Crânio } \\
\text { ao } \\
\text { nascer } \\
(\mathrm{cm})\end{array}$ & $\begin{array}{c}\text { Crânio } \\
\text { no teste } \\
(\mathrm{cm})\end{array}$ & $\begin{array}{c}\text { Índice } \\
\text { Ponderal }\end{array}$ \\
\hline 14 & $\mathrm{M}$ & $405 / 7$ & 6,29 & 9 & 10 & 3640 & 5400 & 51 & 58,5 & 36 & 38 & 2,74 \\
\hline 13 & M & $395 / 7$ & 6,6 & 9 & 9 & 3010 & & 50,5 & & 34 & & 2,34 \\
\hline 15 & $\mathrm{~F}$ & $381 / 7$ & 7 & 9 & 9 & 3445 & 5050 & 48,5 & 57 & 35,5 & 39 & 3,02 \\
\hline 16 & M & $401 / 7$ & 7 & 5 & 9 & 3950 & 5600 & 50 & 58,5 & 36 & 40 & 3,16 \\
\hline 21 & M & $401 / 7$ & 7,71 & 7 & 9 & 3535 & 6100 & 50 & 59 & 36 & 41 & 2,83 \\
\hline 23 & $\mathrm{~F}$ & $392 / 7$ & 8,57 & 8 & 10 & 3175 & 4200 & 49 & 54 & 35 & 39 & 2,70 \\
\hline 45 & M & $39^{1 / 7}$ & 11,25 & 10 & 10 & 3160 & 5900 & 50 & 60 & 35 & 40 & 2,53 \\
\hline 26 & F & $403 / 7$ & 11,57 & 9 & 10 & 3075 & 5693 & 47,5 & 57 & 34,5 & 39 & 2,87 \\
\hline 36 & M & $392 / 7$ & 12 & 9 & 10 & 3080 & 5192 & 51 & 57 & 33 & 39 & 2,32 \\
\hline 19 & M & $373 / 7$ & 13,57 & 9 & 10 & 2750 & 5500 & 48 & 61,5 & 33 & 41 & 2,49 \\
\hline 38 & M & $371 / 7$ & 14,14 & 9 & 10 & 3350 & 6260 & 48 & 58 & 35 & 41 & 3,03 \\
\hline 39 & M & 38 & 15 & 10 & 10 & 2800 & 5100 & 48 & 58 & 32 & 37,5 & 2,53 \\
\hline 37 & F & $385 / 7$ & 16,42 & 8 & 9 & 3440 & 7600 & 49 & 63 & 34 & 40 & 2,92 \\
\hline 40 & $\mathrm{M}$ & $413 / 7$ & 18,43 & 8 & 10 & 3200 & 6700 & 49 & 62 & 35 & 41 & 2,72 \\
\hline 17 & $\mathrm{~F}$ & $393 / 7$ & 19 & 9 & 10 & 3205 & 5150 & 49 & 61 & 34 & 40 & 2,72 \\
\hline 41 & $\mathrm{~F}$ & $391 / 7$ & 19 & 9 & 10 & 3140 & 6650 & 49,5 & 62,5 & 34 & 40 & 2,59 \\
\hline 43 & $\mathrm{M}$ & $395 / 7$ & 19,43 & 9 & 10 & 3130 & 6705 & 51 & 64 & 35 & 43 & 2,36 \\
\hline 46 & M & $384 / 7$ & 24 & 10 & 10 & 3285 & 7780 & 49,5 & 66,5 & 34 & 43 & 2,71 \\
\hline 51 & $\mathrm{M}$ & $384 / 7$ & 6,14 & 9 & 10 & 3415 & & 47 & & 34 & & 3,29 \\
\hline 52 & $\mathrm{~F}$ & $391 / 7$ & 6,71 & 9 & 10 & 3920 & 4850 & 52 & 59 & 34 & 37 & 2,79 \\
\hline 53 & $\mathrm{M}$ & $376 / 7$ & 6,14 & 9 & 9 & 3205 & 4145 & 48,5 & 53 & 34,5 & 39 & 2,81 \\
\hline 57 & M & $402 / 7$ & 7 & 9 & 10 & 3680 & 5230 & 49 & 55 & 34 & 37 & 3,13 \\
\hline 56 & $\mathrm{~F}$ & $386 / 7$ & 5,86 & 9 & 10 & 2915 & 4700 & 47 & 57 & 34 & 38 & 2,81 \\
\hline 49 & $\mathrm{~F}$ & $391 / 7$ & 12,71 & 9 & 10 & 2980 & 6000 & 48 & 56 & 32 & 40 & 2,69 \\
\hline 60 & $\mathrm{~F}$ & $395 / 7$ & 6 & 9 & 10 & 2920 & 4500 & 47 & 54 & 33 & 38 & 2,81 \\
\hline
\end{tabular}


Recém-nascidos adequados para a idade gestacional

\begin{tabular}{|c|c|c|c|c|c|c|c|c|c|c|c|c|}
\hline $\begin{array}{l}\text { Código do } \\
\text { bebêe }\end{array}$ & Gênero & $\begin{array}{c}\text { Idade } \\
\text { Gestacio } \\
\text { nal }\end{array}$ & $\begin{array}{c}\text { Idade no } \\
\text { teste } \\
\text { (sem) }\end{array}$ & $\begin{array}{c}\text { APGAR } \\
1^{\prime}\end{array}$ & $\begin{array}{c}\text { APGAR } \\
5^{\prime}\end{array}$ & $\begin{array}{c}\text { Peso ao } \\
\text { nascer } \\
\text { (gramas) }\end{array}$ & $\begin{array}{c}\text { Peso no } \\
\text { teste } \\
\text { (gamas) }\end{array}$ & $\begin{array}{c}\text { Compri } \\
\text { mento ao } \\
\text { nascer } \\
\text { (cm) }\end{array}$ & $\begin{array}{c}\text { Compri } \\
\text { mento no } \\
\text { teste } \\
\text { (cm) }\end{array}$ & $\begin{array}{c}\text { Crânio } \\
\text { ao } \\
\text { nascer } \\
\text { (cm) }\end{array}$ & $\begin{array}{c}\text { Crânio } \\
\text { no teste } \\
\text { (cm) }\end{array}$ & $\begin{array}{c}\text { Índice } \\
\text { Ponderal }\end{array}$ \\
\hline 61 & $\mathrm{M}$ & $394 / 7$ & 12 & 9 & 10 & 3920 & & 50 & & 33 & & 3,14 \\
\hline 62 & $\mathrm{~F}$ & $381 / 7$ & 10 & 3 & 8 & 2880 & 4920 & 42,5 & 56,5 & 34 & 38,5 & 3,75 \\
\hline 63 & $\mathrm{~F}$ & $385 / 7$ & 10 & 10 & 10 & 2835 & 5000 & 48 & 58,5 & 34 & 40 & 2,56 \\
\hline 64 & $\mathrm{~F}$ & $382 / 7$ & 12 & 9 & 10 & 2925 & 4950 & 47 & 60 & 35 & 38 & 2,82 \\
\hline 65 & M & $402 / 7$ & 12 & 10 & 10 & 3460 & 5900 & 50 & 61 & 36 & 43 & 2,77 \\
\hline 66 & M & $386 / 7$ & 12 & 9 & 9 & 3450 & 6120 & 46 & 58 & 36 & 41 & 3,54 \\
\hline 67 & $\mathrm{~F}$ & $376 / 7$ & 12 & 9 & 10 & 3015 & & 47 & & 35 & & 2,90 \\
\hline 70 & M & 37 & 7 & 10 & 10 & 3015 & 4150 & 48 & 53 & 34 & 40 & 2,73 \\
\hline 71 & M & $383 / 7$ & 7 & 10 & 10 & 3270 & & 49 & & 35 & & 2,78 \\
\hline 72 & M & $383 / 7$ & 7 & 9 & 10 & 3100 & & 48 & & 34,5 & & 2,80 \\
\hline 73 & M & $382 / 7$ & 6 & 9 & 10 & 3445 & 4490 & 51 & 54,5 & 34 & 38 & 2,60 \\
\hline 75 & M & $372 / 7$ & 12 & 10 & 10 & 3005 & 7000 & 46 & 58 & 33 & 40 & 3,09 \\
\hline 77 & M & 39 & 12 & 9 & 10 & 4020 & 6480 & 52 & 60 & 32 & 41 & 2,86 \\
\hline 78 & $\mathrm{M}$ & $413 / 7$ & 11 & 6 & 8 & 3245 & 5700 & 52 & 58,5 & 35 & 41 & 2,31 \\
\hline 79 & $\mathrm{~F}$ & $382 / 7$ & 19 & 8 & 9 & 3080 & 6700 & 50 & 60 & 34 & 41,5 & 2,46 \\
\hline 86 & $\mathrm{~F}$ & $401 / 7$ & 20 & 8 & 10 & 3540 & & 49 & & 35 & & 3,01 \\
\hline 87 & $\mathrm{~F}$ & 38 & 13 & 9 & 9 & 3090 & 6150 & 50 & 58 & 34,5 & 40 & 2,47 \\
\hline 88 & $\mathrm{M}$ & 41 1/7 & 7 & 8 & 9 & 3760 & & 53 & & 37 & & 2,53 \\
\hline 89 & $\mathrm{~F}$ & $385 / 7$ & 11 & 10 & 10 & 3185 & 5600 & 49,5 & 57 & 34 & 37 & 2,63 \\
\hline 90 & $\mathrm{~F}$ & $402 / 7$ & 11 & 9 & 10 & 3010 & 5700 & 47 & 59 & 35,5 & 40,5 & 2,90 \\
\hline 91 & $\mathrm{M}$ & $413 / 7$ & 21 & 10 & 10 & 3990 & & 51 & & 36,5 & & 3,01 \\
\hline 92 & $\mathrm{~F}$ & $405 / 7$ & 8 & 10 & 10 & 3385 & 5100 & 47,5 & 57 & 35 & 40 & 3,16 \\
\hline 93 & $\mathrm{M}$ & $395 / 7$ & 16 & 9 & 10 & 3605 & & 48,5 & & 36 & & 3,16 \\
\hline 94 & $\mathrm{~F}$ & $405 / 7$ & 14 & 8 & 10 & 3155 & & 48 & & 32 & & 2,85 \\
\hline 95 & $\mathrm{~F}$ & $392 / 7$ & 14 & 9 & 10 & 3040 & 5200 & 48 & 57 & 34 & 39,5 & 2,75 \\
\hline
\end{tabular}


Recém-nascidos adequados para a idade gestacional

\begin{tabular}{|c|c|c|c|c|c|c|c|c|c|c|c|c|}
\hline $\begin{array}{l}\text { Código do } \\
\text { bebêe }\end{array}$ & Gênero & $\begin{array}{c}\text { Idade } \\
\text { Gestacio } \\
\text { nal }\end{array}$ & $\begin{array}{c}\text { Idade no } \\
\text { teste } \\
(\text { sem })\end{array}$ & $\begin{array}{c}\text { APGAR } \\
\mathbf{1}^{\prime}\end{array}$ & $\begin{array}{c}\text { APGAR } \\
5^{\prime}\end{array}$ & $\begin{array}{c}\text { Peso ao } \\
\text { nascer } \\
\text { (gramas) }\end{array}$ & $\begin{array}{c}\text { Peso no } \\
\text { teste } \\
\text { (gamas) }\end{array}$ & $\begin{array}{c}\text { Compri } \\
\text { mento ao } \\
\text { nascer } \\
\text { (cm) }\end{array}$ & $\begin{array}{l}\text { Compri } \\
\text { mento no } \\
\text { teste } \\
(\mathrm{cm})\end{array}$ & $\begin{array}{c}\text { Crânio } \\
\text { ao } \\
\text { nascer } \\
(\mathbf{c m})\end{array}$ & $\begin{array}{c}\text { Crânio } \\
\text { no teste } \\
\text { (cm) }\end{array}$ & $\begin{array}{c}\text { Índice } \\
\text { Ponderal }\end{array}$ \\
\hline 99 & $\mathrm{M}$ & $383 / 7$ & 17 & 9 & 10 & 3380 & 7205 & 51 & 65,5 & 34 & 42 & 2,55 \\
\hline 42 & M & $412 / 7$ & 16 & 10 & 10 & 3005 & 8100 & 49 & 63,5 & 34 & 41 & 2,55 \\
\hline 82 & F & $386 / 7$ & 14,4 & 10 & 10 & 2795 & 6510 & 48 & 56,5 & 32 & 39 & 2,53 \\
\hline 109 & F & $433 / 7$ & 7 & 9 & 10 & 3440 & 4785 & 50 & 55 & 34 & 38 & 2,75 \\
\hline 110 & F & $402 / 7$ & 7,3 & 9 & 10 & 3580 & 5340 & 50 & 57 & 34 & 38 & 2,86 \\
\hline 111 & M & $385 / 7$ & 7,6 & 9 & 9 & 3205 & 4490 & 49 & 53 & 34 & 38 & 2,72 \\
\hline 112 & $\mathrm{~F}$ & $382 / 7$ & 7,4 & 8 & 9 & 3780 & 5065 & 48,5 & 54 & 34 & 38,5 & 3,31 \\
\hline 114 & M & $403 / 7$ & 9 & 8 & 9 & 3880 & 5555 & 51 & 59 & 36 & 39 & 2,92 \\
\hline 115 & M & $395 / 7$ & 8,7 & 10 & 10 & 3620 & 5970 & 50 & 63 & 34 & 40,5 & 2,90 \\
\hline 116 & M & $375 / 7$ & 9 & 10 & 10 & 3380 & 5350 & 49 & 56 & 34 & 39 & 2,87 \\
\hline 117 & $\mathrm{~F}$ & $381 / 7$ & 9,1 & 9 & 10 & 3430 & 5150 & 48 & 55,5 & 34 & 38 & 3,10 \\
\hline 119 & F & $392 / 7$ & 7,6 & 10 & 10 & 3240 & 4685 & 49 & 55,5 & 34 & 38 & 2,75 \\
\hline 120 & M & $382 / 7$ & 8,7 & 9 & 10 & 3035 & 4300 & 48,5 & 56,5 & 33 & 38,5 & 2,66 \\
\hline 121 & F & 41 1/7 & 9,6 & 8 & 9 & 3070 & 4945 & 48 & 59 & 34 & 39,5 & 2,78 \\
\hline 122 & M & $381 / 7$ & 9,9 & 10 & 10 & 3120 & 5530 & 48 & 61 & 34 & 41 & 2,82 \\
\hline 123 & F & $401 / 7$ & 8,1 & 8 & 5 & 3440 & 4640 & 49 & 57 & 34,5 & 38 & 2,92 \\
\hline 125 & $\mathrm{M}$ & $401 / 7$ & 10,1 & 10 & 10 & 3430 & 5035 & 50 & 60 & 36 & 40 & 2,74 \\
\hline 126 & $\mathrm{M}$ & $392 / 7$ & 8,1 & 8 & 10 & 3590 & 6090 & 50 & 62 & 35 & 41 & 2,87 \\
\hline 127 & $\mathrm{~F}$ & $392 / 7$ & 8,1 & 10 & 10 & 2915 & 5650 & 49 & 60 & 33 & 38,5 & 2,48 \\
\hline 133 & F & $373 / 7$ & 10,7 & 10 & 10 & 2855 & 6275 & 47 & 53 & 33 & 40,5 & 2,75 \\
\hline 134 & $\mathrm{M}$ & $371 / 7$ & 10,3 & 8 & 10 & 3020 & & 48 & & 33 & & 2,73 \\
\hline 135 & $\mathrm{M}$ & $374 / 7$ & 9 & 7 & 9 & 3420 & & 49 & & 33 & & 2,91 \\
\hline 136 & $\mathrm{M}$ & $396 / 7$ & 11,9 & 10 & 10 & 4130 & 7040 & 52 & 65 & 36 & 41,5 & 2,94 \\
\hline 137 & F & $396 / 7$ & 8,9 & 9 & 10 & 3585 & 5000 & 49 & 55 & 33 & 38,5 & 3,05 \\
\hline 138.1 & $\mathrm{M}$ & $376 / 7$ & 12 & 10 & 10 & 2910 & 5455 & 46 & 55,5 & 34 & 40 & 2,99 \\
\hline
\end{tabular}


Recém-nascidos adequados para a idade gestacional

\begin{tabular}{|c|c|c|c|c|c|c|c|c|c|c|c|c|}
\hline $\begin{array}{l}\text { Código do } \\
\text { bebê }\end{array}$ & Gênero & $\begin{array}{c}\text { Idade } \\
\text { Gestacio } \\
\text { nal }\end{array}$ & $\begin{array}{l}\text { Idade no } \\
\text { teste } \\
\text { (sem) }\end{array}$ & $\begin{array}{c}\text { APGAR } \\
1^{\prime}\end{array}$ & $\begin{array}{c}\text { APGAR } \\
5^{\prime}\end{array}$ & $\begin{array}{c}\text { Peso ao } \\
\text { nascer } \\
\text { (gramas) }\end{array}$ & $\begin{array}{c}\text { Peso no } \\
\text { teste } \\
\text { (gamas) }\end{array}$ & $\begin{array}{c}\text { Compri } \\
\text { mento ao } \\
\text { nascer } \\
\text { (cm) }\end{array}$ & $\begin{array}{l}\text { Compri } \\
\text { mento no } \\
\text { teste } \\
(\mathrm{cm})\end{array}$ & $\begin{array}{l}\text { Crânio } \\
\text { ao } \\
\text { nascer } \\
(\mathrm{cm})\end{array}$ & $\begin{array}{c}\text { Crânio } \\
\text { no teste } \\
\text { (cm) }\end{array}$ & $\begin{array}{c}\text { Índice } \\
\text { Ponderal }\end{array}$ \\
\hline 111.2 & $\mathrm{M}$ & $385 / 7$ & 15,7 & 9 & 9 & 3205 & 6695 & 49 & 61 & 34 & 41 & 2,72 \\
\hline 121.2 & $\mathrm{~F}$ & $411 / 7$ & 15,6 & 8 & 9 & 3070 & 5835 & 48 & 59 & 34 & 41 & 2,78 \\
\hline 115.2 & $\mathrm{M}$ & $395 / 7$ & 15,9 & 10 & 10 & 3620 & 6800 & 50 & 64 & 34 & 42 & 2,90 \\
\hline 122.2 & M & $381 / 7$ & 16 & 10 & 10 & 3120 & 6580 & 48 & 62 & 34 & 42,5 & 2,82 \\
\hline 138 & M & $376 / 7$ & 8,9 & 10 & 10 & 2910 & 5060 & 46 & & 34 & & 2,99 \\
\hline 139 & $\mathrm{~F}$ & $401 / 7$ & 8,3 & 10 & 10 & 3460 & 4855 & 52 & 56 & 35 & 39,5 & 2,46 \\
\hline 116.1 & M & $375 / 7$ & 16,9 & 10 & 10 & 3380 & 6115 & 49 & 63 & 34 & 41,5 & 2,87 \\
\hline 133.1 & $\mathrm{~F}$ & $373 / 7$ & 17 & 10 & 10 & 2855 & 7615 & 47 & 61 & 33 & 41 & 2,75 \\
\hline 126,1 & M & $392 / 7$ & 16,4 & 8 & 10 & 3590 & 7510 & 50 & 65 & 35 & 44 & 2,87 \\
\hline 127,1 & $\mathrm{~F}$ & $392 / 7$ & 16,6 & 10 & 10 & 2915 & 6750 & 49 & 62 & 33 & 41,5 & 2,48 \\
\hline 114.1 & M & $403 / 7$ & 20,3 & 8 & 9 & 3880 & 7210 & 51 & 62 & 36 & 43 & 2,92 \\
\hline 139.1 & $\mathrm{~F}$ & $401 / 7$ & 16,9 & 10 & 10 & 3460 & 7180 & 52 & 58 & 35 & 41 & 2,46 \\
\hline 145 & M & 38 & 7,4 & 10 & 10 & 3700 & 5100 & 51 & 57 & 36 & 41 & 2,79 \\
\hline 110.1 & $\mathrm{~F}$ & $402 / 7$ & 21,4 & 9 & 10 & 3580 & 7200 & 50 & 66 & 34 & 42,5 & 2,86 \\
\hline 135.1 & $\mathrm{M}$ & 37 4/7 & 18 & 7 & 9 & 3420 & 6700 & 49 & 70 & 33 & 42 & 2,91 \\
\hline 136.1 & $\mathrm{M}$ & $396 / 7$ & 19,1 & 10 & 10 & 4130 & 8265 & 52 & 69 & 36 & 44 & 2,94 \\
\hline 109,1 & $\mathrm{~F}$ & $433 / 7$ & 22 & 9 & 10 & 3440 & 6850 & 50 & 63 & 34 & 43 & 2,75 \\
\hline 137,1 & $\mathrm{~F}$ & $396 / 7$ & 20,9 & 9 & 10 & 3585 & 7200 & 49 & 65,5 & 33 & 42,5 & 3,05 \\
\hline
\end{tabular}


Recém-nascidos pequenos para a idade gestacional

\begin{tabular}{|c|c|c|c|c|c|c|c|c|c|c|c|c|}
\hline $\begin{array}{l}\text { Código do } \\
\text { bebêe }\end{array}$ & Gênero & $\begin{array}{c}\text { Idade } \\
\text { Gestacio } \\
\text { nal }\end{array}$ & $\begin{array}{c}\text { Idade no } \\
\text { teste } \\
\text { (sem) }\end{array}$ & $\begin{array}{c}\text { APGAR } \\
1^{\prime}\end{array}$ & $\begin{array}{c}\text { APGAR } \\
5^{\prime}\end{array}$ & $\begin{array}{c}\text { Peso ao } \\
\text { nascer } \\
\text { (gramas) }\end{array}$ & $\begin{array}{c}\text { Peso no } \\
\text { teste } \\
\text { (gamas) }\end{array}$ & $\begin{array}{c}\text { Comprimento } \\
\text { ao nascer } \\
\text { (cm) }\end{array}$ & $\begin{array}{c}\text { Comprimento } \\
\text { no teste }(\mathrm{cm})\end{array}$ & $\begin{array}{c}\text { Crânio } \\
\text { ao } \\
\text { nascer } \\
\text { (cm) } \\
\end{array}$ & $\begin{array}{c}\text { Crânio } \\
\text { no teste } \\
(\mathrm{cm})\end{array}$ & $\begin{array}{c}\text { Índice } \\
\text { Ponderal }\end{array}$ \\
\hline 20 & $F$ & $384 / 7$ & 6,29 & 9 & 9 & 2450 & & 47,5 & & 33 & & 2,29 \\
\hline 22 & M & $391 / 7$ & 6,29 & 9 & 10 & 2450 & 4610 & 48 & 53,5 & 34 & 37 & 2,22 \\
\hline 24 & $\mathrm{~F}$ & $404 / 7$ & 6,71 & 10 & 10 & 2835 & 4100 & 47 & 54,5 & 33 & 36 & 2,73 \\
\hline 25 & F & $402 / 7$ & 6,71 & 10 & 10 & 2655 & 4174 & 47,5 & 52,5 & 33 & 38 & 2,48 \\
\hline 28 & $\mathrm{~F}$ & $386 / 7$ & 7,29 & 8 & 9 & 2700 & 3220 & 46 & 54 & 33 & 38 & 2,77 \\
\hline 28.2 & F & $386 / 7$ & 12,43 & 8 & 9 & 2700 & 5110 & 46 & 56,5 & 33 & 40 & 2,77 \\
\hline 27 & $\mathrm{~F}$ & 39 & 8,57 & 7 & 9 & 2765 & 4680 & 49 & 55 & 33 & 49 & 2,35 \\
\hline 30 & M & $394 / 7$ & 8 & 8 & 9 & 2230 & 4670 & 46 & 56,5 & 32 & 38,5 & 2,29 \\
\hline 18 & M & $401 / 7$ & 8,29 & 8 & 9 & 2895 & 4900 & 48 & 55 & 34 & 38 & 2,62 \\
\hline 33 & $\mathrm{~F}$ & $372 / 7$ & 8,29 & 8 & 9 & 2445 & 4170 & 45 & 53 & 32 & 36 & 2,68 \\
\hline 34 & M & $372 / 7$ & 8,29 & 9 & 9 & 2480 & 5500 & 46,5 & 53,5 & 32,5 & 38 & 2,47 \\
\hline 44 & $\mathrm{~F}$ & $385 / 7$ & 12 & 10 & 10 & 2665 & 5340 & 47 & 57,5 & 33 & 38,5 & 2,57 \\
\hline 31 & M & $38^{1 / 7}$ & 12,43 & 10 & 10 & 2530 & 5500 & 49 & 62 & 34 & 41 & 2,15 \\
\hline 2.2 & $\mathrm{~F}$ & $374 / 7$ & 8,3 & 8 & 9 & 2445 & 4000 & 44,5 & 50,5 & 32 & 36 & 2,77 \\
\hline 50 & $\mathrm{M}$ & 37 & 5,86 & 10 & 10 & 2450 & & 44 & & 34 & & 2,88 \\
\hline 54 & F & $405 / 7$ & 6 & 9 & 10 & 2845 & 4360 & 48 & 53,5 & 34 & 38 & 2,57 \\
\hline 55 & F & $385 / 7$ & 6,71 & 10 & 10 & 2350 & 4150 & 45 & 53 & 33 & 36,5 & 2,58 \\
\hline 48 & $\mathrm{~F}$ & $374 / 7$ & 22,43 & 10 & 10 & 2330 & 6105 & 47 & 66 & 32 & 40 & 2,24 \\
\hline 58 & $\mathrm{~F}$ & $384 / 7$ & 6,4 & 8 & 9 & 2505 & 4250 & 44,5 & 52 & 32,5 & 38 & 2,84 \\
\hline 59 & $\mathrm{~F}$ & 38 & 10 & 9 & 9 & 2340 & 4020 & 47 & 56 & 32 & 38 & 2,25 \\
\hline 68 & $\mathrm{~F}$ & 40 & 6,1 & 9 & 9 & 2485 & 4000 & 45,5 & 52 & 32 & 38,5 & 2,64 \\
\hline 69 & F & $393 / 7$ & 5,9 & 9 & 10 & 2770 & & 49 & & 34 & & 2,35 \\
\hline
\end{tabular}


Recém-nascidos pequenos para a idade gestacional

\begin{tabular}{|c|c|c|c|c|c|c|c|c|c|c|c|c|}
\hline $\begin{array}{l}\text { Código do } \\
\text { bebê }\end{array}$ & Gênero & $\begin{array}{c}\text { Idade } \\
\text { Gestacio } \\
\text { nal }\end{array}$ & $\begin{array}{c}\text { Idade no } \\
\text { teste } \\
\text { (sem) }\end{array}$ & $\begin{array}{c}\text { APGAR } \\
1^{\prime}\end{array}$ & $\begin{array}{c}\text { APGAR } \\
5^{\prime}\end{array}$ & $\begin{array}{c}\text { Peso ao } \\
\text { nascer } \\
\text { (gramas) }\end{array}$ & $\begin{array}{c}\text { Peso no } \\
\text { teste } \\
\text { (gamas) }\end{array}$ & $\begin{array}{c}\text { Comprimento } \\
\text { ao nascer } \\
\text { (cm) }\end{array}$ & $\begin{array}{c}\text { Comprimento } \\
\text { no teste }(\mathrm{cm})\end{array}$ & $\begin{array}{l}\text { Crânio } \\
\text { ao } \\
\text { nascer } \\
\text { (cm) }\end{array}$ & $\begin{array}{c}\text { Crânio } \\
\text { no teste } \\
\text { (cm) }\end{array}$ & $\begin{array}{c}\text { Índice } \\
\text { Ponderal }\end{array}$ \\
\hline 74 & F & $372 / 7$ & 11,4 & 9 & 11 & 2485 & & 46 & & 32 & & 2,55 \\
\hline 76 & $\mathrm{~F}$ & $394 / 7$ & 10 & 10 & 10 & 2770 & 5025 & 45 & 53 & 33 & 38 & 3,04 \\
\hline 80 & M & 37 & 13,4 & 9 & 9 & 2530 & 5975 & 44 & 59 & 33 & 39 & 2,97 \\
\hline 81 & $\mathrm{~F}$ & 43 & 13,7 & 9 & 10 & 2530 & 6600 & 47 & 58 & 33 & 39,5 & 2,44 \\
\hline 83 & F & $382 / 7$ & 8,7 & 9 & 9 & 2635 & & 46 & & 31 & & 2,71 \\
\hline 84 & M & 40 & 12,3 & 10 & 10 & 2510 & 4350 & 46 & 57 & 32 & 39,5 & 2,58 \\
\hline 85 & F & 39 & 19,3 & 3 & 8 & 2455 & & 46 & & 33 & & 2,52 \\
\hline 96 & $\mathrm{~F}$ & $391 / 7$ & 8 & 8 & 9 & 2050 & 3860 & 45 & 53 & 32 & 36 & 2,25 \\
\hline 97 & $M$ & $371 / 7$ & 16,7 & 9 & 10 & 2520 & 5995 & 47 & 61,5 & 33 & 40,5 & 2,43 \\
\hline 98 & $\mathrm{~F}$ & $403 / 7$ & 10,7 & 10 & 10 & 2535 & 5040 & 46 & 57 & 32 & & 2,60 \\
\hline 100 & $\mathrm{~F}$ & $391 / 7$ & 8,4 & 9 & 10 & 2735 & & 48 & & 33 & & 2,47 \\
\hline 101 & $F$ & 37 & 14,4 & 9 & 10 & 1840 & 4400 & 41 & 55 & 32 & 39,5 & 2,67 \\
\hline 83.2 & $F$ & $382 / 7$ & 15 & 9 & 9 & 2635 & 4385 & 46 & 57,5 & 31 & 38,5 & 2,71 \\
\hline 102 & $\mathrm{~F}$ & 37 6/7 & 7,7 & 10 & 10 & 2290 & 3285 & 44 & 50,5 & 32 & 38 & 2,69 \\
\hline 103 & $F$ & $396 / 7$ & 11 & 9 & 10 & 2820 & 4795 & 49 & 61 & 33 & 38 & 2,40 \\
\hline 104 & $F$ & 40 2/7 & 12,7 & 9 & 10 & 2445 & 4875 & 45 & 60 & 33 & 39 & 2,68 \\
\hline 105 & $M$ & 37 3/7 & 15,4 & 10 & 10 & 2485 & 5900 & 45 & 61 & 32 & 39,5 & 2,73 \\
\hline 106 & $F$ & $381 / 7$ & 11,6 & 10 & 10 & 2440 & 6395 & 49 & 60,5 & 32 & 39 & 2,07 \\
\hline 96.2 & F & $391 / 7$ & 22,3 & 8 & 9 & 2050 & 6520 & 45 & 61 & 32 & 41,5 & 2,25 \\
\hline 107 & $\mathrm{~F}$ & $381 / 7$ & 7,3 & 8 & 10 & 2420 & 3745 & 44 & 53 & 34 & 38 & 2,84 \\
\hline 108 & $F$ & 40 & 9 & 7 & 10 & 2740 & 4100 & 47 & 57 & 31 & 38 & 2,64 \\
\hline 113 & $F$ & $396 / 7$ & 6,9 & 8 & 10 & 2690 & 4455 & 45 & 54,5 & 33 & 38 & 2,95 \\
\hline 118 & $\mathrm{M}$ & $381 / 7$ & 9 & 10 & 10 & 2645 & 5535 & 46 & 57,5 & 34 & 38,5 & 2,72 \\
\hline 124 & $F$ & 40 2/7 & 8,9 & 9 & 10 & 2760 & 4805 & 47,5 & & 34 & & 2,58 \\
\hline 128 & $M$ & $391 / 7$ & 7,4 & 9 & 10 & 2710 & 4825 & 49 & 58 & 33 & 38 & 2,30 \\
\hline 107.2 & $\mathrm{~F}$ & $381 / 7$ & 17 & 8 & 10 & 2420 & 5510 & 44 & 60 & 34 & 40,5 & 2,84 \\
\hline 129 & $F$ & $395 / 7$ & 7 & 9 & 10 & 2845 & 4495 & 47 & 57 & 32 & 37 & 2,74 \\
\hline
\end{tabular}


Recém-nascidos pequenos para a idade gestacional

\begin{tabular}{|c|c|c|c|c|c|c|c|c|c|c|c|c|}
\hline $\begin{array}{c}\text { Código do } \\
\text { bebêe }\end{array}$ & Gênero & $\begin{array}{c}\text { Idade } \\
\text { Gestacio } \\
\text { nal }\end{array}$ & $\begin{array}{c}\text { Idade no } \\
\text { teste } \\
\text { (sem) }\end{array}$ & $\begin{array}{c}\text { APGAR } \\
1^{\prime}\end{array}$ & $\begin{array}{c}\text { APGAR } \\
5^{\prime}\end{array}$ & $\begin{array}{c}\text { Peso ao } \\
\text { nascer } \\
\text { (gramas) }\end{array}$ & $\begin{array}{l}\text { Peso no } \\
\text { teste } \\
\text { (gamas) }\end{array}$ & $\begin{array}{c}\text { Comprimento } \\
\text { ao nascer } \\
\text { (cm) }\end{array}$ & $\begin{array}{l}\text { Comprimento } \\
\text { no teste }(\mathrm{cm})\end{array}$ & $\begin{array}{c}\text { Crânio } \\
\text { ao } \\
\text { nascer } \\
\text { (cm) }\end{array}$ & $\begin{array}{c}\text { Crânio } \\
\text { no teste } \\
(\mathrm{cm})\end{array}$ & $\begin{array}{c}\text { Índice } \\
\text { Ponderal }\end{array}$ \\
\hline 130 & $F$ & $392 / 7$ & 7,7 & 8 & 9 & 2705 & 4505 & 48 & 57 & 33 & 38 & 2,45 \\
\hline 131 & $F$ & $395 / 7$ & 6,3 & 9 & 10 & 2620 & 4455 & 46 & 68 & 31 & 38 & 2,69 \\
\hline 132 & $M$ & $401 / 7$ & 7 & 9 & 10 & 2795 & 4740 & 48 & 57 & 34 & 38 & 2,53 \\
\hline 108.1 & $\mathrm{~F}$ & $401 / 7$ & 20,7 & 7 & 10 & 2740 & 5330 & 47 & 64 & 31 & 40 & 2,64 \\
\hline 140 & $\mathrm{~F}$ & $414 / 7$ & 6 & 10 & 10 & 2770 & 3410 & 47 & 51 & 33 & 35 & 2,67 \\
\hline 141 & $\mathrm{~F}$ & 38 & 9 & 9 & 9 & 2765 & 4490 & 48 & 53 & 35 & 39 & 2,50 \\
\hline 142 & $M$ & 38 & 7,86 & 8 & 10 & 2530 & 4625 & 46 & 55,5 & 33 & 38,5 & 2,60 \\
\hline 143 & $F$ & 39 & 6,86 & 5 & 8 & 2775 & 4355 & 46 & 54 & 33 & 38 & 2,85 \\
\hline 124.1 & $\mathrm{~F}$ & 40 2/7 & 17,9 & 9 & 10 & 2760 & 6200 & 47,5 & 60 & 34 & 41 & 2,58 \\
\hline 118,1 & $M$ & $381 / 7$ & 19,3 & 10 & 10 & 2645 & 7480 & 46 & 63 & 34 & 41 & 2,72 \\
\hline 144 & $\mathrm{~F}$ & 38 & 8,1 & 9 & 10 & 2470 & 3640 & 46 & 52 & 32 & 36 & 2,54 \\
\hline 130.1 & $\mathrm{~F}$ & $392 / 7$ & 14,6 & 8 & 9 & 2705 & 6130 & 48 & 61 & 33 & 39 & 2,45 \\
\hline 146 & $\mathrm{~F}$ & 38 2/7 & 14,7 & 8 & 9 & 2640 & 5490 & 46 & 60 & 34 & 40,5 & 2,71 \\
\hline 131.1 & $\mathrm{~F}$ & $395 / 7$ & 16,3 & 9 & 10 & 2620 & 6100 & 46 & 61 & 31 & 40,5 & 2,69 \\
\hline 132.1 & $M$ & $401 / 7$ & 16 & 9 & 10 & 2795 & 6800 & 48 & 64 & 34 & 41,5 & 2,53 \\
\hline 129.1 & $\mathrm{~F}$ & $395 / 7$ & 16 & 9 & 10 & 2845 & 6465 & 47 & 60 & 32 & 40 & 2,74 \\
\hline 147 & $\mathrm{~F}$ & 39 & 9 & 4 & 7 & 2765 & 4915 & 48 & 56 & 34 & 39 & 2,50 \\
\hline 148 & $\mathrm{~F}$ & 39 & 8,7 & 7 & 10 & 2735 & 5100 & 48 & 56,5 & 33 & 39 & 2,47 \\
\hline
\end{tabular}


APÊNDICE D - Tabelas com as medidas antropométricas das mães 
Recém-nascidos adequados para a idade gestacional

\begin{tabular}{|c|c|c|c|c|c|c|}
\hline Código do bebê & $\begin{array}{c}\text { Altura } \\
\text { Materna }(\mathbf{c m})\end{array}$ & $\begin{array}{c}\text { Peso pré- } \\
\text { Gravidez (Kg) }\end{array}$ & $\begin{array}{c}\text { Índice de } \\
\text { Massa corporal } \\
(\mathrm{kg})\end{array}$ & $\begin{array}{c}\text { Ganho de peso } \\
\text { na gravidez } \\
(\mathrm{kg})\end{array}$ & $\begin{array}{c}\text { Ganho de peso } \\
\text { recomendado baseado } \\
\text { no IMC }(\mathrm{Kg})\end{array}$ & $\begin{array}{c}\text { Categoria de peso } \\
\text { baseado no IMC }\end{array}$ \\
\hline 14 & 1,6 & 50 & 19,53 & 12,00 & $12,5-18$ & abaixo do peso \\
\hline 15 & 1,65 & 67 & 24,61 & 8,00 & $11,5-16$ & normal \\
\hline 16 & 1,6 & 65 & 25,39 & 10,00 & $11,5-16$ & normal \\
\hline 17 & 1,6 & 80 & 31,25 & 11,00 & 6 & obesa \\
\hline 21 & 1,57 & 85 & 34,48 & 19,00 & 6 & obesa \\
\hline 23 & 1,6 & 50 & 19,53 & 11,00 & $11,5-16$ & normal \\
\hline 26 & 1,65 & 55 & 20,20 & 32,00 & $11,5-16$ & normal \\
\hline 36 & 1,5 & 49 & 21,78 & 11,00 & $11,5-16$ & normal \\
\hline 37 & 1,52 & 52 & 22,51 & 20,00 & $11,5-16$ & normal \\
\hline 38 & 1,6 & 48 & 18,75 & 17,00 & $12,5-18$ & abaixo do peso \\
\hline 40 & 1,62 & 73 & 27,82 & 15,00 & $7-11,5$ & acima do peso \\
\hline 41 & 1,6 & 62 & 24,22 & 10,00 & $11,5-16$ & normal \\
\hline 43 & 1,63 & 55 & 20,70 & 15,00 & $11,5-16$ & normal \\
\hline 45 & 1,6 & 79 & 30,86 & 13,00 & 6 & obesa \\
\hline 46 & 1,7 & 50 & 17,30 & 10,00 & $12,5-18$ & abaixo do peso \\
\hline 19.2 & 1,77 & 55 & 17,56 & 6,00 & $12,5-18$ & abaixo do peso \\
\hline 13 & 1,49 & 55 & 24,77 & 17,00 & $11,5-16$ & normal \\
\hline 39 & 1,55 & 42 & 17,48 & 10,00 & $12,5-18$ & abaixo do peso \\
\hline 47 & 1,63 & 50 & 18,82 & 15,00 & $12,5-18$ & abaixo do peso \\
\hline 8 & 1,54 & 54 & 22,77 & 32,00 & $11,5-16$ & normal \\
\hline 11 & 1,58 & 50 & 20,03 & 18,00 & $11,5-16$ & normal \\
\hline 9.2 & 1,65 & 54 & 19,83 & 18,00 & $11,5-16$ & normal \\
\hline 51 & 1,5 & 50 & 22,22 & 9,00 & $11,5-16$ & normal \\
\hline 57 & 1,62 & 52 & 19,81 & 16,00 & $11,5-16$ & normal \\
\hline 63 & 1,64 & 54 & 20,08 & 8,00 & $11,5-16$ & normal \\
\hline 65 & 1,64 & 73 & 27,14 & 12,00 & $7-11,5$ & acima do peso \\
\hline
\end{tabular}


Recém-nascidos adequados para a idade gestacional

\begin{tabular}{|c|c|c|c|c|c|c|}
\hline Código do bebê & $\begin{array}{c}\text { Altura } \\
\text { Materna (cm) }\end{array}$ & $\begin{array}{c}\text { Peso pré- } \\
\text { Gravidez (Kg) }\end{array}$ & $\begin{array}{c}\text { Indice de } \\
\text { Massa corporal } \\
(\mathbf{k g}) \\
\end{array}$ & $\begin{array}{c}\text { Ganho de peso } \\
\text { na gravidez } \\
(\mathrm{kg}) \\
\end{array}$ & $\begin{array}{c}\text { Ganho de peso } \\
\text { recomendado baseado } \\
\text { no IMC }(\mathrm{Kg}) \\
\end{array}$ & $\begin{array}{c}\text { Categoria de peso } \\
\text { baseado no IMC }\end{array}$ \\
\hline 67 & 1,65 & 58 & 21,30 & 13,00 & $11,5-16$ & normal \\
\hline 70 & 1,6 & 90 & 35,16 & 12,00 & 6 & obesa \\
\hline 71 & 1,69 & 58 & 20,31 & & $11,5-16$ & normal \\
\hline 72 & 1,69 & 58 & 20,31 & & $11,5-16$ & normal \\
\hline 79 & 1,58 & 66 & 26,44 & 14,00 & $7-11,5$ & acima do peso \\
\hline 87 & 1,75 & 64 & 20,90 & 20,00 & $11,5-16$ & normal \\
\hline 89 & 1,67 & 107 & 38,37 & 5,00 & 6 & obesa \\
\hline 91 & 1,73 & 68 & 22,72 & 16,00 & $11,5-16$ & normal \\
\hline 92 & 1,49 & 50 & 22,52 & 18,00 & $11,5-16$ & normal \\
\hline 93 & 1,63 & 64 & 24,09 & 19,00 & $11,5-16$ & normal \\
\hline 95 & 1,69 & 70 & 24,51 & 7,00 & $11,5-16$ & normal \\
\hline 99 & 1,6 & 45 & 17,58 & 7,00 & $12,5-18$ & abaixo do peso \\
\hline 42 & 1,67 & 66 & 23,67 & 12,00 & $11,5-16$ & normal \\
\hline 110 & 1,55 & 51 & 21,23 & 16,00 & $11,5-16$ & normal \\
\hline 111 & 1,66 & 57 & 20,69 & 5,00 & $11,5-16$ & normal \\
\hline 114 & 1,61 & 52 & 20,06 & 16,00 & $11,5-16$ & normal \\
\hline 115 & 1,54 & 59 & 24,88 & 14,00 & $11,5-16$ & normal \\
\hline 116 & 1,65 & 64 & 23,51 & 21,00 & $11,5-16$ & normal \\
\hline 119 & 1,53 & 52 & 22,21 & 12,00 & $11,5-16$ & normal \\
\hline 120 & 1,58 & 57 & 22,83 & 10,00 & $11,5-16$ & normal \\
\hline 121 & 1,55 & 55 & 22,89 & 10,00 & $11,5-16$ & normal \\
\hline 122 & 1,65 & 62 & 22,77 & 10,00 & $11,5-16$ & normal \\
\hline
\end{tabular}


Recém-nascidos adequados para a idade gestacional

\begin{tabular}{|c|c|c|c|c|c|c|}
\hline Código do bebê & $\begin{array}{c}\text { Altura } \\
\text { materna }(\mathrm{cm})\end{array}$ & $\begin{array}{c}\text { Peso pré- } \\
\text { Gravidez (Kg) }\end{array}$ & $\begin{array}{c}\text { Índice de } \\
\text { Massa corporal } \\
(\mathbf{k g})\end{array}$ & $\begin{array}{c}\text { Ganho de peso } \\
\text { na gravidez } \\
(\mathrm{kg})\end{array}$ & $\begin{array}{c}\text { Ganho de peso } \\
\text { recomendado baseado } \\
\text { no IMC }(\mathrm{Kg})\end{array}$ & $\begin{array}{c}\text { Categoria de peso } \\
\text { baseado no IMC }\end{array}$ \\
\hline 123 & 1,7 & 63 & 21,80 & 9,00 & $11,5-16$ & normal \\
\hline 125 & 1,57 & 57 & 23,12 & 10,00 & $11,5-16$ & normal \\
\hline 126 & 1,67 & 80 & 28,69 & 22,00 & $7-11,5$ & acima do peso \\
\hline 127 & 1,64 & 48 & 17,85 & 20,00 & $12,5-18$ & abaixo do peso \\
\hline 133 & 1,72 & 88 & 29,75 & & $7-11,5$ & acima do peso \\
\hline 134 & 1,56 & 78 & 32,05 & 7,00 & 6 & obesa \\
\hline 135 & 1,6 & 52 & 20,31 & 12,00 & $11,5-16$ & normal \\
\hline 136 & 1,61 & 52 & 20,06 & 28,00 & $11,5-16$ & normal \\
\hline 137 & 1,68 & 61 & 21,61 & 13,00 & $11,5-16$ & normal \\
\hline 138 & 1,66 & 76 & 27,58 & 8,00 & $7-11,5$ & acima do peso \\
\hline 139 & 1,55 & 62 & 25,81 & 9,00 & $11,5-16$ & normal \\
\hline 145 & 1,58 & 70 & 28,04 & 13,00 & $7-11,5$ & acima do peso \\
\hline
\end{tabular}


Recém-nascidos pequenos para a idade gestacional

\begin{tabular}{|c|c|c|c|c|c|c|}
\hline $\begin{array}{c}\text { Código do } \\
\text { bebê }\end{array}$ & $\begin{array}{c}\text { Altura Materna } \\
(\mathbf{c m})\end{array}$ & $\begin{array}{c}\text { Peso pré- } \\
\text { Gravidez }(\mathrm{Kg})\end{array}$ & $\begin{array}{l}\text { Indice de Massa } \\
\text { corporal }(\mathrm{kg})\end{array}$ & $\begin{array}{c}\text { Ganho de peso na } \\
\text { gravidez }(\mathrm{kg})\end{array}$ & $\begin{array}{l}\text { Categoria de peso } \\
\text { baseado no IMC }\end{array}$ & $\begin{array}{c}\text { Ganho de peso recomendado } \\
\text { baseado no IMC }(\mathrm{Kg})\end{array}$ \\
\hline 2.3 & 1,52 & 68 & 29,43 & $-5,00$ & obesa & 6 \\
\hline 18 & 1,65 & & 32,32 & 10,00 & obesa & 6 \\
\hline 22 & 1,58 & 48 & 19,23 & 13,00 & abaixo do peso & $12,5-18$ \\
\hline 24 & 1,6 & & 21,09 & 22,00 & normal & $11,5-16$ \\
\hline 25 & 1,5 & 49 & 21,77 & 13,00 & normal & $11,5-16$ \\
\hline 27 & 1,55 & 57 & 23,73 & 12,60 & normal & $11,5-16$ \\
\hline 28 & 1,75 & 59 & 19,26 & 21,00 & abaixo do peso & $12,5-18$ \\
\hline 30 & 1,73 & 60 & 20,05 & 11,00 & normal & $11,5-16$ \\
\hline 31 & 1,67 & & & 8,00 & & \\
\hline 33 & 1,55 & 47 & 19,56 & 8,00 & abaixo do peso & $12,5-18$ \\
\hline 34 & 1,55 & 45 & 18,73 & 8,00 & abaixo do peso & $12,5-18$ \\
\hline 44 & 1,53 & 57 & 24,35 & 15,00 & normal & $11,5-16$ \\
\hline 42 & 1,67 & 66 & 23,55 & 12,00 & normal & $11,5-16$ \\
\hline 48 & 1,5 & 49 & 21,78 & 13,00 & normal & $11,5-16$ \\
\hline 68 & 1,69 & 62 & 21,71 & 28,00 & normal & $11,5-16$ \\
\hline 69 & 1,74 & 58 & 19,16 & 8,00 & abaixo do peso & $12,5-18$ \\
\hline 74 & 1,62 & 60 & 22,86 & $-2,00$ & normal & $11,5-16$ \\
\hline 76 & 1,4 & 48 & 24,49 & 15,00 & normal & $11,5-16$ \\
\hline 80 & 1,6 & 59 & 23,05 & 15,00 & normal & $11,5-16$ \\
\hline 81 & 1,72 & 52 & 17,58 & 13,00 & abaixo do peso & $12,5-18$ \\
\hline 83 & 1,6 & 54 & 21,09 & 31,00 & normal & $11,5-16$ \\
\hline 84 & 1,56 & 46 & 18,90 & 5,00 & abaixo do peso & $12,5-18$ \\
\hline 85 & 1,6 & 50 & 19,53 & 12,00 & abaixo do peso & $12,5-18$ \\
\hline 96 & 1,46 & 56 & 26,27 & 16,00 & normal & $11,5-16$ \\
\hline 98 & 1,6 & 62 & 24,22 & 10,00 & normal & $11,5-16$ \\
\hline 100 & 1,59 & 57 & 22,55 & 11,00 & normal & $11,5-16$ \\
\hline 101 & 1,61 & 50 & 19,29 & 12,00 & abaixo do peso & $12,5-18$ \\
\hline 102 & 1,6 & 46 & 17,97 & 8,00 & abaixo do peso & $12,5-18$ \\
\hline
\end{tabular}


Recém-nascidos pequenos para a idade gestacional

\begin{tabular}{|c|c|c|c|c|c|c|}
\hline $\begin{array}{c}\text { Código do } \\
\text { bebê }\end{array}$ & $\begin{array}{l}\text { Altura Materna } \\
\text { (cm) }\end{array}$ & $\begin{array}{c}\text { Peso Pré- } \\
\text { Gravidez (Kg) }\end{array}$ & $\begin{array}{l}\text { Indice de Massa } \\
\text { corporal (kg) }\end{array}$ & $\begin{array}{l}\text { Ganho de peso na } \\
\text { gravidez (kg) }\end{array}$ & $\begin{array}{l}\text { Categoria de peso } \\
\text { baseado no IMC }\end{array}$ & $\begin{array}{c}\text { Ganho de peso recomendado } \\
\text { baseado no IMC (Kg) }\end{array}$ \\
\hline 103 & 1,61 & 58 & 22,38 & 12,00 & normal & $11,5-16$ \\
\hline 104 & 1,65 & 43 & 15,79 & 14,00 & abaixo do peso & $12,5-18$ \\
\hline 105 & 1,67 & 45 & 16,14 & 27,00 & abaixo do peso & $12,5-18$ \\
\hline 106 & 1,7 & 70 & 24,22 & 14,00 & normal & $11,5-16$ \\
\hline 107 & 1,55 & 56 & 23,31 & 16,00 & normal & $11,5-16$ \\
\hline 108 & 1,43 & 50 & 24,45 & 5,00 & normal & $11,5-16$ \\
\hline 113 & 1,59 & 65 & 25,71 & 15,40 & normal & $11,5-16$ \\
\hline 118 & & 49 & & 21,00 & & \\
\hline 124 & 1,56 & 70 & 28,76 & 9,20 & acima do peso & $7-11,5$ \\
\hline 129 & 1,65 & 68 & 24,98 & 7,00 & normal & $11,5-16$ \\
\hline 130 & 1,6 & 52 & 20,31 & 16,00 & normal & $11,5-16$ \\
\hline 131 & 1,48 & 48 & 21,91 & 11,00 & normal & $11,5-16$ \\
\hline 132 & 1,45 & 36 & 17,12 & 16,00 & abaixo do peso & $12,5-18$ \\
\hline 140 & 1,47 & 55 & 25,45 & 11,00 & normal & $11,5-16$ \\
\hline 142 & & 51,4 & & 0,50 & & \\
\hline 144 & 1,59 & 59 & 23,34 & 14,00 & normal & $11,5-16$ \\
\hline 146 & 1,64 & 55 & 20,45 & & normal & $11,5-16$ \\
\hline 147 & 1,58 & 78 & 31,24 & 3,00 & obesa & 6 \\
\hline 148 & 1,63 & 47 & 17,69 & 10,00 & abaixo do peso & $12,5-18$ \\
\hline
\end{tabular}


APÊNDICE E - Anamnese Nutricional 
ANAMNESE NUTRICIONAL

Data: Código:

Nome do paciente:

Data de Nascimento:

Nome da mãe:

\section{Caracterização familiar}

1.1. Materna:

Idade: ___ altura $(\mathrm{cm}) \_$peso (pré-gravidez, $\mathrm{kg}$ ): peso (final da gravidez): Ganho de peso na gravidez

(kg): Desnutrição materna? $\mathrm{N}^{\circ}$ de filhos:

Gestação múltipla?

Problemas de saúde no período gestacional: (hipertensão, doença renal, diabetes, etc)?

Teve alguma dessas infecções (toxoplasmose, rubéola, citomegalovírus, herpes viral etc)?

Fez uso de álcool, cigarro e/ou drogas não-permitidas durante a gravidez? Qual (is)? Quantidade:

( ) 1 ou 2 cigarros dia ( ) 3 a 5cigarros dia ( ) mais de 10 cigarros dia.

E durante a amamentação?

Fez pré-natal? $\mathrm{N}^{\circ}$ de consultas?

1.2. Paterna: Idade: Altura: Peso:

\section{Nutrição Materna}

Você consome semanalmente os alimentos abaixo com que freqüência?

Peixe fresco ou enlatados: sardinha atum etc. (tipo: ):

( ) não consome ( ) 1 vez ( ) 2 vezes ( )3 vezes ( ) 4 vezes ( ) mais de 4 vezes

Carne (tipo:

( ) não consome ( ) 1 vez ( ) 2 vezes ( )3 vezes ( ) 4 vezes ( ) mais de 4 vezes

Leite: (tipo )

( ) não consome ( ) 1 vez ( ) 2 vezes ( )3 vezes ( ) 4 vezes ( ) mais de 4 vezes

\section{Ovos:}

( ) não consome ( ) 1 vez ( ) 2 vezes ( )3 vezes ( ) 4 vezes ( ) mais de 4 vezes

\section{Frutas, verduras e legumes:}

( ) não consome ( ) 1 vez ( ) 2 vezes ( )3 vezes ( ) 4 vezes ( ) mais de 4 vezes

\subsection{Durante o período gestacional:}

- Quantas refeições você fazia por dia?

- Geralmente, o que costumava comer e beber no café da manhã?

- No almoço?

- No jantar?

- Qual era a sua Comida preferida ()?

- Tem algum alimento que você não gosta?

-Tem algum alimento que você não pode comer (intolerância alimentar)?

- Tomou suplemento vitamínico?

- Tomou suplemento de ferro?

\subsection{Durante a amamentação:}

- Geralmente, o que costuma comer e beber no café da manhã?

- No almoço?

- No jantar?

- Qual a sua Comida preferida ()?

- Está tomando algum suplemento vitamínico?

- Está tomando algum Tomou suplemento de ferro?

\section{Nutrição do Bebê}

3.1. Peso ao nascimento:

3.2. Comprimento ao nascimento:

3.3. Circunferência craniana:

3.4. Índice Ponderal de Rhorer: 3.5. Classificação: AIG () ou PIG ().

3.6. () Leite Materno. Qual o Intervalo entre as mamadas (horas)?

3.7. () Leite de Fórmula. Qual?__ Quantidade (ml)?

3.8. () Leite Materno e Fórmulas? Quantidade (ml)?

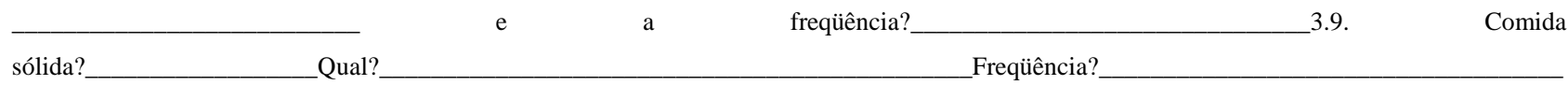
Qual? 